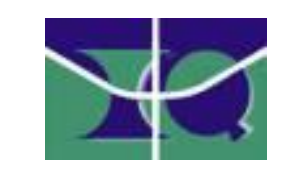

UNIVERSIDADE DE BRASÍLIA

Instituto de Química

Programa de Pós-Graduação em Química

\title{
DESCRIÇÃO TEÓRICA DE COMPLEXOS DE METAIS DE TRANSIÇÃO COM LIGANTES HIDRAZONA COM POTENCIAL APLICAÇÃO FARMACOLÓGICA
}

FERNANDA DE SOUZA TIAGO

BRASÍLIA-DF

2015/1 
UNIVERSIDADE DE BRASÍLIA

INSTITUTO DE QUÍMICA

PROGRAMA DE PÓS-GRADUAÇÃO EM QUÍMICA

Descrição teórica de complexos de metais de transição com ligantes hidrazona com potencial aplicação farmacológica

Fernanda de Souza Tiago*

\begin{abstract}
Texto apresentado ao Programa de Pós Graduação em Química da Universidade de Brasília, como requisito parcial para obtenção do título de DOUTORA EM QUÍMICA (área de concentração FÍSICO-QUÍMICA).
\end{abstract}

Orientador: Prof. Dr. João Batista Lopes Martins

*(Aluna do curso de Doutorado em Química - Matrícula: 11/0092031)

\title{
BRASÍLIA-DF
}

$2015 / 1$ 


\section{COMUNICADO}

Comunicamos a aprovação da Defesa de Tese de Doutorado do (a) aluno (a) Fernanda de Souza Tiago, matrícula $n \cong$ 11/0092031, intitulada "Descrição Teórica de Complexos de Metais de Transição com Ligantes Hidrazona com Potencial Aplicação Farmacológica", apresentada no (a) PROIN no Instituto de Química da Universidade de Brasília (UnB) em 7 de agosto de 2015.

Prof. Dr. João Batista Lopes Martins

Presidente de Banca (IQ/UnB)

Prof. Dr. Ricardo Gargano

Membro Titular (IF / UnB)

Profa. Dra. Glauciete Sarmento Maciel Membro Titular (SEE / DF)

Prof. Dr. José Roberto dos Santos Politi Membro Titular (IQ/UnB)

Prof. Dr. Leonardo Giordano Paterno Membro Titular (IQ/UnB)

Profa. Dra. Cláudia Cristina Gatto Membro Suplente (IQ/UnB) 
"Fís o meu segredo. $\mathfrak{E}$ muito simples: só se vê bem com o coração. O essencial é invisivel aos olhos."

Saint-Exupéry, A., In: O Pequeno Príncipe. Editora Agir, Rio de Janeiro, $48^{\circ}$ edição, 2009. 
Dedico este trabalho à minha princesinha Maria Fernanda, à minha irmäzinha suellene aos mens querídos pais Odorico e Marina. Nada disso tería sentido se não fossem vocês. Amo intensamente! 


\section{AGRADECIMENTOS}

Mais uma etapa chega ao fim e aqui registro as memórias do meu coração.

Obrigada Senhor meu Deus, por ser fiel e nunca me faltar e à Virgem Maria por me proteger com seu manto sagrado.

Ao Prof Dr João Batista Lopes Martins agradeço pela orientação sempre presente, segura, amiga, extremamente profissional, mas ao mesmo tempo muito pessoal. Obrigada por ter me aceito como sua aluna, por me dedicar seu tempo, sua amizade, sua preocupação. Tenho certeza de que se não fosse você e todas as coisas que me ensinou, que vão muito além do laboratório, esse trabalho não teria sido possível.

À Kamilla, meu amorzinho, por suportar minhas ausências, entender meu nervosismo e estar ao meu lado superando todos os desafios e por me fazer rir e rir muito.

À Profa Dra $^{a}$ Claudia Cristina Gatto pelos dados em colaboração que motivaram esse trabalho. Obrigada pelo apoio e grande disponibilidade para que esse trabalho fosse realizado. Ao Pedro Santiago, por ter me ajudado muito com a disponibilização dos dados experimentais, a entender melhor a química de coordenação e estar sempre presente.

À minha querida vozinha Levina e ao meu vovô Simão (saudades) por todo o amor incondicional, apoio e todos os ensinamentos que me trouxeram até aqui.

À amiga Érica Cristina, por todo o apoio, pelas conversas sobre ciência, vida, e pelo grande encorajamento, especialmente sobre o meu papel como mulher cientista. A todos os meus amigos antigos de Uberlândia e aos novos de Brasília que conquistei nesses quatro anos, não dá para citar todos, mas um agradecimento especial à Daliana, minha linda, que sempre me dá muita força e compartilha boas risadas.

Ao meu amigo e cunhado Wesley, obrigada pela amizade, pelas conversas, pela força nos mais diversos momentos, pela comida gostosa, pela diversão, pelas risadas.

Aos Profs Drs Glauciete Sarmento Maciel, José Roberto Politi, Ricardo Gargano e Leonardo Giordano Paterno, agradeço pelas participações nas bancas de seminários, qualificação e defesa, as quais contribuíram bastante para esse trabalho.

Aos colegas de LQC, os que foram e os que ficaram e me ensinaram muito, Jussara, Víctor, Ítalo, Marcos, Rogério, Sérgio, Daniel, Diego.

A todos que de uma forma ou de outra torceram, ajudaram e contribuíram para a realização desse trabalho.

Aos órgãos de fomento CAPES, CNPq e FAP-DF pelo apoio financeiro. 


\section{ÍNDICE}

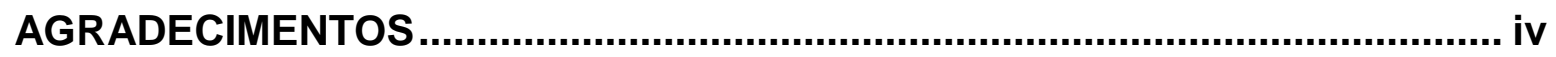

Termos e Siglas Adotados ......................................................................................

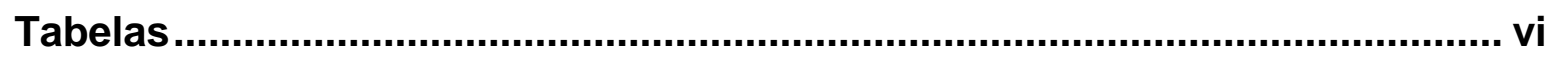

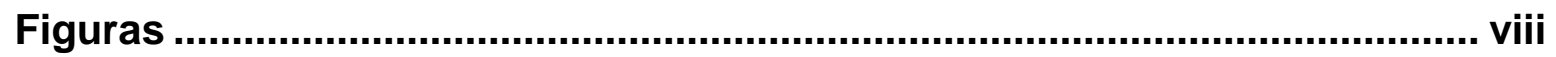

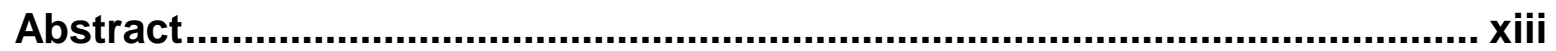

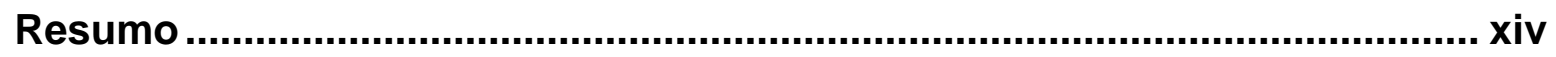

Capítulo 1 - Revisão Bibliográfica ................................................................... 1

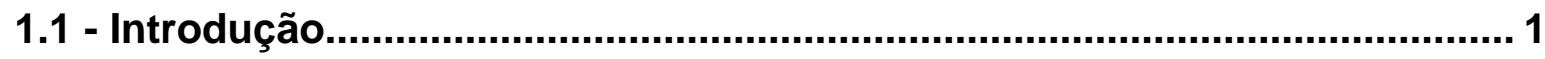

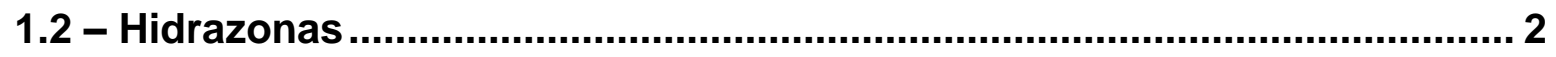

1.3 - Compostos de coordenação de cobre ..................................................... 7

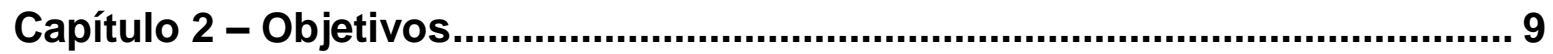

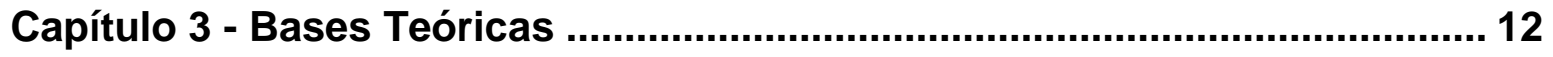

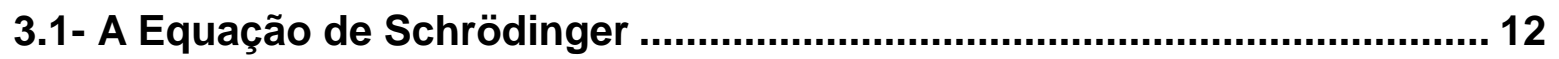

3.2- A Teoria do Funcional da Densidade ...................................................... 14

3.2.1. As Equações de Kohn-Sham …………………………………………………….... 17

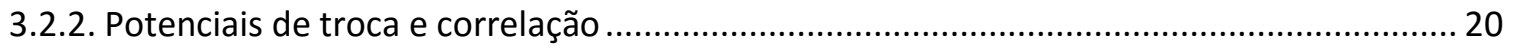

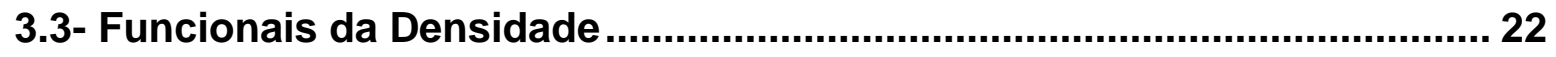

3.4- Teoria do Funcional da Densidade dependente do tempo....................... 33

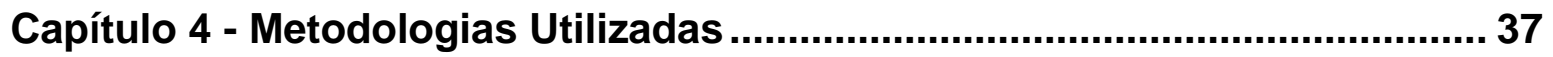

4.1- Otimização Geométrica e Cálculo de Frequências Vibracionais ............. 37

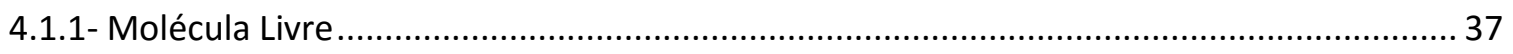

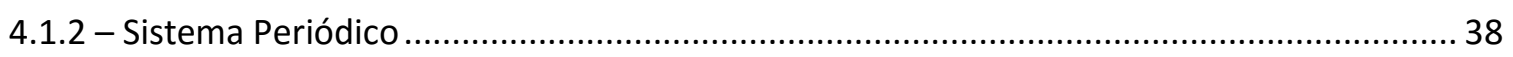

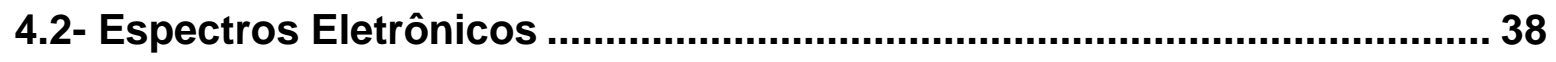

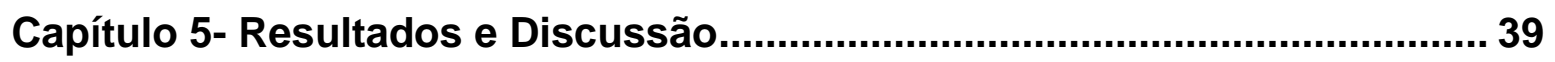


5.1- DiNitrato de 2-acetilpiridina-benzoilhidrazonacobre(II) .......................... 42

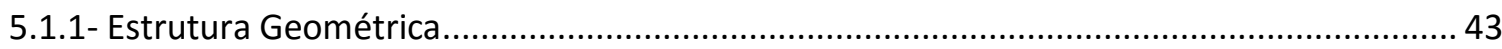

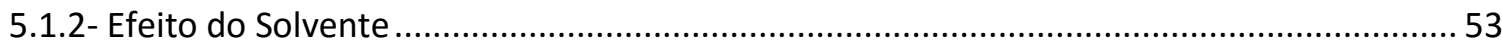

5.1.3- Espectroscopias Vibracional e Eletrônica ......................................................................... 56

5.2- $\mu$-diacetatobis[(2-acetilpiridinabenzoilhidrazona) cobre(II)].....................63

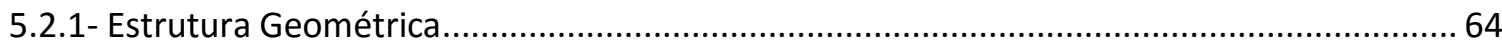

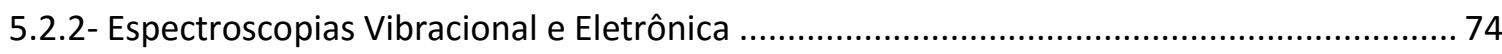

5.3 - Bis $(2$ - acetilpiridinabenzoilhidrazona)cobre(II) ............................... 80

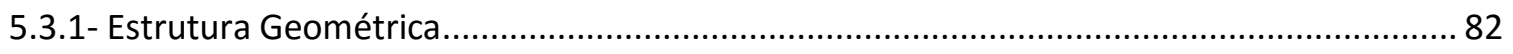

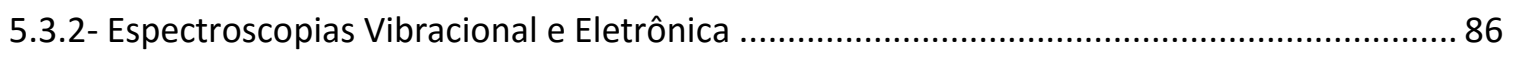

5.4 - $\mu$-sulfatobis[(2-acetilpiridinabenzoilhidrazona) cobre(II)] ...................... 94

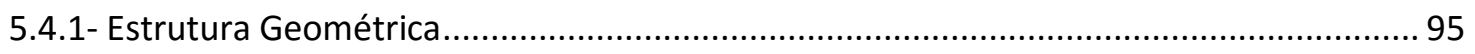

5.4.2- Espectroscopias Vibracional e Eletrônica ............................................................... 103

5.5 - Sobre o desempenho dos funcionais da densidade ........................... 110

Capítulo 6 - Conclusões................................................................................ 114

Capítulo 7 - Sugestões para trabalhos futuros.............................................. 116

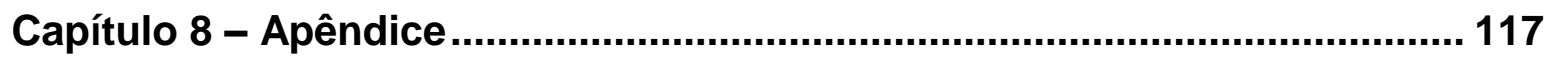

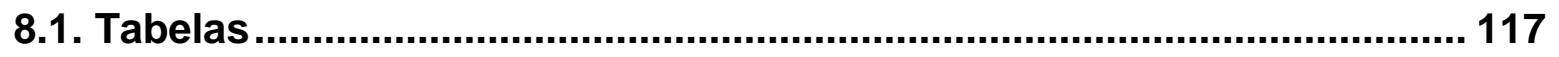

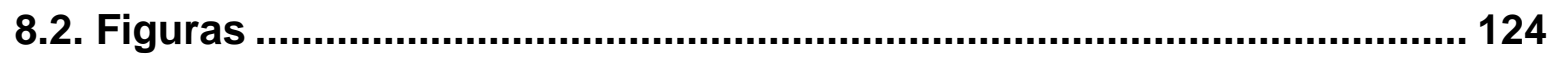

Capítulo 9 - Referências Bibliográficas ...................................................... 127 


\section{Termos e Siglas Adotados}

$\left[\mathrm{Cu}(\mathrm{HL})\left(\mathrm{NO}_{3}\right)_{2}\right] \cdot \mathrm{H}_{2} \mathrm{O},(2$-acetilpiridinabenzoilhidrazona)dinitratocobre(II)

$\left[(\mathrm{Cu})_{2} \mu(\mathrm{CH} 3 \mathrm{COO})_{2}(\mathrm{HL})_{2}\right], \mu$-diacetatobis[(2-acetilpiridinabenzoilhidrazona)cobre(II)

[(Cu)(HL)2], Bis(2-acetilpiridinabenzoilhidrazona)cobre(II)

$\left[\mathrm{Cu}_{2}(\mathrm{HL})_{2}\left(\mathrm{SO}_{4}\right)\right], \mu$-sulfatobis[(2-acetilpiridinabenzoilhidrazona)cobre(II)]

HL, ligante 2-acetilpiridina-benzoilhidrazona

HOMO, "Highest Occupied Molecular Orbital", orbital molecular ocupado de mais alta energia

ICT, "Intramolecular Charge Transfer", transferência de carga intramolecular

IR, do Inglês "Infra Red", que é a região do espectro eletromagnético que tem início em, aproximadamente, $780 \mathrm{~nm}$ e finaliza-se em torno de $300.000 \mathrm{~nm}$

LUMO, "Lowest Unoccupied Molecular Orbital", orbital molecular não ocupado de mais baixa energia

MLCT, "Metal-to-Ligand Charge Transfer", transferência de carga do metal para o ligante

RMSD "Root Mean Square Deviation", refere-se ao desvio médio quadrático.

SCF "Self Consistent Field", campo autoconsistente 


\section{Tabelas}

Tabela 3.1. Desvio médio absoluto para os valores de referencia e amplitude do erro entre parênteses (desvio máximo - desvio minimo) para os diferentes conjuntos de testes. [68] 39

Tabela 5.1.1 Comparação entre as cargas de Mulliken nos átomos envolvidos na coordenação do ligante $\mathrm{HL}$ com o complexo [Cu(HL)(NO$\left.)_{3}\right)_{2}$ e do ligante $\mathrm{HL}$ isolado (M06/LANL2DZ e 6-31g(d,p)) .62

Tabela 5.1.2. Comprimentos de ligação (Å) e ângulos (graus) para o complexo [Cu(HL)(NO$\left.)_{3}\right)_{2}$ calculados com a presença de metanol como solvente (modelo IEFPCM).

Tabela 5.1.3. Comparação entre os comprimentos (angstrom) e ângulos (graus) de ligação selecionados para os complexos de nitrato de cobre (II) [Cu(HL)( $\left.\left.\mathrm{NO}_{3}\right)_{2}\right]$, e acetato de cobre (II) [Cu(HL)(CH3COO)] 2 , medidos experimentalmente e calculados com o funcional MO6. 68

Tabela 5.2.1. Comparação entre os comprimentos (angstrom) e diedro (graus) de ligação selecionados para os complexos de nitrato de cobre (II) [Cu(HL)( $\left.\mathrm{NO}_{3}\right)_{2}$, e acetato de cobre (II) [Cu(HL)(CH3COO)] 2 , medidos experimentalmente e calculados com o funcional MO6. 78

Tabela 5.2.2 Comparação entre as cargas de Mulliken, ChelpG e NBO nos átomos envolvidos na coordenação do ligante $\mathrm{HL}$ com o complexo $\left[(\mathrm{Cu})_{2} \mu(\mathrm{CH} 3 \mathrm{COO})_{2}(\mathrm{HL})_{2}\right]$ e do $\begin{array}{lllll}\text { ligante } H L & \text { isolado } & \text { 6-31g(d,p)) }\end{array}$ 80

Tabela 5.2.3. Bandas nos espectros de infravermelho $\left(\mathrm{cm}^{-1}\right)$ do complexo $\left[(\mathrm{Cu})_{2} \mu(\mathrm{CH} 3 \mathrm{COO})_{2}(\mathrm{HL})_{2}\right]$ para os funcionais especificados na tabela e os conjuntos de bases atômicas LANL2DZ e 6-31g(d,p)). Os valores experimentais relatados são de compostos análogos. [1] 86

Tabela 5.3.1. Comparação entre os comprimentos (angstrom) e diedro (graus) de ligação selecionados para os complexos de acetato de cobre (II) [Cu(HL)(CH3COO)] 2 , e acetilacetona de cobre $\left[(\mathrm{Cu})(\mathrm{HL})_{2}\right]$, medidos experimentalmente e calculados com o funcional MO6. .92

Tabela 5.3.2 Comparação entre as cargas de Mulliken, ChelpG e NBO nos átomos envolvidos na coordenação do ligante $\mathrm{HL}$ com o complexo $\left[(\mathrm{Cu})_{2}(\mathrm{HL})_{2}\right]$ e do ligante $\mathrm{HL}$ isolado (MO6/LANL2DZ e 6-31g(d,p)). 95 
Tabela 5.3.3. Bandas nos espectros de infravermelho $\left(\mathrm{cm}^{-1}\right)$ do complexo $\left[(\mathrm{Cu})_{2}(\mathrm{HL})_{2}\right]$ medidas experimentalmente e para os funcionais especificados na tabela $e$ os conjuntos de bases atômicas LANL2DZ e 6-31g(d,p)). ....................98

Tabela 5.4.1. Comparação entre as cargas de Mulliken e cargas ChelpG nos átomos envolvidos na coordenação do ligante com o complexo $\left[\mathrm{Cu}_{2}\left(\mathrm{HL}_{2}\left(\mathrm{SO}_{4}\right)\right]\right.$ e do ligante $\mathrm{HL}$ isolado (MO6/LANL2DZ e 6-31g(d,p)). .111

Tabela 5.4.2. Bandas nos espectros de infravermelho $\left(\mathrm{cm}^{-1}\right)$ do complexo [Cu $2\left(\mathrm{HL}_{2}\left(\mathrm{SO}_{4}\right)\right]$ para os funcionais especificados na tabela es conjuntos de bases atômicas LANL2DZ e 6-31g(d,p)). 114

Tabela 8.1. Comprimentos (angstrom) e ângulos (graus) de ligação selecionados para o ligante 2-acetilpiridinabenzoilhidrazona $\mathrm{HL}$. 117

Tabela 8.2. Comprimentos (angstrom) e ângulos (graus) de ligação selecionados para - complexo (2-acetilpiridinabenzoilhidrazona) dinitratocobre(II) [Cu(HL)(NO $\left.)_{3}\right)_{2}$. 118

Tabela 8.3. Comprimentos (angstrom) e ângulos (graus) de ligação selecionados para - complexo $\mu$-diacetatobis[(2-acetilpiridinabenzoil hidrazona)cobre(II) $\left[(\mathrm{Cu})_{2} \mu\left(\mathrm{CH} 3 \mathrm{COO}_{2}(\mathrm{HL})_{2}\right]\right.$. 120

Tabela 8.4. Comprimentos (angstrom) e ângulos (graus) de ligação selecionados para o complexo Bis(2-acetilpiridinabenzoilhidrazona)cobre(II) [(Cu)( $\left.\mathrm{HL})_{2}\right]$. 121

Tabela 8.5. Comprimentos (angstrom) e ângulos (graus) de ligação selecionados para - complexo $\mu$-sulfatobis[(2-acetilpiridinabenzoilhidrazona)cobre(II)] [Cu $\left.\mathrm{Cu}_{2}(\mathrm{HL})_{2}\left(\mathrm{SO}_{4}\right)\right]$. 


\section{Figuras}

Figura 1.1. Estrutura genérica das hidrazonas. $R_{1}, R_{2}$ e $R_{3}=$ grupos alquila ou arila.

\begin{tabular}{|c|c|c|c|c|c|c|c|}
\hline Figura & 1.2. & Representação & $d a$ & estrutura & molecular & do & complexo \\
\hline
\end{tabular}

Figura 1.3. Hidrazonas com propriedades biológicas sintetizadas por Salgin-Goksen e colaboradores. Em (a) 2-[2-acetil(5-Metil-2-benzoxazolinona-3-il)]4-clorobenzilideno hidrazina e em (b) 2 - [2-acetil (5-Metil-2-benzoxazolinona-3-il)] -4 - metoxibenzilideno hidrazina. ${ }^{[30]}$ .5

Figura 1.4. Hidrazonas 1 a-3a estudadas por Ros e colaboradores. ${ }^{[9]}$...................6

Figura 1.5. Hidrazonas relatadas por Veljkovic' e colaboradores. ${ }^{[35]}$....................7

Figura 1.6. Estrutura molecular do ligante $A P B H$ à esquerda e do complexo $[(\mathrm{APBH}) \mathrm{CuCl}]_{2 .}(\mathrm{EtOH})_{2}$ (Representação ORTEP - 50\% thermal ellipsoids). ${ }^{[43] . . . . . . . . . .8}$

Figura 3.1. Energias de interação dos dimeros adenina e timina (kcal.mol-1). A melhor estimativa foi feita usando MP2/TZVP e o conjunto de bases 6-31+G(d, p) foi empregado em todos os demais cálculos. [69].

Figura 5.0. Ligante 2-acetilpiridina-benzoilhidrazona, sem hidrogênios e numerado de acordo com o que aparece no texto e na Tabela 8.1...................41

Figura 5.1.1. Nitrato de 2-acetilpiridina-benzoilhidrazonacobre(II), com numeração utilizada nas tabelas e no texto. Átomos de hidrogênio não aparecem para melhorar a visualização. .43

Figura 5.1.2. Detalhe da estrutura apresentada na Figura 5.1.1, evidenciando a numeração do Cu(II) e dos átomos presentes na esfera de coordenação com numeração usada na Tabela 8.2.........................................................45

Figura 5.1.3. Orbital natural HOMO do complexo Nitrato de 2-acetilpiridinabenzoilhidrazonacobre(II) evidenciando o caratér $\mathrm{dz}^{2}$ sobre o cobre(II). .46

Figura 5.1.4. Mapas de potencial eletrostático em (a) ligante HL e em (b) do complexo Nitrato de 2-acetilpiridina-benzoilhidrazonacobre(II). 48

Figura 5.1.5. Cela unitária experimental do complexo Nitrato de 2-acetilpiridinabenzoilhidrazonacobre(II), na qual encontram-se destacadas em preto as distâncias $\mathrm{Cu}$-Cu entre moléculas vizinhas (experimental). 50 
Figura 5.1.6. Estrutura cristalina do complexo $\left[\mathrm{Cu}(\mathrm{HL})\left(\mathrm{NO}_{3}\right)_{2}\right]$ vista ao longo do eixo a. Podemos ver a propagação da cadeia em zig zag decorrente do empacotamento da estrutura. 51

Figura 5.1.7. Comparação entre o espectro de infravermelho experimental (linha continua) e os seu análogo calculado (linha vermelha), do complexo [Cu(HL)(NO$)_{2}$ ], usando o funcional MO6, associado aos conjuntos de bases LANL2DZ para o cobre e 6-31g(d,p) para os demais átomos.. 57

Figura 5.1.8. Espectro eletrônico experimental (linha continua) e teórico (m06/LANL2DZ+6-31g(d,p) no qual cada linha vertical amarelo escuro corresponde a uma excitação eletrônica para o complexo $\left[\mathrm{Cu}(\mathrm{HL})\left(\mathrm{NO}_{3}\right)_{2}\right] \ldots . . . . . .60$

Figura 5.1.9. Orbitais moleculares HOMO-14 (esquerda) e LUMO (direita) do complex $\left[\mathrm{Cu}(\mathrm{HL})\left(\mathrm{NO}_{3}\right)_{2}\right]$ envolvidos na transição eletrônica calculada em 302.7nm. .61

Figura 5.1.10. Orbitais moleculares HOMO-8 (esquerda) e LUMO (direita) do complexo $\left[\mathrm{Cu}\left(\mathrm{HL}_{(}\left(\mathrm{NO}_{3}\right)_{2}\right]\right.$ envolvidos na transição eletrônica calculada em $361,99 \mathrm{~nm}$. 62

Figura 5.1.11. Orbitais moleculares HOMO-17 (esquerda) e LUMO (direita) do complexo [Cu(HL)(NO$\left.{ }_{3}\right)_{2}$ envolvidos na transição eletrônica calculada em 267,49 $\mathrm{nm}$. 63

Figura 5.2.1. O complexo $\mu$-Diacetato de bis (2 - acetilpiridina-benzoilhidrazona cobre(II)), [(Cu $)_{2} \mu\left(\mathrm{CH} 3 \mathrm{COO}_{2}(\mathrm{HL})_{2}\right]$, sem hidrogênios e com numeração usada no texto e na Tabela 8.3. 64

Figura 5.2.2. Detalhe da estrutura do complexo $\left[(\mathrm{Cu})_{2} \mu(\mathrm{CH} 3 \mathrm{COO})_{2}(\mathrm{HL})_{2}\right]$, apresentada na Figura 5.2.1, evidenciando a numeração dos átomos de Cu(II) e dos de oxigênio do grupamento acetato responsáveis pela ponte entre as duas unidades coordenativas com numeração usada na Tabela 8.3......................66

Figura 5.2.3. Detalhe da esfera de coordenação de um dos átomos do cobre (II) do complexo $\left[(\mathrm{Cu})_{2} \mu(\mathrm{CH} 3 \mathrm{COO})_{2}(\mathrm{HL})_{2}\right]$ apresentada na Figura 5.2.1, evidenciando a numeração dos átomos coordenados ao cobre. 71

Figura 5.2.4 Mapa de potencial eletrostático do complexo $\mu$-Diacetato de bis (2 acetilpiridina - benzoilhidrazona cobre(II)). 73

Figura 5.2.5. Espectro vibracional do complexo $\left[(\mathrm{Cu})_{2} \mu(\mathrm{CH} 3 \mathrm{COO})_{2}(\mathrm{HL})_{2}\right]$, advindo das frequências vibracionais calculadas com os funcionais B3LYP (vermelho) e MO6 (amarelo escuro). 75 
Figura 5.2.6. Espectro eletrônico experimental e teórico (m06/LANL2DZ+6-31g(d,p) no qual a linha contínua em preto é o espectro teórico e cada linha vertical amarelo escuro corresponde a uma excitação eletrônica para o complexo $\left[(\mathrm{Cu})_{2} \mu\left(\mathrm{CH} 3 \mathrm{COO}_{2}(\mathrm{HL})_{2}\right]\right.$. . .77

Figura 5.2.7. Orbitais moleculares HOMO-2 (a), LUMO+2 (c) do complexo $\left[(\mathrm{Cu})_{2} \mu\left(\mathrm{CH} 3 \mathrm{COO}_{2}(\mathrm{HL})_{2}\right]\right.$ envolvidos na transição eletrônica calculada em 379,00 $\mathrm{nm}$. .78

Figura 5.2.8. Orbitais moleculares HOMO-2O (a), HOMO-17 (b) e LUMO (c) do complexo $\left[(\mathrm{Cu})_{2} \mu\left(\mathrm{CH} 3 \mathrm{COO}_{2}(\mathrm{HL})_{2}\right]\right.$ envolvidos na transição eletrônica calculada em 453.71 nm. .79

Figura 5.2.9. Orbitais moleculares HOMO-6 (a), e LUMO (b) do complexo $\left[(\mathrm{Cu})_{2} \mu\left(\mathrm{CH} 3 \mathrm{COO}_{2}\left(\mathrm{HL}_{2}\right]\right.\right.$ envolvidos na transição eletrônica calculada em $644,28 \mathrm{~nm}$. .80

Figura 5.3.1. O complexo Bis (2 - acetilpiridinabenzoilhidrazona)cobre(II), [(Cu)(HL)2], sem hidrogênios e com numeração usada no texto e na Tabela 8 ....81

Figura 5.3.2. Cela unitária experimental do complexo Bis $(2$ acetilpiridinabenzoilhidrazona)cobre(II), na qual encontra-se destacada em preto a menor distância entre moléculas vizinhas (em angstron) (experimental)... 83

Figura 5.3.3 Mapa de potencial eletrostático do complexo Bis (2 acetilpiridinabenzoilhidrazona)cobre(II)... 84

Figura 5.3.4. Representação do complexo $\left[(\mathrm{Cu})_{2}(\mathrm{HL})_{2}\right]$, na qual as cores representam as cargas ChelpG (a) e cargas NBO (b) distribuidas no complexo, conforme escala de cores acima, na qual vermelho é o mais negativo e verde o mais positivo. A escala de cores vai de $-0,05$ a $+0,05$ para ambos os esquemas de cargas. .86

Figura 5.3.5. Comparação entre o espectro de infravermelho experimental (linha preta) e o seu análogo calculado (linhas amarelo escuro), do complexo [Cu $2\left(\mathrm{HL}_{2}\right.$ ], usando o funcional MO6, associado aos conjuntos de bases LANL2DZ para o cobre e 6-31g(d,p) para os demais átomos.......................................................................................8 87

Figura 5.3.6. Espectro eletrônico experimental e teórico m06/LANL2DZ+6-31g(d,p) no qual a linha continua em preto é o espectro teórico e cada linha vertical amarelo escuro corresponde a uma excitação eletrônica calculada para o complexo $\left[(\mathrm{Cu})_{2}(\mathrm{HL})_{2}\right]$. .90 
Figura 5.3.7. Orbitais moleculares HOMO-2 (a), HOMO-1 (b) e LUMO do complexo $\left[(\mathrm{Cu})_{2}(\mathrm{HL})_{2}\right]$ envolvidos na transição eletrônica calculada em 382,93 $\mathrm{nm}$........91

Figura 5.3.8. Orbitais moleculares HOMO-3 (a), LUMO (b) do complexo [(Cu)(HL) envolvidos na transição eletrônica calculada em 387,76 nm......................92

Figura 5.3.9. Orbitais moleculares HOMO-5 (a), HOMO-3 (b) e LUMO (c) do complexo [(Cu)(HL) $)_{2}$ envolvidos na transição eletrônica calculada em 476,39 $\mathrm{nm}$. .93

Figura 5.4.1. Estrutura geométrica do complexo [Cu usada na Tabela 5.5.1. Hidrogênios omitidos para melhor visualização.......95

Figura 5.4.2. Orbitais moleculares de Kohn-Sham do complexo [Cu $\left.\mathrm{Cu}_{2}(\mathrm{HL})_{2}\left(\mathrm{SO}_{4}\right)\right]$, em (a) orbital molecular 150 (HOMO-18) e em (b) orbital molecular 153 (HOMO-15). .97

Figura 5.4.3. Representação esquemática da cela unitária do complexo $\left[\mathrm{Cu}_{2}\left(\mathrm{HL}_{2}\left(\mathrm{SO}_{4}\right)\right]\right.$, na qual cada cor representa uma operação de simetria na cela unitária. .99

Figura 5.4.4. Mapa de potencial eletrostático do complexo [Cu $\left(\mathrm{HL}_{2}\left(\mathrm{SO}_{4}\right)\right]$, no qual as cores representam as regiões de cargas distribuidas no complexo, conforme escala de cores, na qual vermelho é o mais negativo e azul o mais positivo. A escala de cores vai de $-0,05$ (extremo vermelho) a +0,05 (extremo azul). ..................................................................................................100

Figura 5.4.5. Representação do complexo $\left[\mathrm{Cu}_{2}(\mathrm{HL})_{2}\left(\mathrm{SO}_{4}\right)\right]$, na qual as cores representam as cargas de Mulliken (a) e cargas ChelpG (b) distribuidas no complexo, conforme escala de cores, na qual vermelho é o mais negativo e verde o mais positivo. A escala de cores vai de -0,05 a +0,05 para ambos os esquemas de cargas. 102

Figura 5.4.6. Espectro de infravermelho do complexo $\left[\mathrm{Cu}_{2}\left(\mathrm{HL}_{2}\left(\mathrm{SO}_{4}\right)\right]\right.$, no qual a linha continua negra é o resultado experimental e a linha amarelo escuro é o cálculo advindo das frequências vibracionais calculadas com MO6. 103

Figura 5.4.7. Espectro de UV-VIS do complexo $\left[\mathrm{Cu}_{2}\left(\mathrm{HL}_{2}\left(\mathrm{SO}_{4}\right)\right]\right.$, no qual a linha continua $\dot{e} o$ resultado experimental $e$ as linhas verticais correspondem as excitações calculadas usando MO6/LANL2DZ + 6-31g(d,p). 106

Figura 5.4.8. Orbitais moleculares com maior contribuição probabilistica envolvidos nas transições eletrônicas principais do complexo [Cu $2\left(\mathrm{HL}_{2}\left(\mathrm{SO}_{4}\right)\right]$, (a) $\mathrm{HOMO}-20$, (b) LUMO, (c) HOMO-9, (d)LUMO+2, (e) HOMO-1, (f)LUMO+5, (g) HOMO-3 e (h) LUMO+ 1 108 
Figura 5.5.1. Gráfico de barras do RMSD comparativo entre os funcionais utilizados neste trabalho e cada um dos quatro complexos estudados..............111

Figura 5.5.2. Máximos, mínimos e média calculados a partir do RMSD para cada um dos funcionais utilizados neste trabalho levando em conta as otimizações geométricas dos quatro complexos estudados............................................112

Figura 8.1. Comparação entre o espectro de infravermelho experimental (linha preta) e o seu análogo calculado (linhas amarelo escuro), do ligante (HL), usando o funcional MO6, associado aos conjuntos de bases LANL2DZ para o cobre e 6-31g(d,p) para os demais. .125

Figura 8.2. Espectro eletrônico experimental e teórico m06/LANL2DZ+6-31g(d,p) no qual a linha continua em preto é o espectro teórico e cada linha vertical amarelo escuro corresponde a uma excitação eletrônica calculada para o complexo

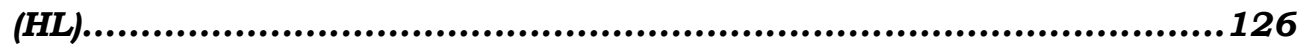




\section{Abstract}

In this work, we have carried out a theoretical study of four copper (II) complexes with hydrazone ligand. The studied copper complexes are: (2-acetylpyridine benzoylhydrazone) dinitratecopper (II), $\mu$-diacetatebis [(2-hydrazone acetylpyridinebenzoyl)copper(II), bis (2-acetylpyridinebenzoylhydrazone)copper(II) and $\mu$ sulfatebis [(2 -acetylpyridinebenzoyl hidrazone) copper (II)].

The choice of these compounds is due to the interest in developing new complex combined with biological activity. This is an experimental theoretical collaboration, in which these compounds were synthesized and characterized by X-ray diffraction, spectroscopy studies including the infrared and ultraviolet-visible, by the Structural Crystalography group, $\mathrm{IQ}$ - UnB, direct by Dr Claudia Cristina Gatto.

The structures from X-ray diffraction measurements were optimized and had their vibrational frequencies calculated, using the DFT, by two types of methodologies: atom located bases and plane waves. For the first methodology we used the density functionals, B3LYP PBE1PBE, B3PW91, M06 and w-B97-XD (hybrids), CAM-B3LYP (long-range hybrid), B97-D (pure), and the set of atomic bases LANL2DZ for copper and 6-31G (d, p) for other atoms.

For the second method, plane waves were used with the version developed for solids of the GGA functional, the PW91 functional. To avaluate the quality of geometry optimization results, we calculated the root mean square deviation, which was related to the characteristics of each functional and allowed the understanding of the differences between calculated and experimental values.

Functional M06 was chosen for the calculations of electronic spectroscopy, as it presented the best results in geometric optimization calculations. The results of these calculations allowed to investigate the nature of the bands involved in major transitions for these compounds. The spectroscopic behavior of the compounds was compared for with experimental measurements and analogous compounds in the literature. All of these results may be useful as descriptors used in the analysis of biological activity. 


\section{Resumo}

Neste trabalho, realizou-se o estudo teórico de quatro complexos de cobre (II) com ligante hidrazona. Os complexos de cobre estudados são: (2-acetilpiridina benzoilhidrazona)dinitratocobre(II), $\quad \mu$-diacetatobis[(2-acetilpiridinabenzoil hidrazona) cobre(II), Bis(2-acetilpiridinabenzoilhidrazona)cobre(II) e $\quad \mu$-sulfatobis[(2acetilpiridinabenzoilhidrazona)cobre(II)].

A escolha destes compostos deve-se ao interesse do desenvolvimento de novos complexos aliados a atividade biológica. Esta é uma colaboração teórico- experimental, no qual estes compostos foram sintetizado e caracterizados por difração de Raios-X, incluindo estudos de espectroscopia no infravermelho e ultravioleta-visível, realizados no Laboratório de Cristalografia Estrutural, IQ - UnB, coordenado pela Prof ${ }^{a}$ Dr $^{\mathrm{a}}$ Claudia Cristina Gatto.

As estruturas provenientes das medidas de difração de Raios-X foram otimizadas e tiveram suas frequências vibracionais calculadas, usando DFT, por dois tipos de metodologias: bases atômicas localizadas e ondas planas. Para a primeira metodologia foram usados os funcionais da densidade B3LYP, PBE1PBE, B3PW91, M06 e w-B97-XD (híbridos), CAM-B3LYP (híbrido de longo alcance), B97-D (puro), e o conjunto de bases atômicas LANL2DZ para o cobre e 6-31G(d, p) para os demais átomos.

Para a segunda metodologia, foi usada a versão desenvolvida para sólidos do funcional GGA, do funcional PW91. Para avaliar a qualidade dos resultados de otimização de geometria, foram calculados o desvio quadrático médio, que foi relacionado às características de cada funcional e possibilitou o entendimento dos desvios entre valores calculados e experimentais.

O funcional M06 foi escolhido para os cálculos de espectroscopia eletrônica, pois apresentou os melhores resultados nos cálculos de otimização geométrica. Os resultados desses cálculos possibilitaram investigar a natureza das bandas envolvidas nas principais transições para esses compostos. O comportamento espectroscópico calculado para os compostos foi comparado com as medidas experimentais e compostos análogos da literatura. Todos estes resultados poderão ser úteis como descritores utilizados na análise da atividade biológica. 


\section{Capítulo 1 - Revisão Bibliográfica}

\section{1 - Introdução}

A modelagem molecular de complexos metálicos para fins terapêuticos pode auxiliar na busca racional de novos potenciais fármacos, através da elucidação da estrutura dos complexos em estudo, além do conhecimento acerca da estrutura eletrônica do composto. [1] [2]

Como aplicação farmacológica, entre outros exemplos, pode-se citar: compostos de platina, utilizados no tratamento do câncer; assim como compostos de ouro, utilizados no tratamento de artrite reumatóide; compostos de prata, usados como agentes antimicrobianos; e compostos de mercúrio, foram utilizados como diuréticos ${ }^{[3]}$ [4] [5]

Hidrazonas compõem uma classe de compostos, que apresentam complexas propriedades biológicas, incluindo antitumoral, antifúngica, antituberculose e anticonvulsivantes. [6] [7] [8] [9] [10] Estes compostos são frequentemente usados como ligantes, em química de coordenação, por possuírem um grupamento azotina $-\mathrm{NHN}=\mathrm{CH}$ - e alguns de seus complexos metálicos apresentam propriedades biológicas acentuadas. [11] [12] Assim, a busca de complexos que potencializem essas propriedades biológicas é um campo em franca expansão.

Dessa forma, ao investigar do ponto-de-vista teórico, produtos de síntese de complexos, com ligantes hidrazona, ${ }^{[13]}\left[{ }^{[14]}\left[{ }^{[15]}\left[{ }^{[16]}\right.\right.\right.$ visando auxiliar na elucidação da estrutura em nível mais fundamental, além desse esclarecimento que por si só, que já seria de grande valia, existe também a possibilidade de aplicação desse conhecimento a fim de propor derivados mais viáveis para aplicação como fármacos, e o desenvolvimento de uma metodologia, que leve em consideração o 
balanço entre esforço computacional e qualidade de resultados, podendo inclusive ser aplicada a sistemas análogos.

Nesse contexto, analisamos teoricamente quatro complexos de cobre(II), derivados do acetato, nitrato, acetilacetona e sulfato de cobre ${ }^{[17]}$, sintetizados e caracterizados por difração de Raios-X, pelo grupo de química de complexos da Profa. Claudia Gatto, do IQ. Estes compostos serão alvo deste estudo estrutural e eletrônico, através de DFT.

\section{2 - Hidrazonas}

Hidrazonas (Figura 1.1) são moléculas extensivamente investigadas na literatura, classificam-se como bases de Schiff. São iminas que possuem grupo hidrocarbil sobre o átomo de nitrogênio $R_{2}$, possuem quimiosseletividade de aldeídos ou cetonas com hidrazidas, seguida por eliminação de uma molécula de água. ${ }^{[18]}$

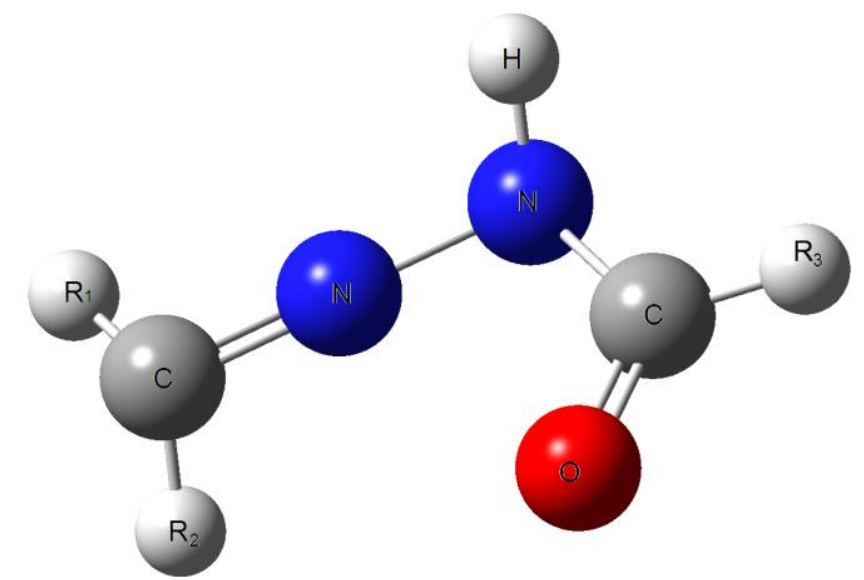

Figura 1.1. Estrutura genérica das hidrazonas. $R_{1}, R_{2}$ e $R_{3}=$ grupos alquila ou arila.

Esses compostos são reconhecidos pela sua versatilidade quanto à coordenação com metais devido a fatores como: flexibilidade, ao assumir diferentes conformações, a possibilidade de tautomerismo, e podem ainda ter características 
diferenciadas ao atuar como ligante na forma neutra ou como um ânion. [19] [20] [21] [22]

Além disso, também são visadas devido a sua já descrita ação biológica. Possuem atividade antibacterial, anticonvulsivante, analgésica, anti-inflamatória, antiplaquetária, anticoagulante, trombolítica entre outras. Sendo, portanto um grupo de moléculas bastante investigado pela Química Bioinorgânica Medicinal. [23] [24] [25] [26]

Em 2006, Gudasi et. al., com o objetivo de estudar as propriedades estruturais dos compostos e as características coordenativas das hidrazonas, sintetizaram complexos com metais de transição, utilizando a 2,6diacetilpirinabis(aminobenzoil-hidrazona) $\left(\mathrm{H}_{2}\right.$ dapa). Pode-se destacar um dos complexos de cádmio(II) (Figura 1.2), preparado refluxando uma solução da hidrazona em clorofórmio com uma solução etanólica do sal de cádmio, obtendo-se monocristais pela técnica da evaporação lenta do solvente. [20]

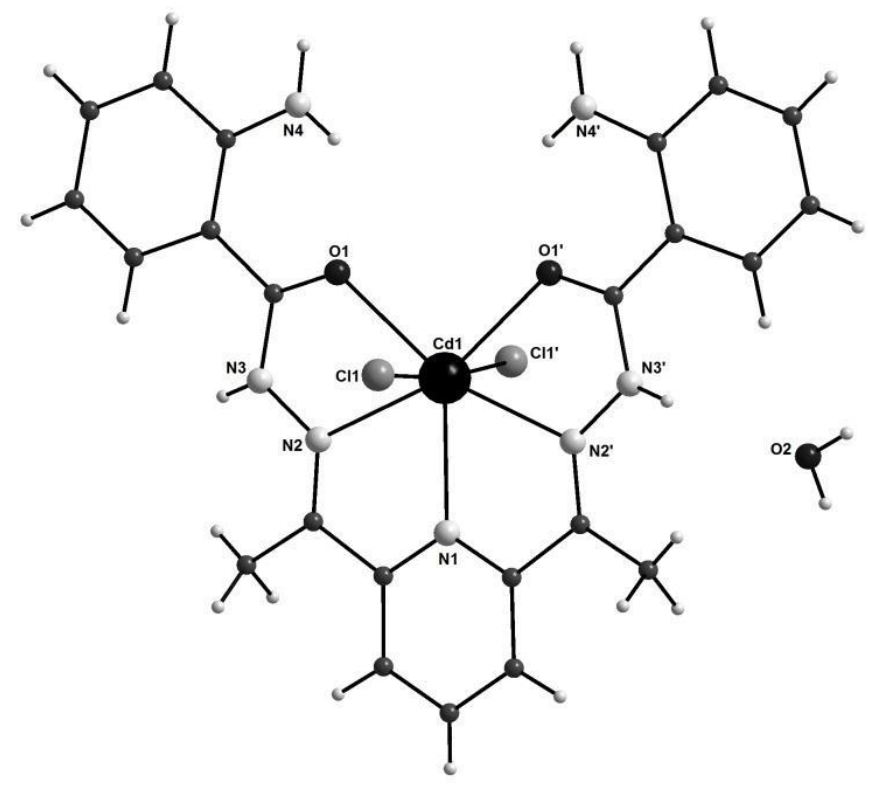

Figura 1.2. Representação da estrutura molecular do complexo [Cd( $\mathrm{H}_{2}$ dapa)( $\left.\mathrm{Cl}_{2} \mathrm{H}_{2} \mathrm{O}\right)$. [20] 
A estrutura simétrica do complexo foi solucionada por análise de difração de Raios-X de monocristais. O átomo de cádmio encontra-se inserido em um poliedro distorcido do tipo bipirâmide pentagonal as posições equatoriais, formando quatro anéis de cinco membros.

Ainda sobre a estrutura da Figura 1.2, é relevante destacar que sua estrutura supramolecular é mantida por interações intermoleculares de hidrogênio estabelecidas devido à presença de moléculas de água como solvente de cristalização. Possuem também ligações de hidrogênio intramoleculares entre átomos de hidrogênios do grupo $\mathrm{NH}_{2}$ e o átomo de oxigênio da carbonila, interações favorecidas ou justificadas pela conformação syn entre os grupos.

Como já mencionado, as hidrazonas possuem ação biológica, desta forma, vários de seus compostos têm suas propriedades estudadas. [27] Uma boa fonte de aprofundamento sobre o assunto é o artigo de revisão de Rollas e Küçükgüzel, que engloba os últimos compostos com ação farmacêutica, sintetizados e testados nesta área, separados pelo tipo de atividade biológica, divididos em atividade anticonvulsiva, atividade antidepressiva, analgésico, anti-inflamatório e anticoagulante, atividade contra malária, antimicrobiana e antibacteriana, antitumoral, vasodilatador, antiviral e contra esquistossomose, além de apresentar no final uma série de outros estudos sobre o mesmo assunto. [8] [28] [29]

Podemos destacar, como exemplos de hidrazonas com atividade biológica, as hidrazidas arilideno com conformação cis e trans sintetizadas por Salgin-Goksen e colaboradores (Figura 1.3). Estas foram avaliadas, quanto à sua atividade analgésica, anti-inflamatória e antimicrobiana. Entre os compostos sintetizados, 2[2-acetil(5-Metil-2-benzoxazolinona-3-il)] 4-clorobenzilideno hidrazina (Figura 1.3a) mostrou uma boa atividade analgésica. Também observaram atividade antiinflamatória exibida por 2 - [2-acetil (5-Metil-2-benzoxazolinona-3-il)] -4 metoxibenzilideno hidrazina (Figura 1.3b) no modelo de carragenina de edema de mão induzido. [30] 

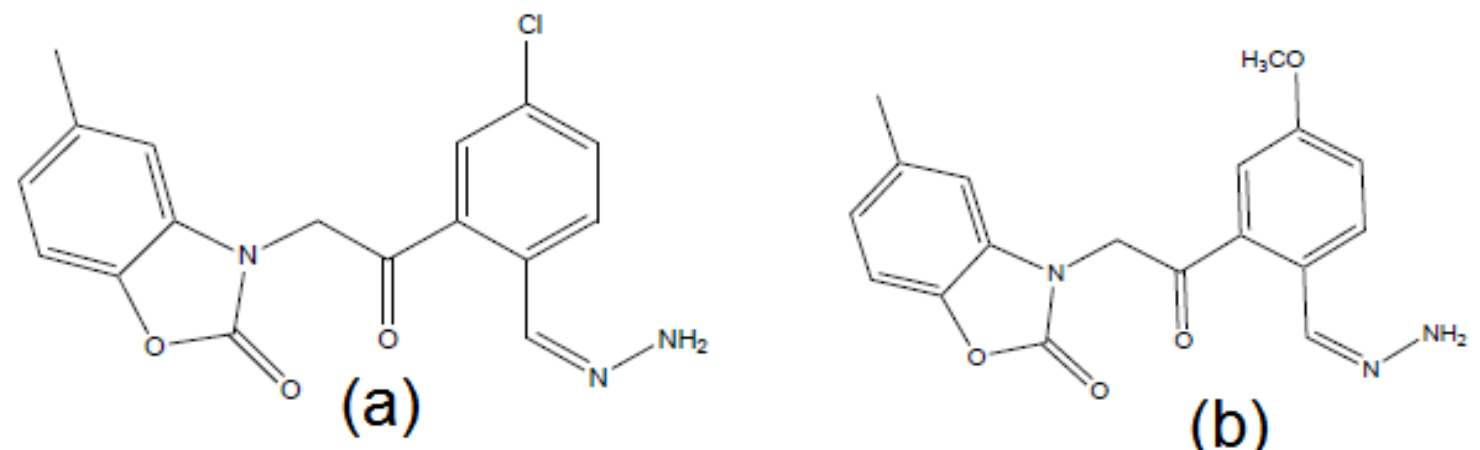

(b)

Figura 1.3. Hidrazonas com propriedades biológicas sintetizadas por Salgin-Goksen e colaboradores. Em (a) 2-[2-acetil(5-Metil-2-benzoxazolinona-3-il)]4-clorobenzilideno hidrazina e em (b) 2 - [2-acetil (5-Metil-2-benzoxazolinona-3-il)] -4 - metoxibenzilideno hidrazina. ${ }^{[30]}$

Considerando a grande versatilidade das hidrazonas e suas promissoras e diversas aplicações biológicas, ${ }^{[11]}$ existe na literatura, uma gama de publicações que buscam esclarecer melhor o comportamento estrutural desses compostos através de cálculos mecânicos quânticos, em geral, aliados aos resultados experimentais de síntese e caracterização. ${ }^{[32]}$

Os complexos hidróxi-hidrazonas N-fenil-N' (2-hidroxi-I-fenilmetileno hydrazina) e N-fenil-N' (2-hidroxi-I-naftilmethileno hidrazina), e seus complexos de cobre foram estudados em misturas de dioxano e água por Ledesma e colaboradores. [33] Foi feita análise estrutural pela técnica de RMN de $13 \mathrm{C}$, espectroscopia de absorção e cálculos semi empíricos (otimização geométrica e calores de formação), usando a metodologia AM1. Com a combinação desses métodos foi possível determinar quais são os isômeros preferenciais e formas ressonantes que estabilizam os ligantes e anions hidróxi-hidrazona estudados.

Ros e colaboradores [9] estudaram as mudanças conformacionais que ocorrem em três compostos do tipo, (2S,5S)-1-amino-2,5-difenilpirrolidina-derivados alifáticos de hidrazonas, em reações de cianolilação assimétrica promovida por $\mathrm{Et}_{2} \mathrm{AICl}$ (Figura 1.4), que resultam em hidrazo nitrilas com alta diasteroseletividade. Os cálculos DFT indicaram que a formação do complexo de hidrazona aumenta a nucleofilicidade do nitrogênio dialquiamino, promovendo a ativação básica do 
trimetilsilil cianida. As geometrias calculadas desses complexos (Figura 1.4) mostram o deslocamento de uma face do silício pela ligação entre carbono e nitrogênio com o auxilio de um dos grupos fenila, provendo dessa forma uma explicação para a configuração absoluta encontrada. [9]
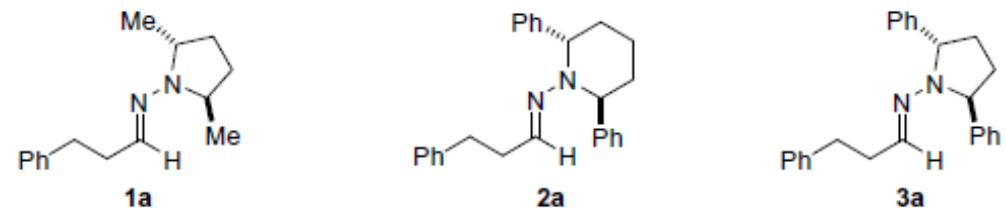

Figura 1.4. Hidrazonas 1 a-3a estudadas por Ros e colaboradores. ${ }^{[9]}$

Usando a mesma metodologia DFT para auxiliar no entendimento dos dados experimentais de estrutura cristalográfica, espectroscopia (UV, IR e massas) e atividade antibacteriana, Ozbek e colaboradores, estudaram a estrutura da hidrazona 2-hidroxi-1-naftaldeído-N-metiletanosulfonilhidrazona e chegaram à conclusão de que a forma tautomérica fenol-imina predomina. Através de cálculos de estrutura eletrônica, foi possível determinar que existe uma ligação de hidrogênio intramolecular forte do tipo O-H N (com distância doador-aceptor de $2.579 \AA$ Å). A disposição angular das ligações sobre o átomo de enxofre promove um desvio da geometria tetraédrica regular como era esperado. Esse desvio pode ser atribuído a interações não ligadas envolvendo as ligações $\mathrm{S}=\mathrm{O}$ e os grupamentos metila tanto na estrutura molecular quanto na cristalina. Assim, os resultados da análise conformacional foram comparados e confirmaram os dados presentes na estrutura cristalográfica. ${ }^{[34]}$

Ainda usando a mesma metodologia DFT, Veljkovic' e colaboradores realizaram uma investigação detalhada de isômeros conformacionais de superbases orgânicas com o pentaciclo [5.4.0.02,6.03,10.05,9]undecano ancorado com aminas e iminas (Figura 1.5), confrontando os dados teóricos com dados experimentais de $\mathrm{RMN}$ e cristalografia de Raios-X. A caracterização estrutural 
realizada por métodos experimentais foi conclusiva e confirmada pelos cálculos teóricos. ${ }^{[35]}$

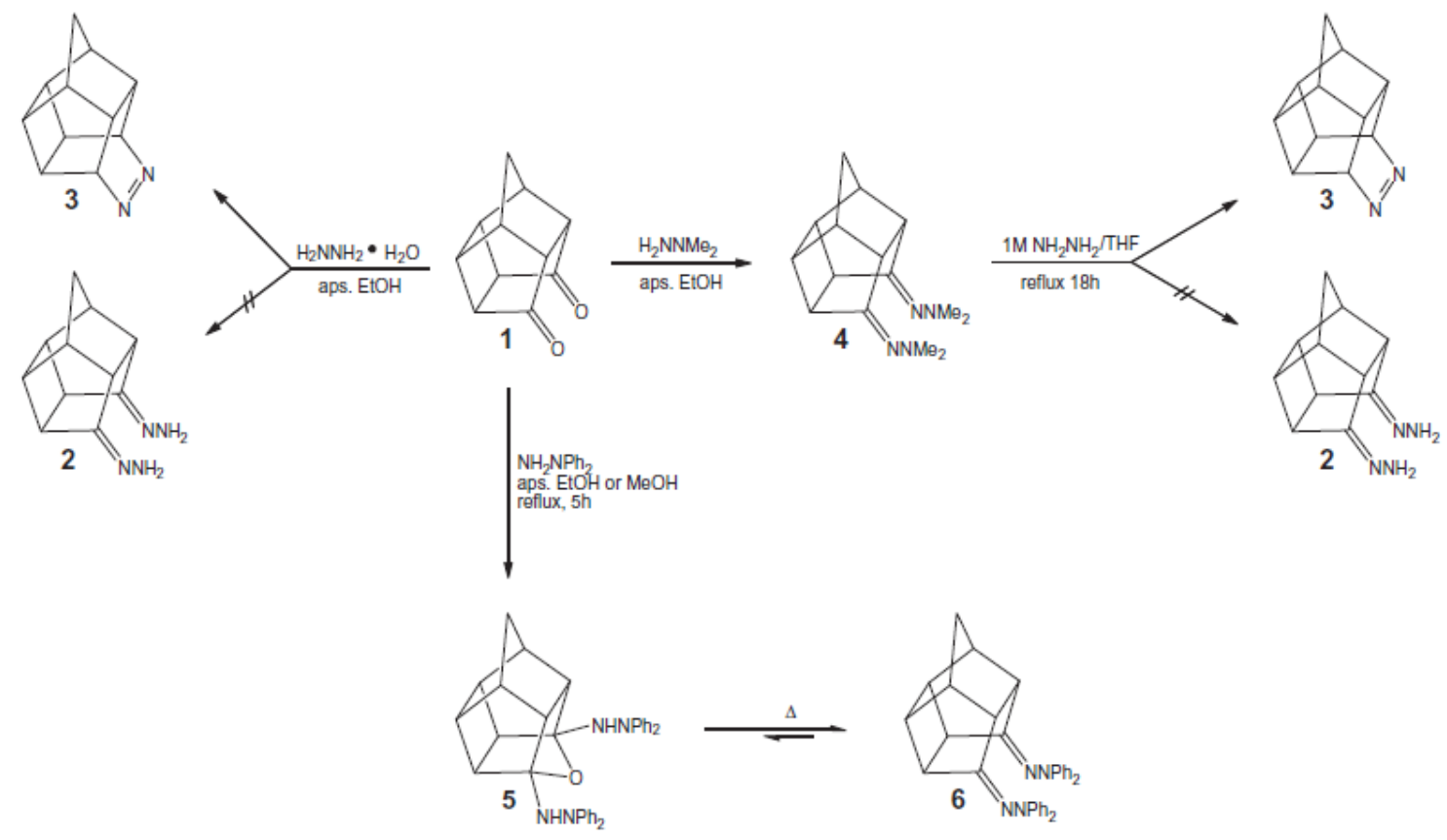

Figura 1.5. Hidrazonas relatadas por Veljkovic' e colaboradores. ${ }^{35]}$

\section{3 - Compostos de coordenação de cobre}

O cobre possui química de coordenação bastante estudada, nos complexos o átomo de cobre (II) pode estar inserido em diferentes poliedros coordenativos. ${ }^{[36]}$ Esse metal normalmente possui número de coordenação variando de quatro a seis que resulta na formação dos seguintes poliedros: quadrado-planar, tetraédricos, piramidal de base quadrada, bipiramidal trigonal ou octaédrica. [37] [38] [39] [40] [41] [42]

O cobre é o terceiro metal de transição mais abundante no corpo humano e também é um elemento vital para plantas e animais. Este metal é um componente catalítico para muitas enzimas, como: citocromo oxidase, ceruloptasmina, emocianina, entre outras. As propriedades biológicas do cobre estimulam 0 desenvolvimento de compostos de coordenação contendo ligantes biologicamente 
ativos, pois drogas administradas na forma de complexos apresentam uma maior atividade em relação às substâncias orgânicas livres.
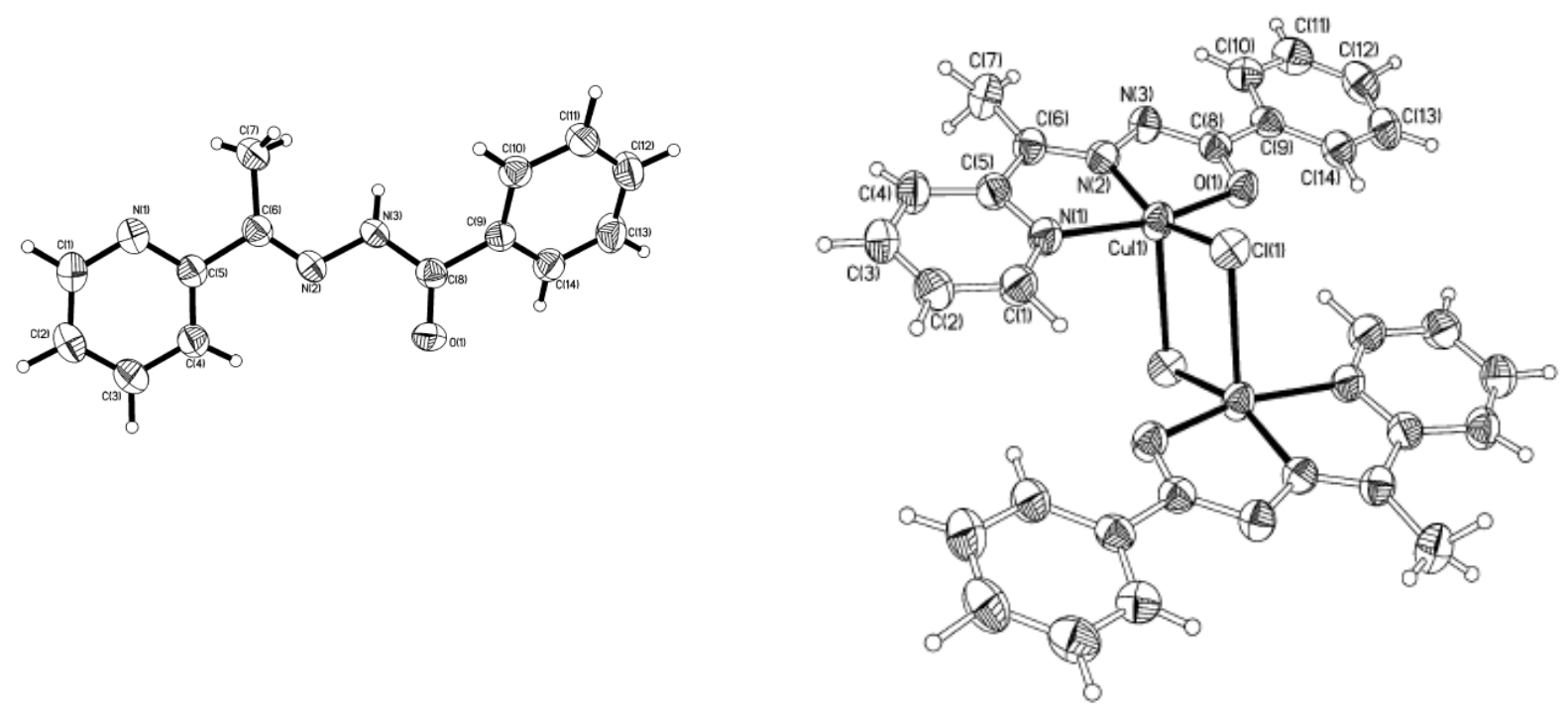

Figura 1.6. Estrutura molecular do ligante APBH à esquerda e do complexo [(APBH)CuCl$]_{2 .}$ (EtOH) $)_{2}$ (Representação ORTEP - 50\% thermal ellipsoids). [43]

Os compostos de cobre são comumente utilizados para síntese de complexos metálicos, principalmente devido à acessibilidade dos seus derivados quanto à disponibilidade e preço. Desta forma, complexos de cobre com ligantes hidrazona têm sido amplamente sintetizados, caracterizados e testadas suas propriedades biológicas para uma série de aplicações. ${ }^{[44] ~[45] ~[46] ~[47] ~[48] ~[49] ~[50] ~[51] ~[52] ~}$ ligante acetilpiridina benzoil hidrazona (APBH), e o complexo de cobre $[(\mathrm{APBH}) \mathrm{CuCl}]_{2 .}(\mathrm{EtOH})_{2}$ (Figura 1.6) foram caracterizados estruturalmente por análise elementar, medidas magnéticas, eletroquímica e difração de Raios-X de monocristal. [43]

O ligante assume a forma de isômero Z e geometria planar no estado sólido, coordenado com o nitrogênio piridínico, nitrogênio da azometina e o oxigênio carbonílico do grupamento benzoil. O complexo de cobre é dimérico e possui geometria octaédrica distorcida com dos átomos de cobre em ponte por dois átomos de cloro. A medida de atividade antimicrobacteriana versus Mycobacterium 
smegmatis do complexo e do ligante mostra claramente um incremento dessa atividade devido à complexação. ${ }^{[43]}$

\section{Capítulo 2 - Objetivos}


O estudo da estrutura eletrônica e propriedades de complexos polinucleares é a vertente mais importante da moderna química de coordenação. Para complexos polinucleares, o padrão de interações de troca depende em detalhes da geometria e estrutura eletrônica das moléculas em maior grau, quando comparado a complexos de coordenação tradicionais. A elucidação da relação entre os parâmetros de interações de troca e as características estruturais dos complexos, atuam como importantes ferramentas para entender as propriedades advindas das interações de acoplamento e troca desses sistemas, resolvendo assim importantes questões estruturais envolvidas. [53]

Objetiva-se uma completa descrição do complexo, incluindo estrutura eletrônica, geometria, energia, propriedades fotofísicas, a fim de prover o estudo experimental de suporte para a determinação estrutural e de espectros.

A combinação entre experimentação e teoria proporciona uma visão aprofundada do problema, e consequentemente leva a uma compreensão mais acurada acerca do sistema em estudo. Dessa forma, os dados experimentais disponibilizados são de fundamental importância para o desenvolvimento e validação da presente proposta.

Este estudo proporciona um ótimo ambiente para análise de performancede funcionais de densidade, desta forma vários níveis de teoria são usados para que haja um balanço adequado entre esforço computacional e qualidade dos resultados a serem obtidos. Assim, é um objetivo importante deste projeto comparar os métodos disponíveis para avaliar a estabilidade estrutural dos complexos em estudos e estimar os parâmetros termodinâmicos relacionados à formação dos mesmos. Ademais, esses dados são comparados com os parâmetros obtidos experimentalmente, a fim de determinar a melhor metodologia.

A partir desse estudo, aliado aos dados experimentais, pretende-se:

a) Contribuir para um melhor conhecimento da relação entre o complexo e o ligante hidrazona, e o modo como essa interação ocorre preferencialmente; 
b) Estudar do ponto-de-vista químico quântico a estrutura dos complexos mono e polinucleares, visando contribuir para a obtenção de compostos com características farmacológicas melhoradas;

c) Empregando os resultados de simulações/modelagem molecular, embasar e enriquecer a interpretação de dados de caracterização estrutural e de propriedades espectroscópicas para os complexos a serem estudados. 


\section{Capítulo 3 - Bases Teóricas}

Neste capítulo serão introduzidas resumidamente os fundamentos da teoria utilizada, sem no entanto detalhar as mesmas, o que pode ser encontrado em diversos livros didáticos.

\section{1- A Equação de Schrödinger}

A equação de Schrödinger, deduzida em 1926 pelo físico austríaco Erwin Schrödinger (1887-1961), é uma equação diferencial, usada em mecânica ondulatória, para a função de onda de uma partícula. A equação de Schrödinger constitui a base do formalismo mais operativo da mecânica quântica e rege o comportamento de uma partícula em nível atômico (o átomo é considerado uma onda - Hipótese de De Broglie). Esta equação leva a um modelo atômico inteiramente baseado em ondas estacionárias e constitui a base da física e química modernas. [54] [55]

A equação de Schrödinger permite calcular a função de onda associada $\Psi$ $(r, t)$ a uma partícula que se move dentro de um campo de forças descrito por um potencial $\vee(r, t)$ (que pode depender da posição $r$ e do tempo $t$ ). A equação pode ser traduzida pela seguinte expressão:

$$
-\frac{\hbar^{2}}{2 m} \nabla^{2} \psi(r, t)+V(r, t) \psi(r, t)=i \hbar \frac{\partial \psi(r, t)}{\partial t}
$$

onde $\hbar=h / 2 \pi$ é a constante de Planck reduzida, $\nabla^{2}$ o laplaciano e $m$ a massa da partícula.

No caso em que o potencial não depende do tempo, pode resolver a parte temporal da equação dando lugar a outra (equação de Schrödinger para estados 
independentes do tempo), cujas soluções são funções estacionárias. É expressa do seguinte modo:

$$
-\frac{\hbar^{2}}{2 m} \nabla^{2} \psi(r)+V(r) \psi(r)=E \psi(r)
$$

A resolução da equação de Schrödinger conduz a um conjunto de funções de onda e a um conjunto de energias correspondentes aos estados do elétron permitidos nesse átomo. Só são permitidas certas funções de onda como soluções da equação. As expressões matemáticas das funções de onda permitem determinar a probabilidade de encontrar o elétron na vizinhança de um ponto próximo do núcleo.

A Equação 3.1 só tem solução exata para casos muito simples, e descreve todas as propriedades estacionárias do sistema. Um dos casos em que a equação de Schrödinger tem solução exata é o caso de um elétron livre. Outro exemplo é o caso do átomo de Hidrogênio, composto somente por um elétron e por um próton, ou seja, até duas partículas.

Mas, para a maioria dos casos de interesse físico, a equação de Schroedinger Independente do Tempo (Equação 3.2) não possui solução exata. Um exemplo disto é sistemas que possuam $\mathrm{N}$ elétrons. [55]

Para a determinação de propriedades de sistemas atômicos e moleculares, utilizando métodos quânticos, é necessária a obtenção de soluções da equação de Schrödinger. Porém, esse é um problema extremamente complicado e ainda impossível de ser resolvido. Devido a esta complexidade, aproximações têm sido propostas a fim de se chegar próximo ao resultado real, levando-se em consideração o sistema a ser estudado. 


\section{2- A Teoria do Funcional da Densidade}

Simulações não relativísticas das propriedades eletrônicas e estruturais de sistemas atômicos e moleculares tornaram-se rotina nos últimos anos em vários laboratórios. ${ }^{1}$ Tais sistemas requerem uma solução mais rigorosa da equação de Schrödinger. Dentre as aproximações existentes a Teoria do Funcional de Densidade (DFT) se destaca em relação aos métodos Hartree-Fock (HF) e pós Hartree-Fock, porque o uso da DFT proporciona economia de recursos computacionais, mantendo a qualidade dos resultados. Em relação aos métodos semi-empíricos a vantagem é que o Hamiltoniano DFT é mais bem definido, não sendo necessárias aproximações empíricas, nas integrais bieletrônicas. [56] [57]

Existe toda uma discussão para considerar o método DFT ab initio ou semiempírico. Nós trataremos o método DFT como nível ab initio, apesar de conhecermos a parte empírica associada ao funcional de correlação. Deixaremos a notação de semi-empírico unicamente para aqueles métodos que fazem tratamento das integrais bi-eletrônicas e de recobrimento.

No final dos anos 20, L. H. Thomas e E. Fermi, afirmaram que considerações estatísticas podem ser utilizadas como uma aproximação para a distribuição de elétrons em um átomo. Com isso, eles plantaram a semente para que nos anos 60, P. Hohenberg, W. Kohn e J. Sham propusessem as bases teóricas do que conhecemos hoje como Teoria do Funcional de Densidade.

A idéia básica da DFT é que a energia de um sistema eletrônico pode ser escrita como uma função da densidade de probabilidade eletrônica, p. [56] [58] [59] [60] Esta densidade é entendida como uma grandeza que tem dependência somente com as três coordenadas de uma determinada região.

Para um sistema com $n$ elétrons, $\rho(r)$ denota a densidade eletrônica total a uma distância $r$. A energia $E$ é um funcional da densidade eletrônica, denotada por $E[\rho]$, onde para uma dada função $\rho(r)$ existe um único valor de energia $E[\rho]$ correspondente. Se $\mathrm{E}[\rho]$ é conhecido, podemos trocar o problema de determinar a 
energia e a densidade eletrônica do estado fundamental em um dado potencial externo pela minimização do funcional $E[\rho]$ da função densidade tridimensional $\rho(r)$.

A DFT tem ainda a vantagem de que a energia de correlação pode ser incluída de forma direta nos cálculos. [56] [57] Isto é, especifica-se o sistema escolhendo o potencial externo o qual é inserido na equação de Schrödinger (ES), resolve-se em seguida esta equação para a função de onda $\Psi$ e então se calcula 0 valor esperado dos observáveis com esta função de onda. Um entre os observáveis que são calculados deste modo é a densidade de carga ou densidade de partículas. [56]

A DFT propõe, a princípio, que se consiga uma função de onda $\Psi$ através do cálculo da densidade, e não o contrário. Assim, formalmente, a DFT fornece uma alternativa versátil de resolver a Equação 3.2. A partir da equação de Schrödinger, é fácil ver que a função de onda $\Psi$ do estado fundamental é um funcional do potencial externo.

A DFT também reconhece explicitamente que sistemas coulombianos não relativísticos diferem somente pelos seus potenciais externos e fornece por fim uma prescrição para lidar com os operadores universais. A isto se soma o fato de que a DFT fornece um meio para mapear o problema de muitos corpos, na presença da interação, a um problema efetivo de uma partícula, sem interação. Tudo isto é feito promovendo a densidade da partícula $n(r)$ de apenas um entre os muitos observáveis para a qualidade de variável-chave, na qual o cálculo de todos os outros observáveis pode ser baseado. Como resultado, toda propriedade eletrônica do sistema é um funcional de $\mathrm{n}(\mathrm{r})$.

Assim, a DFT pode ser sumarizada através da seguinte sequência

$$
n(r) \rightarrow \psi\left(r_{1}, \ldots, r_{N}\right) \rightarrow v_{e x t}(r)
$$

Isto é, o conhecimento de $\mathrm{n}(\mathrm{r})$ implica no conhecimento da função de onda, do potencial, e ainda, dos demais observáveis. ${ }^{[56]}{ }^{[57]}$ O resultado é o surpreendente 
sucesso da DFT para descrever propriedades elétricas, estruturais e magnéticas dos materiais.

A Equação 3.3 mostra que o conhecimento de $n(r)$ implica no conhecimento da função de onda e do potencial externo e, portanto de todas as demais propriedades do sistema (primeiro Teorema de Hohenberg e Kohn, HK), incluindo a energia cinética dos elétrons interagentes $T_{e}$ e a energia de interação entre os elétrons $U_{\text {eee }}$ de forma que a energia total do estado fundamental é um funcional da densidade que envolve os seguintes componentes. [56] [57]

$$
\mathrm{E}[\mathrm{n}]=T_{e}[n]+V_{\text {ext }}[n]+U_{e e}[n]
$$

No segundo Teorema, Hohenberg e Kohn aplicam o método variacional de forma similar ao que já era feito no método Hartree-Fock. Neste último método, o princípio variacional [55], é aplicado à equação de Schroedinger (Equação 3.1) para se encontrar a energia mínima do sistema, procedendo-se à minimização de $\langle\Phi|\widehat{H}| \Phi\rangle$ no espaço de determinantes normalizados de Slater $\Phi$, sujeitos à restrição $\langle\Phi \mid \Phi\rangle=1$.

$\mathrm{Na}$ DFT, busca-se um funcional da densidade. Em vez da derivação original proposta por Hohenberg, Kohn e Sham baseada na "redução ao absurdo", [57] será seguido aqui a aproximação da busca restrita (constrained search) proposta por Levy ${ }^{[55]}$ a qual é em alguns aspectos mais simples e mais abrangente.

Indo além do método Hartree-Fock, a energia do estado fundamental pode ser encontrada por minimizar $\langle\Phi|\widehat{H}| \Phi\rangle$ sobre todas as funções de onda $\mathrm{N}$-eletrônicas antissimétricas normalizadas.

A minimização será separada em dois passos. Primeiro serão consideradas todas as funções de onda $\Psi$ as quais produzem uma dada densidade $n(r)$, e minimizadas sobre todas as funções de onda.

Então se define o funcional universal como aquela função de onda que produzirá o mínimo para uma dada densidade n. Finalmente, tem-se a minimização sobre todas as densidades $n(r)$. 


\subsubsection{As Equações de Kohn-Sham}

De acordo com a Equação 3.4 o funcional da energia em função da densidade é escrito como a soma de três funcionais: energia cinética interagente, energia potencial de atração elétron-núcleo, e energia de interação elétron-elétron. No entanto, Hohenberg-Kohn não mostram como se calcula este funcional, principalmente devido aos termos da energia cinética e ao de interação. Por outro lado, a energia cinética é facilmente calculada a partir da função de onda. Por esta razão, Kohn e Sham, em 1965 propuseram um engenhoso método para relacionar a aproximação da função de onda e da densidade.

Para o desenvolvimento do método, Kohn e Sham consideraram um sistema não-interagente, de forma que o termo de interação eletrônica Ûee do Hamiltoniano

$$
\widehat{H}=\sum_{i}^{N}\left(-\frac{\hbar^{2} \nabla_{i}^{2}}{2 m}+v_{e x t}\left(r_{i}\right)\right)+\sum_{i<j} \frac{q^{2}}{\left|r_{i}-r_{j}\right|}=\widehat{T}_{e}+\widehat{V}_{e x t}+\widehat{U}_{e e}
$$

se reduz ao termo $T_{s}[n]$ :

$$
T_{s}[n]={ }_{\psi \rightarrow n}^{\min }\langle\Phi|\hat{T}| \Phi\rangle={ }_{\psi \rightarrow n}^{\min }\left\langle\Phi_{n}^{\min }|\widehat{T}| \Phi_{n}^{\min }\right\rangle
$$

assim, a partir da equação para um sistema interagente (equação 3.4),

$$
E[n]=T_{e}[n]+V_{e x t}[n]+U_{e e}[n]
$$

a qual pode ser reescrita como:

$$
E[n]=F[n]+V_{\text {ext }}[n]
$$


Kohn e Sham definem, para um sistema não-interagente, um funcional de troca e correlação particionando a energia total nas seguintes partes:

$$
E[n]=T_{S}[n]+\int d^{3} r\left[V_{\text {ext }}(r)+U_{H}(r)\right] n(r)+E_{X C}[n]
$$

sendo que o funcional $F[n]$ passa a ser escrito como:

$$
F_{K S}[n]=T_{S}[n]+E_{H}[n]+E_{X C}[n]
$$

Nas Equações 3.8 e 3.9, $T_{s}[n]$ é a energia cinética de um sistema que tem a mesma densidade $\mathrm{n}$ do sistema real, mas no qual não há interações elétronelétron. O termo $U_{H}[r]$ da Equação 3.8 é o termo clássico de Coulomb de interação entre os elétrons [56] [57], também chamado de termo Hartree.

Este termo inclui uma auto-interação, desde que a energia correspondente seja:

$$
E_{H}[n]=\frac{q^{2}}{2} \int d^{3} r^{\prime} \frac{n(r) n(r \prime)}{|r-r|}
$$

Esta representa a interação da densidade $\mathrm{n}$ com ela própria. Na Equação 3.6, $V_{\text {ext }}(r)$ é o potencial externo devido aos núcleos, e o último funcional, o funcional da energia de troca e correlação, $E_{x c}[n]$ inclui todas as contribuições de energia que não foram levadas em conta nos termos anteriores, isto é: a troca eletrônica $E_{x}, e$ a correlação eletrônica $E_{c}$ não levada em conta no termo Hartree, adicionada de uma parte correspondente à uma porção da energia cinética a qual é necessária para corrigir $T_{s}[n]$ para que se obtenha a energia cinética do sistema real $T_{e}[n]$, ou seja:

$$
T_{e}[n]=T_{s}[n]+T_{c}[n]
$$


onde o subscrito "s" representa partícula não-interagente e o subscrito "c", correlação.

Como se pode notar, todos os problemas difíceis de lidar na teoria de muitos corpos foram agrupados dentro do funcional de troca e correlação (Perdew, 2003). No entanto, nenhuma expressão analítica exata é conhecida para este funcional [ ${ }^{[57]}$. Assim sendo, para cálculos práticos, aproximações precisam ser feitas a este funcional, sendo que algumas comumente utilizadas lançam mão de parâmetros semi-empíricos [57].

O próximo passo no formalismo de Kohn-Sham é a minimização do funcional da energia apresentado na Equação 3.8. O funcional $T_{s}[n]$ não é conhecido exatamente como um funcional de $n$, mas é facilmente expresso em termos de orbitais monoeletrônicos $\ddot{o}_{i}(r)$ de um sistema não-interagente com densidade n,uma vez que para partículas que não interagem entre si, a energia cinética total é apenas a soma das energias cinéticas individuais. Desde que todos os orbitais $\ddot{O}_{\mathrm{i}}(\mathrm{r})$ são funcionais de $n$, para $T_{s}$ é um funcional explícito dos orbitais, mas um funcional implícito da densidade, $T_{s}=T_{s}\left[\left\{\ddot{o}_{i}(r)\right\}\right]$, onde a notação indica que $T_{s}$ depende de um conjunto completo de orbitais $\ddot{o}_{i}(r)$, cada um sendo um funcional de $n$. [60]

A aproximação de Kohn-Sham deve grande parte de seu sucesso ao fato que não trabalha exclusivamente em termos da densidade de carga, mas traz de volta ao jogo as funções de onda mono eletrônicas. Como conseqüência, a DFT no esquema de KS parece uma teoria de partículas não-interagentes, embora efeitos de muitos corpos são ainda incluídos através do funcional de troca e correlação.

Uma vez que $\vartheta_{H}$ e $\vartheta_{\mathrm{xc}}$ dependem de $n$, a qual depende de $\ddot{o}_{\mathrm{i}}(\mathrm{r})$, o qual por sua vez depende de $\vartheta_{s}$, o modo comum utilizado para resolver este problema é através do método auto-consistente ("self-consistency cycle").

A partir desses resultados calcula-se uma nova densidade, e o ciclo se inicia novamente, até que a convergência seja atingida. Uma vez obtida a densidade utilizando-se os orbitais de Kohn-Sham, eles podem ser utilizados para obter a energia eletrônica total do sistema, na qual a energia cinética $T_{s}[n]$ é calculada a partir dos orbitais de KS, em vez da densidade. 
$\mathrm{Na}$ prática, no entanto, a energia é calculada de uma forma mais conveniente, utilizando a densidade $n(r)$ da solução do método SCF e as energias orbitais $\varepsilon_{i}$ como:

$$
E_{0}=\sum_{i}^{N} \varepsilon_{i}-\frac{q^{2}}{2} \int d^{3} r \int d^{3} r^{\prime} \frac{n(r)-n\left(r^{\prime}\right)}{\left|r^{\prime}-r\right|}-\int d^{3} r \vartheta_{X C}(r) n(r)+E_{X C}[n]
$$

\subsubsection{Potenciais de troca e correlação}

$\mathrm{Na}$ seção anterior foi introduzido o formalismo de Kohn-Sham o qual permite um tratamento exato para a maioria das contribuições da energia eletrônica de um sistema atômico ou molecular, incluindo a maior fração da energia cinética. Todas as partes restantes, desconhecidas, são destinadas ao funcional de troca e correlação $E_{x c}[n]$. Essas partes incluem a porção não clássica da interação elétronelétron com a correção para a auto-interação e a componente da energia cinética não tratada pelo sistema de referência não-interagente. Uma vez que não são conhecidas expressões exatas para o funcional $E_{x c}[n]$, todo o esforço de se aplicar o esquema de Kohn- Sham (KS) como uma ferramenta para se obter o domínio da equação de Schroedinger faz sentido somente se aproximações explícitas a este funcional são disponíveis.

A qualidade do funcional da densidade depende somente da precisão da aproximação escolhida para o funcional da energia de troca e correlação, $E_{x c}[n]$, ou para o potencial de troca e correlação $\vartheta_{s}([n] r)$, o qual é a derivada de Exc $[n]$. ${ }^{[57]}$

Portanto, a questão de se encontrar melhores e melhores aproximações para a troca e correlação é um dos pontos centrais da DFT e como resultado, uma coleção de funcionais foram gerados e aplicados. Considerando o caso simples de um sistema mono eletrônico, tal como o átomo de hidrogênio, a energia somente dependerá da energia cinética e do potencial externo devido ao núcleo. Com apenas um elétron não há interação elétron-elétron em tal sistema. Isto parece tão trivial 
que não deveria sequer ser colocado em questão. No entanto, considerando a expressão da energia para um sistema monoeletrônico no esquema de KS.

O termo de repulsão eletrostático clássico não se zera exatamente para um sistema mono eletrônico desde que ele contém a interação espúria da densidade com ela mesma. Portanto, deve ser exigido que para densidades de um único elétron o termo $U_{H}[n]$ se iguale exatamente à $-E_{X C}[n]$ de forma que a auto interação errônea seja cancelada.No modelo Hartree-Fock o termo de troca neutraliza exatamente a porção indesejada de $U_{H}[n]$. Em particular, para um sistema monoeletrônico, o esquema Hartree-Fock é, portanto, livre de erros de autointeração.

Por outro lado, em qualquer aplicação do esquema do funcional da densidade de Kohn-Sham, é necessário empregar aproximações à energia de troca e correlação as quais são independentes de $U_{H}[n]$, para se manter livre de erros de auto-interação.

O livro de Koch e Holthausen [57], Seção 6.7, traz alguns resultados concernentes ao erro de auto-interação para o átomo de hidrogênio, obtidos com funcionais de troca e correlação típicos (LDA, BLYP, B3LYP, BP86 e BPW91), empregando um conjunto de base extenso, o cc-pV5Z de Dunning (Koput, 2002; Wilson, 1999; Woon, 1994; Woon, 1995). A mesma referência traz ainda, a efeito de comparação, resultados obtidos com o método Hartree-Fock usando a mesma base. Os resultados mostram que, em todos os casos nos quais foram utilizados funcionais de troca e correlação aproximados o erro de auto-interação é da ordem de $10^{-3}$ Hartree $\left(\mathrm{EH}_{\mathrm{H}}\right)$ ou alguns centésimos de elétrons-volt. Uma informação adicional mostrada pelos cálculos com o átomo de Hidrogênio é que dos três funcionais de correlação, somente o LYP produz o resultado correto da energia de correlação zero para um elétron simples (isto é, é livre de auto-interação); todos os outros desviam não negligenciavelmente de zero.

Este erro de auto-interação não está limitado somente a sistemas mono eletrônicos, onde tal erro pode ser identificado mais facilmente, mas aplica-se também aos sistemas $N$-eletrônicos. Perdew e Zunger, $1981^{[61]}$ sugeriram uma forma de corrigir o erro da auto-interação (self-interaction correction, SIC); para a 
construção deste tipo de funcional, eles explicitamente subtrairam os termos de auto interação não-físicos. ${ }^{[57]}$

A correção introduzida por Perdew e Zunger é uma das poucas que dão a correção para ambas as partes, troca e correlação. Sem entrar em detalhes, este método modifica a LSDA (local-spin-density approximation, aproximação da densidade local de spin) por incorporar efeitos de orbitais empregando uma correção de autointeração que depende da densidade orbital. [62]

Com um funcional de energia dependente do orbital, a correção de autointeração poderia ser facilmente implementada, a dificuldade é que este procedimento torna problemáticas as equações mono eletrônicas resultantes para os orbitais, ${ }^{[57]}$ ou seja, não há método direto para calcular a derivada funcional de um funcional de energia com dependência orbital, com relação à densidade, e consequentemente, o procedimento convencional de Kohn-Sham não é aplicável com a LDA-SIC, e por este motivo diz-se que este método permanece fora da teoria de Kohn-Sham. [62] [61]

\section{3- Funcionais da Densidade}

A questão de se encontrar melhores aproximações para a troca e correlação é um dos pontos centrais da DFT ${ }^{[57]}$ e como resultado, uma coleção de funcionais foram gerados e aplicados nas últimas décadas. [56] [57]

Dentro destas aproximações, estão as aproximações da densidade local (local-density approximation - LDA), a aproximação generalizada do gradiente (generalized gradient approximation - GGA) e os funcionais híbridos, os quais incorporam uma parte do termo Hartree-Fock para a componente da energia de troca. [57] [63]

Há, no entanto, alguns problemas com os funcionais aproximados, problemas estes que podem ser verificados através de resultados inadequados fornecidos por eles, como por exemplo, para as energias de dissociação, 
transferência de carga, conjugação $\pi$ estendida, potenciais de ionização, gaps de semicondutores e isolantes, e interações fracas. [64] [63]

Esses resultados ruins refletem a deficiência dos potenciais de troca e correlação aproximados em tratar efeitos de correlação eletrônica de longo alcance (comportamento assintótico), erros de auto interação e descontinuidade do potencial de troca e correlação exato (descontinuidade esta que não é descrita pelo potencial aproximado).

Para contornar esses problemas novos funcionais têm sido desenvolvidos e testados nos últimos cinco anos. Nesse trabalho são destacados os funcionais desenvolvidos pelos grupos de pesquisa de Grimme na Alemanha e Truhlar nos Estados Unidos, mostrando sua construção, teste contra algumas bases de dados e exemplos de problemas químicos, para os quais foram obtidos ótimos resultados com o uso desses funcionais.

O funcional B3LYP, híbrido GGA, é o grande responsável pela DFT ter se tornado uma das ferramentas mais populares em química computacional, porém o mesmo apresenta performance insatisfatória em alguns cálculos importantes como:

1- Barreiras de energia: O B3LYP subestima as barreiras de energia em aproximadamente $4,4 \mathrm{kcal} / \mathrm{mol}$ quando comparado a bases de dados experimentais de barreiras de energia. Esse fato é normalmente atribuído a erros de auto-interação (interação não física de um elétron com ele mesmo) na DFT local. [65]

2- Interações não-covalentes: O funcional B3LYP é inadequado para descrever interações complexas de Van der Walls de média distancia, como as interações entre dímeros metano e dímeros benzeno. Essa incapacidade do B3LYP (e de muitos outros funcionais populares) para descrever com precisão a energia de troca e correlação a médio alcance limita sua aplicabilidade em sistemas biológicos e materiais leves, nos quais as interações dispersivas de média distancia exercem papel fundamental. Além disso, alguns estudos recentes têm mostrado que essa imprecisão leva a erros sistemáticos no cálculo de calores de formação em moléculas orgânicas e energias de ligação em sistemas catalíticos organometálicos. [65] 
3- Química de metais de transição: O B3LYP e muitos outros funcionais híbridos não provem resultados confiáveis para química de metais de transição, nos quais a melhor performance é obtida com funcionais locais que não dão bons resultados para a maioria dos grupos orgânicos. Por exemplo, funcionais populares, que contem o termo de troca de Hartree-Fock costumam superestimar a polarização de spin em sistemas contendo metais de transição. [65]

A principal característica dos funcionais especializados é a sua aplicabilidade especifica para algum dado tipo de problema. As principais áreas nas quais a precisão desses funcionais tem sido focada são: termoquímica, magnitude das barreiras de energia, interações não covalentes, espectroscopia eletrônica e ligações químicas em metais de transição. [65]

Os funcionais específicos para termoquímica predizem de maneira mais precisa: estruturas, energias e frequências vibracionais para compostos contendo somente os elementos principais do grupo. Funcionais designados para a área de barreiras de energia predizem de maneira mais precisa as estruturas, energias e frequências vibracionais de estados de transição.

$\mathrm{Na}$ área de interações não covalentes os funcionais foram desenhados para prever as estruturas, energias e frequências vibracionais de complexos unidos por forças não covalentes com especial destaque para o uso em materiais leves e solvatação. Os funcionais mais adequados para aplicação em espectroscopia eletrônica são designados para as estruturas, energias e frequências vibracionais de estados eletronicamente excitados, se o funcional não possui o termo de troca inteiramente de Hartree-Fock, pode-se olhar somente valência e estados de Rydberg não a transferência de carga dos estados excitados.

As melhores previsões de estruturas, energias e frequências vibracionais para compostos contendo metais de transição são feitas pelos funcionais designados para essa área.

Os funcionais são desenvolvidos para se comportarem bem em um ou mais desses cinco nichos, com ou sem a restrição total ou local de Hartree-Fock. Nos estudos feitos para cada área em particular foram encontradas relações entre elas. 
Por exemplo, um funcional designado para termoquímica também pode ser útil para estudar outros tipos de sistemas com caráter multi-referencial. [66]

Dentre as estratégias utilizadas para se produzir aproximações dos funcionais de densidade, temos: ${ }^{[67]}$

1- "Local density approximations" (LDA). Esse grupo inclui funcionais derivados da teoria analítica do gás uniforme de elétrons e aplicados, direta ou com modificações empíricas para densidades não uniformes. Todos os funcionais LDA possuem a forma

$$
E_{x c}^{L D A}[\rho]=\int e_{x c}(\rho) d r
$$

Onde a densidade de energia de correlação é função unicamente de $\rho(r)$.

2- "Density-gradient expansion" (DGE). São análogos formais da expansão de Taylor em três dimensões para a energia de troca e correlação em derivadas da densidade:

$$
E_{x c}^{D G E}=\int\left[e_{x c}^{o}(\rho)+e_{x c}^{1}(\rho) \nabla \rho+e_{x c}^{2}(\rho) \nabla \rho|\nabla \rho|^{2}+\cdots\right] d r
$$

A derivada dos coeficientes é muito dispendiosa matematicamente e o uso desses funcionais como não empíricos só é razoável em densidades com variação suave.

3- "Constraint satisfaction". A abordagem de maior sucesso consiste em funcionais que possuem a forma

$$
E_{x c}[\rho]=\int e_{x c}\left(\rho, \nabla \rho, \nabla^{2} \rho, \tau, \ldots\right) d r
$$


Onde o integrante é construído de modo a satisfazer as exatas restrições escolhidas. As restrições em questão concernem no comportamento assintotico de $e_{x c}$ e $U_{x c}$, nos limites mais altos e mais baixos de energia, transformações escalares de densidade e outras propriedades de um verdadeiro funcional. O numero de aproximações nesse tipo de funcional e totalmente não empirico.

4- "Modeling the exchange-correlation hole". Funcionais deste tipo são baseadas nas equações tradicionais de Kohn-Sham e formam um dos maiores e mais diversos grupos. Por exemplo, a parte de troca pode ser aproximada por uma expansão de séries de Taylor em função do gradiente da densidade, do gradiente quadrático da densidade e do potencial. Essa correlação pode ser derivada de uma correlação aproximada da função de onda ou modelada depois que de correlacionada com um problema possível de resolvido analiticamente. A forma analítica geral desses funcionais é a mesma dos "constraint satisfaction". Funcionais baseados nesse modelo podem ser completamente não empíricos, ou conter parâmetros ajustados.

5- "Empirical fits". Funcionais desse tipo são feito por ajuste de formas analíticas escolhidas para $E_{x c}[\rho]$ a partir de valores experimentais termoquímicos e ou outras propriedades de átomos e moléculas. A forma analítica pode ser obtida diretamente de funcionais ou qualquer outro grupo, ou ainda por rigorosa derivação de simples postulados. Alguns funcionais ajustados são combinações lineares de funcionais pré-existentes. A forma geral de algumas aproximações é:

$$
E_{x c}[\rho]=\sum_{k} C_{k} \int e_{x c}^{(k)}\left(\rho, \nabla \rho, \nabla^{2} \rho, \tau, \ldots ; a_{k}, b_{k}, \ldots\right) d r(3.16)
$$

Onde $C_{k}$, $a_{k}$, bk... são parâmetros ajustáveis.

6- "Mixing exact and approximate exchange". Esses funcionais, chamados de híbridos, tem a forma: 


$$
E_{x c}^{h y b r i d}[\rho]=\int a e_{x}^{e x a c t}(r)+b e_{x}^{D F T}(r)+e_{c}^{D F T}(r) d r
$$

Onde a mistura dos coeficientes a e b pode ser constantes ou dependentes de r. No ultimo caso, os funcionais dessa forma são chamados de "local hybrids".

A maioria das aproximações usadas em funcionais de densidade estão incluídas em uma dessas categorias, ${ }^{[67]}$ alguns dos funcionais a serem discutidos a seguir envolvem mais de uma dessas estratégias para sua construção, como veremos em mais detalhes.

Diante do vasto número de funcionais de densidade especializados desenvolvidos nos últimos seis anos, a fim de ilustração de construção e comparação de performance desse tipo de funcionais, visando a abrangência nos mais diversos nichos, foram escolhidos para discussão nesse trabalho, os funcionais: B-97D, ${ }^{[68]}$ e o conjunto de funcionais M06. ${ }^{[69]}$

O funcional B-97D foi proposto por Grimme com o objetivo de lidar com sistemas grandes, nos quais as forças de dispersão possuem significativa importância. Esse funcional foi desenvolvido usando as técnicas 4 e 5, a partir da abordagem de Becke para funcionais GGA. O funcional B97 foi baseado no remapeamento da variável de gradiente reduzido, desta forma, a parte de troca e correlação deste funcional é baseada na densidade de energia local do gás uniforme de elétrons.

Para a parte dispersiva no funcional, a energia será dada por:

$$
E_{D F T-D}=E_{K S-D F T}+E_{d i s p}
$$

Onde $E_{K S-D F T}$ é a usual energia alto consistente de Kohn-Sham, obtida da escolha do funcional de densidade e $E_{\text {disp }}$ é a correção de dispersão empírica dada por 


$$
E_{\text {disp }}=-s_{6} \sum_{i=1}^{N_{a t}-1} \sum_{j=i+1}^{N_{a t}} \frac{c_{6}^{i j}}{R_{i j}^{6}} f_{d m p}\left(R_{i j}\right)
$$

Na qual $N_{a t}$ é o número de átomos no sistema, $c_{6}^{i j}$ denota o coeficiente de dispersão por um par de átomos ij, $s_{6}$ é o fator global de escalonamento, que depende somente do funcional de densidade usado e $R_{i j}$ é a distancia interatomica. A fim de evitar singularidades próximas para pequenos valores de $R$, a função de amortecimento foi usada, $f_{d m p}$, a mesma depende unicamente dos valores de R.

A parametrização deste funcional consistiu em encontrar valores compatíveis de coeficientes $\mathrm{C}_{6}$ levando em conta uma extensa base de dados que incluiu desde complexos fracamente ligados, pequenos monômeros (2 ou 3 átomos diferentes de hidrogênio) e exemplos típicos como dímero butano e dímero piridina. Com esses valores ótimos para os parâmetros foi possível executar testes para calores de formação, reações químicas e barreiras de energia, interações não covalentes e geometria molecular.

Foram executados testes, essenciais para a validação do novo funcional, que englobam cálculos de calores de formação usando a metodologia G2/97 (148 pequenas moléculas), reações químicas e barreiras de energia incluindo compostos de coordenação (reações de referência, como isomerização do $\mathrm{C}_{20}$ e outras isomerizações de compostos orgânicos, decomposição do ácido sulfúrico e cátion amônio, entre outras que estão melhor detalhadas no texto de Grimme) e interações não-covalentes (complexos envolvendo átomos do terceiro período, dímeros de gases nobres, dímero butano, além de sistemas aromáticos mais complicados como tolueno, piridina, $\mathrm{C}_{6} \mathrm{~F}_{6}$, azuleno e antraceno), os resultados desses testes estão sumarizados na Tabela 3.1. Os valores de desvio médio absoluto em relação aos valores experimentais e amplitude do erro (desvio máximo - desvio mínimo) são dados na Tabela 3.1 para o B97-D, dois outros funcionais GGA puros (PBE e BLYP), um meta-GGA(TPSS) e um funcional híbrido (B3LYP) para comparação. 
Tabela 3.1. Desvio médio absoluto para os valores de referencia e amplitude do erro entre parênteses (desvio máximo - desvio minimo) para os diferentes conjuntos de testes. [68]

\begin{tabular}{ccccc}
\hline Método & G2/97 & Reações & Metais & Não covalente \\
\hline BLYP & $7.1(50.2)$ & $15.5(77.2)$ & $4.8(22.8)$ & $0.71(4.6)$ \\
PBE & $16.7(62.1)$ & $7.9(39.7)$ & $6.6(43.9)$ & $1.02(6.9)$ \\
TPSS & $6.1(39.8)$ & $8.4(38.2)$ & $6.3(44.1)$ & $0.81(5.4)$ \\
B97-D & $3.8(40.2)$ & $7.8(47.1)$ & $2.5(11.9)$ & $0.39(3.2)$ \\
B3LYP & $3.6(29.0)$ & $9.8(58.1)$ & $5.4(31.6)$ & $0.77(5.0)$ \\
\hline
\end{tabular}

[a] Calores de Formação (298K) de um conjunto de dados neutro G2/97

Para os cálculos de calores de formação usando a metodologia G2/97 o functional B97-D, quando comparado a outros não híbridos, possui uma acurácia maior, isso porque o DMA de $3,8 \mathrm{kcal}^{\mathrm{mol}} \mathrm{m}^{-1}$ é bem menor que os demais, pois estão entre 6 e $17 \mathrm{kcal}^{\mathrm{mol}}{ }^{-1}$. De acordo com os dados estatísticos presentes na Tabela 2.1, o B3LYP possui qualidade ligeiramente superior quando comparado aos demais funcionais, porém isso pode ser diretamente atribuído ao conjunto de moléculas escolhido, que por ser de moléculas pequenas, possuem correção dispersiva de menor magnitude.

Como seria de se esperar, o B97-D possui o melhor desempenho tanto para reações química em geral, quanto para as que envolvem metais de transição, levando em conta que possui o menor DMA (Desvio Médio Absoluto) para o conjunto de metais e o segundo menor DMA para reações. Considerando as reações em geral, o funcional TPSS possui melhor desempenho, isso porque leva em conta o problema da auto-interação, que não foi considerado para a construção do B97-D.

O B97-D apresenta os melhores resultados gerais (Tabela 3.1), por conta do ajuste feito na parte de curto alcance para a presença de longo alcance e efeitos de dupla contagem foram evitados. Esses resultados apresentam uma descrição 
bastante balanceada de complexos saturados e aromáticos e uma boa descrição simultânea de complexos que possuem ligação de hidrogênio que não foi alcançada até então com nenhuma outra abordagem de DFT. [68]

A família de Minnesota de funcionais de troca e correlação, consiste em aproximações meta do Gradiente Generalizado (meta-GGAS) e global-híbridos meta-GGAS, tem sido bem sucedida para os cálculos DFT de estrutura molecular, propriedades e termoquímica, cinética, as interações não covalentes, e espectroscopia.

O Funcional M06 é uma reparametrização do funcional M05, [69] mantém em sua essência os objetivos de lidar com metais de transição, espectroscopia UVVIS e barreiras de energia, com o adicional da robustez em sua construção com o objetivo de lidar com termoquímica. [66]

Como descrito no trabalho de Zhao, ${ }^{[69]}$ um grande número de conjuntos de bases de dados energéticos foi utilizado para construir e posteriormente testar a eficiência do funcional, levando-se em consideração os mais diversos fenômenos que o funcional deve prever, tais como: energias de atomização, afinidade eletrônica, termoquímica de sistemas $\pi$, barreiras de energia em átomos pesados, transferência de hidrogênio, energia em interações não covalentes, ligação de hidrogênio, transferência de carga em complexos, interações fracas em complexos, transferência de carga em estados excitados, energias de ligação em metais, dentre outros.

A incorporação de efeitos relativísticos foi feita, em todos os cálculos, incluindo um escalar de efeitos relativísticos. Esse escalar foi desenvolvido para metais de transição, usando um potencial efetivo de 'core' relativístico ou ainda cálculos relativísticos de DFT ou HF. O vetor de efeito relativístico foi incluído somando-se o efeito de acoplamento spin órbita. Em todos os cálculos feitos para construção do funcional a energia de estabilização spin órbita foi somada para átomos e moléculas de camada aberta. 
As partes locais do M06 dependem de três variáveis: densidade de spin $\left(\rho_{\sigma}\right)$, gradiente de densidade de spin reduzido $\left(x_{\sigma}\right)$ e densidade de energia cinética $\operatorname{spin}\left(\mathrm{T} \sigma_{\sigma}\right)$.

O funcional M06 é definido pela aproximação de gradiente (GGA) ${ }^{[70]}$ na parte de troca do funcional, dada por:

$$
E_{x}^{M 06}=\sum_{\sigma} \int d r\left[F_{X \sigma}^{P B E}\left(\rho_{\sigma}, \Delta \rho_{\sigma}\right) f\left(w_{\sigma}\right)+\varepsilon_{X \sigma}^{L S D A} h_{X}\left(x_{\sigma}, Z_{\sigma}\right)\right]
$$

onde $\mathrm{h}_{\mathrm{X}}\left(\mathrm{x}_{\sigma}, \mathrm{Z}_{\sigma}\right)$ foi definido previamente, $F_{X \sigma}^{P B E}\left(\rho_{\sigma}, \Delta \rho_{\sigma}\right)$ é a densidade de energia do modelo de troca PBE e $\varepsilon_{\mathrm{X} \sigma}^{\mathrm{LSDA}}$ é a aproximação de densidade de spin local para a troca e $\mathrm{f}\left(\mathrm{w}_{\sigma}\right)$ é o fator densidade de spin de energia cinética.

A parte de correlação é a mesma para todos os funcionais da classe do M06. É baseada nos funcionais de correlação do M05 e VSXC, trata-se principalmente de considerar tratamento diferenciado para spins opostos e paralelos. [69]

A energia da parte híbrida do funcional de troca e correlação pode ser escrita como se segue:

$$
E_{x c}^{h y b}=\frac{X}{100} E_{X}^{H F}+\left(1-\frac{X}{100}\right) E_{X}^{D F T}+E_{c}^{D F T}
$$

onde $E_{X}^{H F}$ é a energia de troca não local Hartree Fock (HF), $X$ é a porcentagem da parte de troca Hartree Fock no funcional híbrido, $\mathrm{E}_{\mathrm{X}}^{\mathrm{DFT}}$ é a energia de correlação local DFT.

A otimização do parâmetro $X$ é feita por método auto consistente, de modo a obter os limites das variáveis dadas, contra as bases de dados apresentadas. Após a construção do funcional, o mesmo passou por diversos testes que atestaram sua eficiência e precisão para o tratamento de problemas os quais o mesmo se propõe, até dos casos mais difíceis. 


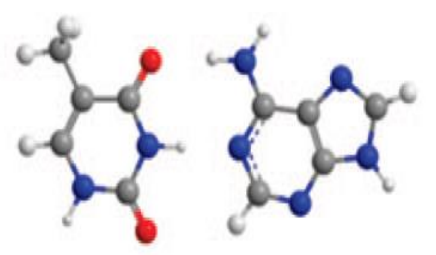

a hydrogen bonded (HB)

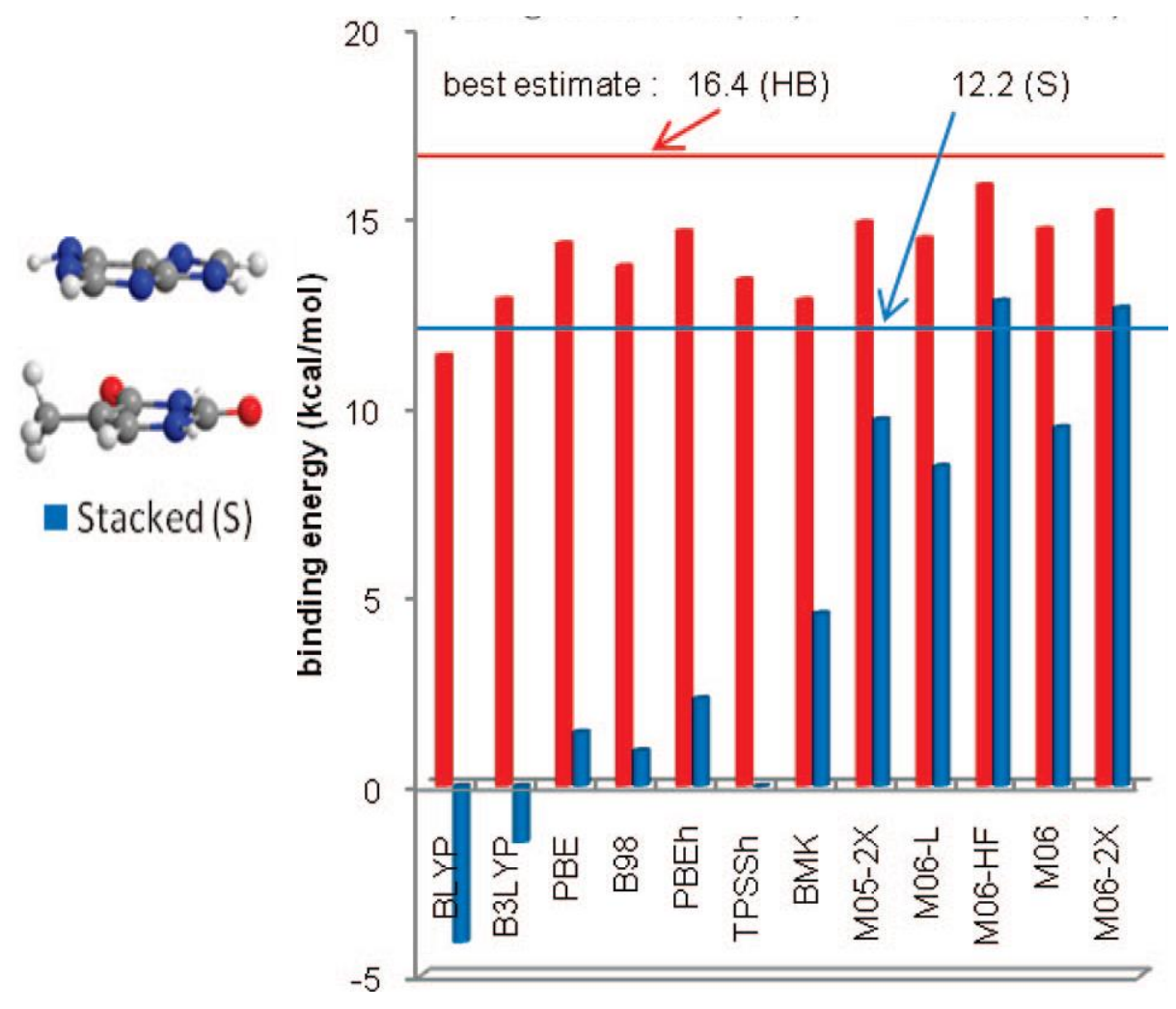

Figura 3.1. Energias de interação dos dimeros adenina e timina (kcal.mol-1). A melhor estimativa foi feita usando MP2/TZVP e o conjunto de bases $6-31+G(d, p)$ foi empregado em todos os demais cálculos. [69]

Dentre os vários exemplos presentes no texto de Zhao de 2008, um review sobre os principais sucessos dos funcionais "M", destacam-se os sistemas de grande importância biológica (estrutura de biopolímeros e concepção de novos medicamentos), formados por dímeros dos ácidos nucleicos adenina e timina, nos quais o primeiro apresenta ligação de hidrogênio e o segundo empilhamento $\pi$. [66]

A Figura 3.1 apresenta energias de ligação do hidrogênio e empilhamento $\pi$ nos dímeros adenina e timina. Analisando a Figura 3.1, podemos ver que todos os funcionais dão um resultado razoável para ligações de hidrogênio, no entanto, para empilhamento $\pi$, BLYP e B3LYP mostram uma interação repulsiva, e PBE, B98, PBEh, TPSSh e BMK subestimam bastante a energia de ligação. Os melhores desempenhos para empilhamento $\pi$ são M06 e M06-2X, seguido de M05-2X, M06-HF, e M06-L. 
O desenvolvimento de funcionais especializados é um campo em franca expansão e detentor de grande sucesso na resolução de problemas antes insatisfatórios usando a teoria do funcional de densidade tais como a química de metais de transição, interações fracas e barreiras de energia.

Assim, apesar de serem muito específicos em suas aplicações, por serem parametrizados contra bases de dados experimentais diretamente ligadas ao problema de interesse em cada caso, esses funcionais apresentam resultados bastante satisfatórios, quando comparados aos dados experimentais, o que justifica seu uso, levando em conta também, que por ser uma metodologia DFT, o tempo computacional é bastante reduzido quando comparado a métodos pós HartreeFock.

\section{4- Teoria do Funcional da Densidade dependente do tempo}

A DFT tem se mostrado adequada na descrição do estado fundamental de muitos sistemas atômicos e moleculares. Devido ao sucesso da aplicação da DFT em sistemas no estado estacionário, surgiu o interesse em descrever estados dependentes do tempo (TD - Time Dependent), em termos do funcional da densidade. Problemas como processos de espalhamento atômico ${ }^{[71]}$ e nuclear ${ }^{[72]}$, e fotoabsorção em átomos ${ }^{[71]}$ têm sido tratados com sucesso nessa abordagem.

No trabalho de 1984, Runge e Gross ${ }^{[73]}$ generalizaram o teorema de Hohenberg-Kohn para o caso da equação de Schrödinger dependente do tempo. Runge e Gross demonstraram que existe uma correspondência unívoca entre o potencial externo dependente do tempo $v(r, t)$ e a densidade eletrônica $\rho(r, t)$ para sistemas de muitos corpos que evoluam de um estado inicial, este é o teorema central da TD-DFT, também conhecido como teorema de Runge-Gross. ${ }^{[58]}$

Este resultado implica que, se a única informação existente sobre o sistema for a sua densidade eletrônica, nós podemos determinar o potencial externo que produz essa densidade. Definido o potencial externo pode-se então resolver a 
equação de Schroedinger dependente do tempo, e assim obter todas as propriedades do sistema. De posse do teorema de Runge-Gross é possível construir um esquema de Kohn-Sham dependente do tempo. Este esquema obedecerá à equação de Schroedinger dependente do tempo.Por construção, a densidade do sistema interagente pode ser determinada a partir dos orbitais de Kohn-Sham.

Como no esquema Kohn-Sham para o estado excitado, o potencial de Kohn-Sham dependente do tempo também é normalmente escrito como a soma de três termos,o primeiro termo é o potencial externo, o segundo representa a interação eletrostática entre elétrons, o terceiro termo, o potencial de troca-correlação $\vartheta_{x c}$ inclui todos os efeitos não triviais de muito corpos, e tem uma dependência funcional, extremamente complexa, com a densidade. Esta dependência é não local, tanto no espaço quanto no tempo, ou seja, o potencial num tempo t e uma posição $r$ dependerão da densidade em todas as outras posições e em todos os instantes de tempo.

O que se faz então é separar do potencial $\vartheta_{K S}$ em dois termos bem conhecidos, o potencial externo e o potencial de Hartree, e o potencial xc é geralmente aproximado usando argumentos físicos e matemáticos. Portanto, a qualidade dos resultados obtidos dependerá da qualidade da aproximação usada. Assim como na teoria do funcional da densidade, para o estado fundamental, esta é a aproximação fundamental na TD-DFT.

Das várias maneiras de se implementar a DFT dependente do tempo, a que tem tido maior sucesso faz uso da Teoria de Resposta Linear. A chave nesse processo é a função de resposta linear da densidade $X\left(r, r^{\prime}, \omega\right)$ que conecta a perturbação externa $\delta_{\vartheta}(r, \omega)$ à perturbação resultante na densidade eletrônica sendo $\rho$ o operador densidade e os estados k de energia $E_{k}$ formam um conjunto completo, $\eta$ é um número infinitesimal positivo.

Os polos da função resposta da densidade correspondem às energias de excitação do sistema e os numeradores estão relacionados às correspondentes forças de oscilador. A partir disso, chega-se a uma equação de autovalores (não linear) que determina as energias de excitação através dos orbitais de Kohn-Sham. 
Para a resolução das equações de Khon-Sham utiliza-se um código computacional, dada a complexidade envolvida nesse processo. Existem diversos códigos computacionais baseados nos mais diversos métodos. Cada código, com seu respectivo método apresenta um bom desempenho para certo conjunto de aplicações. No presente trabalho utilizou-se o pacote de simulação computacional VASP [74] [75] [76] [77] a fim de se determinar a importância da estrutura cristalina no arranjo molecular.

O VASP é um dos códigos mais utilizados atualmente, em versões serial e paralela. Ele permite a realização de simulações "quantum mecânicas" ab initio de grande escala e cálculos de dinâmica molecular (MD - Molecular Dynamics) em temperaturas finitas.

Os cálculos de primeiros princípios foram realizados dentro do formalismo da DFT, usando a aproximação GGA segundo Perdew et al. (PBE) para o potencial de troca e correlação. [78] Os elétrons foram representados pelo método PAW segundo implementação de Kresse e Joubert (1999). [79] [80]

Nos métodos de ondas Aumentadas (augmented waves, AW), o espaço é divido em duas regiões que possuem diferentes comportamentos do determinante de Slater, construído com orbitais-spin de Kohn-Sham, que representam a função de onda eletrônica do sistema, entre os átomos (região intersticial) onde a função de onda varia de um modo suave, e na região ao redor do núcleo (augmentation region $\mathrm{R}$ ), onde a função de onda oscila rapidamente devido ao grande potencial atrativo dos núcleos.

Assim, este método usa para a zona intersticial, onde a função de onda varia de forma suave, a função envolvente de uma sobreposição de ondas planas e para a zona do núcleo uma função resultante da sobreposição de ondas parciais, por exemplo do tipo harmônicas esféricas centradas no núcleo do átomo.

As integrais no espaço recíproco são calculadas segundo o esquema proposto por Mokhorst e Pack. Segundo o Teorema de Bloch é possível associar ao sistema assim formado um potencial que segue a periodicidade da rede. Esse potencial pode ser escrito através de uma série de Fourier dada em termos de um 
conjunto de vetores especiais (vetoresde onda, $k$ ), que formam o espaço recíproco (inverso do espaço real). ${ }^{[80]}$

Assim, a existência de uma rede no espaço real automaticamente implica na existência de uma rede no espaço $k$. A introdução desse espaço também implica que toda informação estará contida na célula unitária da rede recíproca, conhecida como $1^{\circ}$ Zona de Brillouin (ZB).

Por conseguinte, toda problemática envolvida na resolução da equação de Schrödinger para o cristal pode ser simplificada a partir da associação, a cada estado do sistema, de vetores de onda $k$ no espaço recíproco.

Assim, dada uma estrutura cristalina qualquer, esta terá associada a si uma rede de Bravais (espaço real) e uma rede recíproca (espaço recíproco, com dimensões iguais ao inverso do comprimento). Poderíamos dizer que o padrão de difração de um cristal corresponde a um mapa da sua rede recíproca, enquanto que uma imagem microscópica corresponderia a um mapa da sua rede cristalina.

As distribuições eletrônicas são iguais para planos de uma mesma família de planos cristalinos especificados pelos seus índices de Miller ( $h k l)$ em uma determinada rede cristalina. Consequentemente, tais índices podem ser representados por um único ponto na rede recíproca determinado por um vetor de onda $k$, com módulo proporcional ao momento dos elétrons e consequentemente a sua energia.

A determinação de propriedades extensivas, como a energia total, as quais dependem do volume do material, deve ser feita a partir da integração sobre todos os pontos $k$ na $1^{\text {a }}$ ZB da propriedade desejada. A princípio são necessários infinitos pontos $k$ para se ter uma boa descrição. Na prática, torna-se impossível considerar estes infinitos pontos nas integrais sobre a ZB. Assim, faz-se necessário determinar um conjunto finito de pontos que reproduza com precisão aceitável o valor que seria obtido considerando-se todos os pontos da ZB. A este conjunto de pontos finitos dentro da ZB, dá-se o nome de pontos especiais.

Em pontos próximos no espaço $k$, as funções de onda são parecidas e podem ser substituídas por um único ponto representativo no lugar de vários. Cada 
um desses pontos representativos é multiplicado por um fator relacionado ao volume da célula no espaço recíproco.

\section{Capítulo 4 - Metodologias Utilizadas}

\section{1- Otimização Geométrica e Cálculo de Frequências Vibracionais}

\subsection{1- Molécula Livre}

A otimização de todas as geometrias das estruturas, estudos NBO, carga (Mulliken, NBO e ChelpG) e PES foram realizadas com o software Gaussian09 com cálculos teóricos baseados no método da teoria do funcional de densidade (DFT) 
empregando os funcionais B3LYP, PBE1PBE, B3PW91 (híbridos), CAM-B3LYP (híbrido de longo alcance), B97-D (puro), M06 e o conjunto de bases atômicas LANL2DZ para o cobre e 6-31G(d,p) para os demais átomos. [81]

Inicialmente foi feita a otimização da geometria da molécula do complexo no estado fundamental no vácuo. Para isso aplicou-se a Teoria do Funcional de Densidade. Foram calculadas as frequências vibracionais para todos os funcionais utilizados nos cálculos de otimização geométrica, tanto para construção do espectro de infravermelho, quanto para avaliação da viabilidade do mínimo de energia obtido para cada estrutura em face de ausência de frequências imaginárias.

A geometria inicial de cada complexo foi obtida através do arquivo cif, proveniente das medidas experimentais de Raios-X. ${ }^{[17]}$

\subsection{2 - Sistema Periódico}

Os cálculos periódicos foram feitos usando a DFT baseada na teoria de ondas planas no programa VASP. A metodologia "projector augmented waves" (PAW) foi usada. O corte de energia usado foi de $300 \mathrm{eV}$ para o tamanho do conjunto de bases do sistema com alta precisão. O tamanho e a forma das celas unitárias, contendo a quantidade adequada de moléculas para cada grupo espacial, foram fixados com base nos dados cristalográficos. Os cálculos DFT foram feitos com a versão desenvolvida para sólidos do funcional GGA, de troca, 91 (PW91). ${ }^{\text {[77] }}$

A amostragem da zona de Brillouin foi restrita a três pontos $k$, obtidos através do gerador automático do "mesh" de pontos $\mathrm{k}(0.0,0.0,0.0)$, com os tamanhos 2, 2 e 1, no espaço recíproco. Todos os resultados reportados referemse a uma molécula presente na cela unitária, exceto em caso explicitamente citado o contrário.

\section{2- Espectros Eletrônicos}


Os espectros de excitação foram simulados empregando a abordagem dependente do tempo da Teoria do Funcional de Densidade (TD-DFT). [58] [73]O funcional híbrido meta-GGA M06 foi empregado em todos os casos, por apresentar o menor erro absoluto em cálculos de espectro eletrônico para um grande número de moléculas orgânicas, como o ligante hidrazona em questão. [1]

Todos os cálculos TD-DFT foram feitos considerando-se transições eletrônicas para os 30 primeiros estados singleto e tripleto, para a molécula isolada tendo por base as estruturas às quais foram feitas as otimizações geométricas prévias, salvo os casos em que foram necessários cálculos para os 100 primeiros estados excitados, que serão relatados nos resultados. Para todos os cálculos foram usados os conjuntos de bases LANL2DZ com pseudo-potencial para os átomos de cobre e 6-31G(d,p) para os demais átomos.

Todos os cálculos foram feitos empregando o programa Gaussian 09, Revision B.01. [81] Os espectros de excitação e os orbitais moleculares foram construídos empregando-se o programa Gaussview versão 5.0.

\section{Capítulo 5- Resultados e Discussão}

O ligante 2-acetilpiridina-benzoilhidrazona ${ }^{[43]}$ apresenta tautomerismo cetoenólico, e como ligante com grupamento hidrazona é capaz de se coordenar de diferentes formas em complexos metálicos mono, dinucleares ou polinucleares: neutro tridentado, mono-aniônico e neutro bidentado. [82] [83] [10] [84] [85]

O ligante $(\mathrm{HL})$, possui em sua estrutura um nitrogênio piridínico, um nitrogênio imínico e um oxigênio cabonílico. Foram feitos cálculos de otimização geométrica, frequências vibracionais e espectro eletrônico para o ligante $\mathrm{HL}$ a fim de compararmos esses resultados com o dos complexos em estudo. $O$ resultado desses cálculos encontram- se na Tabela 8.1 do Apêndice 8.1 e nas Figuras 8.1 e 8.2 do Apêndice 8.2 . 
A partir desses cálculos foi possível detectar a superioridade da metodologia de ondas planas para os parâmetros geométricos, com desvio médio quadrático de 0,101 , enquanto que o melhor funcional para bases atômicas localizadas, o B97-D teve um desvio de 0,256, valor muito semelhante ao desvio encontrado para os demais funcionais.

O perfil espectroscópico, calculado com o funcional M06 está presente nas Figuras 8.1 e 8.2 e será discutido em mais detalhes no decorrer do texto à medida em que servirá de parâmetro de comparação para esses mesmos cálculos que foram executados para os quatro complexos.

Para proporcionar o melhor entendimento acerca do comportamento estrutural dos complexos formados pelo ligante 2-acetilpiridina-benzoilhidrazona HL (Figura 5.1), e os sais de cobre (II) nitrato, acetato, acetilacetona e sulfato, foram usadas duas abordagens diferentes: as funções de ondas planas e conjuntos de bases atômicas localizados.

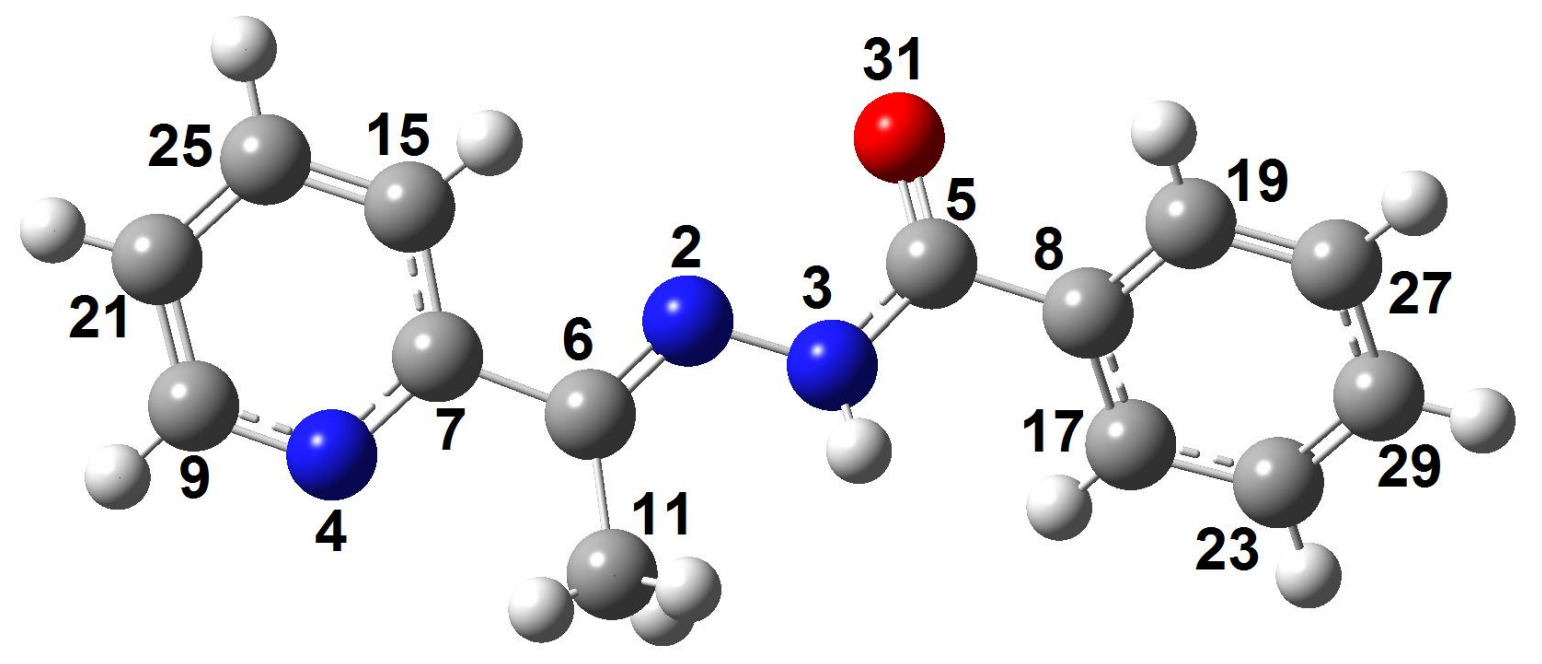

Figura 5.0. Ligante 2-acetilpiridina-benzoilhidrazona, com numeração utilizada no texto e nas tabelas.

Inicialmente, comparamos a geometria de cada complexo otimizada com diferentes funcionais escolhidos, usando os conjuntos de bases atômicas 
localizados, levando em conta a maior diversidade possível entre eles, no que cerne à recomendação de aplicação e método de construção. Esse cálculo foi feito para uma única molécula, sendo assim nos proporcionou dados de comprimentos e ângulos de ligação das estruturas, ligante e complexos, detalhados à seguir e selecionados tendo como foco a esfera de coordenação, com dados presentes nas Tabelas do Apêndice (Capítulo 8).

A segunda abordagem utilizada teve como foco o entendimento acerca da estrutura cristalina das moléculas estudadas. Os cálculos periódicos feitos, usando as funções de ondas planas, são de extrema importância, pois situam as estruturas no meio em que estão inseridas e assim sendo possibilitam o entendimento da vizinhança molecular e sua consequente influência nas propriedades estruturais.

A comparação entre a primeira abordagem e a segunda, levando em consideração as variáveis envolvidas, foi direcionada à influência do ligante hidrazona na esfera de coordenação do metal, bem como as modificações estruturais ocorridas no ligante face à coordenação. Isto pode ser atestado pelas mudanças geométricas presentes no complexo, comparadas a ligantes hidrazona análogos, presentes na literatura com dados teóricos e experimentais, tais como os sintetizados e caracterizados por Veljkovic e colaboradores [35] além de vários outros. [86] [87] [88] [23] [89] [90] [7]

Assim, os comprimentos e ângulos de ligação analisados a seguir, em destaque, levam em consideração essa influência e procuram demonstrar como o ligante complexado possui mudanças em sua geometria devido à presença do metal.

Cálculos complementares foram executados, e serão analisados a seguir, fim de entender melhor essas mudanças e suportar os dados que emergem da estrutura geométrica, são esses os dados sobre cargas atômicas, mapas eletrostáticos e os cálculos de espectroscopia de infravermelho e ultravioleta, que corroboram com a presente análise e serão detalhados a seguir.

A organização das estruturas de coordenação é definida, em grande parte por fatores tais como a geometria preferencial do íon metálico, o tamanho e a forma que se organizam os ligantes orgânicos, a razão entre metal e ligantes, e a presença 
de certos contra íons, bem como o solvente no qual se dá a síntese. Entre os meios de solventes utilizados nos processos de síntese, pode haver influência significativa nas estruturas de coordenação resultantes. [91] [92]

Desta forma, dada a crescente importância direcionada ao entendimento da estrutura de complexos com ligantes e metais de interesse biológico, o presente estudo tem como principal foco as mudanças que ocorrem com o mesmo ligante hidrazona, $\mathrm{HL}$, em diferentes ambientes de síntese resultando em quatro diferentes complexo com cobre (II).

\section{1- DiNitrato de 2-acetilpiridina-benzoilhidrazonacobre(II)}

O complexo DiNitrato de 2-acetilpiridina-benzoilhidrazonacobre(II), $\left[\mathrm{Cu}(\mathrm{HL})\left(\mathrm{NO}_{3}\right)_{2}\right]$, possui em sua estrutura dois ânions nitrato e uma molécula do ligante 2-acetilpiridina-benzoilhidrazona, HL, coordenados ao metal (Figura 5.1.1). Para fins de comparação com os dados experimentais de difração de Raios- $X$, foram selecionados comprimentos e ângulos de ligação que tivessem correlação direta com a formação da esfera de coordenação, pois este é o principal objetivo (Tabela 8.1). 


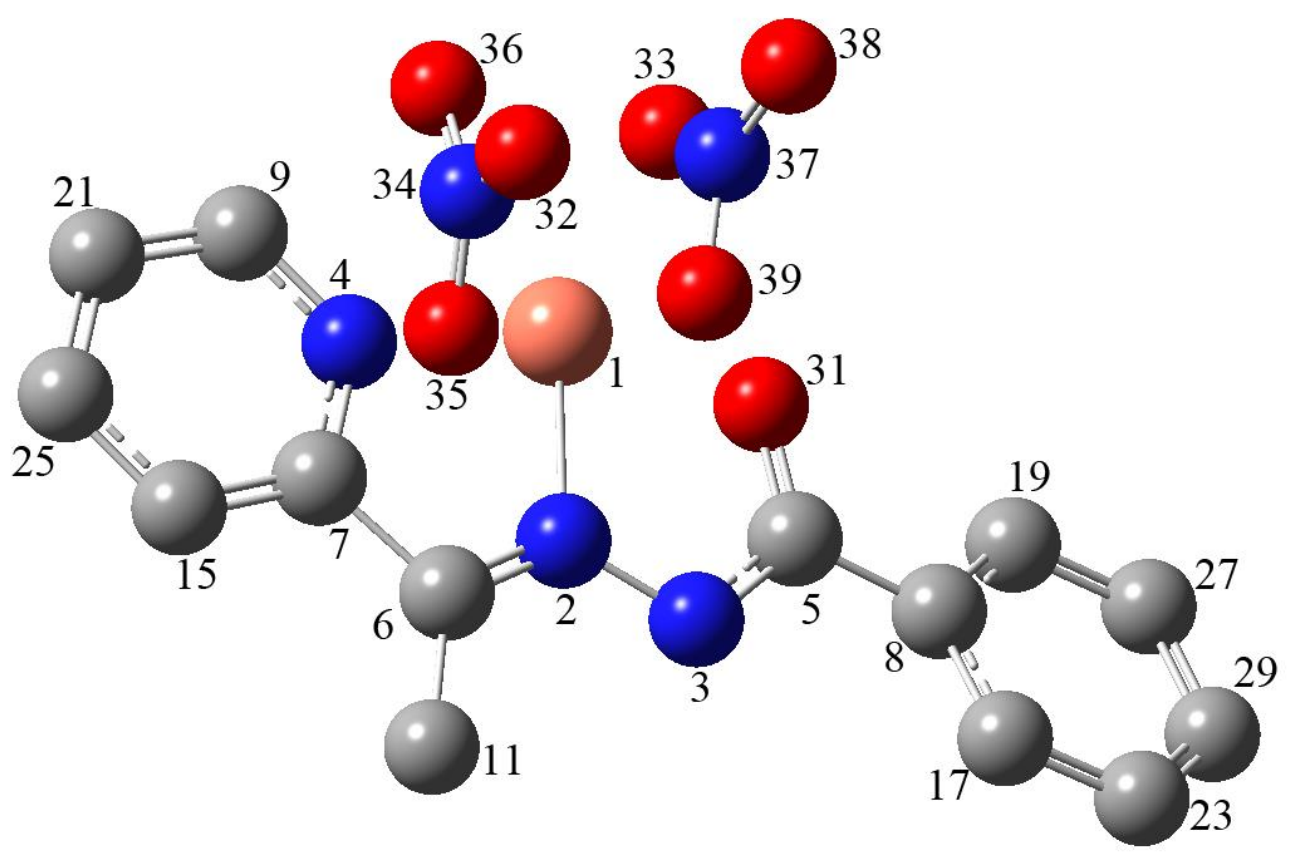

Figura 5.1.1. Nitrato de 2-acetilpiridina-benzoilhidrazonacobre(II), com numeração utilizada nas tabelas e no texto. Átomos de hidrogênio não aparecem para melhorar a visualização.

Esses dados selecionados, provenientes dos cálculos de otimização geométrica, foram usados para avaliar a eficácia das metodologias frente aos dados experimentais e determinaram, qual é o funcional que melhor retratou os dados experimentais, a fim de proceder posteriormente os demais cálculos utilizando tal funcional, de modo a minimizar o tempo computacional comprometendo minimamente os resultados obtidos.

O complexo consiste em uma molécula do ligante hidrazona $\mathrm{HL}$, coordenada de forma tridentada neutra ao metal cobre (II) e duas moléculas do ânion nitrato coordenadas ao Cu(II) (Figura 5.1.1), ambas de forma monodentada.

\subsection{1- Estrutura Geométrica}


Este é o único complexo caracterizado teoricamente nesta tese que já foi encaminhado para publicação até o momento da redação do presente texto. Desta forma, este complexo conta com o número de referência CCDC ("Cambridge Crystallographic Data Center') que é 991639, no qual podem ser encontrados os dados cristalográficos suplementares, que suportaram esse estudo.

O cobre(II) possui numero de coordenação cinco, portanto o complexo apresenta geometria pirâmide de base quadrada distorcida, isso porque os ângulos das ligações diferem muito de $90^{\circ}$, concordando com o observado em complexos com ligantes hidrazona análogos [34] [91]. Complexos pentacoordenados de cobre são largamente encontrados na literatura. [93] [94] [43] [84] [95]

No complexo o cobre possui número de coordenação igual a cinco, apresentando uma geometria bipirâmide trigonal distorcida, com os átomos de oxigênio coordenados pertencentes aos ânions nitrato na posição apical como representado na Figura 5.2. A distorção do poliedro formado é evidenciada, por exemplo, pelos ângulos O33-Cu-O39 de $85,142^{\circ}$ e N2-Cu-O31 de 49,474 (experimental) que são significativamente diferentes de $90^{\circ}$ (Tabela 8.2).

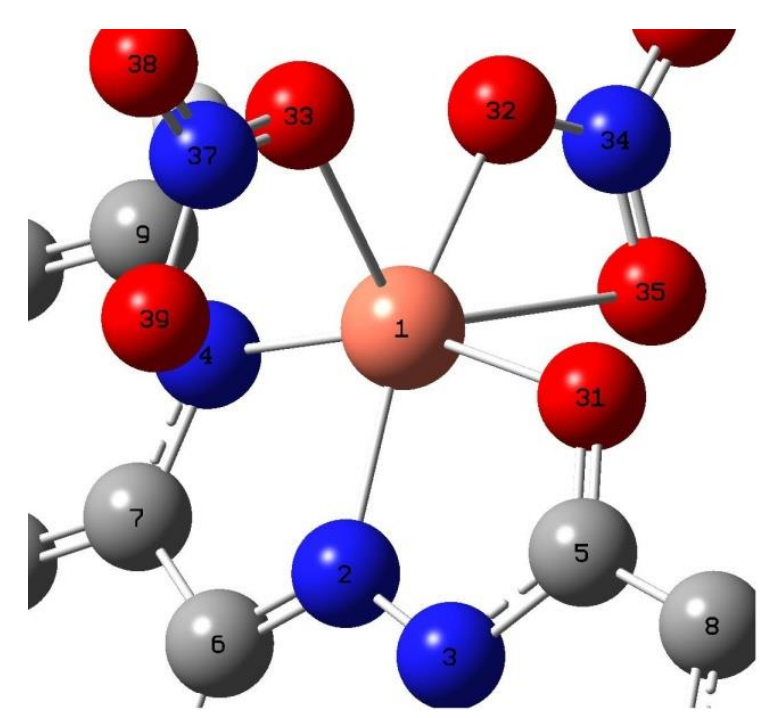

Figura 5.1.2. Detalhe da estrutura apresentada na Figura 5.1.1, evidenciando a numeração do $\mathrm{Cu}(\mathrm{II}) \mathrm{e}$ dos átomos presentes na esfera de coordenação com numeração usada na Tabela 8.2. 
$\mathrm{Na}$ análise dos ângulos que determinam a estrutura geométrica usando a abordagem de Addison e colaboradoradores, [96] calculamos o índice de trigonalidade $\tau=\left(\phi_{1}-\phi_{2}\right) / 60$, onde $\phi_{1}$ e $\phi_{2}$ são os dois maiores ângulos Ligante-MetalLigante da esfera de coordenação, o valor encontrado foi 0,94. Isso está de acordo com outros complexos de hidrazona da literatura [84,93,95].

A ligação entre $\mathrm{C} 5-\mathrm{O} 31$, reportada para ligante isolado com o valor de $1,219(2) \AA$ e o valor de 1,252(13) Å no complexo [Cu(HL)(NO$)_{3}$ ], o que é típico da conformação ceto, com concomitante encurtamento da ligação N2-N3. .[43]. Os comprimentos de ligação observados entre átomos de cobre, nitrogênio e oxigênio estão dentro da faixa reportada para outros complexos de $\mathrm{Cu}$ (II) com ligantes hidrazona similares. [97] [98] [99] Os resultados teóricos, sobretudo os calculados com o funcional PW91 utilizando a teoria de ondas planas no código computacional VASP, confirmam esses valores, com pequenos desvios.

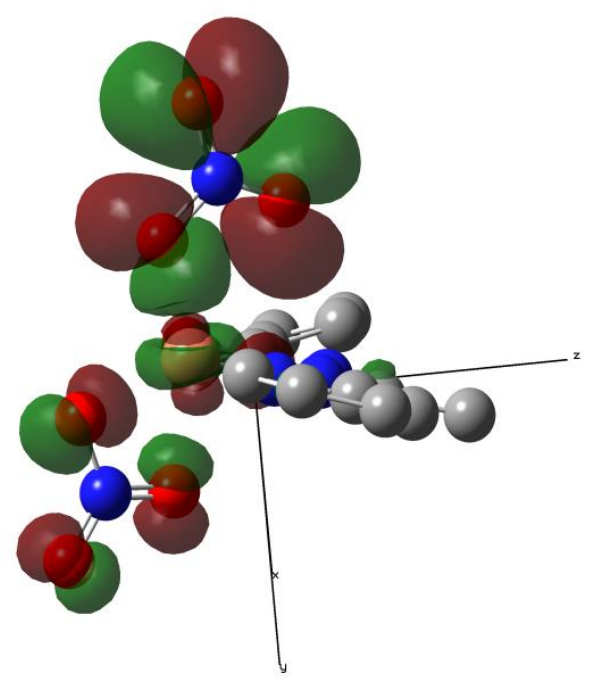

Figura 5.1.3. Orbital natural HOMO do complexo Nitrato de 2-acetilpiridinabenzoilhidrazonacobre(II) evidenciando o caratér $\mathrm{dz}^{2}$ sobre o cobre(II).

A ligação apical entre metal e nitrato foi calculada como sendo $2.217 \AA$ (CuO35) usando ondas planas, é bem maior que a ligação axial metal-nitrato (Cu-O32) 
que tem o valor de $1.985 \AA$. Essa é uma consequência da presença de dois elétrons em orbital $d z^{2}$, que faz com a ligação Cu-O35 seja maior ao longo do eixo $z$, conforme mostrado no orbital natural HOMO calculado para o complexo (Figura 5.1.3).

As previsões teóricas concordam em grande grau com o experimental, os maiores desvios se verificam na planaridade do ligante hidrazona e nos comprimentos de ligação $\mathrm{Cu}-\mathrm{O}$, para os oxigênios do ânion nitrato, presentes na esfera de coordenação. Experimentalmente, o ligante hidrazona encontra-se inclinado, fato este que pode ser atribuído diretamente à coordenação do ligante, já que em ligantes análogos sintetizados a esta hidrazona encontra-se planar. [89] [88]

A ligação entre o cobre (II) e o oxigênio 31 do ligante hidrazona é de 1,999 $\AA$ (experimental), sendo a mais curta entre cobre (II) e oxigênios, o que seria de se esperar, pois este oxigênio ligado ao grupamento mais volumoso possui maior densidade de carga sobre ele encurtando a ligação, conforme mostrado na Figura 5.1.4. Essa densidade de carga é visivelmente mais intensa no ligante. As demais ligações entre cobre e os oxigênios dos grupamentos nitrato possuem valores compatíveis com o de compostos análogos, tais como os complexos de cobre (II) sintetizados e caracterizados por Sen e colaboradores. [95]

A ligação entre Cu-O32 é a mais curta desse tipo encontrada no complexo, com valores em torno de 2,0 , enquanto que a maior distância entre cobre e oxigênio verifica-se entre o Cu-O35, que experimentalmente é de 2,699 Å, porém, podemos perceber pela análise da Tabela 8.2, que todos os funcionais usados, falharam significativamente ao prever essa distância, tendendo a uniformizar as distâncias entre cobre e oxigênio.

Além disso, para os dois íons nitrato, $\mathrm{Cu}-\mathrm{O} 32$ e Cu-O35 apresentam algum efeito de deslocamento ( $\mathrm{Cu}$-O32 é menor que $\mathrm{Cu}$-O35) e há essa inversão em todos os funcionais. A exceção é o M06, que trás como resultado o mesmo deslocamento para essas ligações. Isso também acontece entre $\mathrm{Cu}-\mathrm{O} 35$ and $\mathrm{Cu}-\mathrm{O} 39$, que possuem uma menor interação, e os funcionais tendem a aumentar o fator de repulsão presente nos dois grupamentos nitrato. 
Completando a esfera de coordenação, o cobre encontra-se ligado aos nitrogênios do ligante hidrazona, os comprimentos de ligação encontrados estão em conformidade com compostos análogos. [83] [100]

A Figura 5.1.4 mostra as isosuperficies de potencial eletrostático (MEP), para o ligante hidrazona $\mathrm{HL}$ e o complexo $\left[\mathrm{Cu}(\mathrm{HL})\left(\mathrm{NO}_{3}\right)_{2}\right]$. A análise do MEP do ligante $\mathrm{HL}$ sugere o comportamento doador do grupamento NNO para o nitrogênio piridínico e no complexo esse comportamento também se estende ao oxigênio ligado ao cobre (II). O complexo é descrito pela característica polarização dos grupamentos nitrato. O aumento de densidade de carga é devido principalmente a característica doadora do grupo NNO do ligante hidrazona. Essa tendência está de acordo com o resultado experimental [101], sugerindo que o grupamento azometina tem sua densidade eletrônica reduzida com a formação do complexo. O esquema de partição de cargas nos mostra que a densidade eletrônica do grupamento azometina é reduzida com a formação do complexo. O esquema de partição de cargas NBO mostra o mesmo comportamento. 

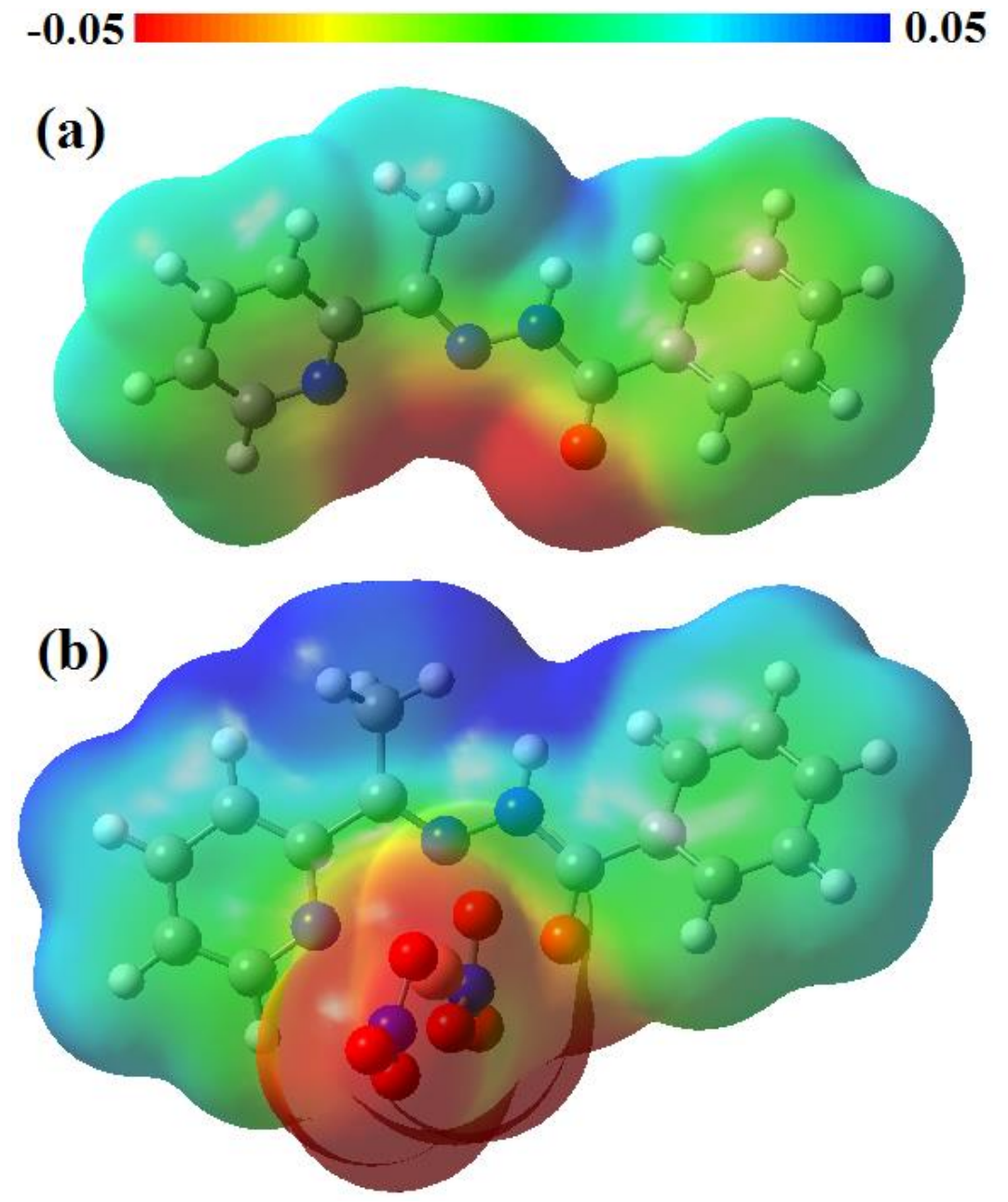

Figura 5.1.4. Mapas de potencial eletrostático em (a) ligante HL e em (b) do complexo Nitrato de 2-acetilpiridina-benzoilhidrazonacobre(II).

Na comparação entre os funcionais utilizados, apesar dos valores de desvio individuais e médios (MSD) consideráveis, quando comparamos cada ligação ou ângulo individualmente, há uma uniformidade entre os resultados. Isso sugere que os desvios com relação aos dados experimentais encontrados não estão relacionados à escolha do funcional, mas sim ao uso de uma molécula isolada para proceder ao cálculo, quando os resultados experimentais tratam-se de um cristal. Esse fato pode ser comprovado observando-se os resultados da última coluna da Tabela 8.2, que são referentes aos cálculos feitos usando ondas planas, nos quais 
a vizinhança molecular teve papel determinante para a maior aproximação com os dados experimentais.

A escolha dos funcionais se deu de forma a ter um espaço amostral o mais diverso possível, o funcional B3LYP, híbrido GGA, foi escolhido por ser o mais usado na literatura e ter sucesso na maioria dos casos, os demais funcionais foram escolhidos levando em conta sua forma de construção e diversidade relacionada ao termo de troca e correlação eletrônica.

Os funcionais de Grimme w-B97-xd e B97-D apresentaram o maior desvio quadrático médio, 0,652 e 0,620 respectivamente, enquanto o menor RMSD foi obtido com o funcional M06, com o valor de 0,426. Entretanto, não há grandes desvios na faixa de variação do RMSD entre os funcionais utilizados, novamente demonstrando a independência da geometria calculada com cada funcional usado.

Em geral, a acurácia dos métodos DFT para ângulos de ligação é de aproximadamente $0,6^{\circ},{ }^{[102]}{ }^{[103]}$ o que foi de fato encontrado nesse estudo, no qual os valores são em geral menores que 0,6 . Os maiores desvios foram encontrados para comprimentos e ângulos de ligação dos ligantes nitrato. Os ângulos entre N2Cu-O32 e N2-Cu-O33 são $163.17(4)^{\circ}$ e $121.18(5)^{\circ}$ indicando que esse complexo adota a geometria pirâmide de base quadrada distorcida mas os valores teóricos desses ângulos, em todos os cálculos aqui reportados (Tabela 8.2) são menores que os experimentais.

A hipótese de que a estrutura cristalina (Figura 5.1.5) é determinante no arranjo molecular fica confirmada ao analisarmos os resultados provenientes dos cálculos feitos com o código computacional VASP. A confirmação desse fato se dá quando comparamos os desvios encontrados nos comprimentos e ângulos de ligação presentes na Tabela 8.2, que retratam exclusivamente os átomos envolvidos na esfera de coordenação. Essa comparação pode ser feita tanto de forma geral, levando em conta o desvio médio significativo, MSD, que foi calculado de $4,43 \%$, quanto individualmente, por exemplo, entre os átomos de nitrogênio do ligante hidrazona. 


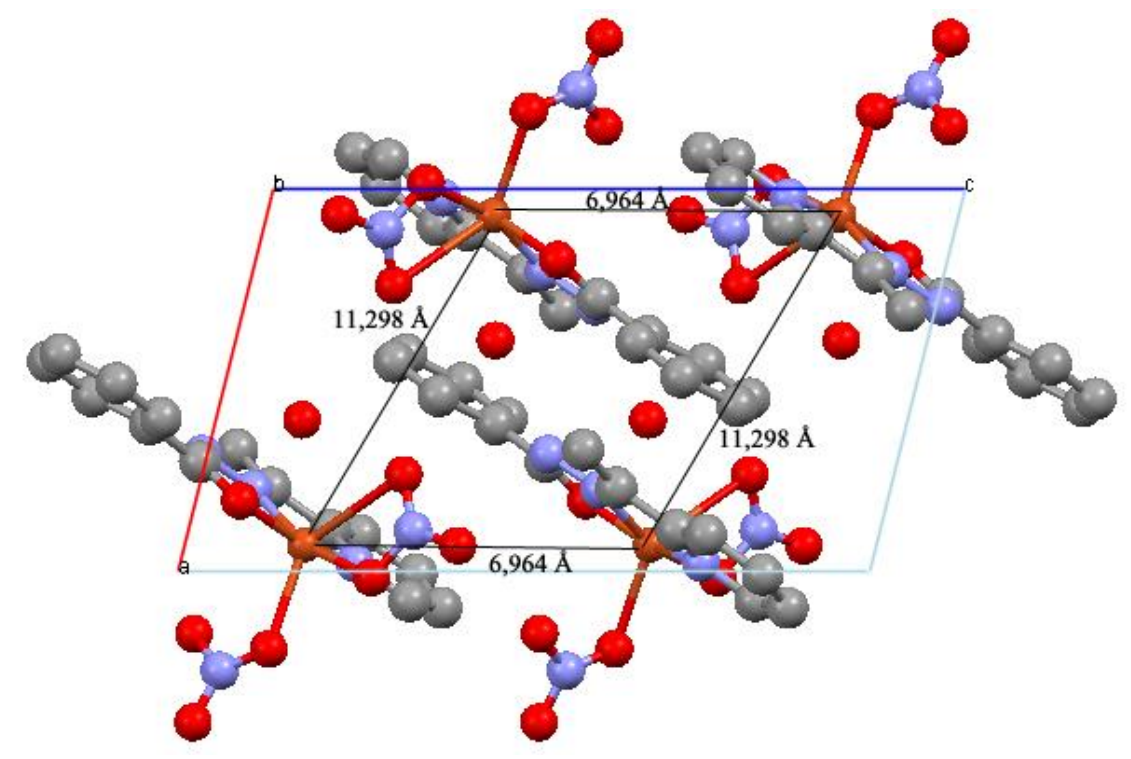

Figura 5.1.5. Cela unitária experimental do complexo Nitrato de 2-acetilpiridinabenzoilhidrazonacobre(II), na qual encontram-se destacadas em preto as distâncias $\mathrm{Cu}$-Cu entre moléculas vizinhas (experimental).

A estrutura cristalina obtida por meio de cálculos usando a teoria de ondas planas (código computacional VASP) está de acordo com o encontrado experimentalmente, podemos atestar esses valores na Tabela 8.2 no Apêndice, na última coluna da tabela, denotada pelo funcional PW91, usado nesse cálculo. As posições das moléculas do complexo na cela unitária, bem como as distâncias entre elas apresentam grande concordância.

Experimentalmente, as distâncias entre os quatro átomos de cobre pertencentes à cela unitária, são de 6,964 $\AA$ e 11,298 $\AA$, e as calculadas com o VASP são 7,864 Å e 14,146 ̊̊ (Figura 5.1.5). Essas distâncias mostram que não há interação alguma entre essas unidades, porém, o ligante hidrazona encontra-se inclinado, e entre dois anéis aromáticos intramoleculares, temos a distância de $3,724 \AA$, calculada por ondas planas, que possui o valor experimental de $3,811 \AA$. Essa distância é consistente com interação do tipo empilhamento $\pi$ entre duas moléculas do complexo. 


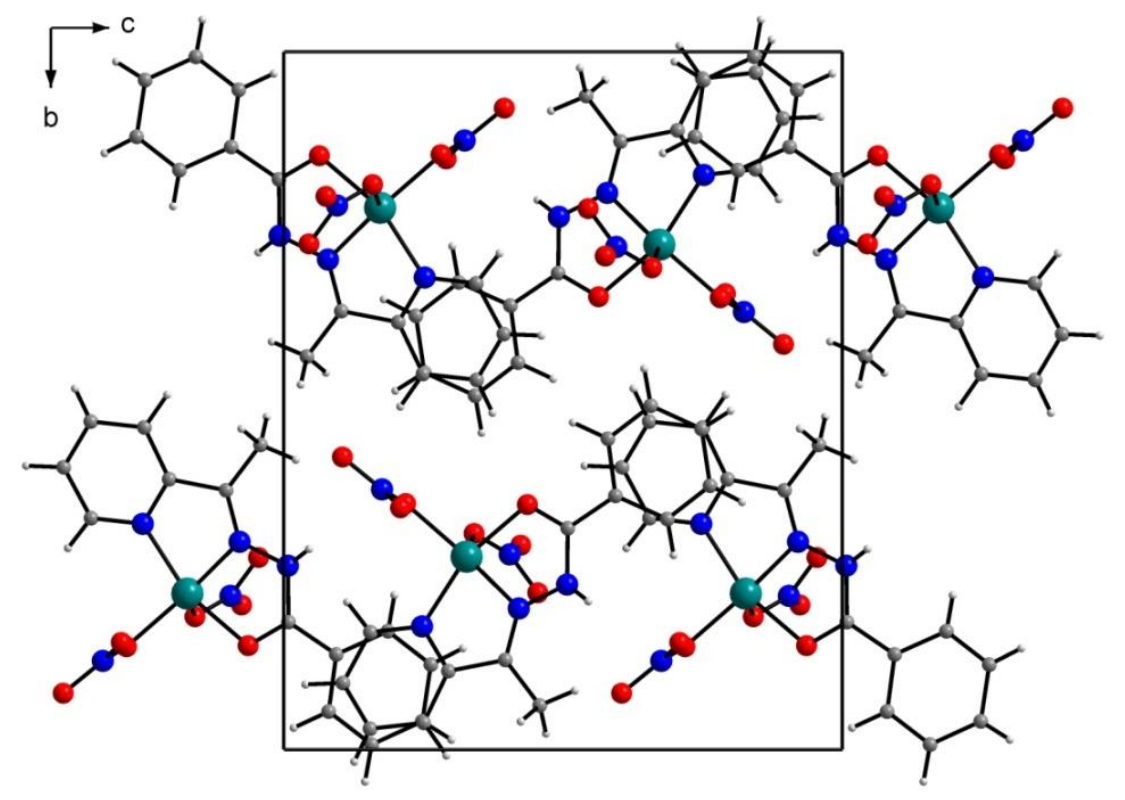

Figura 5.1.6. Estrutura cristalina do complexo [Cu(HL)(NO $\left.\left.{ }_{3}\right)_{2}\right]$ vista ao longo do eixo a. Podemos ver a propagação da cadeia em zig zag decorrente do empacotamento da estrutura.

Curiosamente, essa interação $\pi \cdots \pi$ entre os anéis piridina e fenil em duas moléculas vizinhas proporcionam uma rede em zingue-zague [104] conforme mostrado na Figura 5.1.6. Essa interação foi percebida nos cálculos periódicos DFT com o valor de $3.724 \AA$, apresentando concordância com o valor experimental.

A análise dos resultados de difração de Raios- $X$ indicam ainda a presença de interações do tipo ligações de hidrogênio intermoleculares com a hidrazona e uma molécula de água, $\mathrm{N} 3-\mathrm{H} \cdots \mathrm{O}\left[\mathrm{d}(\mathrm{N} \cdots \mathrm{N})=2.847(14) \AA, \backslash(\mathrm{N} 3 \mathrm{H} \cdots \mathrm{O})=175.5(11)^{\circ}\right]$ formando uma rede de ligações de hidrogênio que se propaga por todo o cristal. Nos cálculos teóricos, a ligação de hidrogênio intermolecular possui distância e ângulo $\left[\mathrm{d}(\mathrm{N} \cdots \mathrm{N})=2.008 \AA\right.$, e $\left.(\mathrm{N} 3 \mathrm{H} \cdots \mathrm{O})=174.68^{\circ}\right]$ o que corrobora com os resultados teóricos encontrados. 
Tabela 5.1.1 Comparação entre as cargas de Mulliken nos átomos envolvidos na

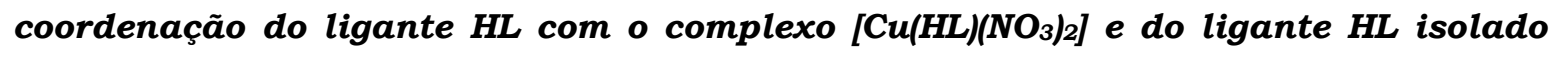
(MO6/LANL2DZ e 6-31g(d,p))

\begin{tabular}{|c|c|c|c|c|c|c|}
\hline $\begin{array}{l}\text { Átomo de } \\
\text { referência }\end{array}$ & $\begin{array}{l}\text { Carga de } \\
\text { Mulliken } \\
\text { Complexo }\end{array}$ & $\begin{array}{c}\text { Carga de } \\
\text { Mulliken } \\
\text { Ligante }\end{array}$ & $\begin{array}{c}\text { Carga } \\
\text { ChelpG } \\
\text { Complexo }\end{array}$ & $\begin{array}{c}\text { Carga } \\
\text { ChelpG } \\
\text { Ligante }\end{array}$ & $\begin{array}{c}\text { Carga } \\
\text { NBO } \\
\text { Complexo }\end{array}$ & $\begin{array}{c}\text { Carga } \\
\text { NBO } \\
\text { Ligante }\end{array}$ \\
\hline $\mathrm{Cu}$ & 0,644 & & 0,995 & & 0,842 & \\
\hline O31 & $-0,474$ & $-0,464$ & $-0,524$ & $-0,459$ & $-0,600$ & $-0,597$ \\
\hline $\mathrm{N} 2$ & $-0,245$ & $-0,417$ & $-0,028$ & $-0,374$ & $-0,308$ & $-0,226$ \\
\hline N4 & $-0,472$ & $-0,458$ & $-0,330$ & $-0,036$ & $-0,364$ & $-0,413$ \\
\hline O32 & -0437 & & $-0,437$ & & $-0,500$ & \\
\hline O33 & $-0,508$ & & $-0,517$ & & $-0,489$ & \\
\hline O35 & $-0,461$ & & $-0,572$ & & $-0,473$ & \\
\hline O39 & $-0,450$ & & 0,879 & & $-0,609$ & \\
\hline
\end{tabular}

Dado o grande número de métodos usados na literatura para calcular cargas atômicas parciais, incluindo esquemas de cargas químicos quânticos e empíricos, foram inclusos nesse estudo as cargas de Mulliken, por serem mais amplamente utilizadas, apesar do grande número de limitações, o esquema ChelpG (cargas advindas de potenciais eletrostáticos usando método de rede) e cargas NBO (provenientes da análise de orbitais naturais).

A Tabela 5.1 mostra os valores das cargas obtidas usando as metodologias Mulliken, ChelpG e NBO, com o funcional M06 e conjuntos de bases LANL2DZ para o cobre e 6-31g(d,p) para os demais átomos.

A análise das cargas pelos três esquemas sugere uma intensa polarização envolvida na esfera de coordenação. O ligante hidrazona complexado com o cobre (II) possui sobre o nitrogênio central N2 carga parcial de -0,028 a.u. (ChelpG), enquanto o nitrogênio lateral N3 possui a carga de -0.437 a.u., no ligante HL nos temos a mesma tendência com o valor de -0.374 a.u. para o N2 e -0.591 a.u. para 
o N3, quando calculados usando ChelpG. Apesar dos valores serem distintos para os demais esquemas de cargas, a tendência qualitativa permanece a mesma. Essa diferença pode ser diretamente atribuída à vizinhança diferenciada proporcionada pelos dois nitratos em posições e coordenações diferentes, mas em ambos os casos, essas cargas reforçam o forte indicio de polarização na esfera de coordenação.

A fim de entender o comportamento das mudanças de cargas relacionadas à complexação, nós analisamos as cargas para o grupo doador hidrazona dos átomos O31, N2 e N3. No ligante HL, a carga desse grupo é -1,424 a.u. (ChelpG), enquanto no complexo $\left[\mathrm{Cu}(\mathrm{HL})\left(\mathrm{NO}_{3}\right)_{2}\right]$ o valor passa a $-0,989$ a.u., atestando o comportamento doador do grupamento. O nitrogênio $\mathrm{N} 4$ da piridina também diminui sua carga após a complexação, mostrando que esse nitrogênio também possui comportamento doador na formação do complexo (Tabela 5.1)

\subsection{2- Efeito do Solvente}

Nos cálculos anteriores temos os resultados do complexo [Cu(HL)(NO$\left.)_{2}\right]$ no vácuo, entretanto dada a grande discordância de valores de alguns comprimentos e ângulos de ligação entre todos os funcionais testados e os dados experimentais promoveram a motivação necessária para simular essa molécula em ambiente solvatado, como aquele em que foi sintetizada.

Portanto, para o complexo $\left[\mathrm{Cu}(\mathrm{HL})\left(\mathrm{NO}_{3}\right)_{2}\right]$, investigou-se a influência do solvente. Os resultados para os comprimentos e ângulos de ligação selecionados usando o modelo de solvatação IEFPCM, ${ }^{[105]}$ usando metanol como solvente, estão mostrados na Tabela 5.2 .

Os cálculos foram feitos para os funcionais B97D e M06, que são os dois extremos de desvio médio quadrático, nos cálculos feitos sem a presença de solvente (Tabela 8.2) e também com o funcional B3LYP, por seu amplo uso em uma larga gama de aplicações. 
Tabela 5.1.2. Comprimentos de ligação (Å) e ângulos (graus) para o complexo $\left[\mathrm{Cu}(\mathrm{HL})\left(\mathrm{NO}_{3}\right)_{2}\right]$ calculados com a presença de metanol como solvente (modelo IEFPCM).

\begin{tabular}{|c|c|c|c|c|}
\hline & Exp,* & $\begin{array}{l}\text { B3LYP } \\
\text { Metanol }\end{array}$ & $\begin{array}{c}\text { M06 } \\
\text { Metanol }\end{array}$ & $\begin{array}{l}\text { B97D } \\
\text { Metanol }\end{array}$ \\
\hline $\mathrm{Cu}-\mathrm{O} 33$ & 2,267 & 2,192 & 2,100 & 2,037 \\
\hline $\mathrm{Cu}-\mathrm{O} 32$ & 1,963 & 1,993 & 2,084 & 2,020 \\
\hline $\mathrm{Cu}-\mathrm{N} 2$ & 1,947 & 2,014 & 2,013 & 2,096 \\
\hline $\mathrm{Cu}-\mathrm{N} 4$ & 1,988 & 2,050 & 2,001 & 2,075 \\
\hline $\mathrm{Cu}-\mathrm{O} 31$ & 1,999 & 2,058 & 2,023 & 3,043 \\
\hline N2-N3 & 1,366 & 1,361 & 1,346 & 1,353 \\
\hline N2-C6 & 1,282 & 1,290 & 1,283 & 1,310 \\
\hline N3-C5 & 1,361 & 1,377 & 1,370 & 1,403 \\
\hline C5-O31 & 1,248 & 1,251 & 1,246 & 1,232 \\
\hline $\mathrm{C} 5-\mathrm{C} 8$ & 1,468 & 1,473 & 1,466 & 1,491 \\
\hline N4-C7 & 1,347 & 1,358 & 1,354 & 1,366 \\
\hline N4-C9 & 1,332 & 1,334 & 1,328 & 1,341 \\
\hline N2-Cu-N4 & 80,26 & 78,83 & 79,08 & 77,75 \\
\hline $\mathrm{O} 2-\mathrm{Cu}-\mathrm{N} 1$ & 97,93 & 98,48 & 97,21 & 95,54 \\
\hline $\mathrm{N} 2-\mathrm{Cu}-\mathrm{O} 31$ & 79,16 & 78,13 & 78,64 & 60,47 \\
\hline $\mathrm{O} 5-\mathrm{Cu}-\mathrm{O} 2$ & 75,64 & 84,93 & 87,45 & 94,03 \\
\hline $\mathrm{N} 2-\mathrm{Cu}-\mathrm{O} 2$ & 163,17 & 158,25 & 137,36 & 169,31 \\
\hline O33-Cu-O31 & 100,34 & 101,45 & 98,64 & 119,47 \\
\hline N4-Cu-O31 & 158,85 & 156,64 & 157,71 & 125,99 \\
\hline $\mathrm{N} 2-\mathrm{Cu}-\mathrm{O} 33$ & 121,18 & 116,81 & 135,17 & 95,6 \\
\hline $\mathrm{N} 4-\mathrm{Cu}-\mathrm{O} 33$ & 101,57 & 98,5 & 96,87 & 153,47 \\
\hline C17-C8-C7-C15 & $-28,08$ & $-27,46$ & $-24,25$ & $-67,99$ \\
\hline RMSD & & 0,280 & 0,383 & 0,941 \\
\hline
\end{tabular}

Os cálculos foram feitos para os funcionais B97D e M06, que são os dois extremos de desvio médio quadrático, nos cálculos feitos sem a presença de 
solvente (Tabela 8.2) e também com o funcional B3LYP, por seu amplo uso em uma larga gama de aplicações.

O uso do modelo contínuo dielétrico de solvatação teve uma grande influência no valor do RMSD. A maior melhoria verificada em razão da inclusão do contínuo dielétrico foi no cálculo com o funcional B3LYP, o qual o RMSD passou de 0,569 no vácuo, para $0,280 \mathrm{com}$ metanol, nos cálculos com M06 houve uma melhoria de 0,043 no RMSD, enquanto que com o uso do funcional B97D ocorreu o oposto, com um aumento de 0,381 no valor do RMSD.

Analisando os valores específicos os quais motivaram a inclusão do solvente, foi possível verificar a mesma tendência que se reflete nos valores de RMSD, mais especificamente a ligação Cu-N2 tem valor experimental 1,947 $\AA$, e na nossa estimativa sem solvente estaria em torno de $2.2 \AA$ para todos os funcionais testados, e com solvente o valor obtido usando o funcional M06 foi de $2.013 \AA$, muito mais próximo da medida experimental.

Para a ligação Cu-N4 a melhora foi ainda mais significativa, isso porque o valor experimental é $1.988 \AA$ e nossa melhor estimativa sem solvente foi de 2.300 Å com PBE1PBE, mas usando o modelo de solvatação e o funcional M06 esse valor foi para $2.001 \AA$.

A conclusão a respeito da correlação entre os dados teóricos e experimentais para esse complexo é de que os resultados teóricos são quase independentes do funcional utilizado, isto é devido, provavelmente, à utilização de uma molécula isolada, enquanto que os resultados experimentais são do cristal.

Foi utilizado neste estudo uma grande variedade de tipos funcionais, incluindo o funcional B3LYP amplamente divulgado e alguns novos funcionais. Desta forma, deve-se notar que os dados experimentais são para um conjunto que têm contribuições de outras conformações, e a influência dessas conformações podem afetar as propriedades do composto e ser observado nos cálculos e medidas espectrais

Investigamos a diferença de energia entre duas conformações em solução, o conhecido poço de equilíbrio ceto enólico. A forma ceto é mais favorável, em seguida, forma enol, quando ambos são simuladas em meios de metanol, por 
modelo contínuo dielétrico, em $38,26 \mathrm{~kJ} \mathrm{~mol}^{-1}$. Este número foi obtido pela diferença de energia total das duas conformações. Portanto, essa variação na energia total entre estas duas conformações mostra que é perfeitamente possível a presença de conformações intermediárias com uma pequena diferença de energia, afetando as propriedades do composto, como ocorre nos espectros, como podemos ver na próxima seção com detalhes.

\subsection{3- Espectroscopias Vibracional e Eletrônica}

A espectroscopia no infravermelho fornece evidencias da presença de vários grupos funcionais na estrutura orgânica devido à interação das moléculas ou átomos com a radiação eletromagnética em um processo de vibração molecular (Figura 5.1.7). As ligações covalentes que constituem as moléculas orgânicas estão em constantes movimentos axiais e angulares. A radiação no infravermelho faz com que átomos e grupos de átomos de compostos orgânicos vibrem com amplitude aumentada ao redor das ligações covalentes que os ligam. Desta forma, esse é um método de investigação estrutural amplamente utilizado.

As frequências vibracionais aqui analisadas, dizem respeito a uma molécula isolada, o que deve ser uma boa aproximação, uma vez que as medidas experimentais são feitas em estado sólido. A Figura 5.1.7 mostra o espectro de infravermelho simulado para todos os funcionais usados nesse trabalho (linhas coloridas) e experimentais obtidos por Gatto e colaboradores representados pela linha negra. ${ }^{[17]}$

Os resultados teóricos abaixo foram obtidos de cálculos de frequência DFT, usando o funcional M06 e os conjuntos de bases LANL2DZ para o $\mathrm{Cu}$ e 6-31G(d,p) para os demais elementos. Apenas os resultados para este funcional são discutidos a seguir, devido à grande uniformidade entre os resultados obtidos, e a já bem entendida até aqui independência dos funcionais utilizados também de frequência, da mesma forma como os cálculos de otimização geométrica, mostrados na sessão anterior. 


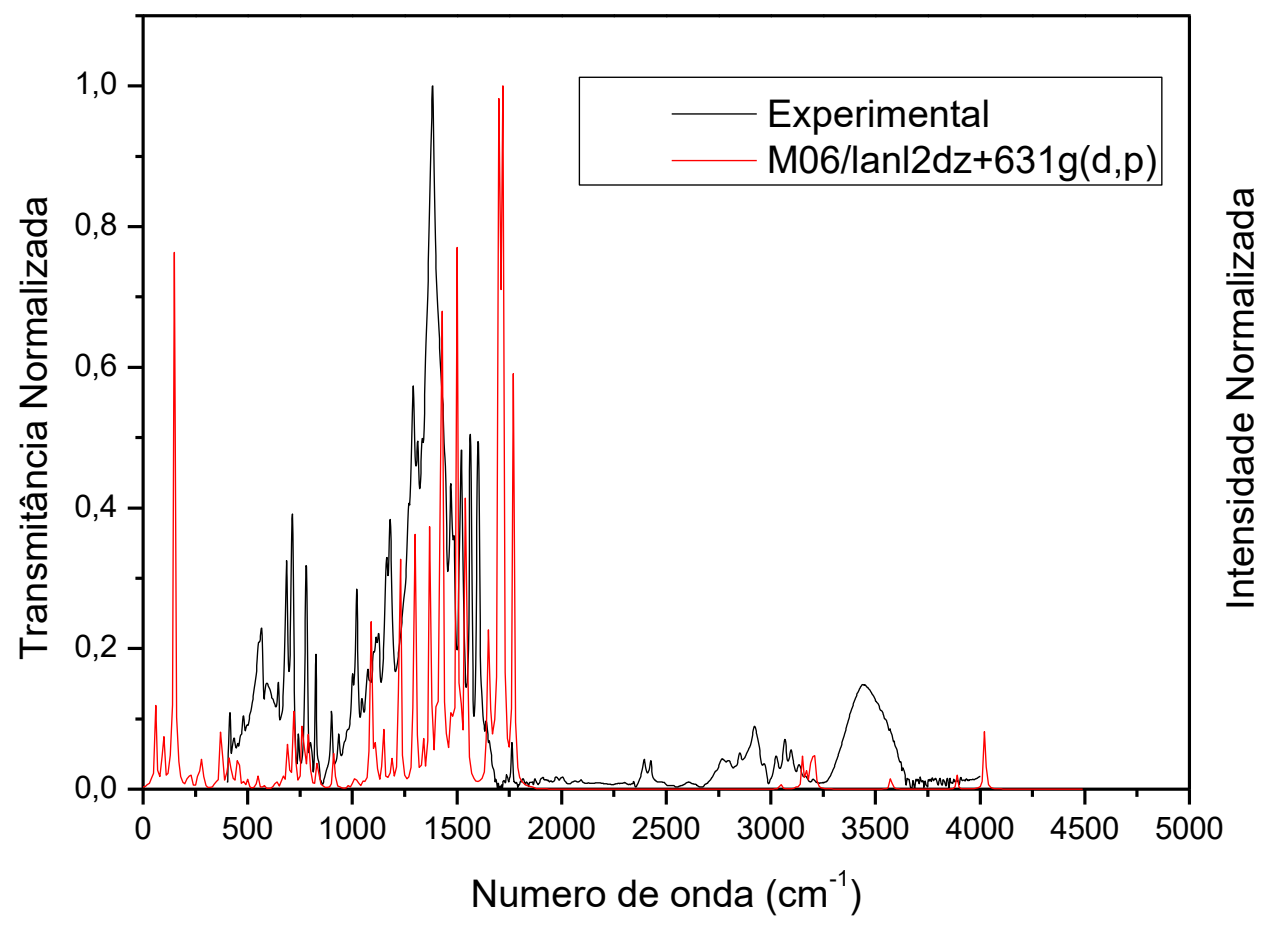

Figura 5.1.7. Comparação entre o espectro de infravermelho experimental (linha continua) e os seu análogo calculado (linha vermelha), do complexo [Cu( $\left.\mathrm{HL})\left(\mathrm{NO}_{3}\right)_{2}\right]$, usando o funcional MO6, associado aos conjuntos de bases LANL2DZ para o cobre e 6-31g(d,p) para os demais átomos.

Patole e colaboradores sintetizaram o ligante acetilpiridina benzoil hidrazona (APBH), e o complexo de cobre [(APBH)CuCl]2.(EtOH)2 (Figura 1.6) e os caracterizaram por várias metodologias, incluindo espectroscopia de infravermelho, conforme detalhado no Capítulo 1, sessão 1.6. ${ }^{[43]}$

A frequência da imina, observada no ligante $\mathrm{HL}$ foi de $1616 \mathrm{~cm}^{-1}$, com deslocamento para $1599 \mathrm{~cm}^{-1}$ no complexo [(APBH)CuCl]2.(EtOH)2 (Figura 1.6), sintetizados por Patole, indicando o envolvimento de nitrogênio do grupamento azometina na complexação. [43]

Essa mesma tendência é verificada no complexo de nitrato de cobre (II) $\left[\mathrm{Cu}(\mathrm{HL})\left(\mathrm{NO}_{3}\right)_{2}\right]$, no qual a banda da imina, que corresponde ao máximo do gráfico 
da Figura 5.1.7, está presente em $1639,21 \mathrm{~cm}^{-1}$ na medida experimental, com análogo em 1704,00 $\mathrm{cm}^{-1}$ calculado com o funcional M06, mostrando aqui uma grande equivalência entre o teórico e experimental. A ligação do nitrogênio priridínico, do ligante hidrazona com o metal é indicada pelo deslocamento da frequência $v(C-N)$ de $1579 \mathrm{~cm}^{-1}$, encontrado na literatura para o ligante $\mathrm{HL}$ isolado [43] para $1471,43 \mathrm{~cm}^{-1}$ no valor experimental e $1496 \mathrm{~cm}^{-1}$ para a previsão teórica, no complexo $\left[\mathrm{Cu}(\mathrm{HL})\left(\mathrm{NO}_{3}\right)_{2}\right]$, também usando o funcional M06.

Tabela 5.1.3.Comparação entre frequências de infravermelho selecionadas para o

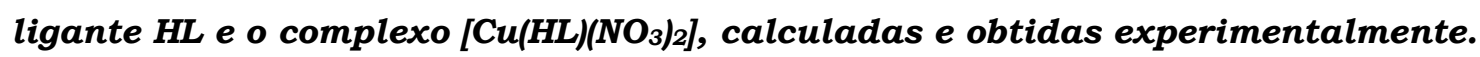

\begin{tabular}{|l|l|l|l|}
\hline Ligante & Exp. ${ }^{[6]}$ [94] [95][96] $^{[\text {M06 }}$ & B3LYP \\
\hline$v N-H$ & 3173 & 3553 & 3561 \\
\hline$v \mathrm{C}=\mathrm{O}$ & 1655 & 1846 & 1794 \\
\hline$\rho($ py) & 620 & 624 & 634 \\
\hline Complexo & Esse trabalho \\
\hline$v N-H$ & 3096 & 3578 & 3397 \\
\hline$v \mathrm{C}=\mathrm{O}$ & - & 1683 & 1649 \\
\hline$\rho($ py) & 623 & 655 & 657 \\
\hline
\end{tabular}

O espectro de infravermelho do complexo $\left[\mathrm{Cu}(\mathrm{HL})\left(\mathrm{NO}_{3}\right)_{2}\right]$, (Figura 5.1.7) foi analisado comparando-se o espectro do ligante hidrazona $\mathrm{HL}$ isolado, presente na Figura 8.1, cujos dados são análogos, medida experimental e cálculos teóricos para todos os funcionais aqui considerados. Nessa comparação é possível notar que as frequências vibracionais no infravermelho $v(\mathrm{O}-\mathrm{H})$ e $v(\mathrm{~N}-\mathrm{H})$ são observadas para 0 complexo em $3439 \mathrm{~cm}^{-1}$ e $3096 \mathrm{~cm}^{-1}$, respectivamente. Nos cálculos teóricos, com o funcional M06, essas atribuições de sinais foram confirmadas em $3889 \mathrm{~cm}^{-1}$ para $v(\mathrm{O}-\mathrm{H})$ e $3574 \mathrm{~cm}^{-1}$ para $v(\mathrm{~N}-\mathrm{H})$. Apesar da diferença numérica entre os resultados teóricos e experimentais, o intervalo teórico entre as frequências de $\mathrm{N}-\mathrm{H}$ e $\mathrm{O}-\mathrm{H}$ é virtualmente o mesmo $\left(315 \mathrm{~cm}^{-1}\right)$ encontrado nas medidas experimentais $\left(343 \mathrm{~cm}^{-}\right.$ 
1). Portanto, os valores teóricos mostram a mesma tendência entre estas duas frequências.

A frequência de absorção $v(C=O)$ que aparece em $1656 \mathrm{~cm}^{-1}$ no espectro do ligante livre não é encontrada no complexo $\left[\mathrm{Cu}(\mathrm{HL})\left(\mathrm{NO}_{3}\right)_{2}\right]$, pontuando a coordenação de $\mathrm{HL}$ junto ao metal central. A frequência de absorção $v(\mathrm{C}=\mathrm{N})$ é observada experimentalmente em $1616 \mathrm{~cm}^{-1}$ para o ligante $\mathrm{HL}$ e em $1601 \mathrm{~cm}^{-1}$ para o complexo de nitrato e $\mathrm{Cu}(\mathrm{II})$, desta forma, apontando mais uma vez para a coordenação de HL e os cálculos DFT corroboram com essa atribuição em 1757 $\mathrm{cm}^{-1}$, usando M06. No complexo também é possível observar uma forte frequência em $1383 \mathrm{~cm}^{-1}$, atribuída a $v(\mathrm{NO})$, com seu análogo calculado em $1425 \mathrm{~cm}^{-1}$ (Tabela 5.1.2).

O modo vibracional de deformação da piridina no plano encontrado entre 672-697 $\mathrm{cm}^{-1}$ no espectro do ligante desloca-se para $685-712 \mathrm{~cm}^{-1}$ no complexo de nitrato de cobre (II), o que está em concordância com a coordenação do átomo de nitrogênio do anel piridinico. Os resultados teóricos (M06) mostram o mesmo comportamento: para ligante $\mathrm{HL}$ o modo da piridina em plano está em $623 \mathrm{~cm}^{-1}$, enquanto que para o complexo, desloca-se para $636 \mathrm{~cm}^{-1}$.

Desta forma, face aos dados experimentais, suportados pelos resultados teóricos aqui reportados, os dados de infravermelho indicam a coordenação de HL através de N2-N4-O31 como átomos quelatos, de acordo com a estrutura determinada por Raios- $\mathrm{X}$ e otimizada por campo autoconsistente e ondas planas para o complexo $\left[\mathrm{Cu}(\mathrm{HL})\left(\mathrm{NO}_{3}\right)_{2}\right] \cdot \mathrm{H}_{2} \mathrm{O}$.

A complexação do ligante hidrazona $\mathrm{HL}$ com cobre (II) foi investigada também por espectroscopia UV-VIS (Figura 5.1.8) e cálculos TD-DFT, em todos os casos foram usados os conjuntos de bases LANL2DZ com pseudopotencial para 0 cobre e $6-31 \mathrm{~g}(\mathrm{~d}, \mathrm{p})$ para os demais átomos e o funcional m06. Os cálculos foram feitos para os 100 primeiros estados excitados singleto e tripleto da molécula isolada. 


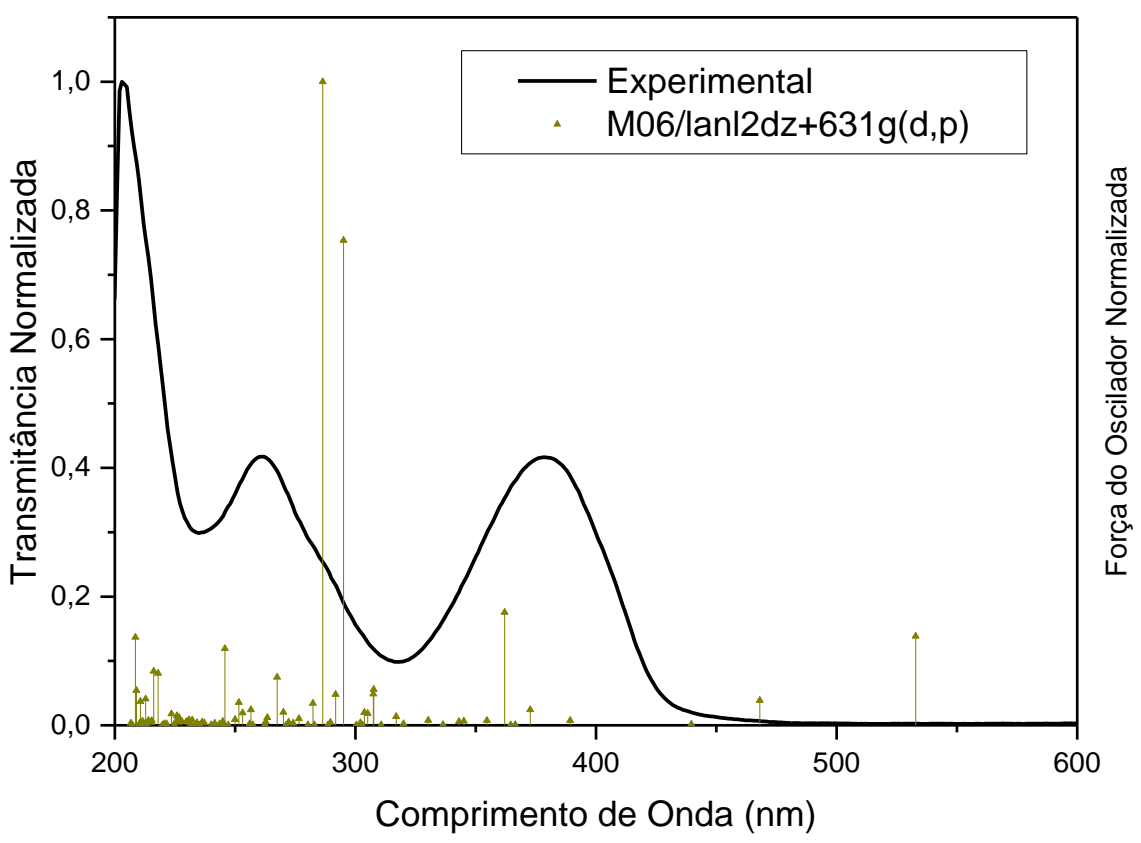

Figura 5.1.8. Espectro eletrônico experimental (linha contínua) e teórico (m06/LANL2DZ+6-31g(d,p) no qual cada linha vertical amarelo escuro corresponde a uma excitação eletrônica para o complexo [Cu(HL)(NO $\left.\left.{ }_{3}\right)_{2}\right]$.

O espectro eletrônico de absorção é uma ferramenta muito útil para validar os resultados fornecidos por outros métodos de investigação estrutural. Através do especto eletrônico é possível atestar a estereoquímica de íons metálicos em complexos, baseando-se nas posições e na quantidade de picos com transições do tipo d-d. [106] [107]

O espectro eletrônico (Figura 5.1.8) apresenta uma grande banda centrada em $541,92 \mathrm{~nm}$ e um ombro em 378,82 nm. Esse ombro é característico de mudança de conjugação em ligantes hidrazona aromáticos, devido à excitação eletrônica. [108] [33]

A absorbância da hidrazona em 300nm aumenta com o aumento da concentração de cobre (II) na solução de metanol, o que pode ser entendido como uma transferência de carga do ligante para o metal, como mostra na Figura 5.1.9, 
na qual estão os orbitais moleculares envolvidos na transição de maior probabilidade.

Nos cálculos teóricos o análogo a esta excitação foi encontrado em 303 nm e força de oscilador de 0.0017 . Os orbitais moleculares envolvidos nessa transição são $94 \beta \rightarrow 109 \beta$ (HOMO-14 $\rightarrow$ LUMO), presentes na Figura 5.1.9. A contribuição probabilística desses orbitais para a transição foi calculada como $53.80 \%$.
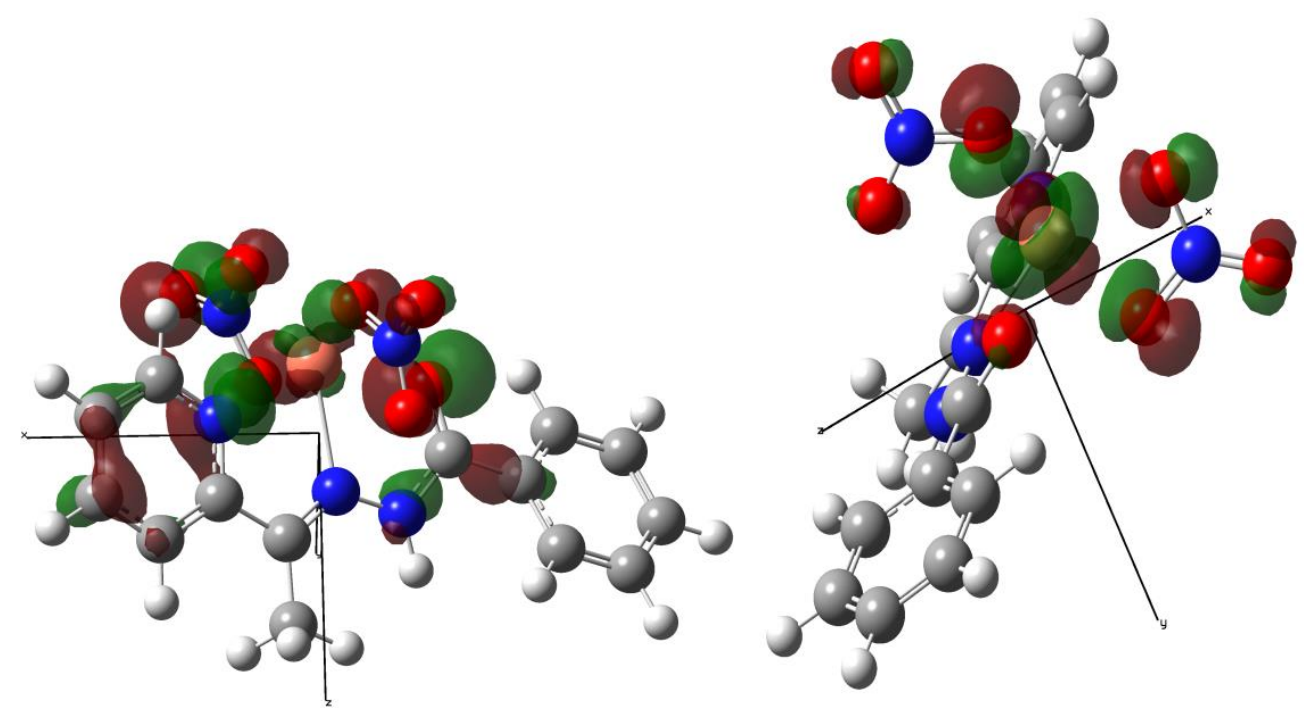

Figura 5.1.9. Orbitais moleculares HOMO-14 (esquerda) e LUMO (direita) do complexo $\left[\mathrm{Cu}(\mathrm{HL})\left(\mathrm{NO}_{3}\right)_{2}\right]$ envolvidos na transição eletrônica calculada em $302.7 \mathrm{~nm}$.

Uma forte banda de absorção é observada no complexo próxima a $380 \mathrm{~nm}$, a qual foi esperada, pelos resultados experimentais, que fosse correspondente à coordenação do ligante $\mathrm{HL}$ ao cobre (II), foi atribuído a essa transição a transferência de carga do par de elétrons isolado do orbital $p$ do nitrogênio do ligante, essa atribuição foi confirmada pelos orbitais moleculares naturais envolvidos na transição calculada teoricamente (Figura 5.1.10).

Nos cálculos teóricos, a excitação análoga foi encontrada em 362 nm com força de oscilador de 0,074 . Os orbitais moleculares envolvidos nessa transição são 
$100 \beta \rightarrow 109 \beta$ (HOMO-8 $\rightarrow$ LUMO), conforme mostrado na Figura 5.1.10. A contribuição desses orbitais para a transição é de 59,16\%.
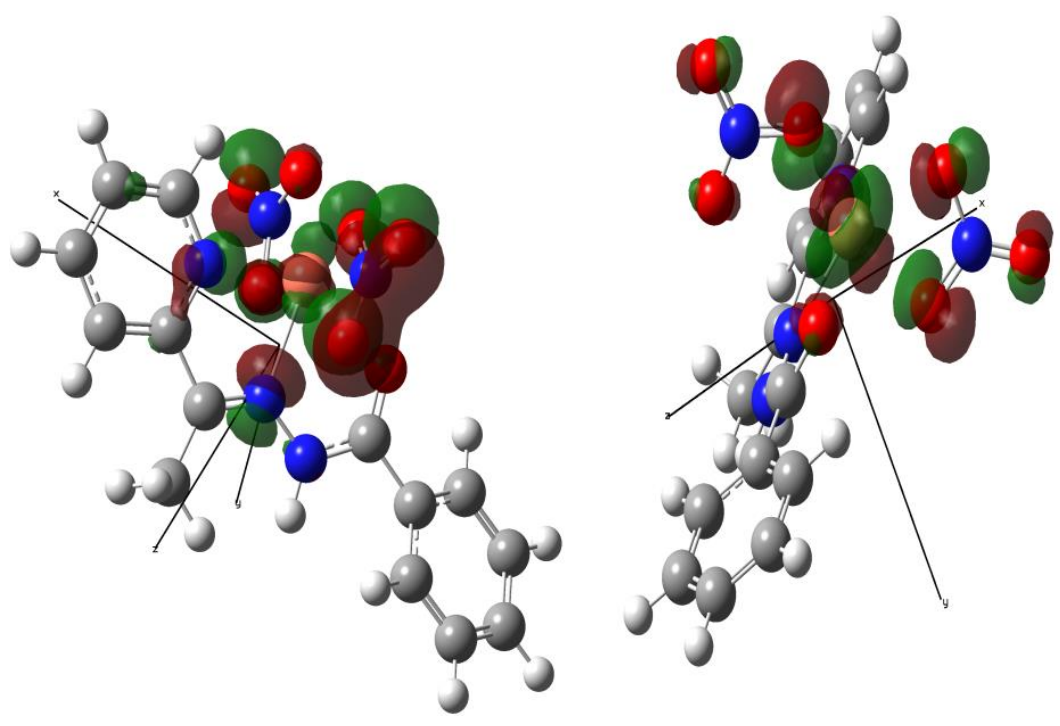

Figura 5.1.10. Orbitais moleculares HOMO-8 (esquerda) e LUMO (direita) do complexo [Cu(HL)(NO$\left.)_{3}\right)_{2}$ envolvidos na transição eletrônica calculada em 361,99 $\mathrm{nm}$.

A outra banda do complexo, por volta de $260 \mathrm{~nm}$, medida experimentalmente, pode ser atribuída a uma transferência de carga do ligante para o metal, LMCT. Na qual o orbital $d z^{2}$ do cobre(II) recebe a transferência de carga por interação com um ligante nitrato. Nos cálculos, essa banda foi detectada com um comprimento de onda de $267 \mathrm{~nm}$ e força do oscilador de 0,0317 .

Os orbitais que contribuem em maior intensidade para essa transição são $91 \beta \rightarrow 109 \beta$ (HOMO-17 $\rightarrow$ LUMO) presentes na Figura 5.1.11. Essa contribuição é de $73,72 \%$. 

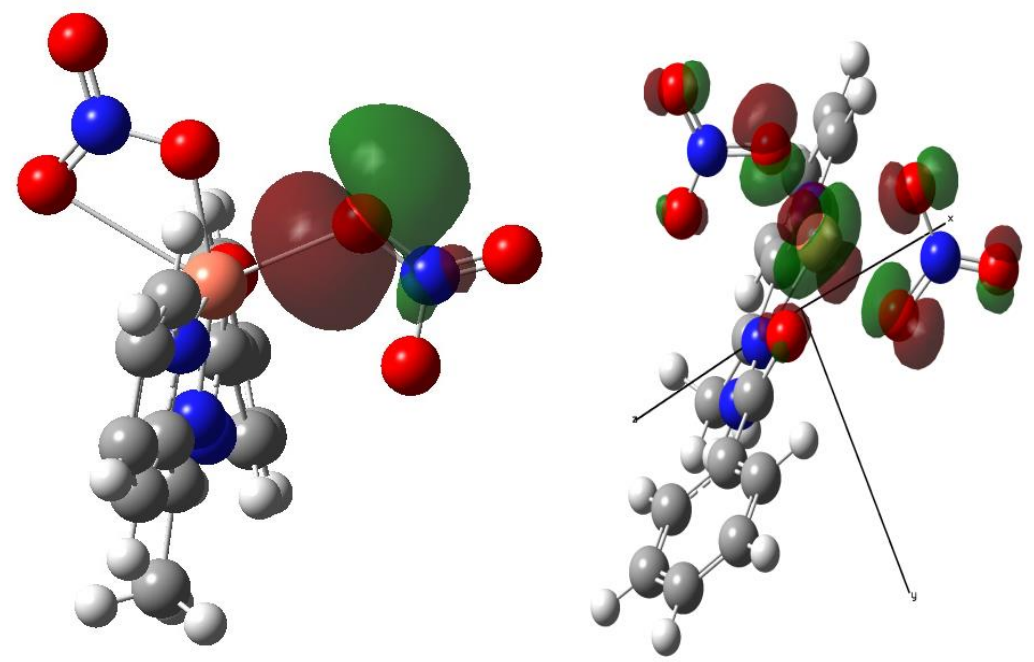

Figura 5.1.11. Orbitais moleculares HOMO-17 (esquerda) e LUMO (direita) do complexo [Cu(HL)(NO $\left.{ }_{3}\right)_{2}$ envolvidos na transição eletrônica calculada em 267,49 $\mathrm{nm}$.

Uma banda análoga a essa foi encontrada para o ligante isolado (Figura 8.2). Essa banda de absorção no ligante é atribuída a uma transição $\pi-\pi^{*}$ intraligante, esse é um pico de absorção típico de Bases de Schiff. [45] [109]

Nessa transição, podemos observar que ocorre transferência de densidade eletrônica do orbital molecular HOMO -17, com característica ligante, presente em maior proporção sobre um dos ligantes nitrato, mais precisamente aquele em que só o oxigênio 33 está coordenado ao metal, para o orbital molecular LUMO, também com característica predominantemente ligante, distribuído por todo o complexo, porém com característica $\mathrm{dz}^{2}$ sobre o cobre(II), justificando a atribuição de uma transição do tipo LMCT. [110]

\section{2- $\mu$-diacetatobis[(2-acetilpiridinabenzoilhidrazona) cobre(II)]}

A seguir temos o estudo teórico da estrutura do complexo $\mu$-diacetatobis[(2acetilpiridinabenzoilhidrazona)cobre(II)], $\left[(\mathrm{Cu})_{2} \mu\left(\mathrm{CH}_{3} \mathrm{COO}\right)_{2}(\mathrm{HL})_{2}\right]$, que é uma base de Schiff. 


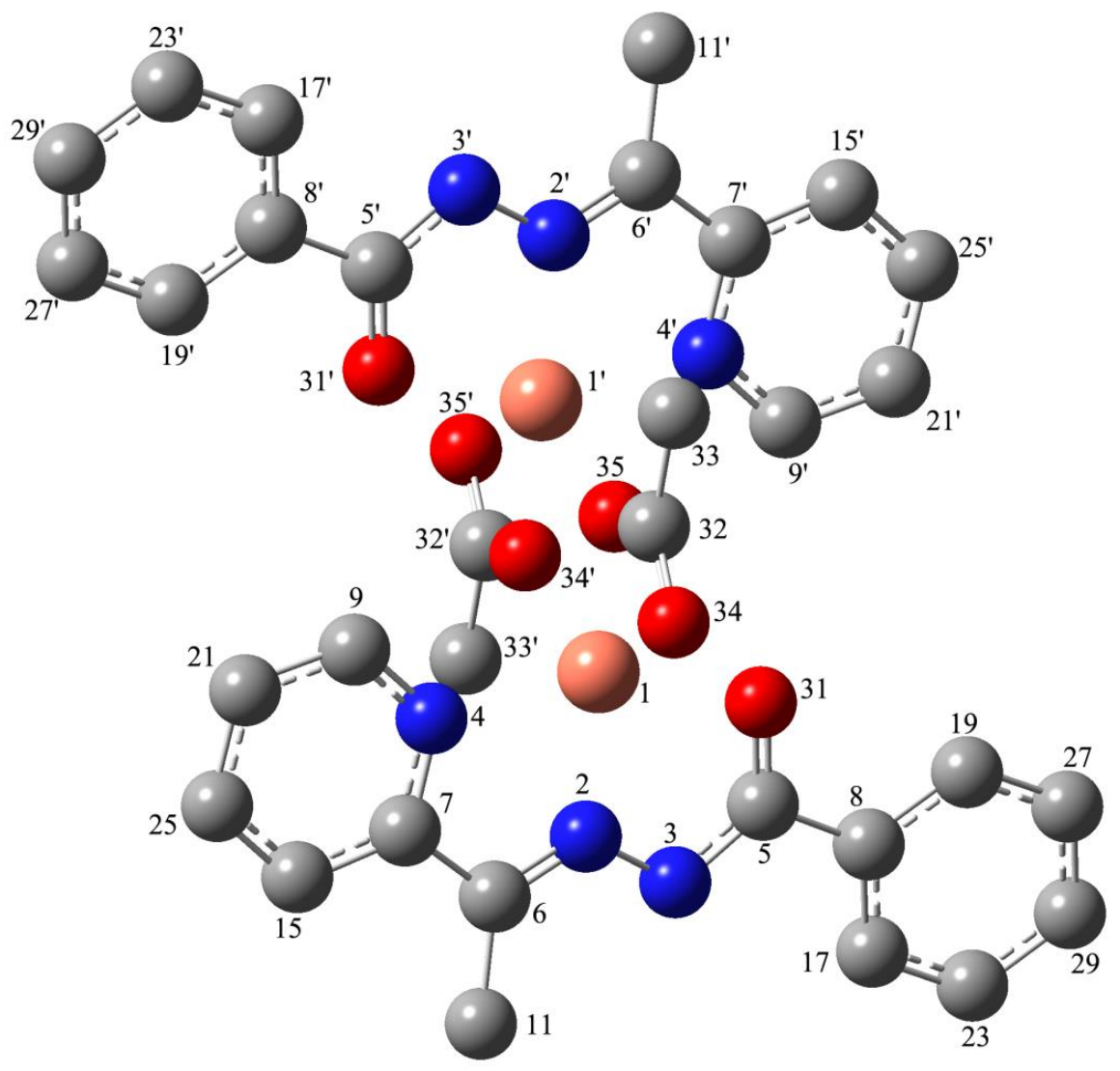

Figura 5.2.1. O complexo $\mu$-diacetato bis[(2-acetilpiridina benzoilhidrazona) cobre(II)], [( $\left.\mathrm{Cu})_{2} \mu\left(\mathrm{CH}_{3} \mathrm{COO}\right)_{2}(\mathrm{HL})_{2}\right]$, sem hidrogênios e com numeração usada no texto $e$ na Tabela 8.3

O referido complexo possui em sua estrutura dois ânions acetato fazendo ponte entre entre os dois átomos de cobre e duas moléculas do ligante 2acetilpiridina-benzoilhidrazona, HL, cada uma coordenada a um átomo de cobre (Figura 5.2.1), completando a esfera de coordenação de cada unidade coordenativa.

\subsection{1- Estrutura Geométrica}


Para o complexo $\mu$-Diacetatobis[(2 - acetilpiridina -benzoilhidrazona) cobre(II)] (Figura 5.2.1), o ligante hidrazona encontra-se desprotonado, na forma aniônica, e utiliza seus três sítios disponíveis, coordenando-se ao íon $\mathrm{Cu}$ (II) pelo nitrogênio piridínico, nitrogênio imínico da hidrazona e pelo oxigênio cabonílico. Há nesse complexo, duas unidades coordenativas idênticas, essas duas unidades estão ligadas quimicamente pela interação dos átomos de $\mathrm{Cu}(\mathrm{II})$ com os oxigênios dos ligantes acetato (Figura 5.2.2).

Esse complexo é formado por duas unidades coordenativas idênticas, cada uma dessas unidades coordenativas é considerada como uma unidade assimétrica nas medidas de difração de Raios-X. Desta forma, as distâncias e ângulos correspondentes, possuem o mesmo valor em ambas as unidades coordenativas. Assim, tomaremos a unidade coordenativa 1 para entendermos os parâmetros estruturais envolvidos. Para assegurar a confiabilidade dessa aproximação, quando tomamos os resultados dos cálculos teóricos, que são feitos com o complexo inteiro, foram feitos para todos os cálculos o RMSD entre as duas unidades coordenativas, para cada funcional usado, apresentando o valor zero em todos os casos, ou seja, tratando-se da mesma estrutura.

Nas duas unidades coordenativas o cobre (II) possui numero de coordenação cinco, portanto o complexo apresenta a geometria pirâmide de base quadrada distorcida (Figura 5.2.3), onde os átomos N2 N4 O31 e O35 formam a base quadrada, e o oxigênio O34' ocupa a posição apical da pirâmide. Com os

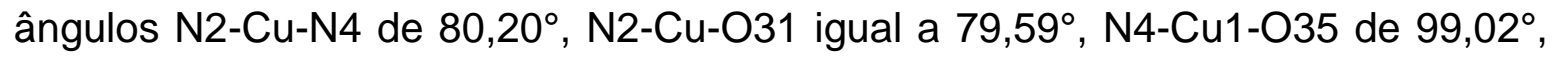
N2-Cu-O35 igual a $163,52^{\circ}$ são os valores experimentalmente medidos, o poliedro formado encontra-se distorcido. [34] [91] 


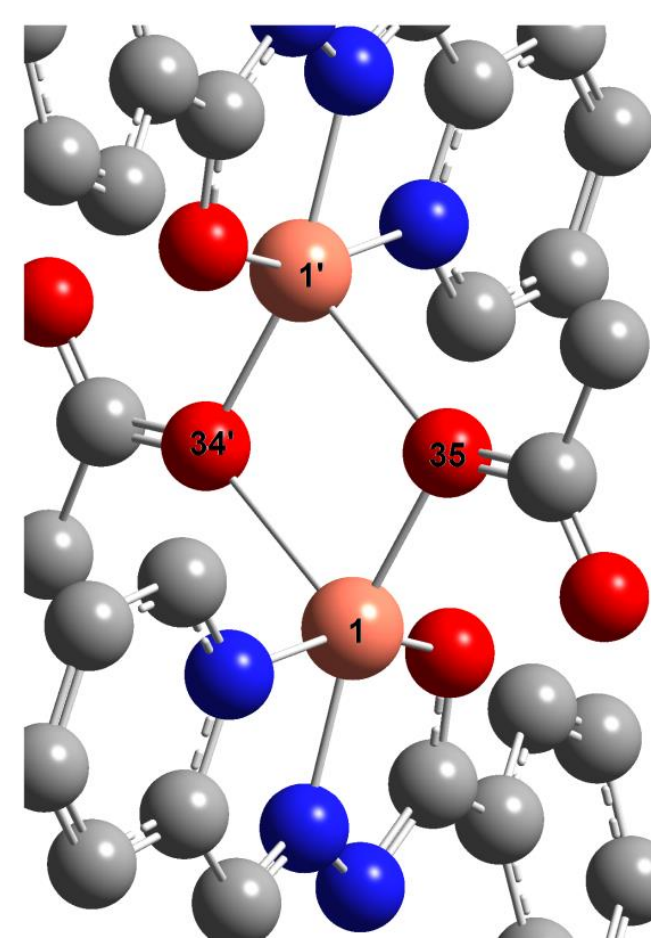

Figura 5.2.2. Detalhe da estrutura do complexo $\left[(\mathrm{Cu})_{2} \mu\left(\mathrm{CH}_{3} \mathrm{COO}\right)_{2}(\mathrm{HL})_{2}\right]$ apresentada na Figura 5.2.1, evidenciando a numeração dos átomos de Cu(II) e dos oxigênios do grupamento acetato responsáveis pela ponte entre as duas unidades coordenativas com numeração usada na Tabela 8.3.

Os melhores valores teóricos, calculados usando campo autoconsistente, para os ângulos do poliedro de coordenação são aqueles calculados com o funcional B3LYP e são eles N2-Cu-N4 de $78,75^{\circ}$, N2-Cu-O31 igual a $77,21^{\circ}$, N4$\mathrm{Cu}-\mathrm{O} 35$ de $99,83^{\circ}$, N2-Cu-O35 igual a $174,07^{\circ}$. Os valores encontrados usando ondas planas são praticamente idênticos aos experimentalmente medidos, são eles:

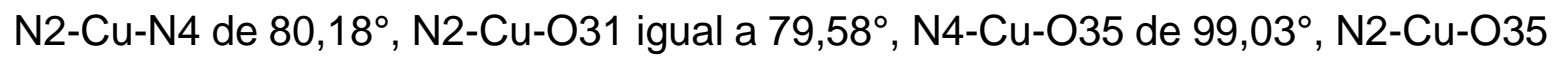
igual a $163,49^{\circ}$. Sendo esses valores coerentes com uma estrutura na qual o metal possui igual coordenação descrita na literatura por Andjelkovic e colaboradores, com os ângulos N1-Cu1-N2 de 78,4(2) ${ }^{\circ}$, N2-Cu1-Cl2 igual a 95,67(8) ${ }^{\circ}, \mathrm{N} 1-\mathrm{Cu} 1-\mathrm{N} 4$ de $77,9(2)^{\circ}$, N4-Cu1-Cl2 igual a 99,96(9) . [111]

Desta maneira são formados dois anéis quelatos de cinco membros que são quase planares, entre o cobre e o ligante $\mathrm{HL}$ para cada unidade coordenativa 
(Figura 5.2.3). O cobre completa seu número de coordenação igual a cinco ligandose a dois íons acetato, de forma monodentada, resultando em um complexo neutro, com o cobre no estado de oxidação (+2). A distorção do poliedro de coordenação do ideal, cujos ângulos diferem bastante de 90ํㅡ é ocasionada pela geometria rígida do ligante hidrazona, HL.

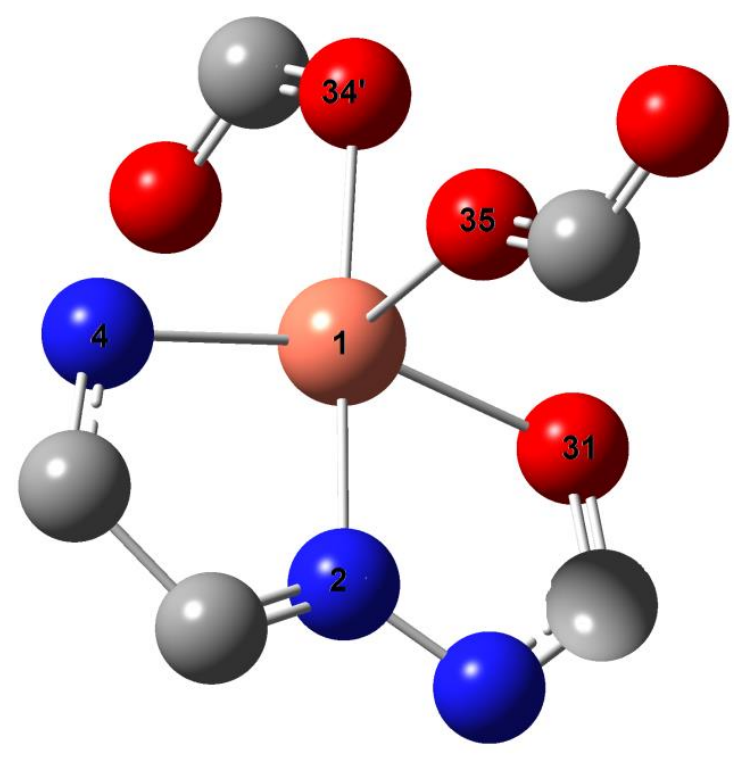

Figura 5.2.3. Detalhe da esfera de coordenação de um dos átomos do cobre (II) do complexo $\left[(\mathrm{Cu})_{2} \mu(\mathrm{CH} 3 \mathrm{COO})_{2}(\mathrm{HL})_{2}\right]$ apresentada na Figura 5.2.1, evidenciando a numeração dos átomos coordenados ao cobre.

As distâncias de ligações Cu-N2 e Cu-N3 (amina), 1,934 Å e 2,843 $\AA$ (exp), $1,990 \AA$ e $2,875 \AA$ (B3LYP) e $1,934 \AA$ e $2,843 \AA$ (vasp), para as ligações Cu-O (carbonila), temos os valores 1,964 $\AA$ (exp), 2,099 $\AA$ (B3LYP) e 1,964 $\AA$ (vasp), e Cu-O35 e Cu-O34' (acetato), os valores são 1,958 $\AA$ e 2,277 $\AA$ (exp), 2,261 $\AA$ e (B3LYP) e 1,964 $\AA$ e 2,277 $\AA$ (vasp), concordam com os valores encontrados para um íon $\mathrm{Cu}$ (II) com geometria piramidal de base quadrada distorcida coordenado por grupos similares. [112]

No complexo $\mu$-Diacetato de bis $(2$ - acetilpiridina - benzoilhidrazona cobre(II)) da Figura 5.2.1, as duas unidades coordenativas são ligadas em ponte 
por um átomo de oxigênio de cada acetato de forma equidistante, proporcionando assim maior estabilidade da estrutura e características coordenativas acentuadas (Figura 5.2.3).

As mudanças estruturais acarretadas pela presença de dois centros de coordenação podem ser percebidas quando comparamos o complexo de acetato de cobre com o de nitrato de cobre, principalmente no que cerne às ligações entre cobre (II) e os átomos do ligante hidrazona (Tabela 5.2.1). Esse fato faz com que o ligante hidrazona se encontre mais planar conforme seria de se esperar.

Tabela 5.2.1. Comparação entre os comprimentos (angstrom) e diedro (graus) de ligação selecionados para os complexos de nitrato de cobre (II) [Cu(HL)(NO acetato de cobre (II) [Cu(HL)(CH3COO)] 2 , medidos experimentalmente e calculados com o funcional MO6.

\begin{tabular}{|l|c|c|c|c|}
\hline & \multicolumn{2}{|c|}{$\left[\mathrm{Cu}(\mathrm{HL})\left(\mathrm{NO}_{3}\right)_{2}\right]$} & \multicolumn{2}{c|}{$\left[(\mathrm{Cu})_{2} \mu(\mathrm{CH} 3 \mathrm{COO})_{2}(\mathrm{HL})_{2}\right]$} \\
\hline & Experimental & $\mathrm{M} 06$ & Experimental & M06 \\
\hline N2N3C8C17 & 169,45 & 157,91 & 162,41 & 168,72 \\
\hline $\mathrm{Cu} 1 \mathrm{~N} 2$ & 1,947 & 2,248 & 1,934 & 1,959 \\
\hline $\mathrm{Cu} 1 \mathrm{~N} 4$ & 2,015 & 2,241 & 1,988 & 2,079 \\
\hline $\mathrm{Cu} 1 \mathrm{O} 31$ & 1,999 & 2,232 & 1,964 & 2,045 \\
\hline
\end{tabular}

Neste complexo, as ligações dos centros de coordenação de cobre (II) são saturadas, portanto a interação entre os átomos de cobre é negligenciável, [113] [114] porém isso não impede que indiretamente seja percebida a influência da existência de dois centros de coordenação. Para o complexo $\left[(\mathrm{Cu})_{2} \mu(\mathrm{CH} 3 \mathrm{COO})_{2}(\mathrm{HL})_{2}\right]$, essa influência pode ser atestada pela proximidade entre o oxigênio não pertencente à esfera de coordenação do ligante acetato e o cobre (II) mais próximo, essa interação ocorre a uma distância experimental de 2,856 ̊̊ que foi calculada como 2,707 com B3LYP e 2,855 $\AA$ com ondas planas, estando esses valores abaixo da soma do raio covalente das duas espécies envolvidas $(1,40 \AA$ do cobre e $1,52 \AA$ do oxigênio), pode-se verificar a existência dessa interação forte. 
$\mathrm{Na}$ Tabela 5.2.1, temos os valores do diedro N2N3C8C17, que dizem respeito à planaridade do ligante hidrazona, vide Figura 5.2.1 e podemos notar que esse valor diminui do complexo mononuclear para o complexo binuclear, assim como as ligações envolvidas na esfera de coordenação que constam nas demais linhas da tabela, demonstrando mais uma vez a força da interação resultante da presença de dois centros coordenativos.

A escolha do funcional presente na Tabela 5.2.1 foi motivada pelo menor desvio médio quadrático encontrado para o complexo $\left[\mathrm{Cu}(\mathrm{HL})\left(\mathrm{NO}_{3}\right)_{2}\right] \quad(\mathrm{RMSD}=$ 0,426 ) e apesar do menor desvio quadrático para o acetato ser alto com relação às outras metodologias utilizadas, quantitativamente representam a mesma tendência.

É possível perceber pela análise da Tabela 8.3 (Apêndice - Capítulo 8) que os desvios verificados entre dados experimentais e teóricos foram bem menores quando comparados ao complexo mononuclear de nitrato de cobre. Este fato corrobora para a afirmação de que centros binucleares promovem interações mais fortes no complexo, sendo assim a influência do meio cristalino e de interações intermoleculares com moléculas vizinhas fica menos importante de forma a não afetar tanto os resultados.

Geralmente, complexos de cobre que possuem pontes de acetato de base quadrada, exibem três tipos diferentes de geometria, com respeito ao arranjo da base quadrada da pirâmide. São eles: base perpendicular (Tipo 1), base paralela (Tipo 2) e base coplanar (Tipo 3). $\mathrm{O}$ arranjo assimétrico da parte $\mathrm{Cu}_{2}\left(\mathrm{CH}_{3} \mathrm{COO}\right) 2$ no complexo $\left[(\mathrm{Cu})_{2} \mu\left(\mathrm{CH}_{3} \mathrm{COO}\right)_{2}(\mathrm{HL})_{2}\right]$, pertence ao Tipo 2. Essa geometria foi reproduzida por todos os funcionais utilizados, e seguindo a mesma linha da análise de comprimentos e ângulos de ligação, o calculo que melhor reproduziu os referidos ângulos foi o de ondas planas.

$\mathrm{Na}$ análise dos ângulos que determinam a estrutura geométrica usando a abordagem de Addison e colaboradoradores, [96] válida para complexos com numero de coordenação igual a cinco, a fim de se decidir entre os dois extremos geométricos pirâmide de base quadrada e bipirâmide trigonal, que tipo de geometria intermediária se encontra cada complexo. 
Esse parâmetro é o índice de trigonalidade, que foi calculado para o complexo para todos os funcionais. O valor referente à estrutura experimental é de 0,72 , o que corresponde à geometria pirâmide de base quadrada distorcida. Entre os valores calculados, todos aqueles dos cálculos SCF possuem valor maior que um, o que corresponderia à geometria bipirâmide trigonal, enquanto o cálculo feito usando ondas planas teve o índice calculado de 0,72, exatamente como o valor experimental. Há vários outros complexos de número de coordenação igual a cinco, com índices de trigonalidade semelhantes, reportados na literatura, que suportam essa afirmação. [93,95].

Tabela 5.2.2 Comparação entre as cargas de Mulliken, ChelpG e NBO nos átomos envolvidos na coordenação do ligante $\mathrm{HL}$ com o complexo $\left[(\mathrm{Cu})_{2} \mu_{(}\left(\mathrm{CH}_{3} \mathrm{COO}\right)_{2}(\mathrm{HL})_{2}\right]$ e do ligante HL isolado (MO6/LANL2DZ e 6-31g(d,p))

\begin{tabular}{|c|c|c|c|c|c|c|}
\hline Átomo & $\begin{array}{c}\text { Carga de } \\
\text { Mulliken }\end{array}$ & $\begin{array}{c}\text { Carga de } \\
\text { Mulliken } \\
\text { Complexo }\end{array}$ & $\begin{array}{c}\text { Carga } \\
\text { ChelpG }\end{array}$ & $\begin{array}{c}\text { Carga } \\
\text { ChelpG } \\
\text { Ligante }\end{array}$ & $\begin{array}{c}\text { Carga } \\
\text { NBO }\end{array}$ & $\begin{array}{c}\text { Carga } \\
\text { NBO }\end{array}$ \\
\hline $\mathrm{Cu}$ & 0,644 & & 0,702 & & 0,813 & \\
\hline $\mathrm{O} 31$ & $-0,474$ & -0.464 & $-0,597$ & $-0,459$ & $-0,673$ & $-0,597$ \\
\hline $\mathrm{N} 2$ & $-0,245$ & -0.417 & $-0,097$ & $-0,374$ & $-0,250$ & $-0,226$ \\
\hline $\mathrm{N} 4$ & $-0,472$ & -0.458 & $-0,526$ & $-0,036$ & $-0,486$ & $-0,413$ \\
\hline $\mathrm{O} 34$ & $-0,437$ & & $-0,653$ & & $-0,650$ & \\
\hline O35 & $-0,508$ & & $-0,509$ & & $-0,719$ & \\
\hline
\end{tabular}

A justificativa para essa distorção do índice, relativa aos cálculos SCF é a mesma para todos os funcionais. O índice de trigonalidade foi definido na Seção anterior como sendo $\tau=\left(\phi_{1}-\phi_{2}\right) / 60$, onde $\phi_{1}$ e $\phi_{2}$ são os dois maiores ângulos LiganteMetal- Ligante da esfera de coordenação.

O ângulo $\phi 1$ tomado foi N2CuO35 para todos os cálculos (Tabela 8.3), já o ângulo $\phi 2$ variou em alguns casos, para o B3LYP o ângulo foi N2CuO34' e para o 
M06 o ângulo foi O31CuO35, nos demais funcionais a variação foi entre esses dois ângulos. Porém essa variação do segundo maior ângulo de coordenação não foi determinante, mas sim o valor desses ângulos, que variou entre 108,67ํㅡ (B3LYP) e $101,51^{\circ}(\mathrm{M} 06)$, bem distintos do experimental N2CuO34' $=120,00^{\circ}$.

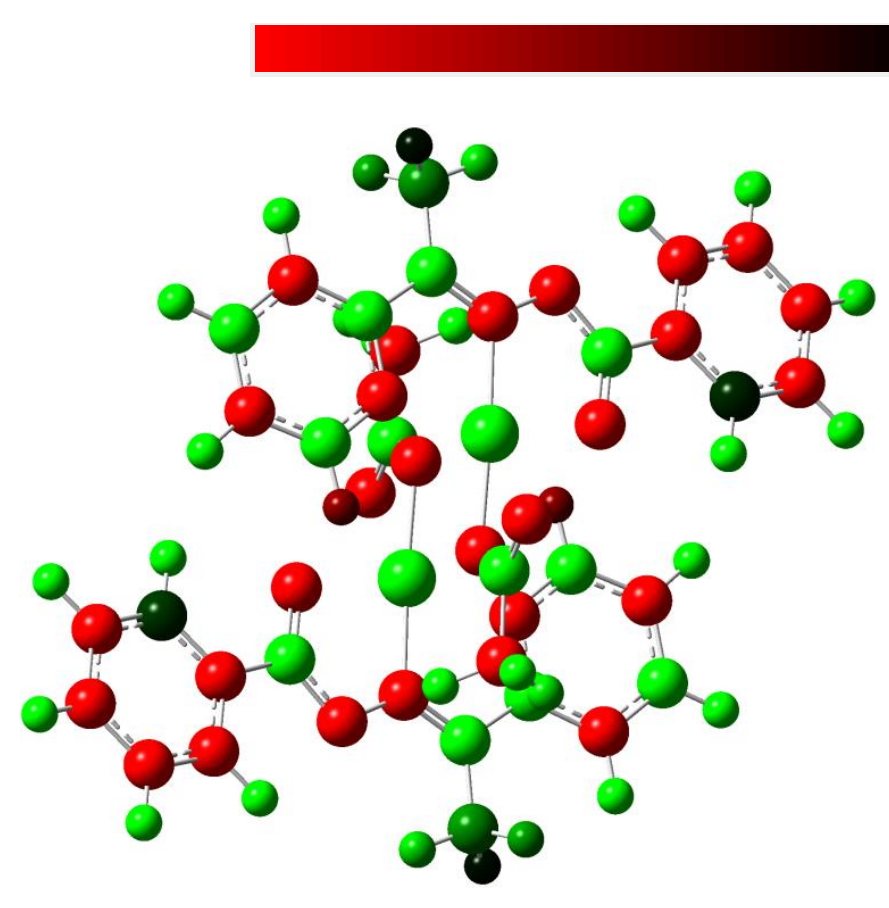

(a)

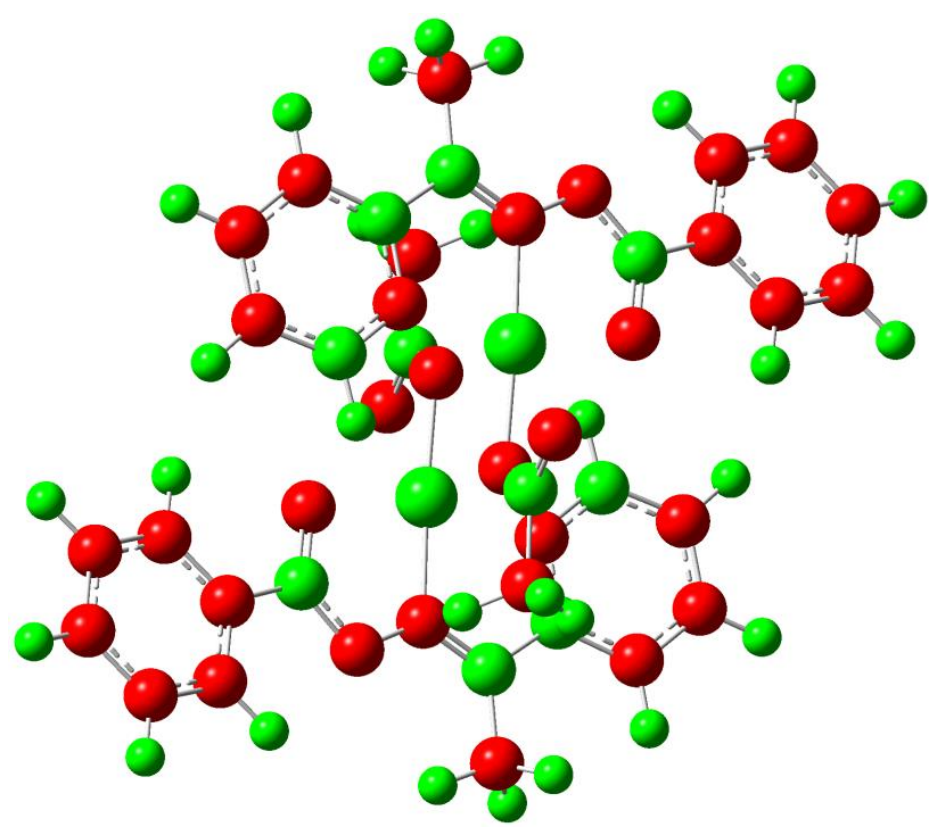

(b)

Figura 5.2.3. Representação do complexo $\left[(\mathrm{Cu})_{2} \mu\left(\mathrm{CH}_{3} \mathrm{COO}\right)_{2}(\mathrm{HL})_{2}\right]$, na qual as cores representam as cargas ChelpG (a) e cargas NBO (b) distribuidas no complexo, conforme escala de cores acima, na qual vermelho é o mais negativo e verde o mais positivo. A escala de cores vai de $-0,05$ a $+0,05$ para ambos os esquemas de cargas.

Assim, esse desvio na descrição angular da esfera de coordenação presente em todos os funcionais usados faz com que a geometria seja prevista de forma errônea. A solução que encontramos para contornar esse problema é o cálculo usando ondas planas, pois a presença de moléculas vizinhas favorece a descrição correta da geometria na grande maioria dos casos. 
A Tabela 5.2.2 mostra os valores das cargas obtidas usando as metodologias Mulliken, ChelpG e NBO, com o funcional M06 e conjuntos de bases LANL2DZ para o cobre e 6-31 $\mathrm{g}(\mathrm{d}, \mathrm{p})$ para os demais átomos.

A análise das cargas pelos três esquemas sugere uma intensa polarização envolvida na esfera de coordenação, que pode ser vista em detalhes na Figura 5.2.4 que mostra o mapa de potencial eletrostático do complexo $\left[(\mathrm{Cu})_{2} \mu\left(\mathrm{CH}_{3} \mathrm{COO}\right)_{2}(\mathrm{HL})_{2}\right]$.

O ligante hidrazona complexado com o cobre (II) possui sobre o nitrogênio central N2 carga parcial de -0,097 a.u. (ChelpG), enquanto o nitrogênio piridínico N4 possui a carga de $-0,526$ a.u., no ligante $\mathrm{HL}$ nos temos a mesma tendência, independente do esquema de carga usado, e uma diminuição do valor da carga dos nitrogênios quando complexados. Apesar dos valores serem distintos para os demais esquemas de cargas, a tendência qualitativa permanece a mesma. Aqui essa diferença também pode ser diretamente atribuída à vizinhança diferenciada devido à presença de outra unidade coordenativa e da ponte de acetato.

$\mathrm{Na}$ Figura 5.2.3, colocou-se os esquemas de cargas ChelpG e NBO sob uma mesma escala e com isso podemos perceber a diferença numérica entre os esquemas, especialmente em átomos mais distantes do centro de coordenação, como por exemplo no carbono do grupamento metila pertencente ao ligante hidrazona, que aparece positivo no esquema ChelpG e negativo no esquema NBO. Apesar de diferenças pontuais como a relatada, quando tratamos dos átomos pertencentes à esfera de coordenação a tendência é semelhante para os três esquemas de carga usados nesse trabalho.

A isosuperficie de potencial eletrostático (MEP), para o complexo $\left[\mathrm{Cu}(\mathrm{HL})\left(\mathrm{NO}_{3}\right)_{2}\right]$. A análise do MEP complexo sugere o comportamento doador do grupamento NNO (hidrazona) para o nitrogênio piridinico com esse comportamento estendendo-se ao oxigênio ligado ao cobre (II). O complexo é melhor descrito pela característica polarização dos oxigênios dos grupamentos acetato. O aumento de densidade de carga é devido principalmente a característica doadora do grupo NNO do ligante hidrazona. Essa tendência está de acordo com o resultado experimental, [19] sugerindo que o grupamento azometina tem sua densidade eletrônica reduzida com a formação do complexo, e a presença de duas unidades coordenativas torna 
esse comportamento ainda mais pronunciado que o ocorrido com o complexo de nitrato de cobre descrito na Seção anterior. O esquema de partição de cargas nos mostra que a densidade eletrônica do grupamento azometina é reduzida com a formação do complexo.
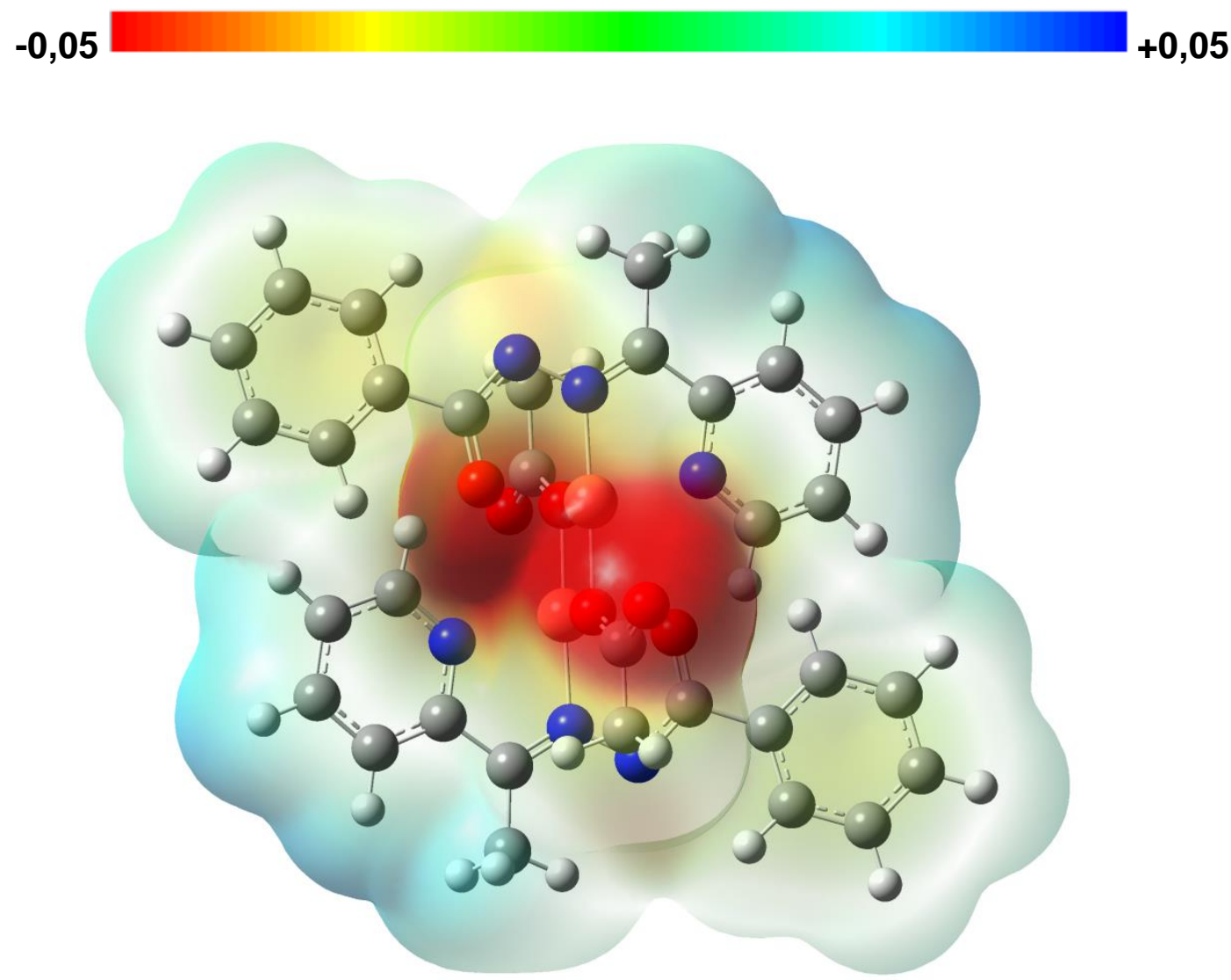

Figura 5.2.4 Mapa de potencial eletrostático do complexo $\mu$-Diacetato de bis (2 acetilpiridina - benzoilhidrazona cobre(II)).

O desvio médio quadrático é um bom parâmetro para atestar a diferença de estabilidade ocasionada pela presença de duas unidades coordenativas no complexo, pois diferente do que se verifica para o complexo $\left[\mathrm{Cu}(\mathrm{HL})\left(\mathrm{NO}_{3}\right)_{2}\right]$, aqui há diferenças acentuadas nesse valor (Tabela 8.3). Para os funcionais B3LYP e PBE1PBE os valores são 0,396 e 0,397, já para os funcionais CAM-B3LYP e B3PW91 esse valores sobem para 0,414 e 0,410, para o B97-D temos 0,548. Os 
maiores valores de RMSD, 0,600 e 0,626 foram calculados para os funcionais wB97xd e M06.

Para os funcionais w-B97-xd e B97-D o maior desvio quadrático médio, já era esperado, uma vez que também apresentaram um resultado semelhante para o complexo $\left[\mathrm{Cu}(\mathrm{HL})\left(\mathrm{NO}_{3}\right)_{2}\right.$ ]. Enquanto que para o menor RMSD foi obtido com o funcional B3LYP, com o valor semelhante para o funcional PBE1PBE, fato este surpreendente, já que nenhum desses funcionais possui parametrização especifica do termo de troca e correlação para complexos metálicos.

Entretanto, para os cálculos de espectroscopia vibracional e UV-VIS relatados a seguir, optamos por utilizar o funcional M06, a fim de viabilizar uma melhor comparação dos resultados com os demais complexos relatados neste trabalho.

\subsection{2- Espectroscopias Vibracional e Eletrônica}

O espectro vibracional simulado para o complexo $\left[(\mathrm{Cu})_{2} \mu\left(\mathrm{CH}_{3} \mathrm{COO}\right)_{2}(\mathrm{HL})_{2}\right]$, encontra-se na Figura 5.2.5. A linha vermelha é referente ao cálculo vibracional usando o funcional B3LYP, enquanto a linha preta é resultante das medidas experimentais. ${ }^{[17]} \mathrm{O}$ funcional M06 foi escolhido para esse cálculo principalmente para possibilitar que se estabeleçam relações entre os cálculos feitos para os outros complexos, assim a uniformidade do funcional se faz necessária. Na Tabela 5.2.3 encontram-se as principais bandas nos espectros de infravermelho relacionadas ao referido complexo. 


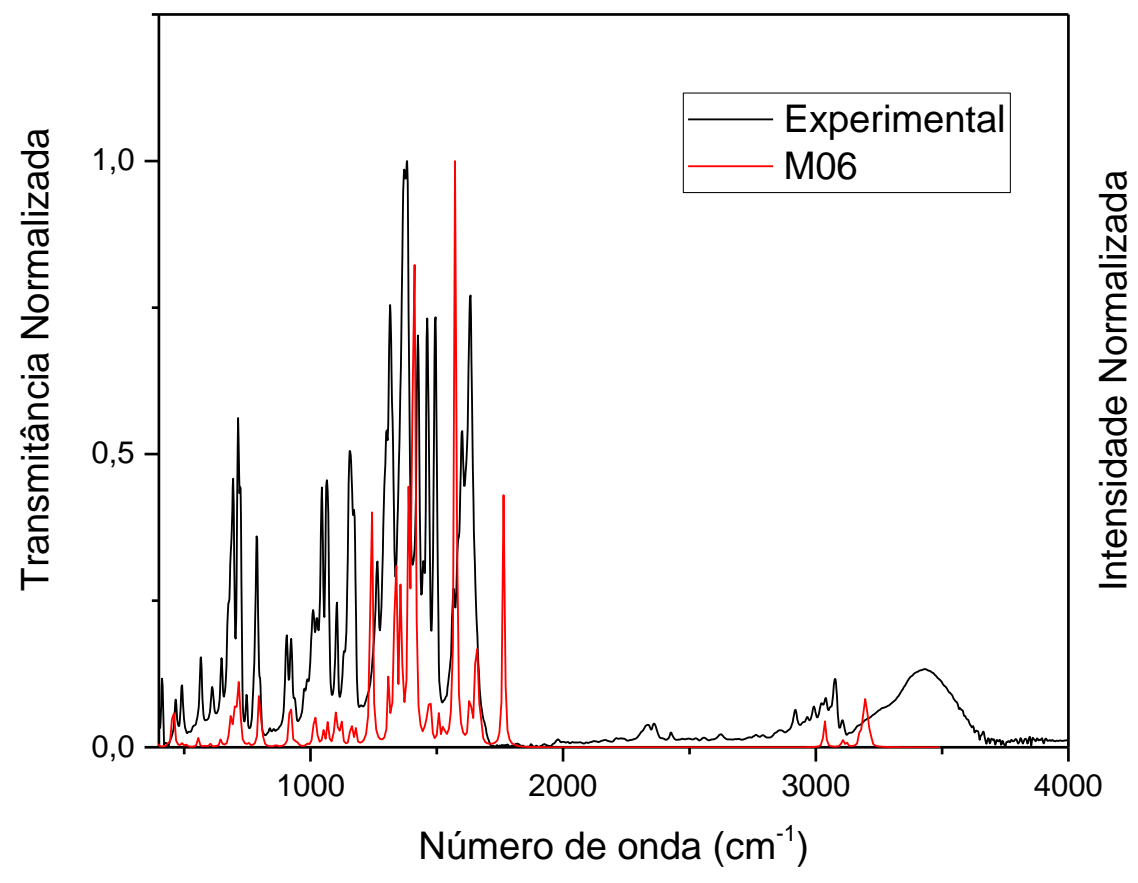

Figura 5.2.5. Espectro vibracional do complexo $\left[(\mathrm{Cu})_{2} \mu\left(\mathrm{CH}_{3} \mathrm{COO}\right)_{2}(\mathrm{HL})_{2}\right]$, advindo das frequências vibracionais calculadas com os funcionais B3LYP (vermelho) $e$ experimentalmente calculadas (preto).

O espectro vibracional possui uma banda de forte intensidade por volta de $1626 \mathrm{~cm}^{-1}$, típica do estiramento de ligação $\mathrm{C}=\mathrm{N}$ conjugada. Essa banda foi encontrada entre 1587 e $1618 \mathrm{~cm}^{-1}$, nos espectros das hidrazonas livres, ${ }^{[43]}$ se desloca para 1631,52 $\mathrm{cm}^{-1}$ (M06) no espectro do complexo de cobre(II) indicando a coordenação pelo nitrogênio central do ligante HL (N2).

O estiramento carbono-oxigênio em $1541 \mathrm{~cm}^{-1}$ indica a coordenação do átomo de oxigênio com o átomo do metal. No complexo $\left[(\mathrm{Cu})_{2} \mu\left(\mathrm{CH}_{3} \mathrm{COO}\right)_{2}(\mathrm{HL})_{2}\right]$, essa vibração foi encontrada em 1573,80 cm-1 (M06) sugerindo a coordenação pelo oxigênio carbonílico (Tabela 5.2.3). Assim, foi possível detectar e isolar as bandas que normalmente são mais afetadas pela coordenação aos metais, que são aquelas referentes a $v(\mathrm{C}=\mathrm{N})$ e $\mathrm{v}(\mathrm{C}=\mathrm{O}) .{ }^{[43]}$ 
Tabela 5.2.3. Bandas nos espectros de infravermelho $\left(\mathrm{cm}^{-1}\right)$ do complexo $\left[(\mathrm{Cu})_{2} \mu\left(\mathrm{CH}_{3} \mathrm{COO}\right)_{2}(\mathrm{HL})_{2}\right]$ para os funcionais especificados na tabela e os conjuntos de bases atômicas LANL2DZ e 6-31g(d,p)).

\begin{tabular}{|c|c|c|c|c|}
\hline & $v(\mathrm{C}=\mathrm{O})$ & $v(\mathrm{C}=\mathrm{N})$ & $\rho(\mathrm{py})$ & $v\left(\mathrm{COO}^{-}\right)$ \\
\hline Experimental* $^{*}$ & 1492 & 1598 & 694 & 1631 \\
\hline Experimental** $^{*} 1541$ & 1626 & 620 & 1750 \\
\hline B3LYP & 1545,55 & 1612,34 & 648,54 & 1709,45 \\
\hline PBE1PBE & 1585,37 & 1645,84 & 649,40 & 1755,18 \\
\hline CAM-B3LYP & 1579,13 & 1664,43 & 657,12 & 1771,63 \\
\hline B97-D & 1495,97 & 1544,88 & 629,82 & 1650,01 \\
\hline B3PW91 & 1568,13 & 1626,43 & 646,09 & 1726,78 \\
\hline M06 & 1573,80 & 1631,52 & 644,98 & 1764,79 \\
\hline w-B97XD & 1583,86 & 1661,74 & 660,09 & 1778,71 \\
\hline *117] & \multicolumn{4}{|l}{}
\end{tabular}

**Os valores experimentais relatados são de compostos análogos. [43] [27] [48] [115]

A deformação no plano no anel piridina que se encontra em $614-624 \mathrm{~cm}^{-}$ 1, nos espectros dos ligantes hidrazona, [116] e neste complexo essa banda é encontrada $648,54 \mathrm{~cm}^{-1}$ (B3LYP) e $644,98 \mathrm{~cm}^{-1}$ (M06), nos espectros teóricos do complexo, mostrando a coordenação do nitrogênio piridinico. ${ }^{[117]}$

Assim, os espectros teóricos de infravermelho demonstram a coordenação pelo sistema quelante $\mathrm{Npy}-\mathrm{N}-\mathrm{O}$. ${ }^{[118]}$ Esses dados estão melhor detalhados na Tabela 5.2.3, a seguir, a qual mostra com detalhes as principais bandas experimentalmente e calculadas para cada funcional utilizado nesse estudo.

É importante salientar que as vibrações encontradas no composto são totalmente simétricas, ou seja, as duas unidades de coordenação vibram da mesma forma e intensidade em ambos os núcleos, pelo fato de serem iguais. [119] [89] [115]

Complexos de cobre(II) pentacoordenados podem assumir geometrias piramidal de base quadrada ou bipirâmide trigonal e os espectros eletrônicos mostram tipicamente uma banda de absorção mais intensa em mais alta energia e uma menos intensa em menor energia para geometria piramidal de base quadrada, 
enquanto que uma banda de absorção menos intensa em mais alta energia e uma mais intensa em menor energia para geometria bipirâmide trigonal. [96]

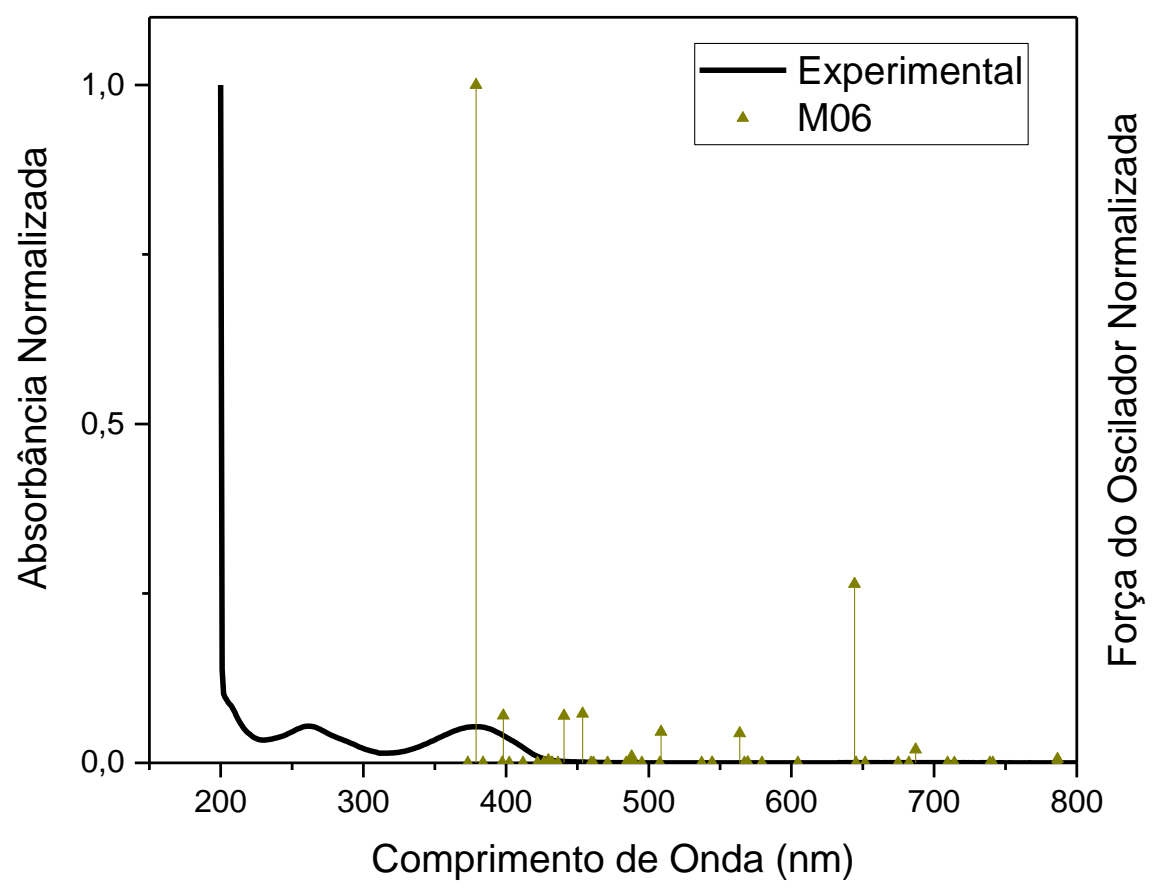

Figura 5.2.6. Espectro eletrônico experimental e teórico (m06/LANL2DZ+6-31g(d,p) no qual a linha contínua em preto é o espectro teórico e cada linha vertical amarelo escuro corresponde a uma excitação eletrônica para o complexo $\left[(\mathrm{Cu})_{2} \mu\left(\mathrm{CH} 3 \mathrm{COO}_{2}(\mathrm{HL})_{2}\right]\right.$.

Os espectros de absorção, experimental e calculado com o funcional M06, do complexo $\left[(\mathrm{Cu})_{2 \mu}(\mathrm{CH} 3 \mathrm{COO})_{2}(\mathrm{HL})_{2}\right]$, são mostrados na Figura 5.2.6. O espectro calculado encontra-se deslocado para menor energia quando comparado ao experimental, essa diferença pode ser atribuída a limitações inerentes à própria construção do funcional, porém quantitativamente os resultados apresentam-se muito uteis uma vez que descrevem bem as transições.

O grande pico presente em 199,95 nm, no espectro eletrônico é atribuído a transferências eletrônicas intraligante (ILCT). Essa transição teve seu análogo calculado em $379,00 \mathrm{~nm}$ com força de oscilador de 0,267 . Os orbitais envolvidos 
nessa transição são HOMO-2 $\rightarrow$ LUMO+2 (Figura 5.2.7), com probabilidade de $50,80 \%$. O orbital HOMO-2 tem característica ligante estando em sua maior porção sobre a ligação $\mathrm{C}=\mathrm{N}$, já o orbital de destino da transição $\mathrm{LUMO}+2$ possui a mesma natureza. Sendo assim, é confirmada a natureza da transição intraligante (ILCT).

(a)
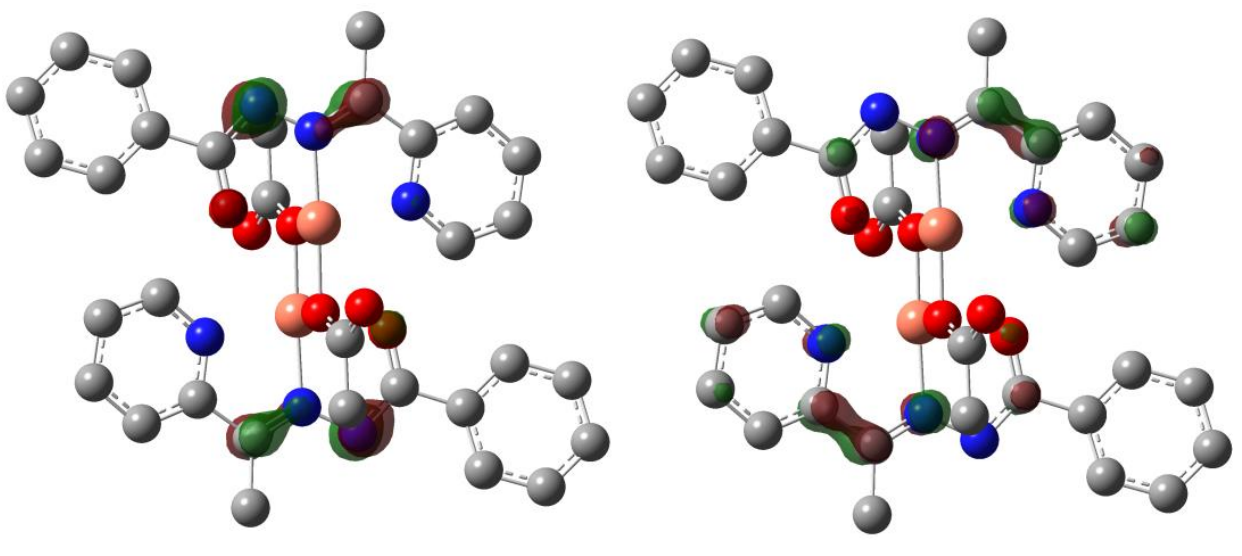

(b)

Figura 5.2.7. Orbitais moleculares HOMO-2 (a), LUMO+2 (b) do complexo $\left[(\mathrm{Cu})_{2} \mu\left(\mathrm{CH} 3 \mathrm{COO}_{2}(\mathrm{HL})_{2}\right]\right.$ envolvidos na transição eletrônica calculada em 379,00 $\mathrm{nm}$.

O espectro eletrônico do complexo $\left[(\mathrm{Cu})_{2} \mu(\mathrm{CH} 3 \mathrm{COO})_{2}(\mathrm{HL})_{2}\right]$, também é dominado por duas transições $d$ - $d$, sendo que a banda em menor energia é mais intensa e a em maior energia é menos intensa indicando coordenação piramidal de base quadrada quando em solução. ${ }^{[120]}$

O ombro medido experimentalmente em 259,97 nm atribuido a uma terceira transição de campo ligante foi calculado em 453,71 nm, com respectiva força de oscilador de 0,019. Para essa transição, a probabilidade de ocorrer do orbital HOMO-20 para o LUMO é de $37,86 \%$ e a probabilidade de ocorrer do orbital HOMO17 para o LUMO é 38,53\% (Figura 5.2.8). 


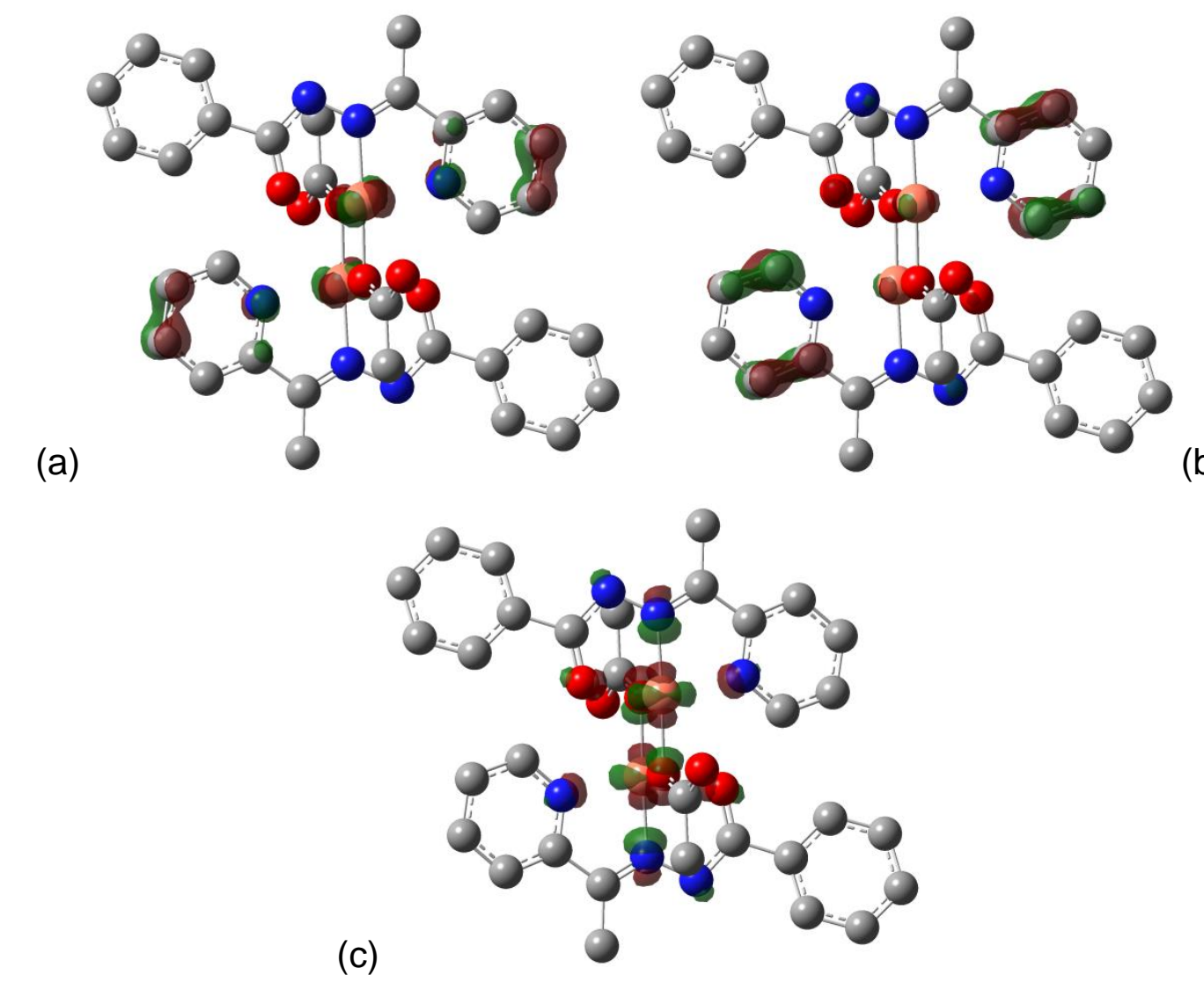

(b)

Figura 5.2.8. Orbitais moleculares HOMO-2O (a), HOMO-17 (b) e LUMO (c) do complexo $\left[(\mathrm{Cu})_{2} \mu\left(\mathrm{CH}_{3} \mathrm{COO}\right)_{2}(\mathrm{HL})_{2}\right]$ envolvidos na transição eletrônica calculada em 453,71 $\mathrm{nm}$.

Os orbitais moleculares HOMO-20 e HOMO-17 (Figura 5.2.8) possuem natureza ligante e estão localizados sobre os átomos de carbono da piridina e em pequena porção sobre o átomo de cobre, já o LUMO possui característica $d x^{2}-y^{2}$. Assim sendo, essa transição é classificada como LMCT, transferência de carga do ligante para o metal.

O estado excitado 26 foi calculado em $644,28 \mathrm{~nm}$ com força de oscilador 0,070 e envolvimento dos orbitais moleculares HOMO-6 $\rightarrow$ LUMO (Figura 2.3.9) com probabilidade de 50,37\%. O orbital HOMO-6 tem característica predominantemente ligante, com os lobos do orbital localizados sobre os átomos de carbono do benzoil e o orbital LUMO é localizado sobre o metal em sua maioria, 
com característica $d x^{2}-y^{2}$. De forma que essa transição é LMCT, assim como o ombro descrito anteriormente.

(a)
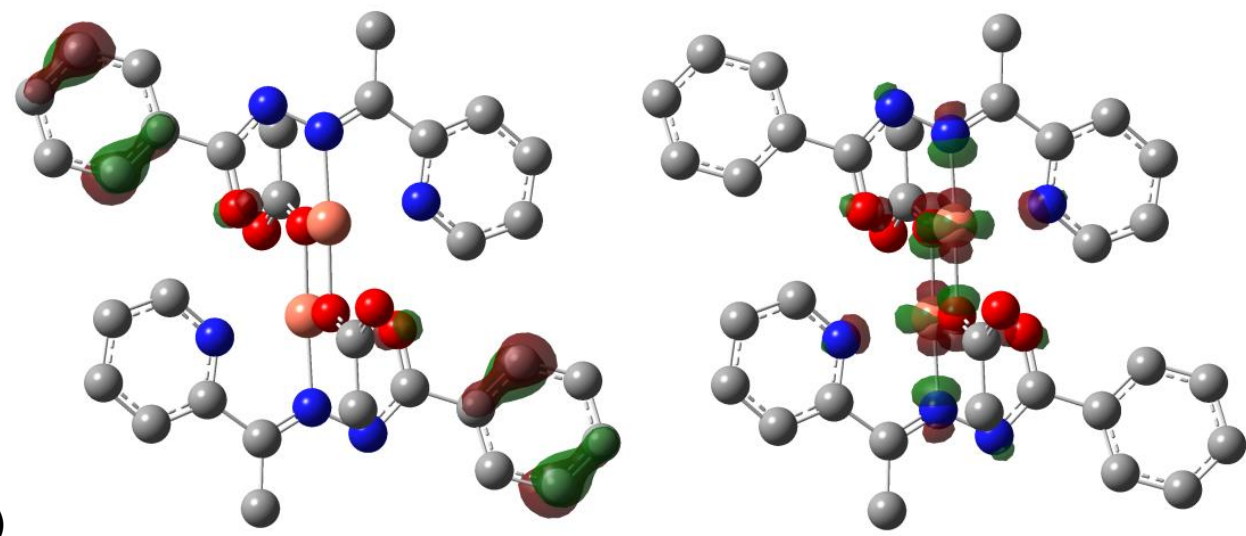

(b)

Figura 5.2.9. Orbitais moleculares HOMO-6 (a), e LUMO (b) do complexo $\left[(\mathrm{Cu})_{2} \mu\left(\mathrm{CH}_{3} \mathrm{COO}\right)_{2}(\mathrm{HL})_{2}\right]$ envolvidos na transição eletrônica calculada em $644,28 \mathrm{~nm}$.

O complexo $\left[(\mathrm{Cu})_{2} \mu\left(\mathrm{CH}_{3} \mathrm{COO}\right)_{2}(\mathrm{HL})_{2}\right]$, apresenta comportamento espectral característico de complexos de cobre(II) com geometria piramidal de base quadrada ${ }^{[121]}$ apresentando duas bandas com valores medidos experimentalmente, uma mais intensa na região de $200 \mathrm{~nm}$ e uma menos intensa em menor energia 380,99 nm, ambas atribuídas a transições de campo ligante, além de um ombro em 259,97 nm atribuído a uma terceira transição de campo ligante. As análises dos orbitais moleculares envolvidos nessas transições atestam tal comportamento.

\section{3 - Bis (2 - acetilpiridinabenzoilhidrazona)cobre(II)}

O complexo Bis (2 - acetilpiridinabenzoilhidrazona)cobre(II), [(Cu)(HL)2], diferente dos demais, apresenta em sua estrutura, presente na Figura 5.3.1, ligados ao centro de coordenação, apenas duas unidades do ligante hidrazona. Assim sendo, a estrutura é determinada unicamente pela interação das duas unidades do ligante com o cobre (II). 
Os dois ligantes hidrazona encontram-se em T um em relação ao outro, fazendo com que a geometria octaédrica distorcida da esfera de coordenação seja preservada, seguindo o padrão estrutural presente em complexos de cobre (II) e hidrazona como os caracterizados por Shit e colaboradores. ${ }^{[122]}$ Essa distorção na geometria octaédrica, se deve à estrutura rígida dos ligantes HL envolvidos na esfera de coordenação.

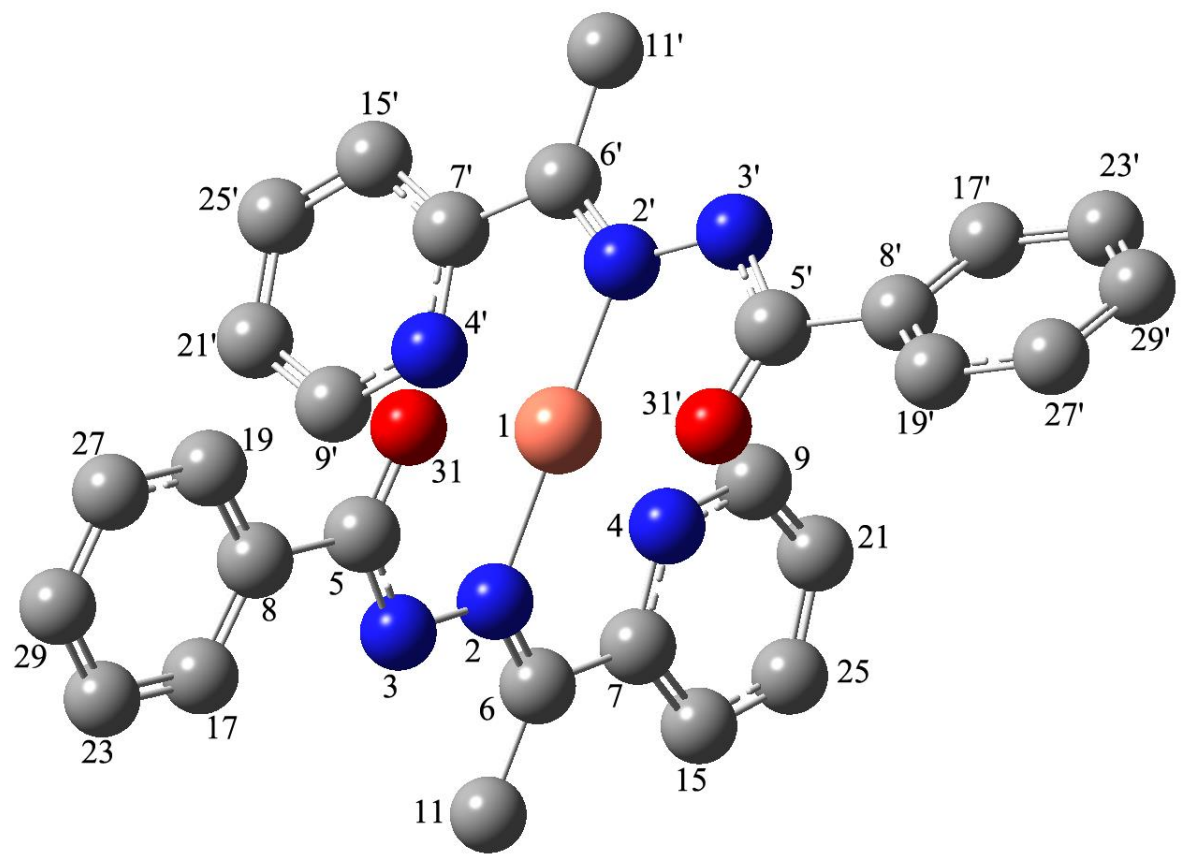

Figura 5.3.1. O complexo Bis (2 - acetilpiridinabenzoilhidrazona) cobre(II), [(Cu)(HL)2], sem hidrogênios e com numeração usada no texto e na Tabela 8.4

Todas as distâncias e ângulos envolvidos na esfera de coordenação, mostrada de maneira detalhada na Figura 5.3.1, estão incluídos na Tabela 8.4 (Apêndice 8.1), na qual é feita uma comparação entre os dados experimentais e teóricos calculados com diferentes funcionais. Esses resultados estão detalhados a seguir. 


\subsection{1- Estrutura Geométrica}

No complexo Bis (2 - acetilpiridinabenzoilhidrazona) cobre $(\mathrm{II})$, [(Cu)(HL)2], o cátion cobre(II), possui número de coordenação seis, encontra-se em um ambiente octaédrico distorcido e está coordenado a duas moléculas da hidrazona aniônica que atuam como ligantes tridentados formando um sistema Npy-N-O. As posições de coordenação estão ocupadas pelos dois ligantes $\mathrm{HL}$, cada qual coordenado de forma tridentada.

Tabela 5.3.1. Comparação entre os comprimentos (angstrom) e diedro (graus) de ligação selecionados para o ligante isolado $\mathrm{HL}$ e o complexo [Cu(HL)2], medidos experimentalmente e calculados com o funcional MO6.

\begin{tabular}{|l|c|c|c|c|}
\hline & \multicolumn{2}{|c|}{$\left[\mathrm{Cu}(\mathrm{HL})\left(\mathrm{NO}_{3}\right)_{2}\right]$} & \multicolumn{2}{c|}{$\left[(\mathrm{Cu})(\mathrm{HL})_{2}\right]$} \\
\hline & Experimental & M06 & Experimental & M06 \\
\hline N3N2C7N4 & 174,31 & 174,12 & 172,06 & 174,42 \\
\hline Cu1N2 & 1,947 & 2,248 & 1,973 & 1,986 \\
\hline Cu1N4 & 1,998 & 2,241 & 2,231 & 2,207 \\
\hline Cu1O31 & 1,999 & 2,233 & 2,239 & 2,159 \\
\hline
\end{tabular}

Foram feitos cálculos de RMSD entre os dois ligantes HL para a estrutura experimental e para todas as estruturas finais resultantes dos cálculos de otimização geométrica para cada funcional. Destes cálculos, o valor do desvio quadrático médio esteve em 0,99 , para todos os casos. Desta forma, os dois ligantes possuem os mesmos comprimentos e ângulos de ligação, e para a presente análise da estrutura do complexo, tomaremos apenas um dos ligantes HL.

$O$ fragmento do esqueleto hidrazona $\operatorname{Py}(\mathrm{C}=\mathrm{N}) \mathrm{N}-(\mathrm{C}=\mathrm{O})$ determina o plano de coordenação, esse plano é definido pelo ângulo N3N2C7N4 presente na Tabela 5.3.1. Na análise da Tabela podemos perceber que há uma pequena superestimativa desse ângulo no cálculo com M06 para o complexo com dois ligantes, e em razão disso, não podemos perceber a sensível mudança que ocorre 
nesse ângulo, entre os dois complexos comparados. Essa estimativa encontra-se acima da acurácia dos métodos DFT para ângulos de ligação que é de aproximadamente $0,6^{\circ},{ }^{[102]}$ em razão disso foi verificado o mesmo ângulo para os demais funcionais, e ainda assim esse é o resultado mais próximo do experimental.

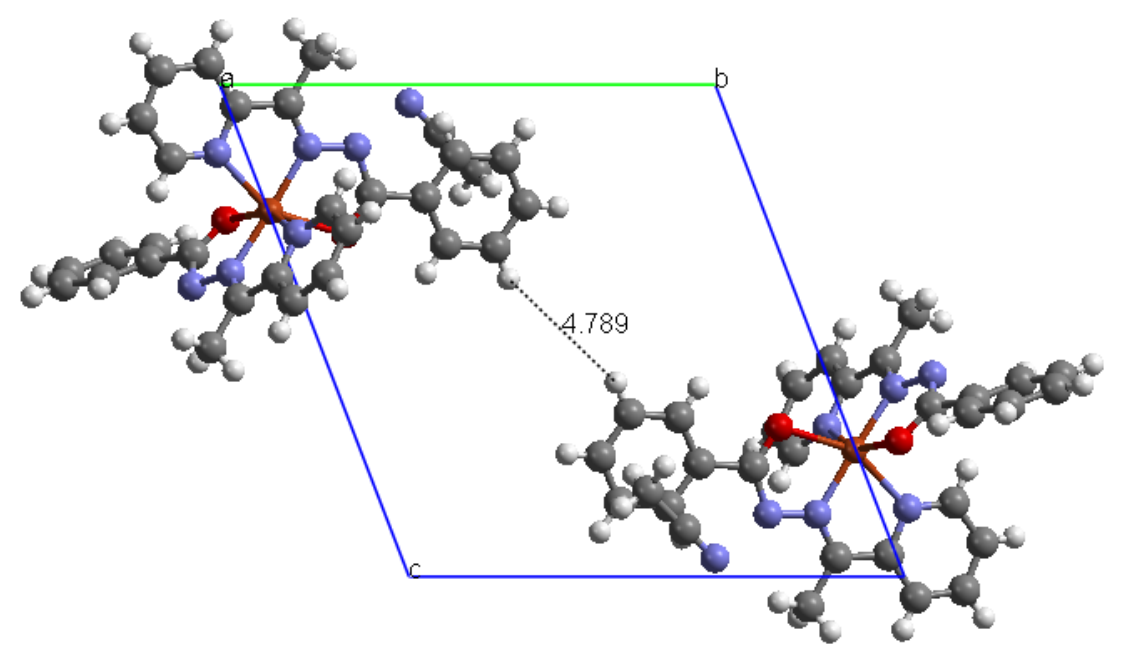

Figura 5.3.2. Cela unitária experimental do complexo Bis $(2$ acetilpiridinabenzoilhidrazona)cobre(II), na qual encontra-se destacada em preto a menor distância entre moléculas vizinhas (em angstron) (experimental).

O anel fenílico e o plano de coordenação formam ângulos diedros de $-28,44^{\circ}$ (experimental) e -0,39 (M06) determinados pelos átomos N3-C5-C8-C17 (Tabela

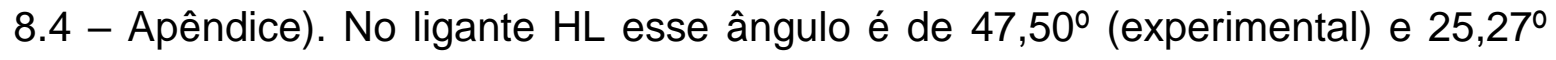
(M06), conforme consta na Tabela 8.1, assim podemos afirmar que existe nesse complexo uma planarização decorrente da coordenação entre o anel fenílico e o plano.

No complexo $\left[(\mathrm{Cu})(\mathrm{HL})_{2}\right]$ as distâncias de ligações Cu1-N2, Cu1-N4 e Cu1$\mathrm{O} 31$ são similares às do complexo $\left[\mathrm{Cu}(\mathrm{HL})\left(\mathrm{NO}_{3}\right)_{2}\right]$, tanto nas medidas experimentais quanto nos cálculos teóricos, ou seja, não há alteração significativa das distâncias entre os átomos coordenados do ligante $\mathrm{HL}$ devido à presença de dois ligantes.

Os ângulos das ligações envolvidas na esfera de coordenação diferem bastante de $90^{\circ}$ entre os átomos das moléculas de hidrazona e o Cu(II) (Tabela 8.4), 
por exemplo N2-Cu-N4' tem valor de 99,92- (experimental), isso porque o ligante $\mathrm{HL}$ apresenta estrutura rígida. Essas diferenças levaram a um arranjo octaédrico distorcido no centro metálico.
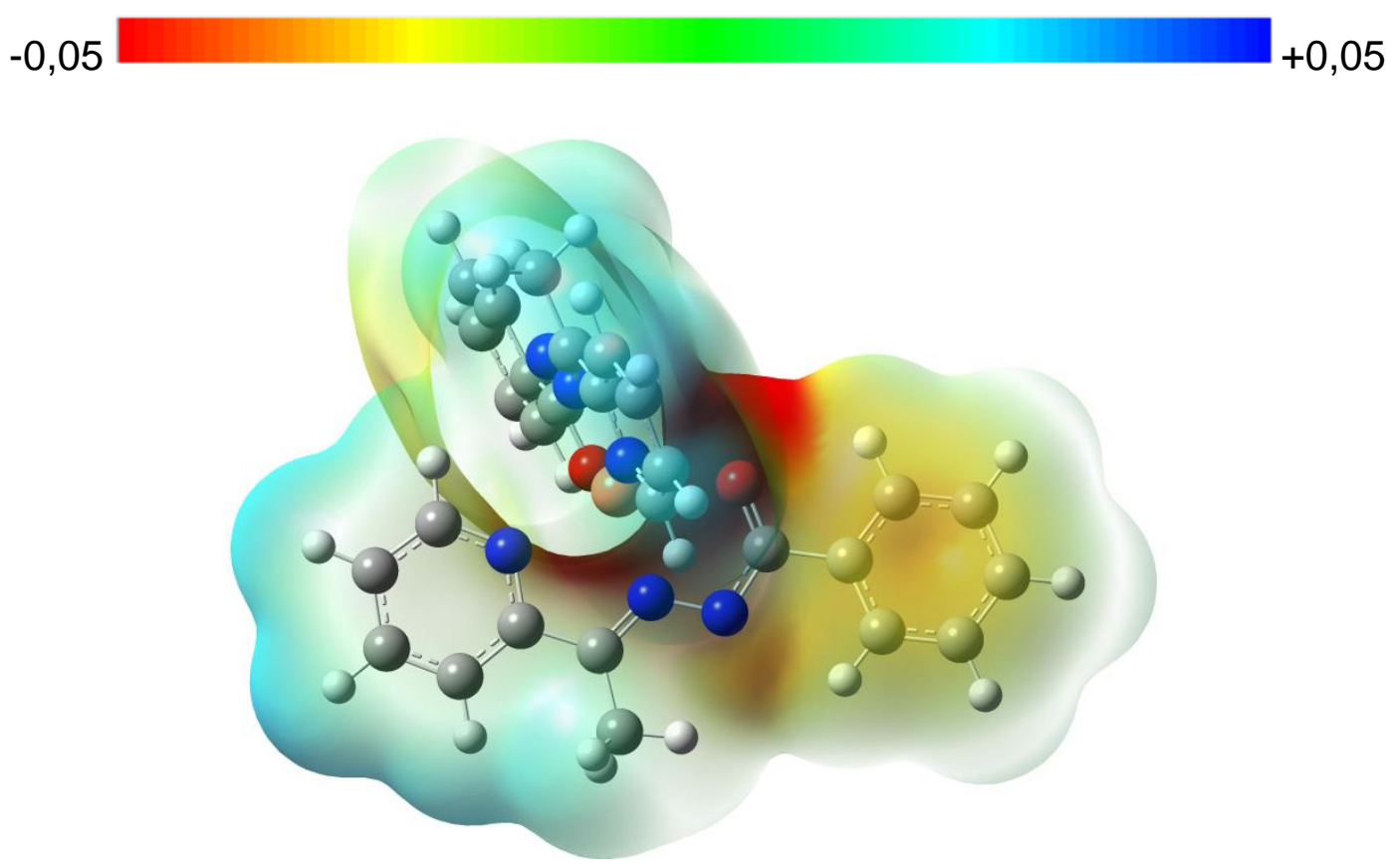

Figura 5.3.3 Mapa de potencial eletrostático do complexo Bis (2 acetilpiridinabenzoilhidrazona)cobre(II).

A distância de ligação Cu-O31 tem valores de 2,133 Å, medidos experimentalmente no complexo e 2,159 Å no cálculo M06, estando ambos os valores em concordância, e indicando um maior caráter de ligação simples, que será melhor investigado na próxima seção, com o auxílio dos resultados de espectroscopias ultravioleta e UV-VIS.

Pela análise da Tabela 8.4, podemos perceber que os dados teóricos conseguem reproduzir bem, em linhas gerais, o comportamento experimental. É importante neste caso perceber, que diferente dos demais complexos aqui relatados, esse foi o único caso em que os cálculos SCF produziram um resultado mais consistente que o cálculo usando ondas planas. 
Uma justificativa possível para tal comportamento pode ser encontrada na análise da Figura 5.3.2, que mostra a cela unitária experimental do complexo $\left[\mathrm{Cu}(\mathrm{HL})_{2}\right]$, que possui duas moléculas do complexo. A menor distância entre duas moléculas vizinhas é de 4,789 Å conforme mostrado na Figura 5.3.2. Desta forma, com a grande distância entre as moléculas e o fato de estarem paralelas na cela unitária, tornam a importância da vizinhança molecular diminuta, quando comparada aos outros complexos estudados. Em razão disso, os resultados de otimizações com uma só molécula foram satisfatórios para esse complexo.

Tabela 5.3.2 Comparação entre as cargas de Mulliken, ChelpG e NBO nos átomos envolvidos na coordenação do ligante $\mathrm{HL}$ com o complexo $\left[(\mathrm{Cu})(\mathrm{HL})_{2}\right]$ e do ligante $\mathrm{HL}$ isolado (MO6/LANL2DZ e 6-31g(d,p))

\begin{tabular}{|c|c|c|c|c|c|c|}
\hline Atom & $\begin{array}{c}\text { Mulliken charge } \\
\text { Complex }\end{array}$ & $\begin{array}{c}\text { Mulliken charge } \\
\text { Ligand }\end{array}$ & $\begin{array}{c}\text { ChelpG charge } \\
\text { Complex }\end{array}$ & $\begin{array}{c}\text { ChelpG charge } \\
\text { Ligand }\end{array}$ & $\begin{array}{c}\text { NBO charge } \\
\text { Complex }\end{array}$ & Ligand \\
\hline $\mathrm{Cu}$ & 0,644 & & 0,656 & & 0,847 & \\
\hline $\mathrm{O} 31$ & $-0,474$ & $-0,464$ & $-0,587$ & $-0,459$ & $-0,667$ & $-0,597$ \\
\hline $\mathrm{N} 2$ & $-0,245$ & $-0,417$ & 0,123 & $-0,374$ & $-0,258$ & $-0,226$ \\
\hline $\mathrm{N} 4$ & $-0,472$ & $-0,458$ & 0,519 & $-0,036$ & $-0,492$ & $-0,413$ \\
\hline
\end{tabular}

Os melhores resultados foram obtidos usando o funcional híbrido B3PW91, com desvio médio quadrático de 0,392 , valor este perfeitamente aceitável como um bom resultado levando-se em consideração que o mesmo advém de um cálculo de molécula isolada.

Os demais funcionais também apresentaram resultados satisfatórios, o destaque no caso do complexo $\left[\mathrm{Cu}(\mathrm{HL})_{2}\right]$ fica por conta do desempenho do funcional w-B97xd, que foi o segundo melhor, com RMSD com o valor de 0,323, diferente dos demais complexos, os quais o referido funcional figurou entre os piores resultados. 


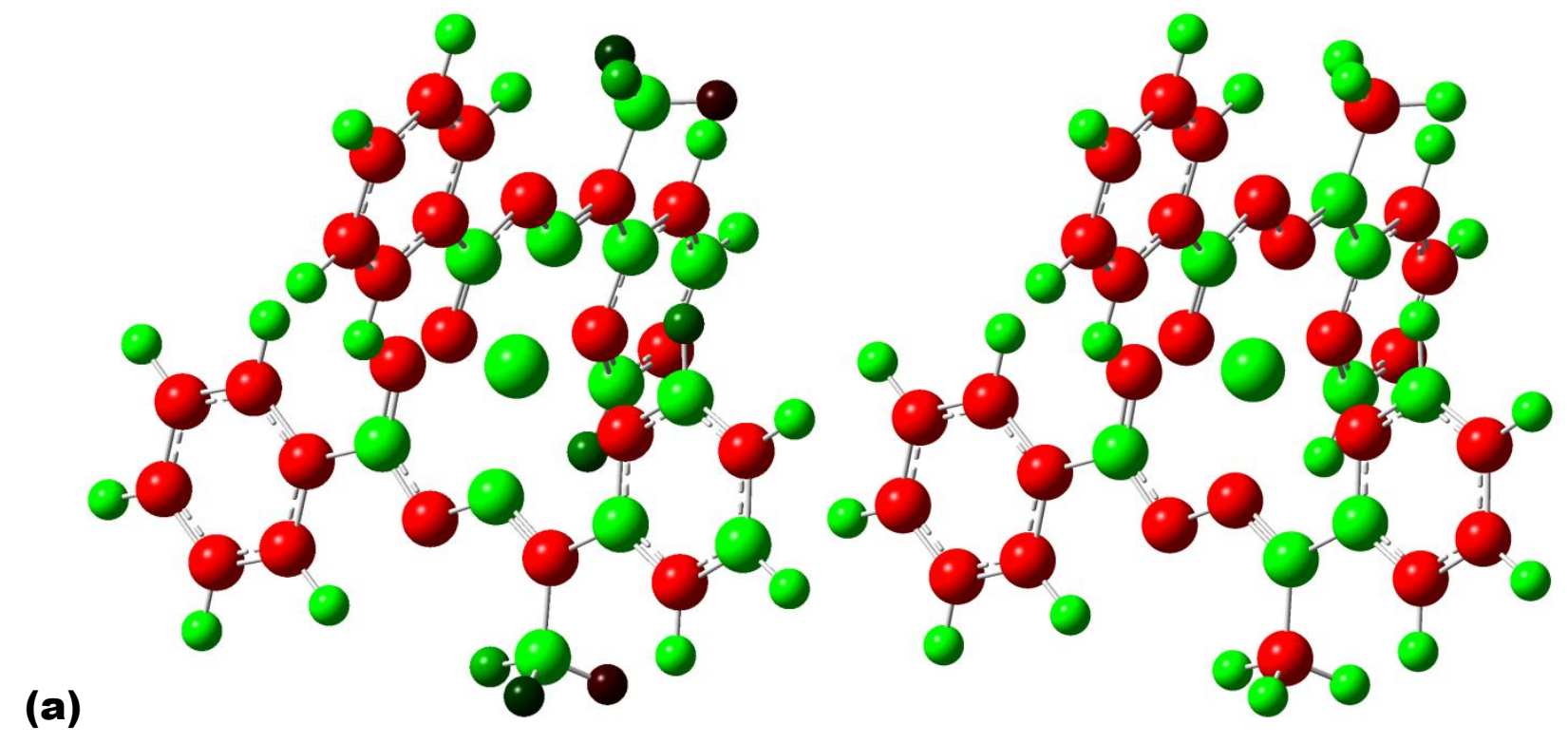

(b)

Figura 5.3.4. Representação do complexo $\left[(\mathrm{Cu})(\mathrm{HL})_{2}\right]$, na qual as cores representam as cargas ChelpG (a) e cargas NBO (b) distribuidas no complexo, conforme escala de cores acima, na qual vermelho é o mais negativo e verde o mais positivo. A escala de cores vai de $-0,05$ a $+0,05$ para ambos os esquemas de cargas.

Considerando que este funcional é o único usado que possui componente de dispersão incorporado, ${ }^{[123]}$ este fator pode ter atuado de forma decisiva para descrever bem a interação em $\mathrm{T}$ dos ligantes $\mathrm{HL}$, podemos dizer que esse fato contribuiu de forma decisiva para esse bom resultado.

O mapa de potencial eletrostático do complexo $\operatorname{Bis}(2$ - acetilpiridinabenzoil hidrazona)cobre(II), (Figura 5.3.3), mostra como área de carga negativa da molécula os dois átomo de oxigênio de cada ligante $\mathrm{HL}$, e como áreas mais positivas os anéis piridina dos dois ligantes $(\mathrm{HL})$. Esse fato é confirmado pela Figura 5.3.4, na qual as cargas ChelpG e NBO denotam o mesmo comportamento. As cargas de Mulliken (Tabela 5.3.2) apesar de divergirem nos valores numéricos, demonstram o mesmo comportamento.

\subsection{2- Espectroscopias Vibracional e Eletrônica}


O espectro de infravermelho do complexo Bis (2 - acetilpiridinabenzoil hidrazona)cobre(II), [Cu(HL)2], possui várias bandas proeminentes entre $3280 \mathrm{e}$ $1550 \mathrm{~cm}^{-1}$ devido aos modos vibracionais de estiramentos de $\mathrm{v}(\mathrm{N}-\mathrm{H})+\mathrm{v}(\mathrm{O}-\mathrm{H})$ e $\mathrm{v}(\mathrm{C}=\mathrm{N})$ (azometínico e piridinico).

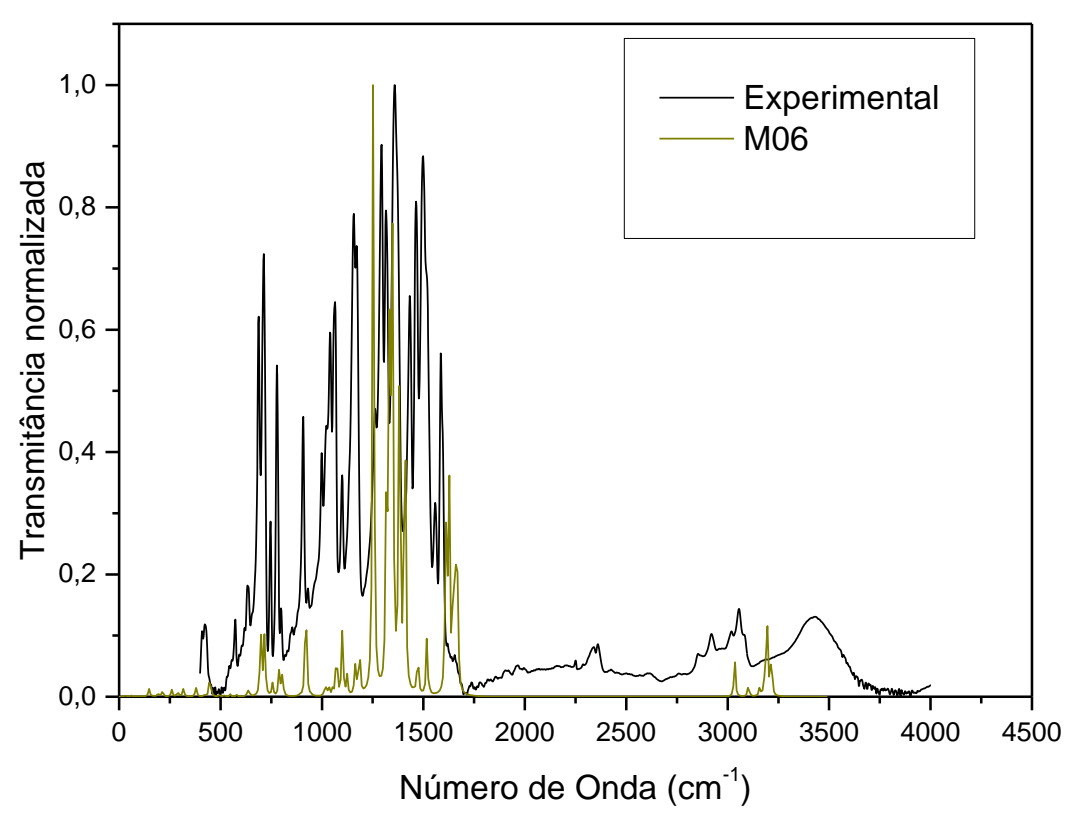

Figura 5.3.5. Comparação entre o espectro de infravermelho experimental (linha preta) e o seu análogo calculado (linhas amarelo escuro), do complexo [Cu(HL)2], usando o funcional MO6, associado aos conjuntos de bases LANL2DZ para o cobre e 6-31g(d,p) para os demais átomos.

Essas bandas foram detectadas nos cálculos teóricos por todos os funcionais usados, em concordância com os dados experimentais do complexo [Cu(HL)2], e de complexos análogos já publicados. [21]

No gráfico da Figura 5.3.5 temos a comparação entre os dados experimentais e os dados provenientes do cálculo de frequências vibracionais feito com o funcional M06. Esse funcional foi o escolhido para uma melhor visualização no gráfico e para efeito de comparação com os demais complexos relatados nesse trabalho. 
O estiramento $\mathrm{C}=\mathrm{N}$ da piridina foi detectado em $1557 \mathrm{~cm}^{-1}$ (experimental), e foi calculado em 1609,97 $\mathrm{cm}^{-1} \mathrm{com}$ o funcional M06. $O$ estiramento $\mathrm{C}=\mathrm{N}$ do grupo azometínico foi deslocado para $1586 \mathrm{~cm}^{-1}$ (experimental) e $1625,71 \mathrm{~cm}^{-1}$ (M06), enquanto no ligante $\mathrm{HL}$ é de $1616 \mathrm{~cm}^{-1}$, esse deslocamento pode ser entendido como sinal da participação do nitrogênio na esfera de coordenação.

Tabela 5.3.3. Bandas nos espectros de infravermelho $\left(\mathrm{cm}^{-1}\right)$ do complexo $\left[(\mathrm{Cu})(\mathrm{HL})_{2}\right]$ medidas experimentalmente e para os funcionais especificados na tabela $e$ os conjuntos de bases atômicas LANL2DZ e 6-31g(d,p)).

\begin{tabular}{|c|c|c|c|}
\hline & $v(\mathrm{C}=\mathrm{O})$ & $v(\mathrm{C}=\mathrm{N})$ & $\rho(\mathrm{py})$ \\
\hline Experimental & 1368 & 1586 & 687 \\
\hline B3LYP & 1569,52 & 1602,40 & 643,36 \\
\hline PBE1PBE & 1611,30 & 1637,17 & 642,72 \\
\hline CAM-B3LYP & 1603,41 & 1656,27 & 649,54 \\
\hline B97-D & 1524,45 & 1539,74 & 630,85 \\
\hline B3PW91 & 1590,95 & 1617,14 & 640,27 \\
\hline M06 & 1609,97 & 1625,71 & 637,45 \\
\hline w-B97xd & 1619,45 & 1656,52 & 653,26 \\
\hline
\end{tabular}

As bandas de amida, presentes no ligante $\mathrm{HL}$ isolado (Figura 8.1Apêndice), característica do grupamento CONH- são observadas entre 1675 e 1275 $\mathrm{cm}^{-1}$ (experimental) e entre 1544 e $1231 \mathrm{~cm}^{-1}$ (M06), indicam que o ligante é encontrado na forma ceto no estado sólido. Para o complexo [Cu(HL)2], essas bandas características de amida, particularmente aquelas associadas ao estiramento da ligação N-H desaparecem, indicando a ausência do grupo $\mathrm{C}=\mathrm{O}$ e a perda do próton $\mathrm{N}-\mathrm{H}$ através da enolização do ligante $\mathrm{HL}$ coordenado, indicando que o ligante de coordenação está na forma enólica. Essa atribuição está de acordo com o comportamento detectado em compostos análogos. [124]

O estiramento da ligação $\mathrm{C}=\mathrm{O}$ da carbonila, encontrado em $1656 \mathrm{~cm}^{-1}$ no ligante $\mathrm{HL}$ isolado (Tabela 5.5.3), no complexo $\left[\mathrm{Cu}(\mathrm{HL})_{2}\right]$ deslocou-se para $1368 \mathrm{~cm}^{-}$ ${ }^{1}$ (experimental) e $1609,97 \mathrm{~cm}^{-1}$ (M06). Essa região no espectro de infravermelho é 
relatada como sendo de estiramento da ligação C-O, desta forma podemos afirmar que existe um favorecimento do tautomero enol, do ligante $\mathrm{HL}$ coordenado ao centro metálico.

A deformação no plano da piridina foi para $687 \mathrm{~cm}^{-1}$ (experimental) e 637,45 $\mathrm{cm}^{-1}$ (M06) (Tabela 5.5.3) é encontrada em $712 \mathrm{~cm}^{-1}$ no ligante $\mathrm{HL}$ isolado. Esse deslocamento denota a coordenação do nitrogênio piridínico ao metal.

Depois da enolização do ligante $\mathrm{HL}$, o espectro de infravermelho do complexo $\left[\mathrm{Cu}(\mathrm{HL})_{2}\right]$ apresenta algumas bandas que não são detectadas no ligante isolado. Uma banda fina em $1600 \mathrm{~cm}^{-1}$ (experimental) e em 1612,31 $\mathrm{cm}^{-1}$ (M06), pode ser atribuída ao grupamento $\mathrm{C}=\mathrm{N}-\mathrm{N}=\mathrm{C}$ indicando a transformação da carbonila para a forma enólica por tautomerismo ceto-enólico e subsequente coordenação do oxigênio enólico com o metal, após a desprotonação do ligante HL.

Novamente, o aparecimento de uma nova banda em $1492 \mathrm{~cm}^{-1}$ (experimental) e em 1609,97 $\mathrm{cm}^{-1}$ (M06), é característica do estiramento v(NCO-), apoia a coordenação do oxigênio enólico. Uma banda fraca, v(N-N) aparece em 991 $\mathrm{cm}^{-1}$ (experimental) e em 1029,12 $\mathrm{cm}^{-1}$ (M06), enquanto no espectro de infravermelho do ligante $(\mathrm{HL})$ essa banda está deslocada para frequência mais alta de $1030 \mathrm{~cm}^{-1}$, o que demonstra a coordenação do átomo de nitrogênio azometínico. [125]

O espectro eletrônico de absorção é uma ferramenta muito útil para a avaliação dos resultados fornecidos pelos outros métodos de investigação estrutural. As medidas de espectros eletrônicos são frequentemente utilizadas para atribuir a estereoquímica de íons metálicos nos complexos baseados nas posições e número de picos de transição $\mathrm{d}$-d. 


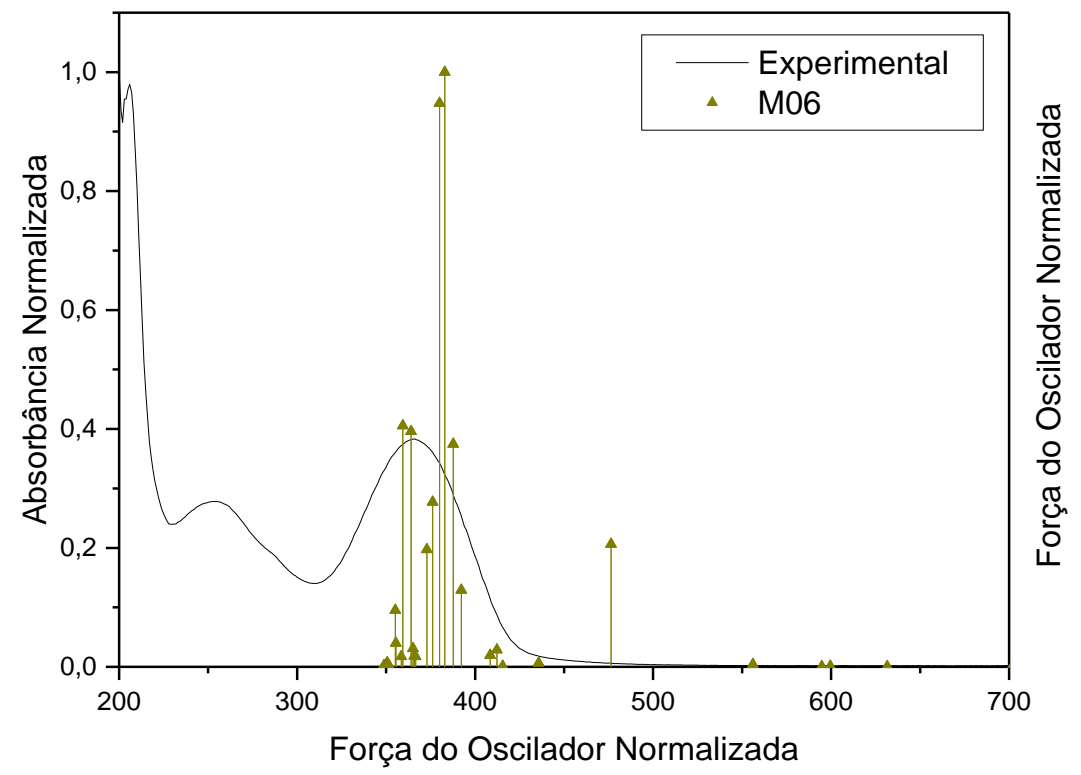

Figura 5.3.6. Espectro eletrônico experimental e teórico m06/LANL2DZ+6-31g(d,p) no qual a linha continua em preto é o espectro teórico e cada linha vertical amarelo escuro corresponde a uma excitação eletrônica calculada para o complexo $\left[(\mathrm{Cu})(\mathrm{HL})_{2}\right]$.

O espectro eletrônico do complexo de $\mathrm{Cu}(\mathrm{II}),\left[\mathrm{Cu}(\mathrm{HL})_{2}\right]$ mostrado na Figura 5.3.6, mostra três excitações principais. Em comum, as três transições eletrônicas possuem a mesma natureza, determinada pela análise dos orbitais envolvidos (Figuras 5.3.7 a 5.3.9), que possibilita atribuir às transições o caráter $t_{2 g} \rightarrow e_{g}$, indicando o ambiente octaédrico distorcido.

Essas transições são resultado da transferência que ocorre entre um grande intervalo de orbitais t2g para orbitais eg. Esse grande intervalo é causado pela distorção na geometria octaédrica, porém um octaedro regular de complexos de $\mathrm{Cu}$ (II) é bastante incomum, há geralmente um achatamento do octaedro, presumivelmente como consequência do efeito Jahn-Teller aumentar a degenerescência do estado fundamental t2g. ${ }^{[108]}[33]$ 
(a)

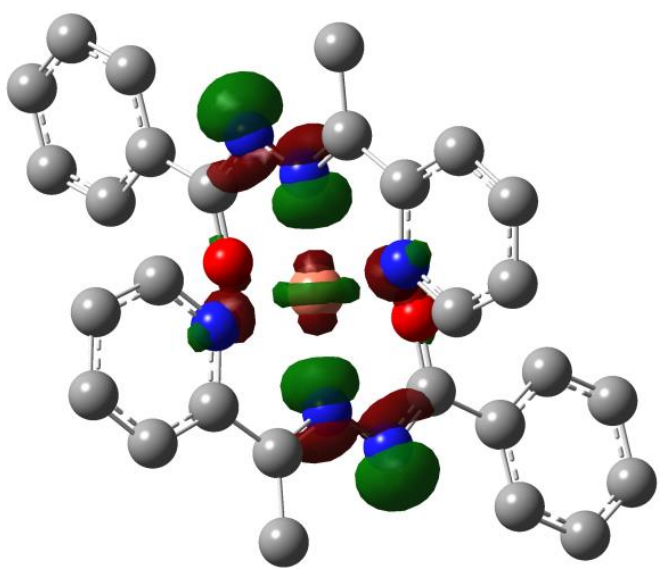

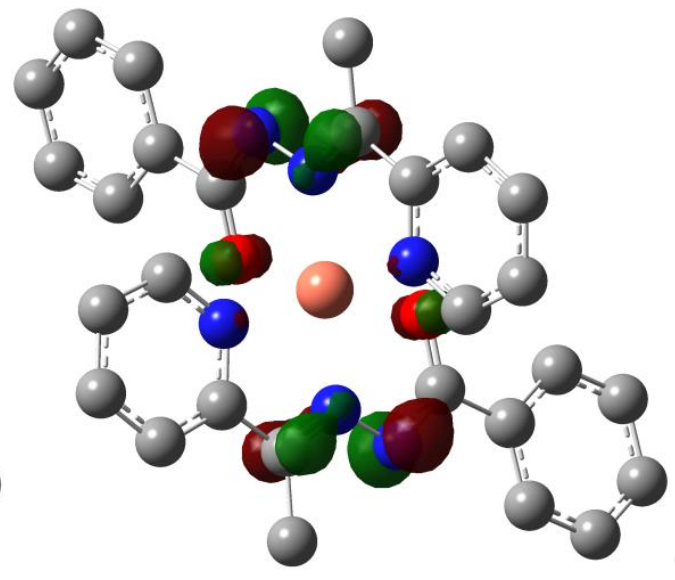

(b)

(c)

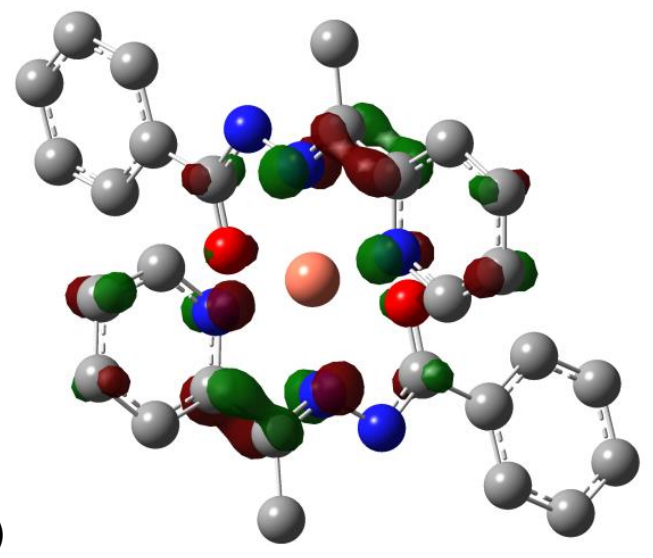

Figura 5.3.7. Orbitais moleculares HOMO-2 (a), HOMO-1 (b) e LUMO do complexo [(Cu)(HL)2] envolvidos na transição eletrônica calculada em 382,93 $\mathrm{nm}$.

O espectro eletrônico (Figura 5.3.6) apresenta uma grande banda centrada em $365,00 \mathrm{~nm}$ e um ombro em 253,99 nm, além de uma banda fina responsável pelo comprimento de onda com máxima absorbância em 199,95 nm, medidos experimentalmente.

A banda fina com máxima absorbância foi medida experimentalmente em 199,95 nm e possui seu análogo calculado com o funcional M06 em 382,93nm, com força de oscilador de 0,1682, correspondendo ao estado excitado de número dezesseis. Essa transição ocorre com probabilidade de 46,04\% de transferência de carga do orbital HOMO-1 para o LUMO, e com probabilidade de $50,15 \%$ do orbital HOMO-2 para o LUMO (Figura 5.3.7). O orbital molecular HOMO-2 tem característica ligante, e está distribuído entre os átomo de nitrogênio do ligante 
hidrazona e $\mathrm{dx}^{2}-\mathrm{y}^{2}$ sobre o cobre (II), já o orbital HOMO-1 está distribuído unicamente sobre os átomos de nitrogênio. Ambos efetuam transferência de carga para o orbital LUMO, que possui característica ligante sobre as duas unidades de HL.

Assim, a transferência de cargas com menor probabilidade é do tipo MLCT, na qual a densidade eletrônica sobre o metal, presente no orbital HOMO-2 é transferida para os ligantes $\mathrm{HL}$, no orbital LUMO, enquanto na transferência de maior probabilidade, a transferência é intraligante, do tipo ILCT.

(a)
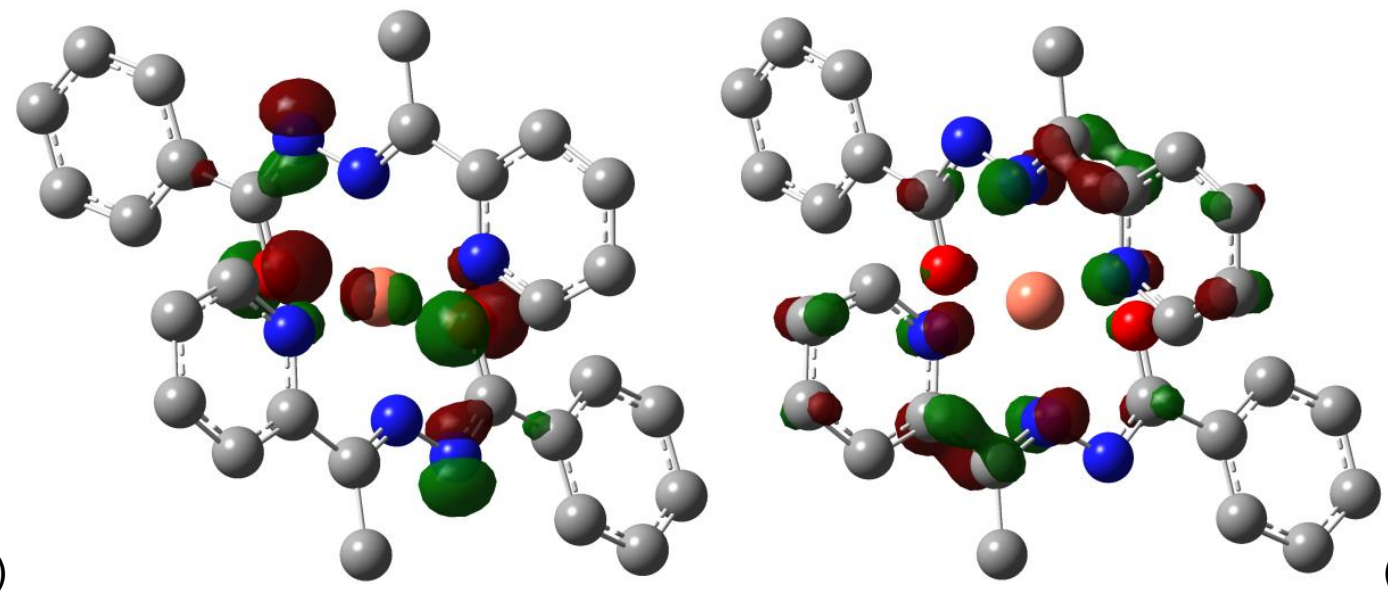

(b)

Figura 5.3.8. Orbitais moleculares HOMO-3 (a), LUMO (b) do complexo [(Cu)(HL) envolvidos na transição eletrônica calculada em 387,76 $\mathrm{nm}$.

O ombro em 253,99 $\mathrm{nm}$ medido experimentalmente teve seu análogo encontrado nos cálculos teóricos no estado excitado de número quinze com comprimento de onda de $387,76 \mathrm{~nm}$ e força do oscilador de 0,06 . Os orbitais moleculares envolvidos na transição com maior probabilidade de ocorrência estão presentes na Figura 5.3.8.

A transição que ocorre com probabilidade de $80,16 \%$ é HOMO-3 $\rightarrow$ LUMO. Essa transição também é do tipo MLCT, pois o orbital HOMO-3 além de estar distribuído entre o N3 e O31 do ligante hidrazona, uma parte está presente no cobre (II), enquanto o orbital LUMO, conforme já mencionado está sobre o ligante HL. 


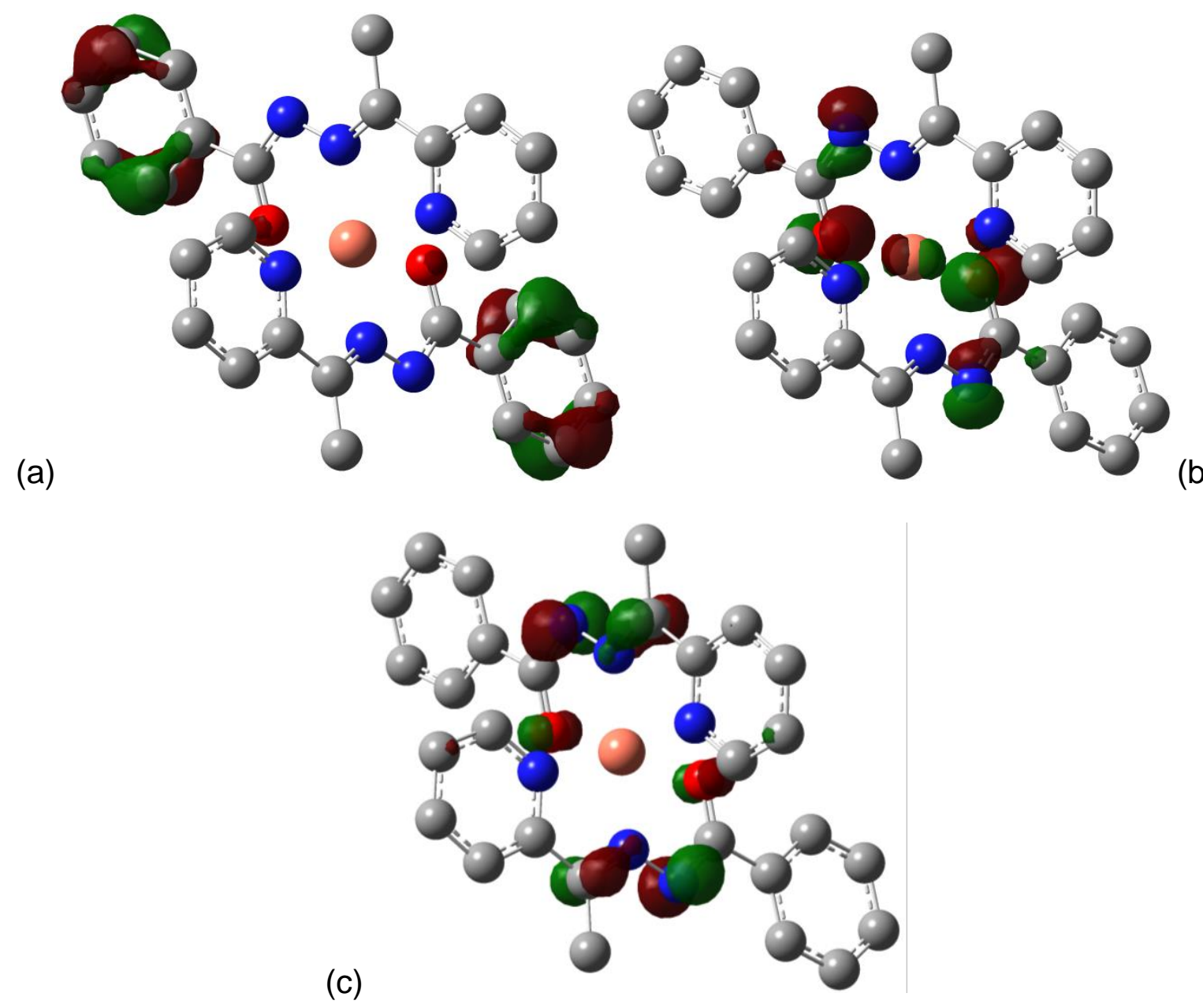

Figura 5.3.9. Orbitais moleculares HOMO-5 (a), HOMO-3 (b) e HOMO (c) do complexO [(Cu)(HL) $)_{2}$ envolvidos na transição eletrônica calculada em 476,39 $\mathrm{nm}$.

A banda larga no espectro de UV-VIS experimental teve seu análogo calculado em $476,39 \mathrm{~nm}$, no estado excitado nove e força de oscilador 0,03 . Duas transições contribuem em alta probabilidade para esse comprimento de onda, são elas, HOMO-5 $\rightarrow$ HOMO, com probabilidade de 70,06\% e HOMO-3 $\rightarrow$ HOMO, com probabilidade de $52,46 \%$. Os orbitais envolvidos nessa transição estão presentes na Figura 5.3.9.

Essa transição ocorre em maior probabilidade como uma transferência de carga intraligante, ILCT, do orbital HOMO-5 (Figura 5.3.9(a)), que está localizado 
de forma ligante sobre os átomos de carbono do benzoil do ligante $H L$, para o orbital HOMO (Figura 5.3.9(c)), localizado sobre os átomos de nitrogênio da hidrazona N2 e N3 e o oxigênio 31. Em menor probabilidade temos uma transição do tipo MLCT, onde a densidade eletrônica sobre o cobre (II) no orbital HOMO-3 (Figura 5.3.9(b)), se transfere para o HOMO (Figura 5.3.9(c)), que está localizado sobre os átomos de nitrogênio e o átomo de oxigênio do ligante $\mathrm{HL}$.

Desta forma, podemos dizer que o perfil espectral do complexo corrobora com as premissas determinadas pela geometria molecular e contribuiu significativamente para a confirmação da mesma. Os cálculos teóricos usando o funcional M06 foram bastante úteis para a atribuição dos sinais tanto no infravermelho quanto no ultravioleta figurando como uma ferramenta muito importante quando aliada ao dado experimental.

\section{4 - $\mu$-sulfatobis[(2-acetilpiridinabenzoilhidrazona) cobre(II)]}

O ânion simples $\mathrm{SO}_{4}{ }^{2-}$ possui um papel muito importante na formação de estruturas de coordenação. Moléculas de solventes variados, como DMF são ligantes terminais e competem com grupamentos sulfato na ligação com cátions metálicos. Entretanto, ainda não existe um pleno entendimento acerca do papel do solvente e do íon na organização das estruturas dos complexos organometálicos. [126]

A fim de explorar esse tópico atrativo, reportaremos aqui o estudo de dois complexos com o ligante orgânico com grupamento hidrazona $\mathrm{HL}$, e o sal sulfato de cobre (II). A estrutura do complexo $\left[(\mathrm{Cu})_{2} \mu\left(\mathrm{SO}_{4}\right)(\mathrm{HL})_{2}\right]$ é centrossimétrica, o cobre (II) está tetracoordenado, ligado a uma molécula de hidrazona, que atua como ligante tridentado, coordenando-se ao centro metálico através dos nitrogênios piridínico e imínico e pelo oxigênio cabonílico, o ânion sulfato faz a ponte entre os dois átomos de cobre presentes na estrutura, a coordenação dos dois átomos de 
cobre (II) é a mesma e um ligante HL encontra-se de forma especular com relação ao outro (Figura 5.5.1).

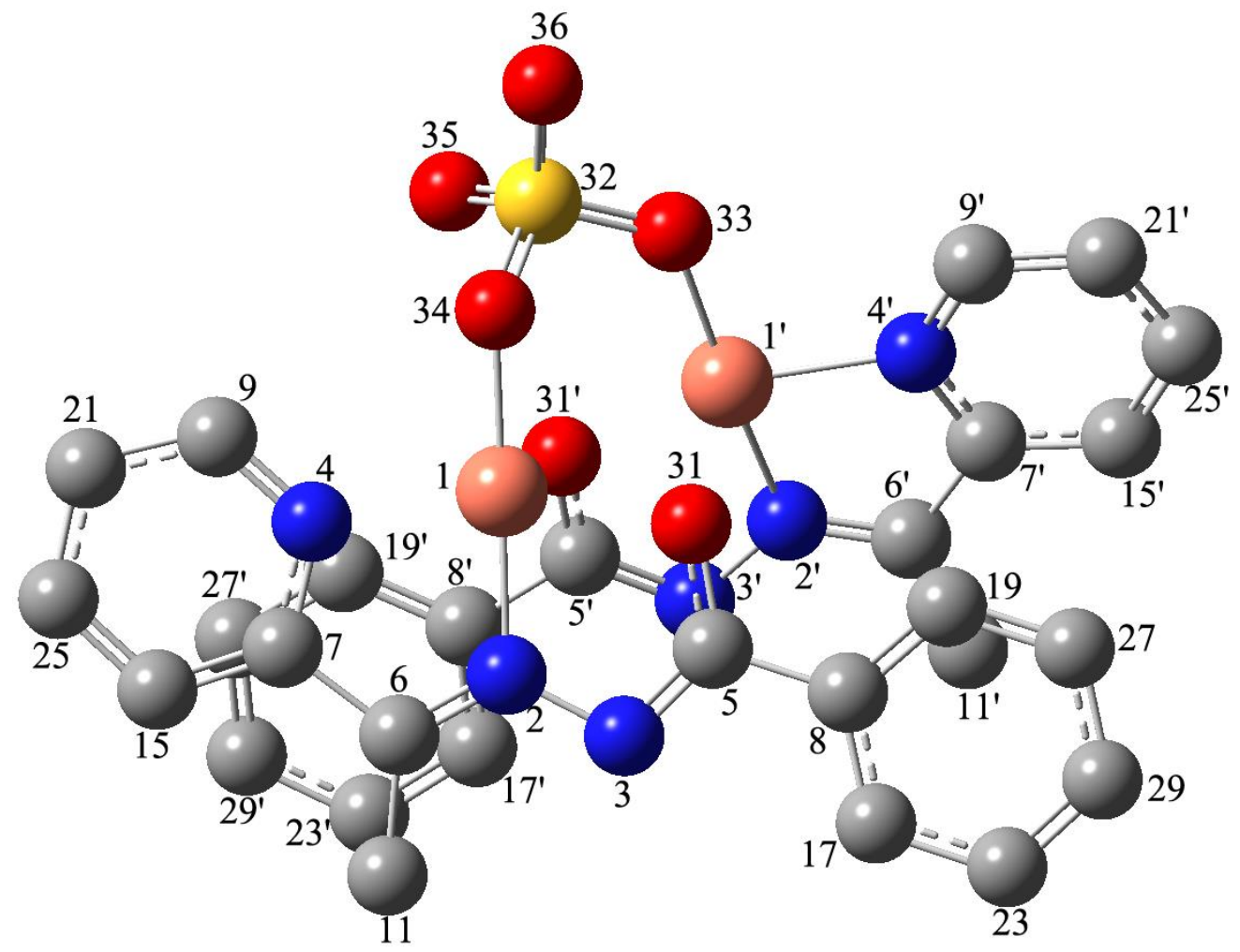

Figura 5.4.1. Estrutura geométrica do complexo $\left[\mathrm{Cu}_{2}(\mathrm{HL})_{2}\left(\mathrm{SO}_{4}\right)\right]$, com numeração usada na Tabela 5.5.1. Hidrogênios omitidos para melhor visualização

O composto $\left[\mathrm{Cu}_{2}(\mathrm{HL})_{2}\left(\mathrm{SO}_{4}\right)\right]$, analisado a seguir (Figura 5.5.1), com base em nossos resultados teóricos, comparados aos resultados experimentais obtidos por meio de síntese e caracterização feitos por Gatto e colaboradores, é um complexo binuclear de cobre tetracoordenado com uma geometria plano quadrática.

\subsection{1- Estrutura Geométrica}


$\mathrm{Na}$ estrutura de $\left[\mathrm{Cu}_{2}(\mathrm{HL})_{2}\left(\mathrm{SO}_{4}\right)\right]$ o íon de cobre(II) está tetracoordenado, ligado a uma molécula do ligante hidrazona, na forma aniônica, que atua como ligante tridentado, coordenando-se ao centro metálico através dos nitrogênios piridínico e imínico e pelo oxigênio cabonílico, a coordenação restante é ocupada por um oxigênio do grupamento sulfato.

Desta forma, temos a geometria quadrática planar, onde o $\mathrm{Cu}(\mathrm{II})$ ocupa $\mathrm{O}$ centro do quadrado e cada um dos átomos dos ligantes ocupa um vértice do quadrado. A estrutura bidimensional formada pelas duas unidades $\mathrm{Cu}(\mathrm{HL})$ quando conectadas, por meio do ânion $\mathrm{SO}_{4}{ }^{2-}$ formam a estrutura tridimensional do complexo.

Neste complexo os átomos N2, O31, O34 e N4 ocupam o plano basal de um quadrado planar e formam entre eles os ângulos $\mathrm{N} 2 \mathrm{CuO} 31=80,17^{\circ}, \mathrm{O}^{\circ} \mathrm{CuO}^{\mathrm{Cu}}$ $=101,30^{\circ}, \mathrm{N} 2 \mathrm{CuN} 4=81,62^{\circ}$ e N4CuO34 = 96,86을 (experimentalmente), apesar dos desvios, esses valores foram reproduzidos quantitativamente pelos dados teóricos, sendo que o resultado mais próximo foi encontrado usando o funcional M06, conforme mostrado pelo desvio médio quadrático, RMSD, calculado para os diversos funcionais os quais foram utilizados para os calculos SCF, presentes na Tabela 5.4.1.

A geometria quadrática plana é considerada como um caso especial de distorção tetragonal, onde os ligantes axiais são distanciados ao infinito, ou seja, eles são removidos do sistema de coordenação do complexo. Com este distanciamento dos ligantes ao longo do eixo $z$, os orbitais que contém a componente z serão bastante estabilizados. Quando temos este caso, os ligantes que provocam um maior desdobramento do campo, ou seja, os ligantes de campo forte serão favorecidos, ou seja, os complexos que possuem ligantes de campo forte e número de coordenação igual a 4 , terão preferência em se organizar com a geometria quadrático plano. [40] [126] [127] 


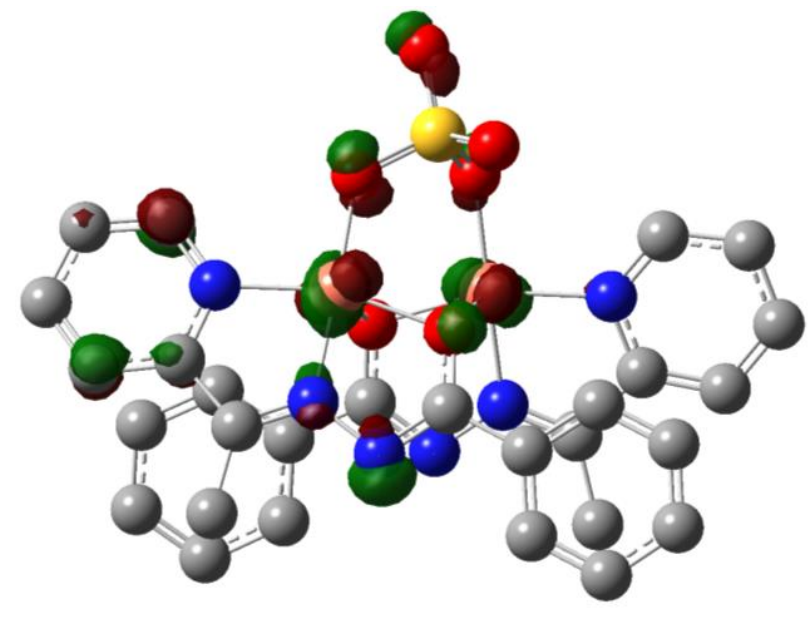

(a)

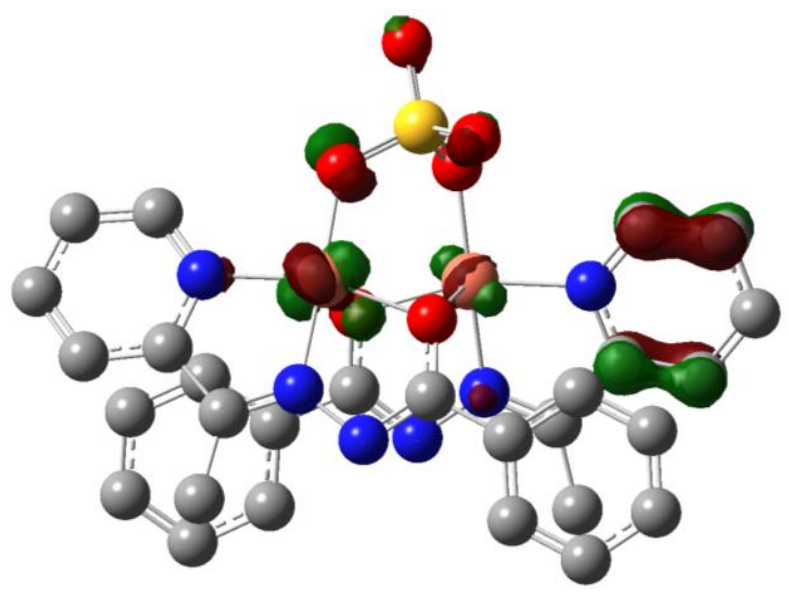

(b)

Figura 5.4.2. Orbitais moleculares de $\mathrm{Kohn}$-Sham do complexo [ $\mathrm{Cu}_{2}\left(\mathrm{HL}_{2}\left(\mathrm{SO}_{4}\right)\right]$, em (a) orbital molecular 150 (HOMO-18) e em (b) orbital molecular 153 (HOMO-15).

Dos complexos que foram apresentados os resultados até agora, este foi o primeiro no qual o funcional wB97-XD apresenta o menor valor de RMSD. Esse fato se explica levando em conta que o funcional em questão apresenta correção de dispersão com uma função de Grimme mais moderna, a função de amortecimento original D3, quando comparado ao B97-D, que também apresenta esse tipo de função mas tem a desvantagem de ser um funcional puro. ${ }^{[68]}$

Uma análise dos orbitais moleculares reais e virtuais que compõem a distribuição eletrônica da molécula demonstra a estabilidade da componente $z$ relatada. O complexo possui 168 orbitais moleculares ocupados, destes foram analisados os 20 orbitais moleculares mais externos, além de 20 orbitais moleculares virtuais, do LUMO (169) até o orbital 180. Destes, do 150 até o 157, temos a presença da componente $z$ nos orbitais moleculares, exemplo disso, são os orbitais moleculares $150\left(\mathrm{dz}^{2}\right)$ e $157(\mathrm{dxz})$, presentes na Figura 5.4.2.

O ângulo entre N4-C7-C6 tem valores em torno de 115ㅇe experimentalmente e em todas as metodologias computacionais utilizadas (Tabela 5.5.1). Comparando esses valores com o do ligante, verifica-se que não há uma grande variação devida a uma mudança na configuração da hidrazona, da forma $Z$ como ligante livre para 
E nos complexos, como seria de se esperar face os dados presentes na literatura. [43]

Já para o ângulo N2-C6-N4 que varia do valor experimental de 141,03ํㅜ para o ligante até 81,89 no complexo, devido à formação do anel quelato N2-Cu-N4, temos essa grande variação, devida também à mudança conformacional do ligante em razão da complexação. De forma similar o ângulo N2-N3-C5 muda de 117,02ㅜㅡ, no ligante para 106,94ㄴ, no complexo, em razão da formação do anel quelato N2Cu-O1. O mesmo ocorre em todos os cálculos executados, sendo o desvio mais significativo ocorre no cálculo VASP e o valor encontrado mais próximo ao experimental é de $107,63^{\circ}$ usando o funcional CAM-B3LYP.

As posições de coordenação livres tornariam este composto de interesse para ser estudado em reações de polimerização ou outro tipo de reações nas quais é possível a adição de algum outro ligante de interesse, conforme existem casos relatados na literatura [41], porém, para este composto, uma das posições de coordenação livres de ambos os átomos de cobre(II) encontra-se impedida estéricamente (Figura 5.4.1), devido à presença de duas unidades coordenativas.

Esse impedimento estérico também pode ser mais bem entendido pela análise da Figura 5.4.3, na qual operações de simetria replicam a molécula, cada operação tem uma cor, a fim de obter o $z=4$, ou seja, quatro unidades assimétricas para cada cela unitária. Tal comportamento foi reproduzido nos cálculos usando ondas planas com o funcional PW91, no qual a distância entre duas moléculas do complexo vizinhas foram calculadas como sendo a distância entre os átomos de cobre de posição semelhante. 


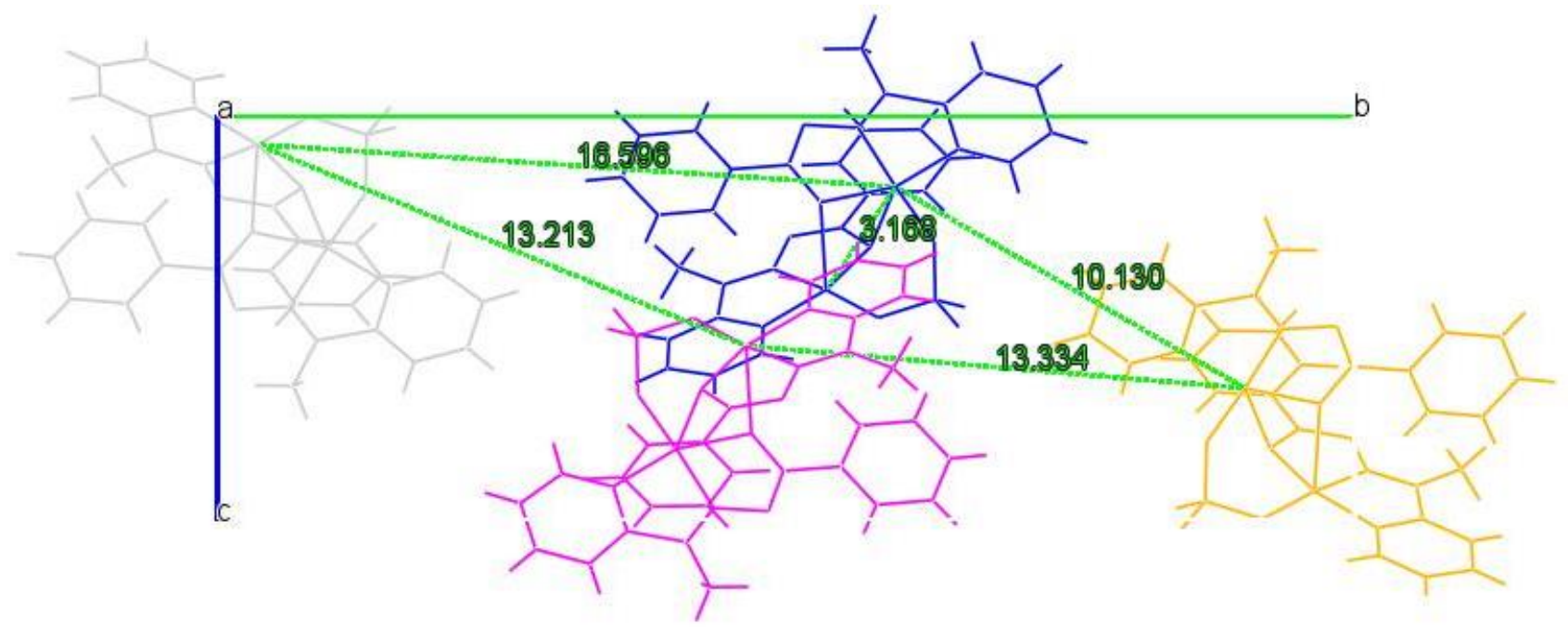

Figura 5.4.3. Representação esquemática da cela unitária do complexo $\left[\mathrm{Cu}_{2}\left(\mathrm{HL}_{2}\left(\mathrm{SO}_{4}\right)\right]\right.$, na qual cada cor representa uma operação de simetria na cela unitária.

Assim, tomando-se as medidas experimentais temos um losango formado pelos átomos de cobre com valores $16,596 \AA$, 13,334 $\AA$, 13,213 $\AA$ e 10,130 $\AA$, Figura 5.4.3, as medidas calculadas formam um retângulo com os lados medindo 11,829 $\AA$ e $10,449 \AA$. O perímetro das duas figuras apresenta diferença considerável, isso demonstra que existem interações intramoleculares, provavelmente de natureza repulsiva, dada a maior distância encontrada experimentalmente, presentes que não foram computadas pelo cálculo e ainda assim, a reprodução da cela unitária ocorreu de forma satisfatória. 


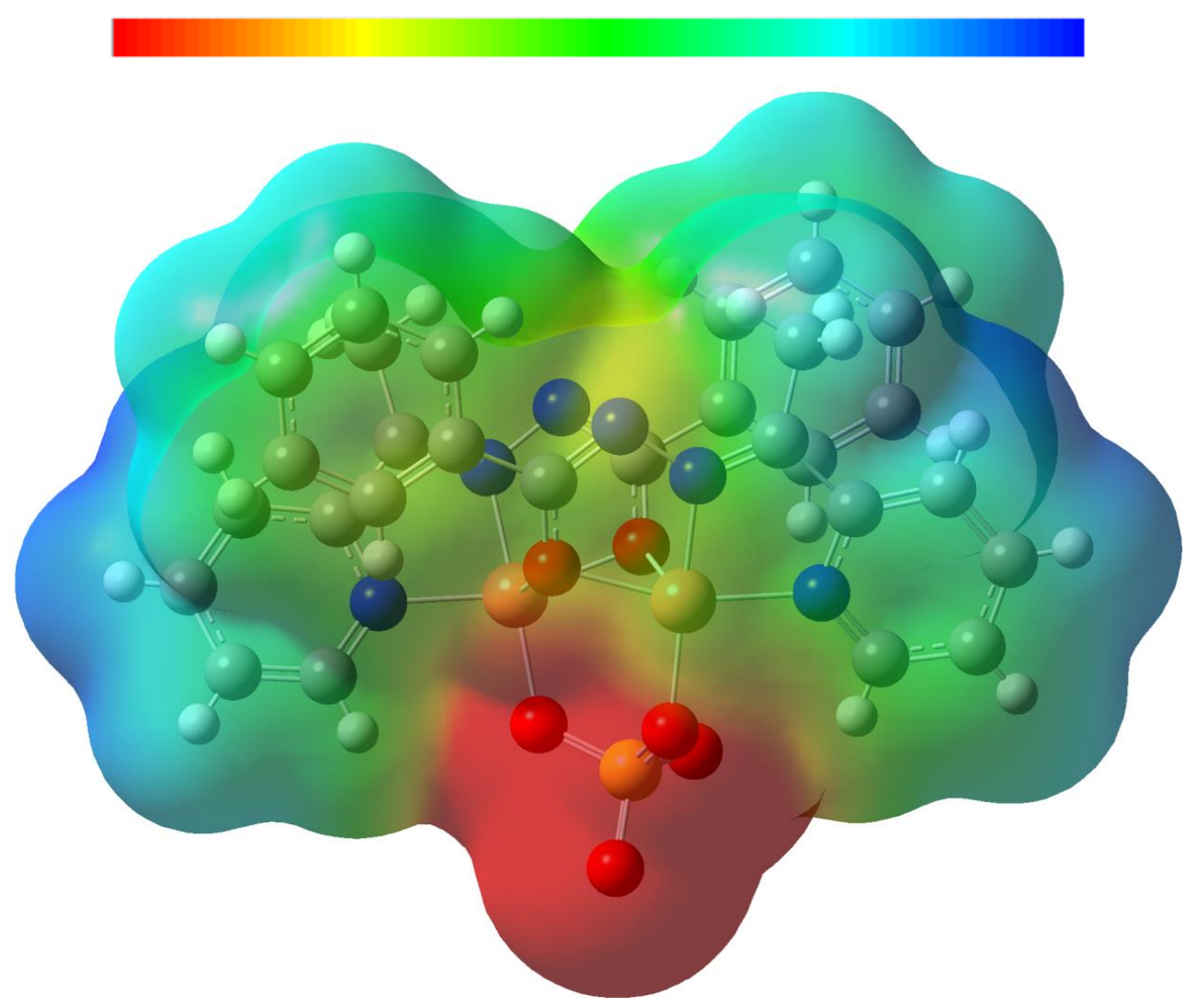

Figura 5.4.4. Mapa de potencial eletrostático do complexo $\left[\mathrm{Cu}_{2}\left(\mathrm{HL}_{2}\left(\mathrm{SO}_{4}\right)\right]\right.$, no qual as cores representam as regiões de cargas distribuidas no complexo, conforme escala de cores, na qual vermelho é o mais negativo e azul o mais positivo. A escala de cores vai de -0,05 (extremo vermelho) a +0,05 (extremo azul).

Desta forma, a grande vantagem do cálculo usando o código computacional VASP para o sistema em questão é fornecer uma visão da cela unitária como um todo, pois nesse caso em específico, de forma diferente dos anteriores os comprimentos e ângulos de ligação calculados usando ondas planas não foram mais próximos ao experimental quando comparados aos cálculos para uma molécula. 
Tabela 5.4.1. Comparação entre as cargas de Mulliken e cargas ChelpG nos átomos envolvidos na coordenação do ligante com o complexo [ $\mathrm{Cu}_{2}\left(\mathrm{HL}_{2}\left(\mathrm{SO}_{4}\right)\right]$ e do ligante $\mathrm{HL}$ isolado (MO6/LANL2DZ e 6-31g(d,p))

\begin{tabular}{|c|c|c|c|c|}
\hline Atom & $\begin{array}{c}\text { Mulliken charge } \\
\text { Complex }\end{array}$ & $\begin{array}{c}\text { Mulliken charge } \\
\text { Ligand }\end{array}$ & $\begin{array}{c}\text { ChelpG charge } \\
\text { Complex }\end{array}$ & $\begin{array}{c}\text { ChelpG charge } \\
\text { Ligand }\end{array}$ \\
\hline $\mathrm{Cu}$ & 0.551 & & 0.523 & \\
\hline O31 & -0.552 & -0.464 & -0.546 & -0.459 \\
\hline $\mathrm{N} 2$ & -0.319 & -0.417 & -0.182 & -0.374 \\
\hline N4 & -0.507 & -0.458 & -0.707 & -0.036 \\
\hline O34 & -0.657 & & -1.679 & \\
\hline O35 & -0.617 & & -1.520 & \\
\hline O33 & -0.666 & & -1.720 & \\
\hline $\mathrm{Cu}$ & 0.530 & & 0.342 & \\
\hline O31' & -0.546 & & -0.814 & \\
\hline N2' & -0.356 & & -0.096 & \\
\hline N4' & -0.518 & & -0.410 & \\
\hline$S$ & 1.522 & & 6.699 & \\
\hline
\end{tabular}

Para complexos com ânion sulfato, não é possível executar os cálculos de "Natural Atomic Orbital" e "Natural Bond Orbital Analysis", isso porque o software Gaussian, usado por nós para esse tipo de cálculo para os demais complexos, apresenta um "bug", já relatado desde 2009, por vários usuários, nas versões 03 e 09, porém ainda sem explicação oficial ou perspectiva de correção. Esse problema técnico é relativo a um erro na sub-rotina de programação NBO dentro do software, que impede logo no inicio do cálculo que um orbital de core do tipo $\mathrm{S}$ seja encontrado no enxofre, tornando assim inviável o prosseguimento do cálculo.

Assim, as análises de carga desses dois complexos será feita levando em conta as cargas de Mulliken e ChelpG, presentes na Tabela 5.4.2 e os orbitais 
moleculares apresentados a fim de corroborarem nossas análises serão do tipo Khon-Sham e não orbitais naturais como foi feito até agora neste trabalho.

(a)

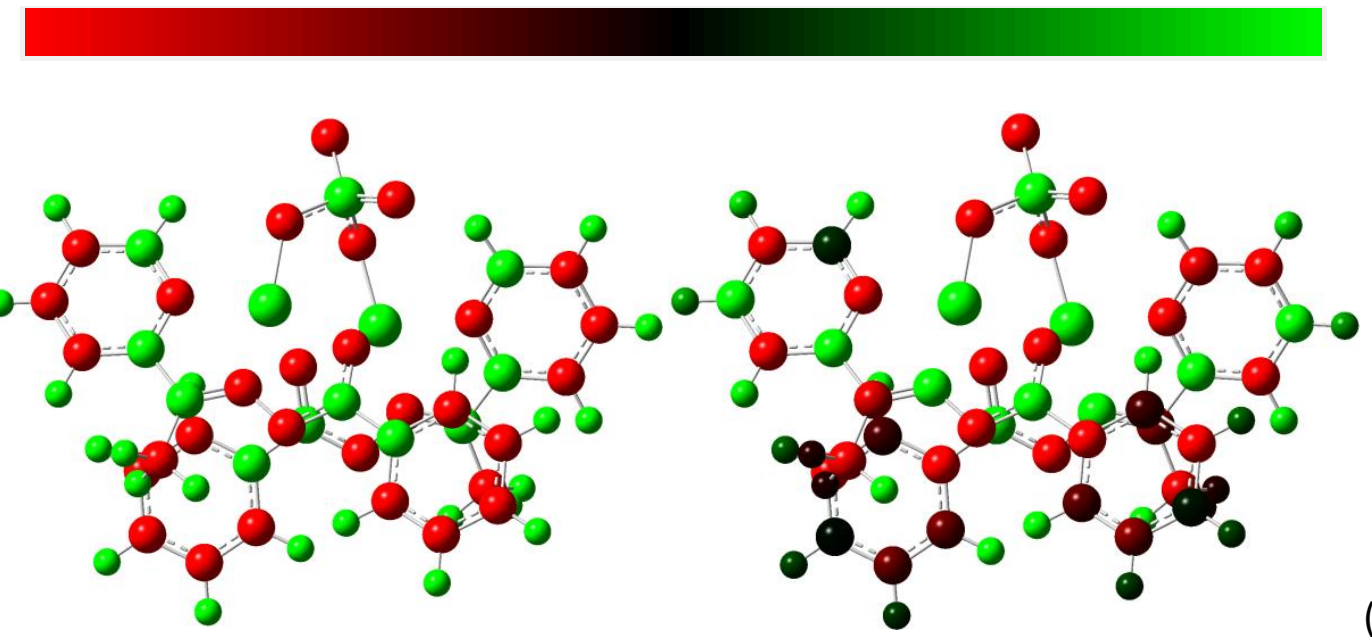

(b)

Figura 5.4.5. Representação do complexo [Cu $2\left(\mathrm{HL}_{2}\left(\mathrm{SO}_{4}\right)\right]$, na qual as cores representam as cargas de Mulliken (a) e cargas ChelpG (b) distribuidas no complexo, conforme escala de cores, na qual vermelho é o mais negativo e verde o mais positivo. A escala de cores vai de -0,05 a +0,05 para ambos os esquemas de cargas.

O mapa de densidade eletrônica do complexo (Figura 5.4.4), mostra como área com maior carga negativa da molécula o ânion $\mathrm{SO}_{4}{ }^{2-}$, e como áreas mais positivas os anéis piridina dos dois ligantes $(\mathrm{HL})$. Esse fato é confirmado pela Figura 5.5.5 (b), na qual as cargas ChelpG denotam o mesmo comportamento. Para as cargas de Mulliken (Figura 5.5.5 (a)) mostra um extremismo muito grande no valor das cargas.

Essa diferença entre os dois esquemas de carga pode ser atestada com a análise da Tabela 5.5.2, na qual tanto cargas de Mulliken quanto ChelpG mantem a mesma tendência, porém a diferença de valores é muito grande e o maior extremo ocorre para o enxofre, com o valor 1,522 em Mulliken e 6,699 em ChelpG. 


\subsection{2- Espectroscopias Vibracional e Eletrônica}

O espectro de infravermelho do complexo $\left[\mathrm{Cu}_{2}\left(\mathrm{HL}_{2}\left(\mathrm{SO}_{4}\right)\right]\right.$, encontra-se na Figura 5.5.6. A linha negra contínua é referente aos dados experimentais, enquanto as linhas coloridas são referentes a cada funcional através do qual as frequências vibracionais foram calculadas. As principais bandas nos espectros de infravermelho das hidrazonas e seus complexos de cobre(II) encontram-se na Tabela 5.4.3.

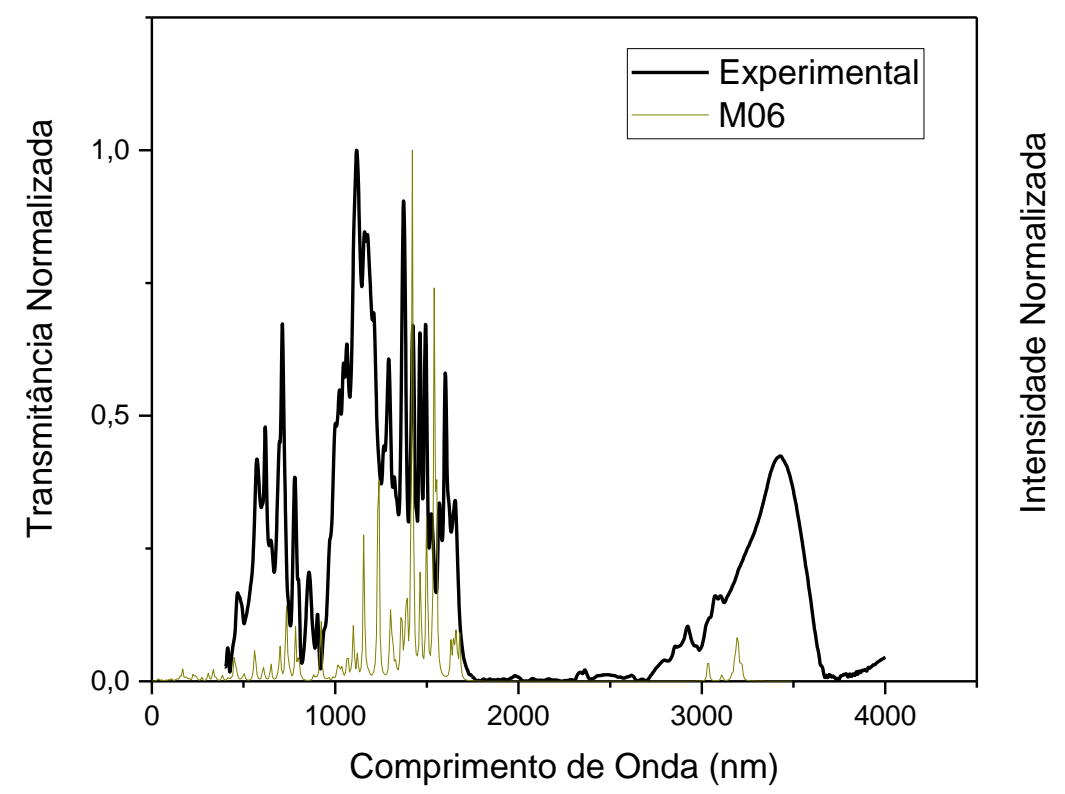

Figura 5.4.6. Espectro de infravermelho do complexo $\left[\mathrm{Cu}_{2}(\mathrm{HL})_{2}\left(\mathrm{SO}_{4}\right)\right]$, no qual a linha continua negra é o resultado experimental e a linha amarelo escuro é o cálculo advindo das frequências vibracionais calculadas com MO6.

Experimentalmente, a vibração encontrada entre 1587 e $1618 \mathrm{~cm}^{-1}$,

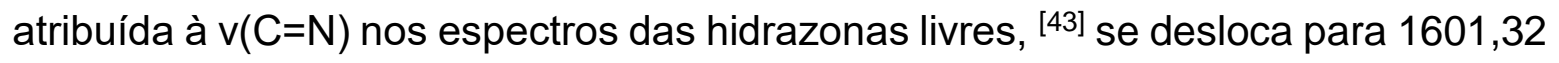
$\mathrm{cm}^{-1}$ no espectro do complexo de cobre(II) indicando a coordenação pelo nitrogênio azometínico (N2). A vibração $\mathrm{v}(\mathrm{C}=\mathrm{O})$, observada em 1651 e $1663 \mathrm{~cm}^{-1}$ nos espectros das hidrazonas, [106] desloca-se para $1492,16 \mathrm{~cm}^{-1}$ no complexo sugerindo a coordenação pelo oxigênio carbonílico (Tabela 5.4.3). As bandas que 
normalmente são mais afetadas pela coordenação aos metais são aquelas referentes a $\mathrm{v}(\mathrm{C}=\mathrm{N})$ e $\mathrm{v}(\mathrm{C}=\mathrm{O})$.

A deformação no plano no anel piridina que se encontra em $614-624 \mathrm{~cm}^{-1}$, nos espectros das hidrazonas, desloca-se para $619,04 \mathrm{~cm}^{-1}$ no espectro experimental do complexo, sugerindo coordenação no nitrogênio heterocromático. [43] A análise dos espectros de infravermelho indica a coordenação pelo sistema quelante Npy-N-O. Esses dados estão melhor detalhados na Tabela 5.4.2, a seguir, a qual mostra com detalhes as principais bandas experimentalmente e calculadas para cada funcional utilizado nesse estudo.

É importante salientar que as vibrações encontradas no composto são totalmente simétricas, ou seja, as duas unidades de coordenação vibram da mesma forma e intensidade em ambos os núcleos, pelo fato de serem iguais.

Tabela 5.4.2. Bandas nos espectros de infravermelho $\left(\mathrm{cm}^{-1}\right)$ do complexo [Cu $2\left(\mathrm{HL}_{2}\left(\mathrm{SO}_{4}\right)\right]$ para os funcionais especificados na tabela es conjuntos de bases atômicas LANL2DZ e 6-31g(d,p))

\begin{tabular}{|l|l|l|l|}
\hline & $v(\mathrm{C}=\mathrm{O})$ & $v(\mathrm{C}=\mathrm{N})$ & $\rho($ py $)$ \\
\hline Experimental & 1492,16 & 1601,32 & 619,04 \\
\hline B3LYP & 1537,54 & 1618,46 & 654,26 \\
\hline PBE1PBE & 1568,02 & 1558,86 & 655,60 \\
\hline CAM-B3LYP & 1572,87 & 1666,20 & 664,18 \\
\hline B97-D & 1491,09 & 1555,41 & 635,81 \\
\hline B3PW91 & 1551,80 & 1629,77 & 652,31 \\
\hline M06 & 1541,18 & 1633,20 & 649,74 \\
\hline w-B97xd & 1566,50 & 1664,25 & 664,02 \\
\hline
\end{tabular}

Foram observados nos cálculos teóricos grandes variações de intensidade em uma mesma banda. Assim, os valores para o estiramento $\mathrm{C}=\mathrm{N}$ apresentados na Tabela 5.4.2, são relativos ao mesmo modo de vibração para cada funcional utilizado, que é de número 162 para o $(\mathrm{C}=\mathrm{N})$ e 163 para o $(\mathrm{C}=\mathrm{N})$ ', o que muda é a intensidade, que foi bem maior quando foi usado o funcional CAM-B3LYP e bem 
menor quando o funcional B97-D foi usado. Isso se deve a diferenças de parametrização inerentes à construção de cada funcional e sua consequente sensibilidade para retratar o espectro vibracional.

Esse resultado obtido já era esperado e é justificado, pois a melhoria aplicada no funcional B3LYP com a introdução da correção proporcionada pela metodologia "Coulomb-attenuating method" (CAM) teve o objetivo justamente de melhorar dados espectroscópicos, enquanto que a componente de dispersão existente no funcional B97-D, que tem por objetivo resolver problemas com interações fracas não contribuiria de forma significativa no problema em questão. [123]

Em todos os funcionais o "twist" da piridina, nas duas unidades do ligante HL é detectado de forma bastante intensa, por ser uma banda bastante estudada, contando assim com condições ótimas de parametrização, e corresponde aos modos vibracionais 69 e 68 dos espectros teóricos. Os modos de vibração relativos a cada estiramento são os mesmo para cada funcional utilizado.

O espectro de UV-VIS do complexo [ $\left.\mathrm{Cu}_{2}(\mathrm{HL})_{2}\left(\mathrm{SO}_{4}\right)\right]$, foi calculado levandose em consideração as 100 mais intensas transições eletrônicas, isso porque a reprodutibilidade do espectro experimental foi muito fraca quando levamos em consideração um número menor de excitações. Essas transições correspondem as excitações calculadas usando M06/LANL2DZ + 6-31g(d,p), conforme mostrado no gráfico da Figura 5.4.7. 


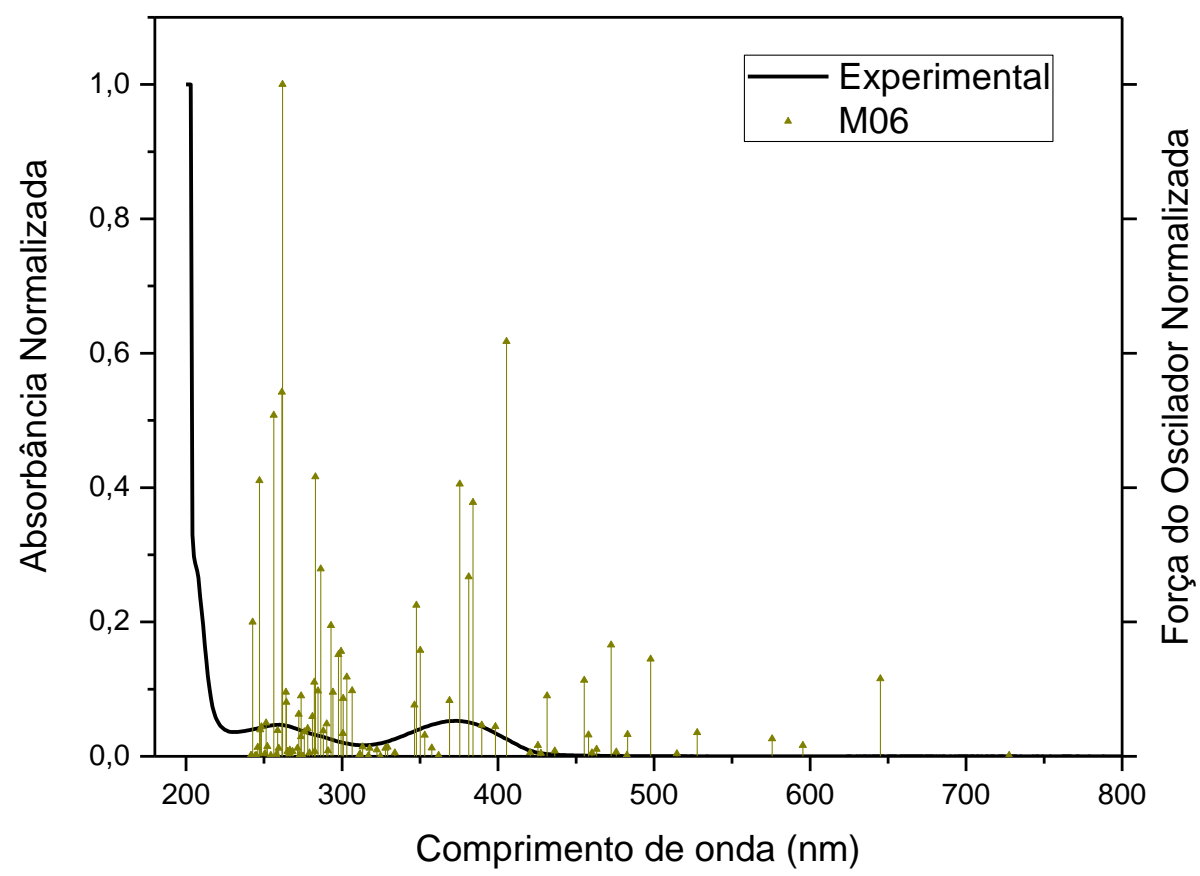

Figura 5.4.7. Espectro de UV-VIS do complexo $\left[\mathrm{Cu}_{2}\left(\mathrm{HL}_{2}\left(\mathrm{SO}_{4}\right)\right]\right.$, no qual a linha continua é o resultado experimental e as linhas verticais correspondem as excitações calculadas usando MO6/LANL2DZ + 6-31g(d,p).

O complexo binuclear de sulfato de cobre(II) e hidrazona absorve em absorbância máxima no comprimento de onda $\lambda=202,23 \mathrm{~nm}$, uma outra transição importante é o pequeno ombro 257,93 nm e um outro pico em 374,94 nm. Como era de se esperar face alguns complexos binucleares de cobre(II) relatados na literatura, apenas dois picos maiores são detectados (Figura 5.4.7).

Sabendo que não houve um deslocamento de bandas muito grande entre o complexo e o ligante hidrazona isolado, as bandas de emissão puderam ser com o auxílio da análise dos orbitais moleculares fornecidos pelos cálculos teóricos atribuídos respectivas transições, que devido a essa concordância são do tipo intraligante (IL), transições $\pi \rightarrow \pi^{*}$ (Figura 5.4.8). [112] [128] 


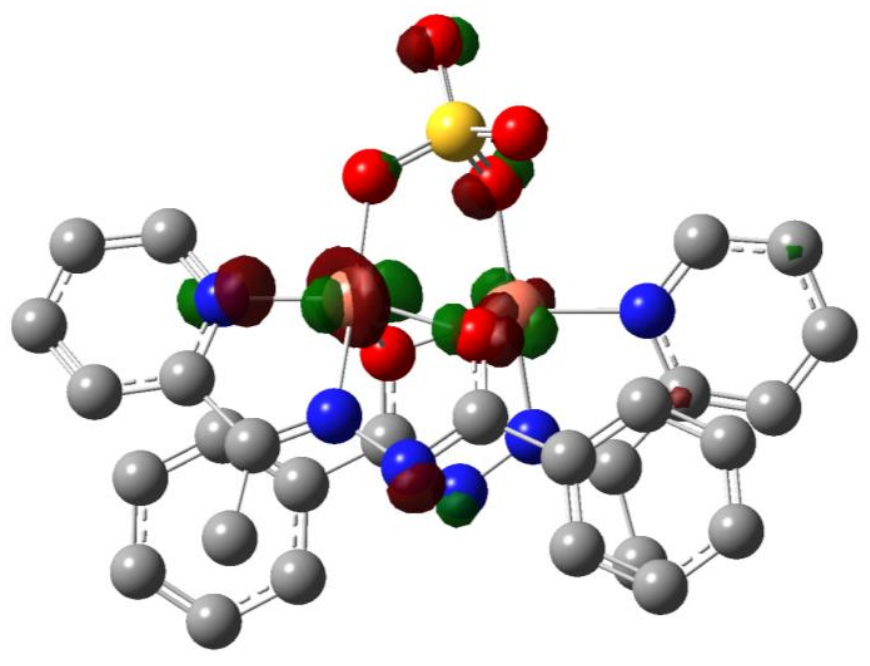

(a)

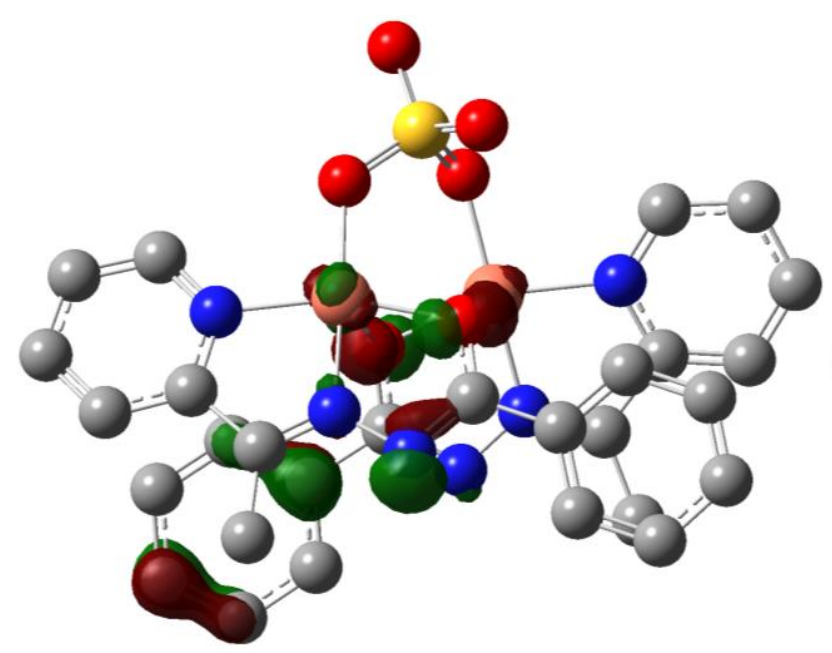

(c)

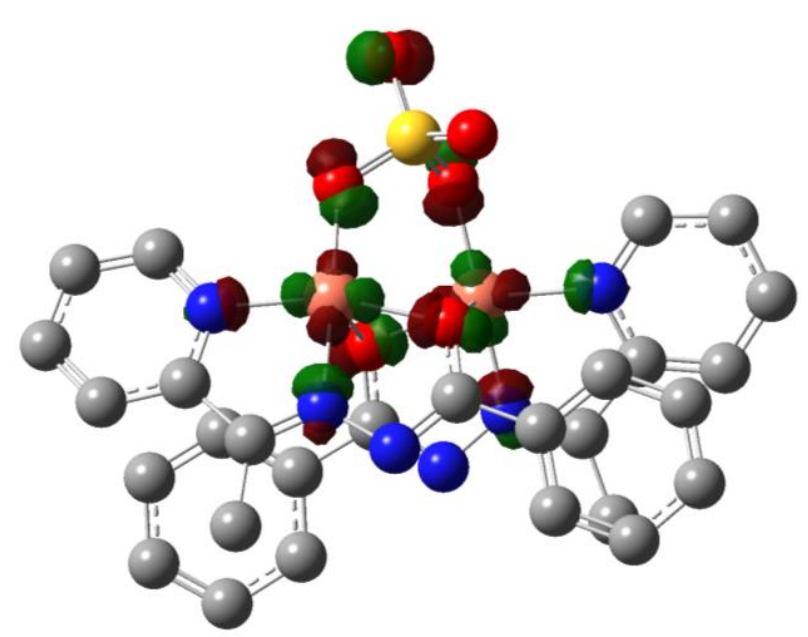

(b)

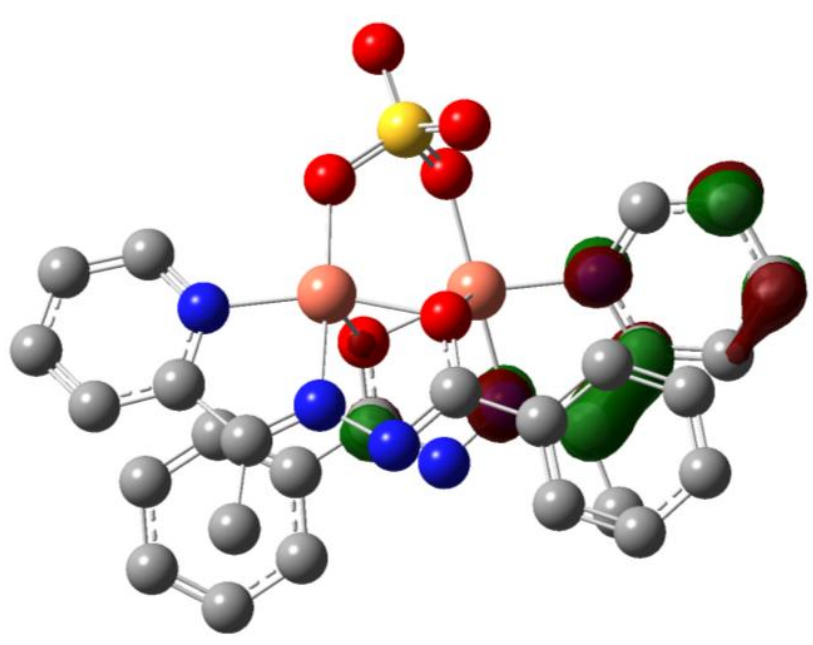

(d) 


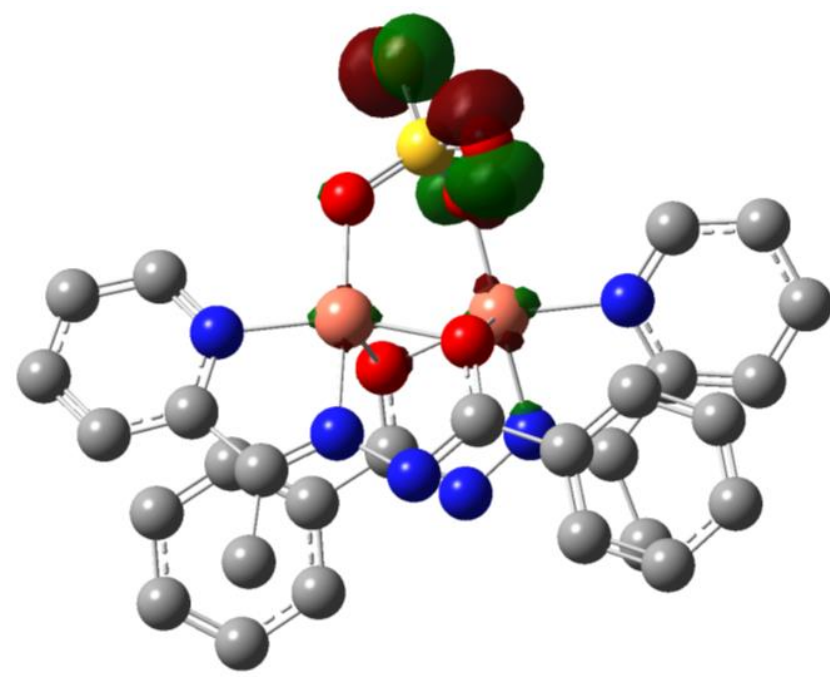

(e)

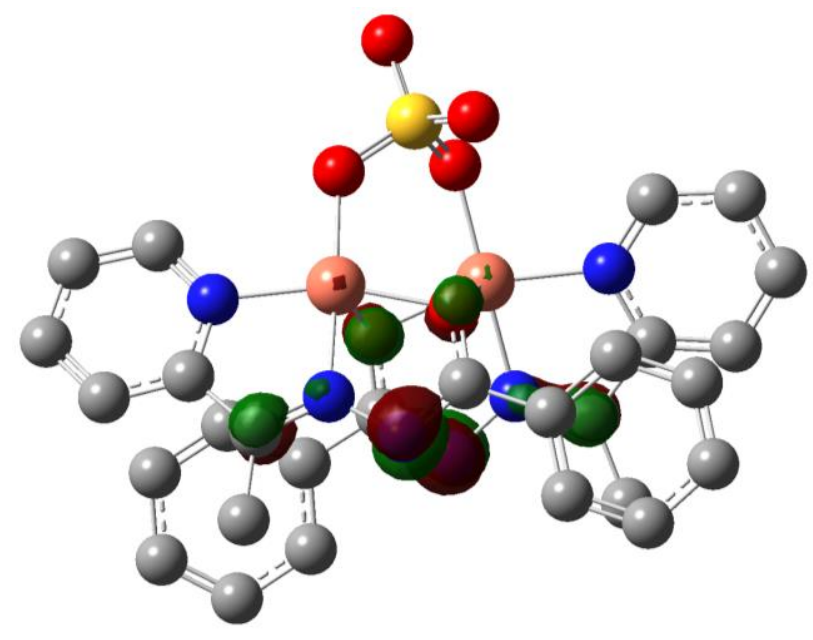

(g)

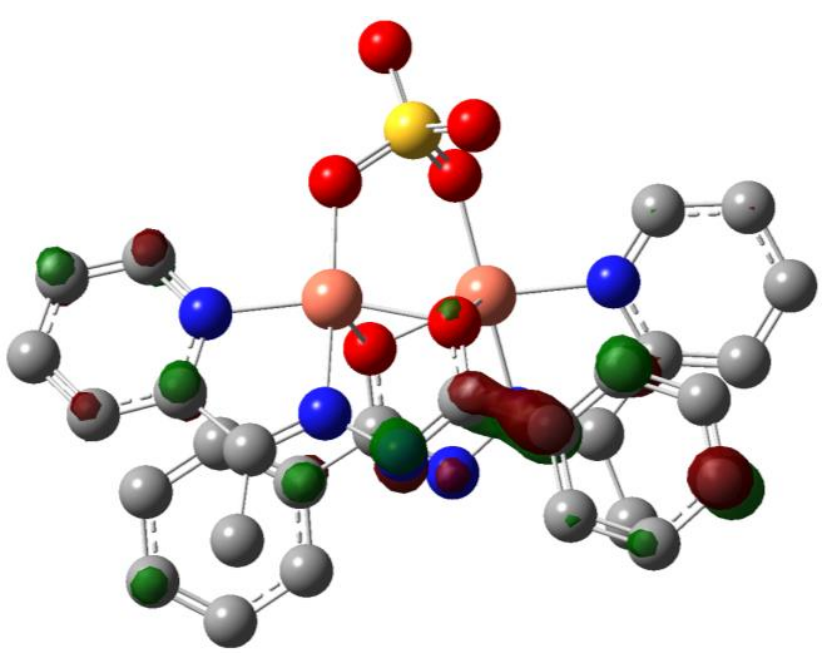

(f)

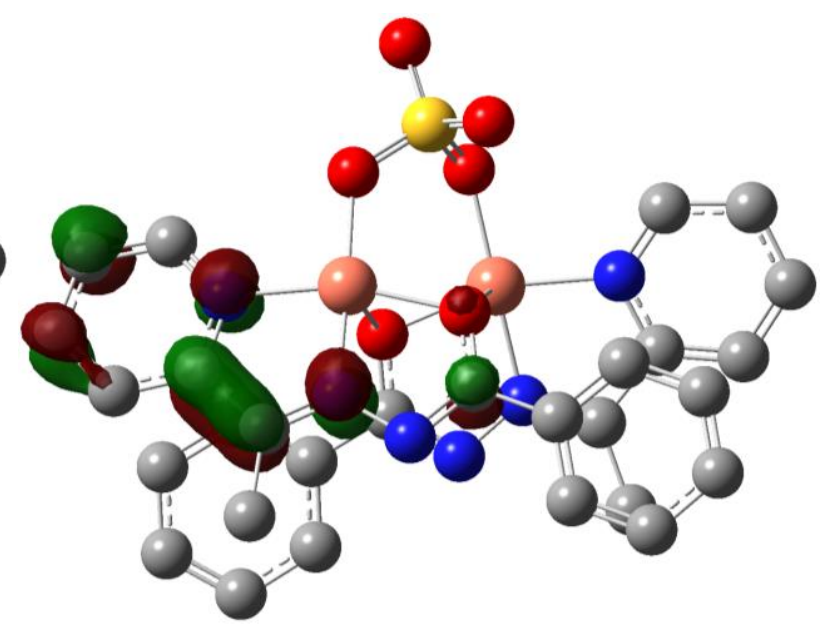

(h)

Figura 5.4.8. Orbitais moleculares com maior contribuição probabilistica envolvidos nas transições eletrônicas principais do complexo [Cu $2\left(\mathrm{HL}_{2}\left(\mathrm{SO}_{4}\right)\right]$, (a) $\mathrm{HOMO}-20$, (b) LUMO, (c) HOMO-9, (d)LUMO+2, (e) HOMO-1, (f)LUMO+5, (g) HOMO-3 e (h) LUMO+1.

O estado excitado 82 corresponde ao pico de maior intensidade do espectro calculado usando M06. Ele está localizado no comprimento de onda de 259, $38 \mathrm{~nm}$ com força de oscilador 0,2414 e os orbitais que tem probabilidade maior de executar essa transição são HOMO-20 (138) $\rightarrow$ (169) LUMO, com probabilidade de 45\%. 
Conforme podemos ver na Figura 5.4.8, itens (a) e (b) ambos possuem natureza antiligante e a julgar pelos orbitais de Kohn - Sham representados, a transição interna de ligante para ligante ocorre com densidade eletrônica deixando o ânion $\mathrm{SO}_{4}{ }^{2-}$ em direção ao ligante $\mathrm{HL}$, com intensidade semelhante para as duas unidades do ligante. [129]

Já o ombro calculado em 282,98 nm tem força de oscilador mais baixa das três transições destacadas, com valor de 0,1005. Para a existência desse ombro temos duas transições com grande probabilidade de ocorrência, HOMO-9 (159) $\rightarrow$ (171) LUMO+2, e HOMO-1 (167) $\rightarrow$ (174) LUMO+5, sendo a primeira com probabilidade de ocorrência de $38,97 \%$ e a segunda com $32,81 \%$.

Ambas as transições responsáveis pela formação do ombro em 282,98 nm possuem como característica a transferência de carga de ligante para ligante (Figura 5.4.8 itens (c), (d), (e) e (f)) Porém, na primeira delas, a transferência de carga ocorre do anel benzênico de $(H L)$ para a piridina de $(H L)$ e $(H L)$ ', já na segunda transição a carga se transfere do ânion $\mathrm{SO}_{4}{ }^{2-}$ (Figura 5.4 .8 (e)) para um orbital ligante localizado em (HL) e (HL)'.

A terceira transição eletrônica importante na análise do comportamento do complexo $\left[\mathrm{Cu}_{2}(\mathrm{HL})_{2}\left(\mathrm{SO}_{4}\right)\right]$ é a calculada como sendo o estado excitado 27 . Ela possui força de oscilador 0,1491 e comprimento de onda de 405,42 nm. A transição de maior probabilidade de ocorrência para esse comprimento de onda ocorre entre os orbitais moleculares HOMO-3 (165) $\rightarrow$ (170) LUMO+1, sendo provável em $64,74 \%$. Sendo essa transição em sua maior parte da piridina de $(H L)$ para a piridina de $(\mathrm{HL})^{\prime}$. [130]

Complexos binucleares de cobre (II) com características eletrônicas semelhantes a esse tem sido aplicados largamente como biomateriais para sensores de detecção de glicoproteínas após imobilização na matriz correta. [131] Nesse sentido, essa caracterização teórica efetuada, aponta o complexo $\left[\mathrm{Cu}_{2}(\mathrm{HL})_{2}\left(\mathrm{SO}_{4}\right)\right]$, como forte candidato para esse tipo de aplicação. 


\section{5 - Sobre o desempenho dos funcionais da densidade}

Foram feitos cálculos de otimização geométrica e frequências vibracionais, para os quatro complexos estudados, usando duas diferentes abordagens: as funções de ondas planas e conjuntos de bases atômicas localizados. Aqui, trataremos quantitativamente os resultados desses cálculos, a fim de entender melhor a relação entre a abordagem utilizada, o respectivo funcional e o sistema de estudo.

Nos cálculos de campo auto-consistente foram empregados os funcionais B3LYP, PBE1PBE, B3PW91 (híbridos), CAM-B3LYP (híbrido de longo alcance), B97-D (puro), M06 e os conjuntos de bases atômicas LANL2DZ para o cobre e 6$31 \mathrm{G}(\mathrm{d}, \mathrm{p})$ para os demais átomos, foram usados em todos os cálculos. Os cálculos periódicos foram feitos usando a DFT baseada na teoria de ondas planas no programa VASP, e o funcional utilizado foi uma versão do PW91, desenvolvida especialmente para sólidos.

Tendo em vista os cálculos executados, procedemos à comparação entre os parametros geométricos obtidos em decorrência de cada otimização feita com cada um dos diferentes funcionais escolhidos. A escolha dos funcionais usados nos cálculos com os conjuntos de bases atômicas localizados, levou em conta a maior diversidade possível entre eles, a qual engloba uma variedade de métodos usados para construção de funcionais e recomendação de aplicação.

Até aqui, durante o presente texto, o foco da discussão relativa a resultados da otimização geométrica, deu-se principalmente com relação à influência da coordenação na estrutura do ligante hidrazona e as mudanças geométricas acarretadas pela coordenação. Sendo assim, fez-se necessária a comparação presente nesse ítem, pois a mesma nos possibilitou um entendimento mais fundamental do papel que exerce a escolha do funcional, bem como um impacto numérico entre a escolha de ondas planas ou funções de base localizadas. 


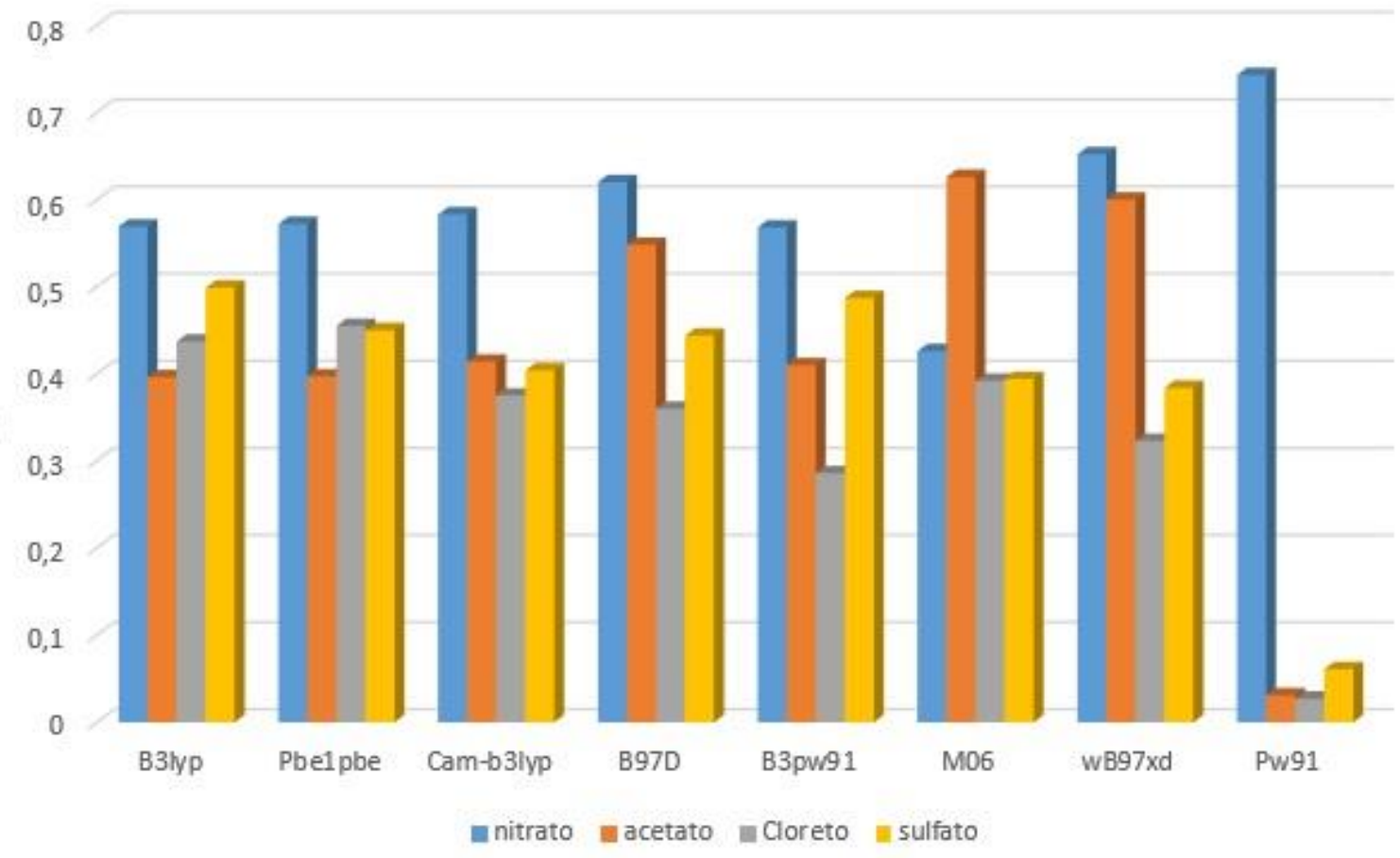

Figura 5.5.1. Gráfico de barras do RMSD comparativo entre os funcionais utilizados neste trabalho e cada um dos quatro complexos estudados.

Os valores de RMSD calculados para cada um dos cálculos de otimização dos quatro complexos foram os parâmetros utilizados para a construção do gráfico presente na Figura 5.5.1. A partir desses valores podemos notar que os cálculos de ondas planas, executados com o funcional PW91, apresentam regularidade e desvios inferiores a 0,1 para os complexos $\left[(\mathrm{Cu})_{2} \mu(\mathrm{CH} 3 \mathrm{COO})_{2}(\mathrm{HL})_{2}\right]$ (acetato), $\left[(\mathrm{Cu})(\mathrm{HL})_{2}\right]$ (cloreto) e $\left[\mathrm{Cu}_{2}(\mathrm{HL})_{2}(\mathrm{SO} 4)\right]$ (sulfato).

Apenas para o complexo $\left[\mathrm{Cu}(\mathrm{HL})\left(\mathrm{NO}_{3}\right)_{2}\right]$ (nitrato) houve o maior desvio encontrado, mesmo quando comparado a qualquer outro resultado presente no gráfico. Esse desvio, conforme já foi discutido durante o texto, com detalhes na seção 5.1.1, é atribuído a alguns comprimentos e ângulos de ligação específicos, que não foram bem retratados por essa metodologia. Desta forma, essa é uma metodologia adequada para a descrição de três desses complexos, sendo que para o complexo de nitrato de cobre (II) e hidrazona, há desvios significativos em todos os funcionais utilizados, e o que melhor retratou o sistema foi o M06. 
Quanto aos cálculos feitos usando conjuntos de bases atômicas, o gráfico da Figura 5.5.1, sintetiza muito bem a independência com relação aos funcionais, já discutida ao longo do texto em vários pontos, já que para todos os quatro complexos, usando todos os funcionais nos cálculos SCF, o desvio médio quadrático encontra-se, na grande maioria dos cálculos, entre 0,4 e 0,6. O menor valor de RMSD nesse tipo de cálculo foi 0,286 , encontrado para o complexo $\left[(\mathrm{Cu})(\mathrm{HL})_{2}\right]$, usando o funcional B3PW91. Já o maior valor foi 0,652 , relativo ao cálculo com o funcional w-B97xd, para o complexo $\left[\mathrm{Cu}(\mathrm{HL})\left(\mathrm{NO}_{3}\right)_{2}\right]$.

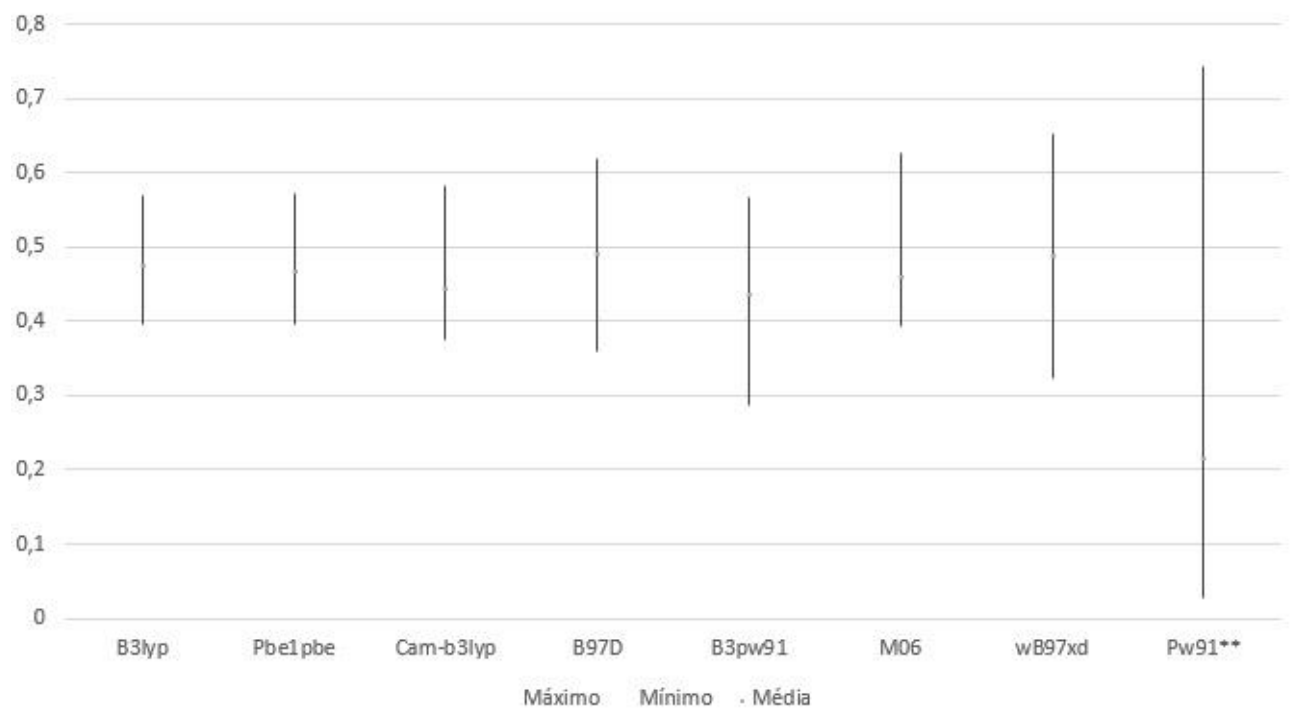

Figura 5.5.2. Máximos, mínimos e média calculados a partir do RMSD para cada um dos funcionais utilizados neste trabalho levando em conta as otimizações geométricas dos quatro complexos estudados.

Essa discrepância de valores, quando comparamos os sistemas estudados e a gama de funcionais com os quais foram realizados os cálculos, se deve a especificidade de cada funcional no que cerne à sua construção, especialmente com relação a parâmetros usados para a parte de troca e correlação. Tais parâmetros, que possibilitam uma melhor descrição dos efeitos de correlação 
eletrônica, são bastante específicos, pois são obtidos através de um grande número de sistemas de referência, definidos pelo objetivo de aplicação de cada funcional.

A Figura 5.5.2 retrata em termos numéricos o desvio que ocorre entre os cálculos com cada funcional para os quatro sistemas estudados, no qual uma faixa mais ampla compreendida entre os valores de máximos, mínimos e média, corresponde a dizer que o funcional se comportou de forma mais irregular entre os sistemas, ou seja, um funcional que oscila no valor do RMSD entre os cálculos para os quatro complexos estudados. Desta forma, a regularidade foi mantida para os funcionais usados nos cálculos SCF, sendo que os funcionais mais regulares foram B3LYP, PBE1PBE e M06. Essa regularidade não pode ser notada no PW91, com o qual foram feitos os cálculos de ondas planas, devido ao grande desvio encontrado no complexo $\left[\mathrm{Cu}(\mathrm{HL})\left(\mathrm{NO}_{3}\right)_{2}\right]$, o qual foi discutido e entendido anteriormente no texto. 


\section{Capítulo 6 - Conclusões}

As propriedades estruturais dos quatro complexos foram estudadas através de cálculos DFT com funções atômicas localizadas e ondas planas. Através desses cálculos foi possível detectar e compreender as mudanças estruturais ocorridas no ligante HL em decorrência da coordenação com o cobre (II) em todos os complexos estudados.

O primeiro passo deste trabalho foi calcular a geometria e frequências vibracionais com os funcionais B3LYP, PBE1PBE, B3PW91 (híbridos), CAMB3LYP(híbrido de longo alcance), B97-D (puro), M06 com os conjuntos de bases atômicas LANL2DZ (Chiodo, 2006) para o cobre e 6-31G(d, p) para de uma molécula livre de todos os complexos e a geometria do cristal com o funcional PW91 usando a teoria de ondas planas.

Através desses cálculos foi possível afirmar em todos os casos que não há mudanças significativas nos átomos fora da esfera de coordenação da estrutura do ligante, quando ocorre a formação dos complexos, isso porque a estrutura rígida do ligante se mantém.

O principal parâmetro para comparação entre os funcionais usados nos cálculos DFT foi o desvio médio quadrático, RMSD, o qual nos mostrou que em todos os casos existe uma superioridade dos cálculos feitos usando ondas planas e não houve um consenso absoluto para os cálculos com conjuntos de bases atômicas sobre qual seria o melhor funcional, uma vez que os desvios não apresentaram um padrão ou uma grande diferenciação entre eles. Assim sendo, podemos concluir que há nesses cálculos uma independência do funcional utilizado. Todos os cálculos apresentaram concordância com os valores experimentais dos referidos complexos e de análogos da literatura.

Para os espectros de infravermelho, todas as bandas características dos complexos foram detectadas e analisadas, apresentando concordância com os valores medidos experimentalmente. Também nos cálculos de espectroscopia de 
infravermelho, a independência entre os funcionais foi detectada, uma vez que não há grande diferença entre os resultados para cada funcional usado.

Nos cálculos de espectroscopia eletrônica, os espectros de UV-VIS foram simulados e além de encontrar as principais transições eletrônicas características as mesmas foram analisadas e foi atribuída a natureza de cada uma dessas transições, que comparadas aos dados presentes na literatura para compostos análogos, coloca os novos compostos com perfil espectral semelhante.

Assim, foi cumprido o objetivo inicial deste trabalho, ou seja, foi feita a caracterização teórica dos compostos de cobre (II) e hidrazona, bem como seu perfil espectral no infravermelho e ultravioleta. Neste trabalho, temos a descrição de uma metodologia segura e eficiente para trabalhar com descrição teórica de complexos possibilitando sua aplicação em outros sistemas de interesse.

Pretende-se, na continuidade desse trabalho, de posse da estrutura eletrônica elucidada para o composto, realizar cálculos a fim de possibilitar a proposição de outras propriedades que possibilitem habilitar algum desses compostos, ou ainda todos eles, para aplicações farmacológicas. 


\section{Capítulo 7 - Sugestões para trabalhos futuros}

7.1. Cálculos de hiperpolarizabilidade a fim de se determinar a presença de propriedades magnéticas acentuadas, uma vez que há presença de átomos doadores na esfera de coordenação Sendo esta uma propriedade de interesse para entendimento e aplicações dos referidos complexos, a mesma deve ser estudada na continuidade deste trabalho.

7.2. Cálculos de otimização e frequência dos principais estados excitados de cada complexo, com o objetivo de visualizar as formas relaxadas dessas estruturas, a fim de esclarecer melhor o papel dos orbitais $d$ na estabilidade de cada estrutura.

7.3. Execução dos cálculos de otimização e frequência em ambiente solvatado, a fim de se determinar o papel da solvatação e as possíveis diferenças com o ambiente cristalino.

7.4- Busca de formas que viabilizem o deslocamento de bandas nos complexos para a janela fototerapêutica, como a substituição de ligantes ou inclusão de substituintes a fim de credencia-los como possíveis agentes fototerapeuticos.

7.5- Determinar a possível viabilidade do uso de métodos computacionalmente mais exigentes, tanto para as otimizações geométricas quanto para a determinação de parâmetros termodinâmicos que poderão inferir a respeito da estabilidade das referidas estruturas dos complexos. 
Capítulo 8 - Apêndice

\subsection{Tabelas}

Tabela 8.1. Comprimentos (angstrom) e ângulos (graus) de ligação selecionados para o ligante 2-acetilpiridinabenzoilhidrazona HL.

\begin{tabular}{|c|c|c|c|c|c|c|c|c|c|}
\hline & Exp* & B3LYP & PBE1PBE & $\begin{array}{c}\text { CAM- } \\
\text { B3LYP }\end{array}$ & B97D & B3PW91 & M06 & wB97-XD & PW91** \\
\hline $\begin{array}{l}\text { N3-C5- } \\
\text { C8-C17 }\end{array}$ & 47,50 & 25,93 & 26,23 & 25,53 & 27,92 & 27,15 & 25,27 & 28,36 & 38,41 \\
\hline N2-N3 & 1,375 & 1,354 & 1,343 & 1,353 & 1,351 & 1,346 & 1,348 & 1,353 & 1,353 \\
\hline N2-C6 & 1,264 & 1,291 & 1,287 & 1,281 & 1,304 & 1,290 & 1,287 & 1,283 & 1,296 \\
\hline N3-C5 & 1,347 & 1,393 & 1,384 & 1,384 & 1,404 & 1,388 & 1,389 & 1,384 & 1,411 \\
\hline C5-031 & 1,219 & 1,218 & 1,214 & 1,212 & 1,225 & 1,216 & 1,212 & 1,212 & 1,217 \\
\hline C5-C8 & 1,491 & 1,502 & 1,496 & 1,499 & 1,507 & 1,499 & 1,494 & 1,501 & 1,491 \\
\hline N4-C7 & 1,324 & 1,345 & 1,338 & 1,335 & 1,354 & 1,341 & 1,338 & 1,337 & 1,349 \\
\hline N4-C9 & 1,339 & 1,338 & 1,333 & 1,333 & 1,344 & 1,333 & 1,332 & 1,334 & 1,338 \\
\hline N3-N2-C5 & 31,13 & 30,42 & 30,47 & 30,48 & 30,38 & 30,430 & 30,60 & 30,50 & 31,07 \\
\hline $\begin{array}{c}\text { C5-N3- } \\
\text { O31 }\end{array}$ & 26,80 & 26,39 & 26,36 & 26,35 & 26,30 & 26,37 & 26,28 & 26,25 & 26,43 \\
\hline N2-N3-C6 & 29,07 & 29,99 & 30,21 & 29,95 & 30,24 & 30,13 & 30,20 & 30,06 & 29,46 \\
\hline C6-N2-C7 & 35,75 & 34,60 & 34,58 & 34,71 & 34,43 & 34,59 & 34,53 & 34,84 & 34,89 \\
\hline C7-N4-C6 & 33,95 & 33,40 & 33,45 & 33,49 & 33,33 & 33,43 & 33,34 & 33,57 & 32,93 \\
\hline $\begin{array}{l}\text { N3-N2- } \\
\text { C6-C7 }\end{array}$ & 176,93 & 179,68 & 179,73 & 179,72 & 179,77 & 179,70 & 179,99 & 179,88 & 178,21 \\
\hline $\begin{array}{l}\text { C17-C8- } \\
\text { C6-C11 }\end{array}$ & 33,50 & 26,95 & 27,10 & 26,31 & 28,55 & 28,09 & 25,37 & 28,00 & 35,45 \\
\hline
\end{tabular}




\begin{tabular}{|c|c|c|c|c|c|c|c|c|c|}
\hline $\begin{array}{c}\text { C15-N4- } \\
\text { C17-C19 }\end{array}$ & 21,70 & 33,59 & 31,24 & 30,53 & 32,62 & 32,30 & 29,25 & 32,16 & $\mathbf{2 2 , 8 2}$ \\
\hline $\begin{array}{c}\text { O31-C5- } \\
\text { C8 }\end{array}$ & 120,68 & 122,65 & 122,66 & $\mathbf{1 2 2 , 4 5}$ & 123,15 & 122,71 & 122,89 & 122,68 & 123,42 \\
\hline C6-N2-N3 & 119,02 & 118,40 & 118,13 & 118,24 & 118,29 & 118,30 & 118,01 & 118,07 & $\mathbf{1 1 9 , 6 6}$ \\
\hline $\begin{array}{c}\text { O31-C5- } \\
\text { N3 }\end{array}$ & 123,32 & 123,07 & 123,21 & 123,20 & 123,19 & 123,17 & 123,23 & $\mathbf{1 2 3 , 4 0}$ & 122,53 \\
\hline N3-C5-C8 & 115,99 & 114,28 & 114,11 & $\mathbf{1 1 4 , 3 5}$ & 113,65 & 114,11 & 113,87 & 113,92 & 114,03 \\
\hline C5-N3-N2 & 117,02 & 120,09 & 120,07 & 119,80 & 120,50 & 120,16 & 119,79 & $\mathbf{1 1 9 , 7 6}$ & 119,28 \\
\hline $\begin{array}{c}\text { C7-C6- } \\
\text { N2-N3 }\end{array}$ & 176,93 & 179,68 & 179,73 & 179,71 & 179,77 & 179,70 & 179,99 & 179,88 & $\mathbf{1 7 8 , 2 1}$ \\
\hline RMSD & & 0,259 & 0,257 & 0,267 & 0,256 & 0,259 & 0,258 & $\mathbf{0 , 2 4 7}$ & $\mathbf{0 , 1 0 1}$ \\
\hline
\end{tabular}

${ }^{*}[23]$, Valores em negrito correspondem aos mais próximos ao experimental.

** Ondas planas

Tabela 8.2. Comprimentos (angstrom) e ângulos (graus) de ligação selecionados para o complexo (2-acetilpiridinabenzoilhidrazona) dinitratocobre(II) [Cu(HL)( $\left.\left.\mathrm{NO}_{3}\right)_{2}\right]$.

\begin{tabular}{|c|c|c|c|c|c|c|c|c|c|}
\hline & Exp* & B3LYP & PBE1PBE & $\begin{array}{c}\text { CAM- } \\
\text { B3LYP }\end{array}$ & B97D & B3PW91 & M06 & wB97-XD & PW91*** \\
\hline $\mathrm{Cu}-\mathrm{N} 2$ & 1,947 & 2,201 & 2,190 & 2,184 & 2,214 & 2,181 & 2,247 & 2,210 & $\mathbf{1 , 9 4 8}$ \\
\hline $\mathrm{Cu}-\mathrm{N} 4$ & 1,988 & 2,330 & 2,300 & 2,302 & 2,303 & 2,311 & 2,241 & 2,287 & $\mathbf{1 , 9 9 0}$ \\
\hline $\mathrm{Cu}-\mathrm{O} 31$ & 1,999 & 2,303 & 2,272 & 2,246 & 2,451 & 2,311 & 2,233 & 2,241 & $\mathbf{2 , 0 1 7}$ \\
\hline $\mathrm{Cu}-\mathrm{O} 32$ & 1,963 & 2,128 & 2,123 & 2,118 & 2,163 & $\mathbf{2 , 1 1 2}$ & 1,898 & 2,152 & 2,218 \\
\hline $\mathrm{Cu}-\mathrm{O} 33$ & 2,267 & 1,919 & 1,905 & 1,896 & 1,975 & 1,914 & $\mathbf{2 , 1 6 5}$ & 1,903 & $\mathbf{1 , 9 8 5}$ \\
\hline $\mathrm{Cu}-\mathrm{O} 35$ & 2,699 & 2,036 & 2,012 & 1,994 & 2,124 & 2,033 & 2,011 & 1,994 & $\mathbf{3 , 1 6 1}$ \\
\hline $\mathrm{Cu}-\mathrm{O} 39$ & 2,957 & 2,980 & 2,923 & $\mathbf{2 , 9 5 7}$ & 3,049 & 2,945 & 2,826 & 2,969 & 2,831 \\
\hline $\mathrm{N} 2-\mathrm{Cu}-\mathrm{N} 4$ & 80,21 & 70,93 & 71,09 & 71,21 & 71,84 & 71,39 & 71,19 & 71,01 & $\mathbf{8 0 , 8 7}$ \\
\hline $\mathrm{N} 2-\mathrm{Cu}-\mathrm{O} 31$ & 79,22 & 72,24 & 72,42 & 72,79 & 70,48 & 72,33 & 71,81 & 72,54 & $\mathbf{7 9 , 2 9}$ \\
\hline $\mathrm{N} 2-\mathrm{Cu}-\mathrm{O} 32$ & 163,17 & 152,08 & 150,07 & 150,90 & 152,05 & $\mathbf{1 5 2 , 5 6}$ & 143,85 & 149,83 & 120,48 \\
\hline $\mathrm{N} 2-\mathrm{Cu}-\mathrm{O} 33$ & 121,36 & 108,81 & 109,08 & 107,62 & 109,61 & 109,47 & $\mathbf{1 1 5 , 5 2}$ & 107,13 & 162,54 \\
\hline $\mathrm{N} 4-\mathrm{Cu}-\mathrm{O} 31$ & 158,89 & 143,09 & 143,45 & 143,94 & 142,21 & 143,65 & 142,79 & 143,51 & $\mathbf{1 5 9 , 6 5}$ \\
\hline $\mathrm{N} 4-\mathrm{Cu}-\mathrm{O} 32$ & 97,97 & 95,12 & 92,76 & 91,98 & 93,98 & 97,69 & 92,94 & 91,21 & $\mathbf{1 0 1 , 4 6}$ \\
\hline
\end{tabular}




\begin{tabular}{|c|c|c|c|c|c|c|c|c|c|}
\hline N4-Cu-O33 & 101,96 & 96,13 & 96,19 & 95,80 & 101,39 & 95,80 & 94,66 & 95,83 & 96,92 \\
\hline $\begin{array}{c}\mathrm{O} 31-\mathrm{Cu}- \\
\mathrm{O} 32\end{array}$ & 100,33 & 117,01 & 118,75 & 119,56 & 118,63 & 113,81 & 119,87 & 120,71 & 92,50 \\
\hline $\begin{array}{c}\mathrm{O} 31-\mathrm{Cu}- \\
\mathrm{O} 33\end{array}$ & 92,77 & 97,70 & 97,46 & 96,83 & 93,75 & 98,11 & 97,58 & 96,21 & 100,64 \\
\hline $\begin{array}{c}\mathrm{O} 32-\mathrm{Cu}- \\
\mathrm{O} 33\end{array}$ & 75,44 & 96,37 & 97,33 & 97,34 & 96,55 & 96,41 & 97,53 & 98,56 & 76,97 \\
\hline N2-N3 & 1,366 & 1,347 & 1,335 & 1,346 & 1,342 & 1,338 & 1,336 & 1,346 & 1,365 \\
\hline N2-C6 & 1,282 & 1,288 & 1,283 & 1,277 & 1,301 & 1,287 & 1,279 & 1,277 & 1,297 \\
\hline N3-C5 & 1,361 & 1,388 & 1,380 & 1,379 & 1,402 & 1,384 & 1,384 & 1,381 & 1,364 \\
\hline C5-O31 & 1,248 & 1,228 & 1,224 & 1,224 & 1,232 & 1,225 & 1,225 & 1,224 & 1,263 \\
\hline $\mathrm{C} 5-\mathrm{C} 8$ & 1,468 & 1,486 & 1,480 & 1,482 & 1,491 & 1,483 & 1,478 & 1,483 & 1,465 \\
\hline N4-C7 & 1,347 & 1,348 & 1,341 & 1,340 & 1,356 & 1,344 & 1,342 & 1,341 & 1,360 \\
\hline N4-C9 & 1,332 & 1,332 & 1,327 & 1,326 & 1,338 & 1,329 & 1,327 & 1,328 & 1,331 \\
\hline C6-C7 & 1,489 & 1,491 & 1,485 & 1,492 & 1,487 & 1,486 & 1,486 & 1,494 & 1,465 \\
\hline $\begin{array}{c}\mathrm{O} 33-\mathrm{Cu}- \\
\text { O39 }\end{array}$ & 45,07 & 47,61 & 48,24 & 47,63 & 46,44 & 48,01 & 50,31 & 47,37 & 51,11 \\
\hline $\begin{array}{c}\mathrm{O} 32-\mathrm{Cu}- \\
\mathrm{O} 35\end{array}$ & 52,02 & 62,39 & 56,30 & 62,70 & 60,89 & 62,34 & 61,63 & 62,17 & 44,44 \\
\hline O31-C5-C8 & 120,82 & 123,03 & 123,01 & 122,78 & 123,53 & 123,15 & 122,63 & 122,98 & 120,09 \\
\hline C6-N2-N3 & 126,14 & 122,72 & 122,94 & 123,13 & 121,71 & 122,56 & 125,36 & 123,82 & 126,66 \\
\hline N3-C5-O31 & 119,60 & 121,03 & 121,19 & 121,05 & 121,61 & 121,17 & 121,37 & 121,46 & 120,07 \\
\hline N3-C5-C8 & 119,58 & 115,89 & 115,75 & 116,11 & 114,84 & 115,64 & 115,98 & 115,51 & 119,84 \\
\hline C5-N3-N2 & 112,90 & 117,57 & 117,29 & 116,61 & 118,59 & 117,81 & 116,75 & 116,15 & 112,74 \\
\hline C7-C6-N2 & 111,79 & 115,06 & 114,75 & 114,80 & 115,11 & 115,01 & 114,21 & 114,43 & 112,42 \\
\hline N4-C7-C6 & 115,03 & 116,14 & 116,03 & 115,90 & 116,13 & 116,12 & 116,66 & 116,12 & 115,92 \\
\hline $\begin{array}{c}\mathrm{Cu}-\mathrm{O} 31- \\
\mathrm{C} 5-\mathrm{C} 8\end{array}$ & 178,94 & $-168,69$ & $-168,97$ & $-167,21$ & $-166,20$ & $-169,89$ & 178,20 & $-163,21$ & 177,82 \\
\hline $\begin{array}{c}\text { N3-C5-C8- } \\
\text { C17 }\end{array}$ & $-19,22$ & $-31,61$ & $-32,43$ & $-33,35$ & $-33,06$ & $-32,50$ & $-26,71$ & $-40,90$ & $-19,76$ \\
\hline $\begin{array}{c}\text { N3-N2-C6- } \\
\text { C7 }\end{array}$ & 177,57 & 176,89 & 176,74 & 176,79 & 179,42 & 176,85 & 177,78 & 175,78 & 176,36 \\
\hline
\end{tabular}




\begin{tabular}{|c|c|c|c|c|c|c|c|c|c|}
\hline $\begin{array}{c}\text { C15-C7- } \\
\text { C8-C17 }\end{array}$ & 28,01 & 22,76 & 24,31 & 24,08 & 47,58 & 23,65 & 17,80 & 32,48 & $\mathbf{2 8 , 2 2}$ \\
\hline RMSD** & & 0,569 & 0,572 & 0,583 & 0,620 & 0,568 & $\mathbf{0 , 4 2 6}$ & 0,652 & 0,743 \\
\hline
\end{tabular}

${ }^{*}[23]$, Valores em negrito correspondem aos mais próximos ao experimental, ** Ondas planas

Tabela 8.3. Comprimentos (angstrom) e ângulos (graus) de ligação selecionados para - complexo $\mu$-diacetatobis[(2-acetilpiridinabenzoil hidrazona)cobre(II) $\left[(\mathrm{Cu})_{2} \mu\left(\mathrm{CH} 3 \mathrm{COO}_{2}(\mathrm{HL})_{2}\right]\right.$.

\begin{tabular}{|c|c|c|c|c|c|c|c|c|c|}
\hline & Exp* & B3LYP & PBE1PBE & $\begin{array}{l}\text { CAM- } \\
\text { B3LYP }\end{array}$ & B97D & B3PW91 & M06 & wB97-XD & PW91*** \\
\hline $\mathrm{Cu}-\mathrm{O} 35$ & 1,958 & 1,957 & 1,940 & 1,924 & 1,964 & 1,951 & 1,930 & 1,917 & 1,958 \\
\hline $\mathrm{Cu}-\mathrm{O} 34$ & 2,856 & 2,707 & 2,681 & 2,720 & 2,914 & 2,665 & 2,722 & 2,752 & 2,855 \\
\hline $\mathrm{Cu} 1-\mathrm{Cu}{ }^{\prime}$ & 3,332 & 3,305 & 3,273 & 3,208 & 3,242 & 3,306 & & 3,159 & 3,332 \\
\hline $\mathrm{Cu}-\mathrm{O} 31$ & 1,964 & 2,099 & 2,084 & 2,060 & 2,119 & 2,098 & 3,175 & 2,046 & 1,964 \\
\hline N2-N3 & 1,379 & 1,340 & 1,331 & 1,347 & 1,333 & 1,332 & 1,336 & 1,347 & 1,378 \\
\hline N2-C6 & 1,280 & 1,304 & 1,300 & 1,290 & 1,318 & 1,303 & 1,297 & 1,291 & 1,280 \\
\hline N3-C5 & 1,323 & 1,349 & 1,344 & 1,336 & 1,366 & 1,347 & 1,347 & 1,341 & 1,323 \\
\hline C5-O31 & 1,295 & 1,273 & 1,266 & 1,270 & 1,278 & 1,268 & 1,266 & 1,268 & 1,294 \\
\hline C5-C8 & 1,479 & 1,490 & 1,484 & 1,489 & 1,492 & 1,487 & 1,481 & 1,490 & 1,479 \\
\hline N4-C7 & 1,353 & 1,355 & 1,348 & 1,347 & 1,366 & 1,351 & 1,351 & 1,349 & 1,353 \\
\hline N4-C9 & 1,339 & 1,331 & 1,326 & 1,326 & 1,337 & 1,328 & 1,325 & 1,327 & 1,340 \\
\hline C6-C7 & 1,483 & 1,472 & 1,467 & 1,478 & 1,468 & 1,467 & 1,468 & 1,480 & 1,483 \\
\hline $\begin{array}{l}\text { O34-Cu- } \\
\text { O35 }\end{array}$ & 49,88 & 53,98 & 54,28 & 53,55 & 115,18 & 54,67 & 53,62 & 52,94 & 49,88 \\
\hline $\begin{array}{l}\text { O31-Cu- } \\
\text { O34 }\end{array}$ & 97,83 & 98,27 & 98,49 & 99,18 & 97,79 & 97,20 & 103,79 & 99,55 & 100,90 \\
\hline $\begin{array}{l}\mathrm{O} 31-\mathrm{Cu}- \\
\mathrm{N} 2\end{array}$ & 79,59 & 77,21 & 77,42 & 77,95 & 77,01 & 77,15 & 78,49 & 78,39 & 79,58 \\
\hline $\begin{array}{l}\mathrm{N} 2-\mathrm{Cu}- \\
\mathrm{N} 4\end{array}$ & 80,20 & 78,75 & 79,20 & 79,25 & 79,30 & 78,96 & 80,30 & 79,92 & 80,18 \\
\hline $\begin{array}{l}\text { O31-C5- } \\
\text { C8 }\end{array}$ & 117,18 & 118,92 & 118,80 & 118,31 & 119,04 & 119,05 & 118,31 & 117,76 & 117,19 \\
\hline
\end{tabular}




\begin{tabular}{|l|l|l|l|l|l|l|l|l|l|}
\hline $\begin{array}{l}\text { C6-N2- } \\
\text { N3 }\end{array}$ & 123,13 & 123,14 & 123,13 & 123,16 & 123,84 & 122,94 & 124,46 & 123,77 & 123,44 \\
\hline $\begin{array}{l}\text { N3-C5- } \\
\text { O31 }\end{array}$ & 124,98 & 124,83 & 124,99 & 125,08 & 124,66 & 124,88 & 125,26 & 125,46 & 125,02 \\
\hline $\begin{array}{l}\text { N3-C5- } \\
\text { C8 }\end{array}$ & 117,84 & 116,25 & 116,20 & 116,61 & 116,29 & 116,08 & 116,41 & 116,76 & 117,78 \\
\hline $\begin{array}{l}\text { C5-N3- } \\
\text { N2 }\end{array}$ & 107,59 & 110,46 & 110,17 & 109,73 & 110,54 & 110,39 & 109,47 & 109,14 & 107,56 \\
\hline $\begin{array}{l}\text { C7-C6- } \\
\text { N2 }\end{array}$ & 112,89 & 115,02 & 114,84 & 114,73 & 114,83 & 114,93 & 114,62 & 114,39 & 112,92 \\
\hline $\begin{array}{l}\text { N4-C7- } \\
\text { C6 }\end{array}$ & 114,42 & 115,98 & 115,89 & 115,70 & 116,17 & 115,94 & 116,11 & 115,81 & 114,39 \\
\hline $\begin{array}{l}\text { Cu-O31- } \\
\text { C5-C8 }\end{array}$ & 179,54 & 177,88 & 176,86 & 175,95 & 171,75 & 177,80 & 170,78 & 169,83 & 179,53 \\
\hline $\begin{array}{l}\text { N3-C5- } \\
\text { C8-C17 }\end{array}$ & $-24,83$ & 6,37 & 5,32 & 5,28 & 2,36 & 7,64 & 5,342 & 2,844 & $-24,83$ \\
\hline $\begin{array}{l}\text { N3-N2- } \\
\text { C6-C7 }\end{array}$ & $-178,74$ & $-179,21$ & $-179,06$ & $-179,28$ & $-175,23$ & $-179,72$ & $-174,63$ & $-175,05$ & $-178,75$ \\
\hline $\begin{array}{l}\text { C15-C7- } \\
\text { C8-C17 }\end{array}$ & $-33,02$ & 5,62 & 3,305 & 3,52 & $-13,01$ & 8,26 & $-7,32$ & $-9,58$ & $-33,00$ \\
\hline \begin{tabular}{l} 
RMSD \\
\hline
\end{tabular} & & 0,396 & 0,397 & 0,414 & 0,548 & 0,410 & 0,626 & 0,600 & 0,031 \\
\hline
\end{tabular}

${ }^{*}[23]$, Valores em negrito correspondem aos mais próximos ao experimental, ** Ondas planas

Tabela 8.4. Comprimentos (angstrom) e ângulos (graus) de ligação selecionados para o complexo Bis(2-acetilpiridinabenzoilhidrazona)cobre(II) [(Cu)(HL)2].

\begin{tabular}{|c|c|c|c|c|c|c|c|c|c|}
\hline & Exp* & B3LYP & PBE1PBE & $\begin{array}{c}\text { CAM- } \\
\text { B3LYP }\end{array}$ & B97D & B3PW91 & M06 & wB97-XD & PW91** \\
\hline N2-N2' & 3,927 & 4,013 & 3,980 & 3,976 & 4,122 & 3,989 & 3,963 & 3,969 & $\mathbf{3 , 9 3 5}$ \\
\hline N4-N4' & 3,201 & 3,323 & 3,291 & 3,317 & 3,522 & 3,289 & 3,298 & 3,371 & $\mathbf{3 , 2 3 2}$ \\
\hline Cu-O31 & 2,133 & 2,152 & $\mathbf{2 , 1 3 9}$ & 2,070 & 2,300 & 2,148 & 2,159 & 2,138 & 2,347 \\
\hline N2-N3 & 1,377 & 1,342 & 1,332 & $\mathbf{1 , 3 4 5}$ & 1,327 & 1,334 & 1,334 & $\mathbf{1 , 3 4 5}$ & 1,342 \\
\hline N2-C6 & 1,292 & 1,308 & 1,304 & $\mathbf{1 , 2 9 3}$ & 1,323 & 1,307 & 1,304 & 1,296 & 1,312 \\
\hline N3-C5 & 1,340 & 1,356 & 1,352 & 1,293 & 1,380 & 1,354 & 1,358 & $\mathbf{1 , 3 4 8}$ & 1,354 \\
\hline C5-O31 & 1,261 & 1,263 & 1,257 & 1,264 & $\mathbf{1 , 2 6 0}$ & $\mathbf{1 , 2 6 0}$ & 1,253 & 1,257 & 1,259 \\
\hline C5-C8 & 1,495 & 1,493 & 1,487 & 1,489 & 1,499 & 1,489 & 1,486 & $\mathbf{1 , 4 9 3}$ & 1,485 \\
\hline N4-C7 & 1,342 & 1,355 & 1,348 & 1,346 & 1,365 & 1,351 & 1,348 & $\mathbf{1 , 3 4 5}$ & 1,348 \\
\hline
\end{tabular}




\begin{tabular}{|c|c|c|c|c|c|c|c|c|c|}
\hline N4-C9 & 1,333 & 1,332 & 1,327 & 1,327 & 1,338 & 1,329 & 1,326 & 1,329 & 1,323 \\
\hline C6-C7 & 1,474 & 1,469 & 1,464 & 1,474 & 1,463 & 1,465 & 1,464 & 1,476 & 1,451 \\
\hline $\begin{array}{c}\text { N2-Cu- } \\
\text { N2' }\end{array}$ & 175,23 & 179,37 & 178,74 & 177,57 & 170,17 & 178,79 & 172,62 & 172,26 & 178,23 \\
\hline $\begin{array}{l}\text { N2-Cu- } \\
\text { N4' }\end{array}$ & 99,92 & 103,68 & 101,83 & 101,75 & 96,73 & 103,73 & 96,99 & 97,61 & 99,97 \\
\hline $\begin{array}{c}\mathrm{O} 31-\mathrm{Cu}- \\
\mathrm{N} 2\end{array}$ & 76,57 & 76,46 & 76,52 & 77,54 & 73,18 & 76,50 & 76,42 & 76,64 & 74,70 \\
\hline $\begin{array}{c}\mathrm{N} 2-\mathrm{Cu}- \\
\mathrm{N} 4\end{array}$ & 77,65 & 76,77 & 77,34 & 77,85 & 77,42 & 77,11 & 78,03 & 77,28 & 77,42 \\
\hline $\begin{array}{c}\text { O31-C5- } \\
\text { C8 }\end{array}$ & 119,53 & 119,21 & 119,16 & 118,71 & 120,32 & 119,23 & 119,50 & 118,99 & 126,62 \\
\hline $\begin{array}{c}\text { C6-N2- } \\
\text { N3 }\end{array}$ & 119,95 & 121,17 & 121,16 & 121,98 & 122,11 & 121,11 & 121,64 & 121,14 & 113,26 \\
\hline $\begin{array}{c}\text { N3-C5- } \\
\text { O31 }\end{array}$ & 126,02 & 125,23 & 125,38 & 125,10 & 125,03 & 125,28 & 125,59 & 125,74 & 126,62 \\
\hline $\begin{array}{c}\text { N3-C5- } \\
\text { C8 }\end{array}$ & 114,44 & 115,56 & 115,46 & 116,19 & 114,64 & 115,49 & 114,91 & 115,25 & 113,86 \\
\hline $\begin{array}{c}\text { C5-N3- } \\
\text { N2 }\end{array}$ & 108,57 & 111,04 & 110,65 & 109,81 & 112,12 & 110,93 & 110,62 & 110,31 & 113,26 \\
\hline $\begin{array}{c}\text { C7-C6- } \\
\text { N2 }\end{array}$ & 114,10 & 116,21 & 115,92 & 115,19 & 115,79 & 116,08 & 116,08 & 115,74 & 115,89 \\
\hline $\begin{array}{c}\text { N4-C7- } \\
\text { C6 }\end{array}$ & 114,81 & 116,94 & 116,78 & 116,26 & 116,83 & 116,91 & 116,71 & 116,36 & 116,28 \\
\hline $\begin{array}{c}\mathrm{Cu}-\mathrm{O} 31- \\
\mathrm{C} 5-\mathrm{C} 8\end{array}$ & 167,55 & 179,12 & 179,93 & 179,79 & $-168,40$ & 178,85 & $-176,76$ & $-173,28$ & $-175,80$ \\
\hline $\begin{array}{l}\text { N3-C5- } \\
\text { C8-C17 }\end{array}$ & $-28,44$ & $-0,95$ & $-0,43$ & $-0,81$ & $-0,91$ & $-1,04$ & $-0,39$ & 2,59 & 1,16 \\
\hline $\begin{array}{l}\text { N3-N2- } \\
\text { C6-C7 }\end{array}$ & 174,06 & 179,82 & 179,84 & 179,81 & 178,14 & 179,94 & 179,19 & 177,97 & 176,94 \\
\hline $\begin{array}{l}\text { C15-C7- } \\
\text { C8-C17 }\end{array}$ & $-32,38$ & $-6,97$ & $-6,90$ & $-7,99$ & $-13,39$ & $-6,43$ & $-9,22$ & $-12,64$ & $-1,80$ \\
\hline RMSD & & 0,437 & 0,455 & 0,375 & 0,360 & 0,286 & 0,392 & 0,323 & $\mathbf{0 , 0 2 7}$ \\
\hline
\end{tabular}

*[23], Valores em negrito correspondem aos mais próximos ao experimental, ** Ondas planas 
Tabela 8.5. Comprimentos (angstrom) e ângulos (graus) de ligação selecionados para o complexo $\mu$-sulfatobis[(2-acetilpiridinabenzoilhidrazona)cobre(I)] [Cu $2\left(\mathrm{HL}_{2}\left(\mathrm{SO}_{4}\right)\right]$.

\begin{tabular}{|c|c|c|c|c|c|c|c|c|c|}
\hline & Exp* & B3LYP & PBE1PBE & $\begin{array}{c}\text { CAM- } \\
\text { B3LYP }\end{array}$ & B97D & B3PW91 & M06 & wB97-XD & PW91** \\
\hline $\mathrm{Cu}-\mathrm{O} 33$ & 3,390 & 3,467 & 3,249 & 3,322 & 3,443 & 3,424 & 3,340 & 3,332 & 3,313 \\
\hline $\mathrm{Cu}-\mathrm{O} 34$ & 1,897 & 1,905 & 1,892 & 1,922 & 1,931 & 1,898 & 1,889 & 1,878 & 1,912 \\
\hline $\mathrm{Cu}-\mathrm{S}$ & 3,039 & 3,057 & 3,044 & 3,048 & 3,027 & 3,028 & 2,962 & 2,991 & 3,027 \\
\hline S-O34 & 1,500 & 1,560 & 1,550 & 1,500 & 1,575 & 1,553 & 1,547 & 1,552 & 1,511 \\
\hline $\begin{array}{l}\text { O34-S- } \\
\text { O33 }\end{array}$ & 107,11 & 104,69 & 104,53 & 107,11 & 105,57 & 104,63 & 104,63 & 103,86 & 106,09 \\
\hline $\mathrm{Cu}-\mathrm{Cu}$ ' & 3,168 & 3,185 & 3,068 & 3,167 & 3,200 & 3,124 & 3,036 & 2,988 & 3,123 \\
\hline $\mathrm{Cu}-\mathrm{O} 31$ & 1,307 & 2,046 & 2,048 & 1,986 & 2,100 & 2,044 & 2,047 & 2,027 & 1,954 \\
\hline N2-N3 & 1,387 & 1,346 & 1,336 & 1,367 & 1,340 & 1,338 & 1,342 & 1,355 & 1,381 \\
\hline N2-C6 & 1,294 & 1,300 & 1,296 & 1,290 & 1,313 & 1,299 & 1,295 & 1,287 & 1,293 \\
\hline N3-C5 & 1,321 & 1,341 & 1,335 & 1,302 & 1,356 & 1,339 & 1,337 & 1,325 & 1,330 \\
\hline C5-O31 & 1,307 & 1,285 & 1,281 & 1,309 & 1,288 & 1,281 & 1,278 & 1,286 & 1,327 \\
\hline C5-C8 & 1,472 & 1,487 & 1,480 & 1,469 & 1,489 & 1,483 & 1,480 & 1,486 & 1,482 \\
\hline N4-C7 & 1,354 & 1,385 & 1,349 & 1,349 & 1,367 & 1,354 & 1,351 & 1,349 & 1,396 \\
\hline N4-C9 & 1,313 & 1,332 & 1,326 & 1,314 & 1,339 & 1,329 & 1,327 & 1,329 & 1,356 \\
\hline C6-C7 & 1,463 & 1,475 & 1,471 & 1,502 & 1,470 & 1,471 & 1,470 & 1,481 & 1,512 \\
\hline $\begin{array}{l}\text { O33-Cu- } \\
\text { O34 }\end{array}$ & 43,70 & 43,76 & 48,63 & 45,58 & 45,77 & 44,48 & 46,29 & 46,11 & 45,93 \\
\hline $\begin{array}{l}\text { O31-Cu- } \\
\text { O34 }\end{array}$ & 101,30 & 100,22 & 109,61 & 100,49 & 101,45 & 100,22 & 100,54 & 100,05 & 100,48 \\
\hline $\begin{array}{l}\mathrm{O} 31-\mathrm{Cu}- \\
\mathrm{N} 2\end{array}$ & 80,17 & 77,75 & 77,41 & 79,32 & 76,63 & 77,77 & 77,78 & 78,01 & 81,31 \\
\hline $\begin{array}{l}\mathrm{N} 2-\mathrm{Cu}- \\
\mathrm{N} 4\end{array}$ & 81,62 & 79,41 & 78,96 & 81,75 & 79,30 & 79,67 & 80,13 & 79,69 & 80,55 \\
\hline $\begin{array}{l}\text { O31-C5- } \\
\text { C8 }\end{array}$ & 118,20 & 118,37 & 118,17 & 117,01 & 118,48 & 118,54 & 118,23 & 117,50 & 120,24 \\
\hline C6-N2-N3 & 123,50 & 124,06 & 123,35 & 122,72 & 123,73 & 123,95 & 124,21 & 123,48 & 122,05 \\
\hline $\begin{array}{l}\text { N3-C5- } \\
\text { O31 }\end{array}$ & 124,89 & 116,92 & 124,96 & 125,33 & 124,78 & 124,73 & 125,10 & 125,22 & 121,42 \\
\hline
\end{tabular}




\begin{tabular}{|l|c|c|c|c|c|c|c|c|c|}
\hline N3-C5-C8 & 116,92 & $\mathbf{1 1 6 , 9 2}$ & 116,87 & 117,66 & 116,73 & 116,73 & 116,64 & 117,27 & 118,34 \\
\hline N2-N3-C5 & 106,94 & 109,68 & 109,57 & $\mathbf{1 0 7 , 6 3}$ & 109,96 & 109,64 & 109,35 & 108,93 & 111,69 \\
\hline C7-C6-N2 & 112,21 & 114,15 & 113,91 & $\mathbf{1 1 2 , 8 9}$ & 114,08 & 114,00 & 114,04 & 113,85 & 107,42 \\
\hline N4-C7-C6 & 115,65 & 115,93 & $\mathbf{1 1 5 , 7 0}$ & 113,91 & 116,28 & 115,85 & 115,89 & 115,50 & 118,16 \\
\hline N2-C6-N4 & 81,89 & 83,60 & 83,35 & $\mathbf{8 3 , 2 5}$ & 83,53 & 83,42 & 83,51 & 83,30 & \\
\hline $\begin{array}{l}\text { Cu-O31- } \\
\text { C5-C8 }\end{array}$ & 179,56 & 178,89 & 178,99 & $\mathbf{1 7 9 , 4 5}$ & 174,51 & 179,93 & 175,07 & 176,07 & 179,26 \\
\hline $\begin{array}{l}\text { N3-C5- } \\
\text { C8-C17 }\end{array}$ & 13,63 & 6,45 & 13,00 & 0,01 & 7,07 & 8,48 & 9,05 & $\mathbf{1 3 , 1 1}$ & 1,56 \\
\hline $\begin{array}{l}\text { N3-N2- } \\
\text { C6-C7 }\end{array}$ & 179,12 & 178,46 & 179,59 & 178,22 & 174,15 & $\mathbf{1 7 9 , 2 5}$ & 173,90 & 175,96 & 178,22 \\
\hline $\begin{array}{l}\text { C15-C7- } \\
\text { C8-C17 }\end{array}$ & 8,68 & 5,92 & 5,99 & 7,30 & 2,32 & $\mathbf{9 , 3 6}$ & 0,94 & 3,41 & 7,40 \\
\hline \begin{tabular}{l} 
RMSD \\
\hline
\end{tabular} & & 0,499 & 0,450 & 0,404 & 0,444 & 0,487 & 0,394 & $\mathbf{0 , 3 8 4}$ & $\mathbf{0 , 0 6 1}$ \\
\hline
\end{tabular}

${ }^{*}[23]$, Valores em negrito correspondem aos mais próximos ao experimental, ** Ondas planas

\subsection{Figuras}




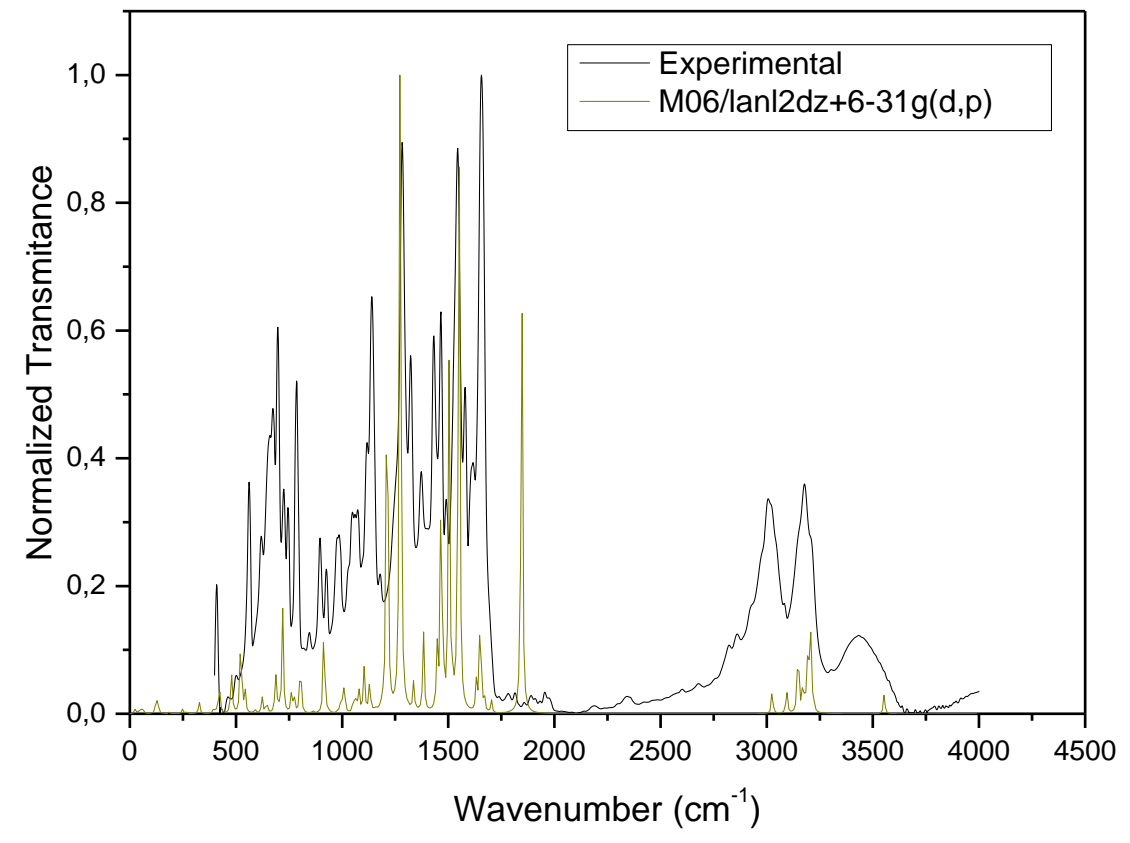

Figura 8.1. Comparação entre o espectro de infravermelho experimental (linha preta) e o seu análogo calculado (linhas amarelo escuro), do ligante (HL), usando o funcional MO6, associado aos conjuntos de bases LANL2DZ para o cobre e 6-31g(d,p) para os demais átomos. 


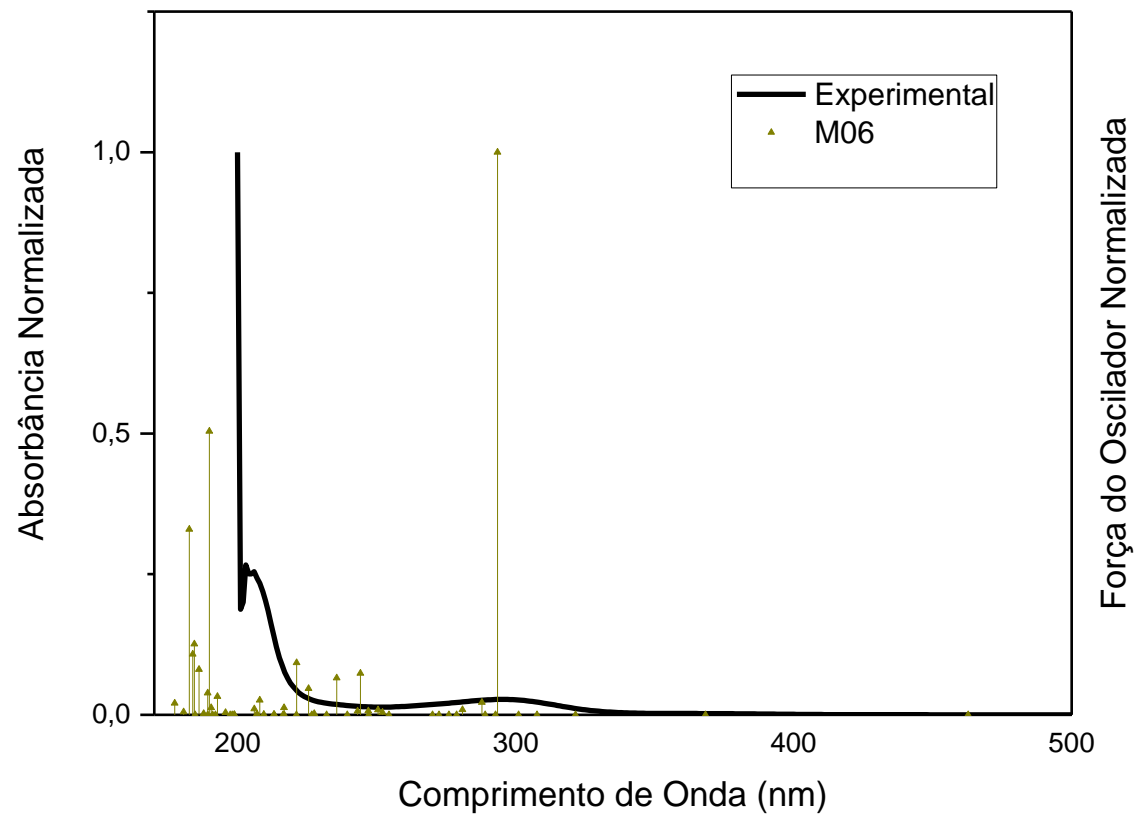

Figura 8.2. Espectro eletrônico experimental e teórico m06/LANL2DZ+6-31g(d,p) no qual a linha continua em preto é o espectro teórico e cada linha vertical amarelo escuro corresponde a uma excitação eletrônica calculada para o complexo (HL). 


\section{Capítulo 9 - Referências Bibliográficas}

[1]. Bakale, R. P.; Pathan, A. H.; Naik, G. N.; Machakanur, S. S.; Mangannavar, C. V.; Muchchandi, I. S.; Gudasi, K. B., Applied Organometallic Chemistry 2014, 28, 720.

[2]. Gudasi, K. B.; Patil, S. A.; Vadavi, R. S.; Shenoy, R. V.; Nethaji, M.; Bligh, S. W. A., Inorganica Chimica Acta 2006, 359, 3229.

[3]. Narang, R.; Narasimhan, B.; Sharma, S., Current Medicinal Chemistry 2012, 19, 569.

[4]. Ros, A.; Diez, E.; Marques-Lopez, E.; Martin-Zamora, E.; Vazquez, J.; IglesiasSiguenza, J.; Pappalardo, R. R.; Alvarez, E.; Lassaletta, J. M.; Fernandez, R., Tetrahedron-Asymmetry 2008, 19, 998.

[5]. Veljkovic, J.; Sekutor, M.; Molcanov, K.; Lo, R.; Ganguly, B.; Mlinaric-Majerski, K., Journal of Molecular Structure 2011, 997, 46.

[6]. Patole, J.; Sandbhor, U.; Padhye, S.; Deobagkar, D. N.; Anson, C. E.; Powell, A., Bioorganic \& Medicinal Chemistry Letters 2003, 13, 51.

[7]. Zhao, Y.; Truhlar, D., Theor Chem Account 2008, 120, 215.

[8]. Jacquemin, D.; Wathelet, V.; Perpete, E. A.; Adamo, C., Journal of Chemical Theory and Computation 2009, 5, 2420.

[9]. Jiang, K. Z.; Bian, G. F.; Qiu, H. Y.; Pan, Y. J.; Lai, G. Q., Journal of Physical Chemistry A 2009, 113, 697.

[10]. Ang, W. H.; Khalaila, I.; Allardyce, C. S.; Juillerat-Jeanneret, L.; Dyson, P. J., Journal of the American Chemical Society 2005, 127, 1382.

[11]. negi, v. j., International Journal of Pharmaceutical Chemistry; Vol 2, No 4 (2012): OctDec 2013.

[12]. Abou-Seri, S. M., Eur J Med Chem 2010, 45, 4113.

[13]. el-Sabbagh, O. I.; Rady, H. M., Eur J Med Chem 2009, 44, 3680.

[14]. Reis, R. D.; Azevedo, E. C.; de Souza, M. C. B. V.; Ferreira, V. F.; Montenegro, R. C.; Araujo, A. J.; Pessoa, C.; Costa-Lotufo, L. V.; de Moraes, M. O.; Filho, J. D. B. M.; de Souza, A. M. T.; de Carvalho, N. C.; Castro, H. C.; Rodrigues, C. R.; Vasconcelos, T. R. A., European Journal of Medicinal Chemistry 2011, 46, 1448.

[15]. Rollas, S.; Kucukguzel, S. G., Molecules 2007, 12, 1910.

[16]. Verma, G.; Marella, A.; Shaquiquzzaman, M.; Akhtar, M.; Ali, M. R.; Alam, M. M., Journal of Pharmacy \& Bioallied Sciences 2014, 6, 69. 
[17]. Chimenti, F.; Maccioni, E.; Secci, D.; Bolasco, A.; Chimenti, P.; Granese, A.; Carradori, S.; Alcaro, S.; Ortuso, F.; Yanez, M.; Orallo, F.; Cirilli, R.; Ferretti, R.; La Torre, F., Journal of Medicinal Chemistry 2008, 51, 4874.

[18]. Sharma, R. N.; Sharma, K. P.; Dixit, S. N., Asian Journal of Chemistry 2010, 22, 7683.

[19]. Nenaidenko, V. G.; Korotchenko, V. N.; Shastin, A. V.; Tyurin, D. A.; Balenkova, E. S., Russian Journal of Organic Chemistry 2004, 40, 1750.

[20]. Simeonov, M. F.; Fulop, F.; Sillanpaa, R.; Pihlaja, K., Journal of Organic Chemistry 1997, 62, 5089.

[21]. Evranos-Aksoz, B.; Yabanoglu-Ciftci, S.; Ucar, G.; Yelekci, K.; Ertan, R., Bioorganic \& Medicinal Chemistry Letters 2014, 24, 3278.

[22]. Francisco, A. I.; Vargas, M. D.; Fragoso, T. P.; Carneiro, J. W. D.; Casellato, A.; da Silva, F. D.; Ferreira, V. F.; Barbosa, J. P.; Pessoa, C.; Costa-Lotufo, L. V.; Marinho, J. D. B.; de Moraes, M. O.; Mangrich, A. S., Journal of the Brazilian Chemical Society 2010, 21, 1293.

[23]. Gatto, C. C., et al, Unpublished Data 2015.

[24]. Prabhakaran, R.; Huang, R.; Renukadevi, S. V.; Karvembu, R.; Zeller, M.; Natarajan, K., Inorganica Chimica Acta 2008, 361, 2547.

[25]. Naskar, S.; Corbella, M.; Blake, A. J.; Chattopadhyay, S. K., Dalton Transactions 2007, 1150.

[26]. Saadeh, S. M., Arabian Journal of Chemistry 2013, 6, 191.

[27]. Singh, R. N.; Rawat, P.; Kumar, A., Journal of Molecular Structure 2014, 1074, 738.

[28]. Stadler, A. M.; Harrowfield, J., Inorganica Chimica Acta 2009, 362, 4298.

[29]. Gatto, C. C.; Lang, E. S.; Burrow, R. A.; Abram, U., Journal of the Brazilian Chemical Society 2006, 17, 1612.

[30]. Gatto, C. C.; Lang, E. S.; Kupfer, A.; Hagenbach, A.; Abram, U., Zeitschrift Fur Anorganische Und Allgemeine Chemie 2004, 630, 1286.

[31]. Gatto, C. C.; Lang, E. S.; Kupfer, A.; Hagenbach, A.; Wille, D.; Abram, U., Zeitschrift Fur Anorganische Und Allgemeine Chemie 2004, 630, 735.

[32]. Pavan, F. R.; Maia, P. I. D.; Leite, S. R. A.; Deflon, V. M.; Batista, A. A.; Sato, D. N.; Franzblau, S. G.; Leite, C. Q. F., European Journal of Medicinal Chemistry 2010, 45, 1898.

[33]. Aly, H. M., Monatshefte Fur Chemie 2011, 142, 935. 
[34]. Bernhardt, P. V.; Wilson, G. J.; Sharpe, P. C.; Kalinowski, D. S.; Richardson, D. R., Journal of Biological Inorganic Chemistry 2008, 13, 107.

[35]. Bernhardt, P. V.; Mattsson, J.; Richardson, D. R., Inorganic Chemistry 2006, 45, 752.

[36]. Bottoni, A.; Frenna, V.; Lanza, C. Z.; Macaluso, G.; Spinelli, D., Journal of Physical Chemistry A 2004, 108, 1731.

[37]. Ledesma, G. N.; Gonzalez Sierra, M.; Escandar, G. M., Polyhedron 1998, 17, 1517.

[38]. Ozbek, N.; Kavak, G.; Ozcan, Y.; Ide, S.; Karacan, N., Journal of Molecular Structure 2009, 919, 154.

[39]. Zhang, J. G.; Zhang, L.; Wei, Y. L.; Chao, J. B.; Shuang, S. M.; Cai, Z. W.; Dong, C., Spectrochimica Acta Part a-Molecular and Biomolecular Spectroscopy 2014, 132, 191.

[40]. Bertini, I.; Pierattelli, R., Pure and Applied Chemistry 2004, 76, 321.

[41]. Sedaghat, T.; Yousefi, M.; Bruno, G.; Rudbari, H. A.; Motamedi, H.; Nobakht, V., Polyhedron 2014, 79, 88.

[42]. Seleem, H. S.; El-Inany, G. A.; El-Shetary, B. A.; Mousa, M. A., Chemistry Central Journal 2011, 5.

[43]. Senthil Raja, D.; Bhuvanesh, N. S. P.; Natarajan, K., European Journal of Medicinal Chemistry 2012, 47, 73.

[44]. Siddappa, K.; Mayana, N. S., Bioinorganic Chemistry and Applications 2014, 2014, 483282.

[45]. Zhang, L.; Zhang, X. H., Spectrochimica Acta Part a-Molecular and Biomolecular Spectroscopy 2014, 133, 54.

[46]. Bryleva, M. A.; Kravtsova, A. N.; Shcherbakov, I. N.; Levchenkov, S. I.; Popov, L. D.; Kogan, V. A.; Tupolova, Y. P.; Zubavichus, Y. V.; Trigub, A. L.; Soldatov, A. V., Journal of Structural Chemistry 2012, 53, 295.

[47]. Dragancea, D.; Addison, A. W.; Zeller, M.; Foster, M. E.; Prushan, M. J.; Thompson, L. K.; Revenco, M. D.; Hunter, A. D., Inorganica Chimica Acta 2010, 363, 2065.

[48]. Duncan, C.; White, A. R., Metallomics 2012, 4, 127.

[49]. Khanmohammadi, H.; Erfantalab, M.; Azimi, G., Spectrochimica Acta Part a-Molecular and Biomolecular Spectroscopy 2013, 105, 338.

[50]. Krishnamoorthy, P.; Sathyadevi, P.; Senthilkumar, K.; Muthiah, P. T.; Ramesh, R.; Dharmaraj, N., Inorganic Chemistry Communications 2011, 14, 1318. 
[51]. Mukherjee, S.; Basu, C.; Chowdhury, S.; Chattopadhyay, A. P.; Ghorai, A.; Ghosh, U.; Stoeckli-Evans, H., Inorganica Chimica Acta 2010, 363, 2752.

[52]. Ray, A.; Rizzoli, C.; Pilet, G.; Desplanches, C.; Garribba, E.; Rentschler, E.; Mitra, S., European Journal of Inorganic Chemistry 2009, 2915.

[53]. Ray, S.; Konar, S.; Jana, A.; Das, K.; Butcher, R. J.; Mondal, T. K.; Kar, S. K., Polyhedron 2013, 50, 51.

[54]. Zhang, L.; Xu, G. C.; Xu, H. B.; Mereacre, V.; Wang, Z. M.; Powell, A. K.; Gao, S., Dalton Transactions 2010, 39, 4856.

[55]. Kogan, V. A.; Lukov, V. V., Russian Journal of Coordination Chemistry 2004, 30, 205.

[56]. Eisberg, R., Resnick, R., , Física Quântica - Átomos, Moléculas, Sólidos, Núcleos e Partículas., Rio de Janeiro, 1979.

[57]. Levine, I. N., Quantum Chemistry, 4th ed., Prentice-Hall International, 1991.

[58]. Capelle, K., A bird's-eye view of density-functional theory, Escola Brasileira de Estrutura Eletrônica, Juiz de Fora, 2002.

[59]. Koch, W., Holthausen, M.C., , A Chemist's Guide to Density Functional Theory, New York, 2001.

[60]. Marques, M. A. L.; Gross, E. K. U., Annual Review of Physical Chemistry 2004, 55, 427.

[61]. Parr, R. G., Yang, W., , Density functional theory of atoms and molecules, New York, 1989.

[62]. Ziegler, T., Chemical Reviews 1991, 91, 651.

[63]. Perdew, J. P.; Zunger, A., Physical Review B 1981, 23, 5048.

[64]. Chen, Y. Y.; Wang, L.; Zhang, L.; Zhu, J.; Wang, H.; Zhang, D. W.; Li, Z. T., Tetrahedron 2014, 70, 5483.

[65]. Reimers, J. R.; Cai, Z.-L.; Bilić, A.; Hush, N. S., Annals of the New York Academy of Sciences 2003, 1006, 235.

[66]. Ciofini, I.; Adamo, C.; Chermette, H., Chemical Physics 2005, 309, 67.

[67]. Zhao, Y.; Truhlar, D. G., Accounts of Chemical Research 2008, 41, 157.

[68]. Zhao, Y.; Schultz, N. E.; Truhlar, D. G., Journal of Chemical Theory and Computation 2006, 2, 364.

[69]. Scuseria, G. E., Staroverov, V.N., , Theory and Applications of Computational Chemistry: The First 40 Years (A Volume of Technical and Historical Perspectives), Elsevier ed., Amsterdam, 2005. 
[70]. Grimme, S., Journal of Computational Chemistry 2006, 27, 1787.

[71]. Zhao, Y.; Schultz, N. E.; Truhlar, D. G., The Journal of Chemical Physics 2005, 123, 161103.

[72]. Horbatsch, M.; Dreizler, R. M., Z Physik A 1981, 300, 119.

[73]. Holzwarth, G., Physics Letters B 1977, 66, 29.

[74]. Runge, E.; Gross, E. K. U., Physical Review Letters 1984, 52, 997.

[75]. Kresse, G.; Hafner, J., Physical Review B 1993, 47, 558.

[76]. Kresse, G.; Hafner, J., Physical Review B 1994, 49, 14251.

[77]. Kresse, G.; Furthmüller, J., Computational Materials Science 1996, 6, 15.

[78]. Kresse, G.; Furthmüller, J., Physical Review B 1996, 54, 11169.

[79]. Perdew, J. P.; Burke, K.; Ernzerhof, M., Physical Review Letters 1996, 77, 3865.

[80]. Kresse, G.; Joubert, D., Physical Review B 1999, 59, 1758.

[81]. Blöchl, P. E., Physical Review B 1994, 50, 17953.

[82]. Frisch, M. J.; Trucks, G. W.; Schlegel, H. B.; Scuseria, G. E.; Robb, M. A.; Cheeseman, J. R.; Scalmani, G.; Barone, V.; Mennucci, B.; Petersson, G. A.; Nakatsuji, H.; Caricato, M.; Li, X.; Hratchian, H. P.; Izmaylov, A. F.; Bloino, J.; Zheng, G.; Sonnenberg, J. L.; Hada, M.; Ehara, M.; Toyota, K.; Fukuda, R.; Hasegawa, J.; Ishida, M.; Nakajima, T.; Honda, Y.; Kitao, O.; Nakai, H.; Vreven, T.; J. A. Montgomery, J.; Peralta, J. E.; Ogliaro, F.; Bearpark, M.; Heyd, J. J.; Brothers, E.; Kudin, K. N.; Staroverov, V. N.; Kobayashi, R.; Normand, J.; Raghavachari, K.; Rendell, A.; Burant, J. C.; lyengar, S. S.; Tomasi, J.; Cossi, M.; Rega, N.; Millam, J. M.; Klene, M.; Knox, J. E.; Cross, J. B.; Bakken, V.; Adamo, C.; Jaramillo, J.; Gomperts, R.; Stratmann, R. E.; Yazyev, O.; Austin, A. J.; Cammi, R.; Pomelli, C.; Ochterski, J. W.; Martin, R. L.; Morokuma, K.; Zakrzewski, V. G.; Voth, G. A.; Salvador, P.; Dannenberg, J. J.; Dapprich, S.; Daniels, A. D.; Farkas, O.; Foresman, J. B.; Ortiz, J. V.; Cioslowski, J.; Fox, D. J., Gaussian, Inc., Wallingford CT, 2009.

[83]. Giordano, T. J.; Palenik, G. J.; Palenik, R. C.; Sullivan, D. A., Inorganic Chemistry 1979, 18, 2445.

[84]. Barbazan, P.; Carballo, R.; Vazquez-Lopez, E. M., Crystengcomm 2007, 9, 668.

[85]. Sen, S.; Mitra, S.; Hughes, D. L.; Rosair, G.; Desplanches, C., Polyhedron 2007, 26, 1740.

[86]. Vrdoljak, V.; Pisk, J.; Agustin, D.; Novak, P.; Parlov Vukovic, J.; Matkovic-Calogovic, D., New Journal of Chemistry 2014, 38, 6176. 
[87]. Abran, A.; Csampai, A.; Kotschy, A.; Barabas, O.; Sohar, P., Journal of Molecular Structure 2001, 569, 185.

[88]. Figueroa, W.; Fuentealba, M.; Manzur, C.; Carrillo, D.; Vega, A. I.; Saillard, J. Y.; Hamon, J. R., Organometallics 2004, 23, 2515.

[89]. Langa, F.; de la Cruz, P.; Delgado, J. L.; Haley, M. M.; Shirtcliff, L.; Alkorta, I.; Elguero, J., Journal of Molecular Structure 2004, 699, 17.

[90]. Tamasi, G.; Chiasserini, L.; Savini, L.; Sega, A.; Cini, R., Journal of Inorganic Biochemistry 2005, 99, 1347.

[91]. Raspopova, E. A.; Popov, L. D.; Morozov, A. N.; Shcherbakov, I. N.; Kogan, V. A.; Levchenkov, S. I., Russian Journal of General Chemistry 2008, 78, 1586.

[92]. Liu, T.; Zhang, H. X.; Zhou, X.; Xia, B. H., European Journal of Inorganic Chemistry 2008, 1268.

[93]. Aggarwal, N.; Kumar, R.; Srivastva, C.; Dureja, P.; Khurana, J. M., Journal of Agricultural and Food Chemistry 2010, 58, 3056.

[94]. Despaigne, A. A. R.; Da Silva, J. G.; do Carmo, A. C. M.; Piro, O. E.; Castellano, E. E.; Beraldo, H., Inorganica Chimica Acta 2009, 362, 2117.

[95]. Despaigne, A. A. R.; Vieira, L. F.; Mendes, I. C.; da Costa, F. B.; Speziali, N. L.; Beraldo, H., Journal of the Brazilian Chemical Society 2010, 21, 1247.

[96]. Sen, S.; Mitra, S.; Hughes, D. L.; Rosair, G.; Desplanches, C., Inorganica Chimica Acta 2007, 360, 4085.

[97]. Addison, A. W.; Rao, T. N.; Reedijk, J.; Vanrijn, J.; Verschoor, G. C., Journal of the Chemical Society-Dalton Transactions 1984, 1349.

[98]. Bikas, R.; Hosseini-Monfared, H.; Zoppellaro, G.; Herchel, R.; Tucek, J.; Owczarzak, A. M.; Kubicki, M.; Zboril, R., Dalton Transactions 2013, 42, 2803.

[99]. Das, K.; Datta, A.; Sinha, C.; Huang, J.-H.; Garribba, E.; Hsiao, C.-S.; Hsu, C.-L., ChemistryOpen 2012, 1, 80.

[100]. Despaigne, A. A. R.; Parrilha, G. L.; Izidoro, J. B.; da Costa, P. R.; dos Santos, R. G.; Piro, O. E.; Castellano, E. E.; Rocha, W. R.; Beraldo, H., European Journal of Medicinal Chemistry 2012, 50, 163.

[101]. Backes, G. L.; Neumann, D. M.; Jursic, B. S., Bioorganic \& Medicinal Chemistry 2014, 22, 4629.

[102]. Kandil, F.; Chebani, M. K.; Al Zoubi, W., ISRN organic chemistry 2012, 2012, 208284. 
[103]. Riley, K. E.; Vondrasek, J.; Hobza, P., Physical Chemistry Chemical Physics 2007, 9, 5555.

[104]. Burke, K., Journal of Chemical Physics 2012, 136.

[105]. Burns, L. A.; Vazquez-Mayagoitia, A.; Sumpter, B. G.; Sherrill, C. D., Journal of Chemical Physics 2011, 134.

[106]. Foresman, J. B.; Keith, T. A.; Wiberg, K. B.; Snoonian, J.; Frisch, M. J., The Journal of Physical Chemistry 1996, 100, 16098.

[107]. Raman, N.; Ravichandran, S.; Thangaraja, C., Journal of Chemical Sciences 2004, $116,215$.

[108]. Dos Santos, N. V.; Silva, A. F.; Oliveira, V. X.; Homem-de-Mello, P.; Cerchiaro, G., Journal of Inorganic Biochemistry 2012, 114, 1.

[109]. Kovarikova, P.; Vavrova, K.; Tomalova, K.; Schongut, M.; Hruskova, K.; Haskova, P.; Klimes, J., J Pharm Biomed Anal 2008, 48, 295.

[110]. Basak, S.; Chopra, D.; Rajak, K. K., Journal of Organometallic Chemistry 2008, 693, 2649.

[111]. Becke, A. D., Journal of Chemical Physics 2014, 140.

[112]. Datta, A.; Chuang, N.-T.; Wen, Y.-S.; Huang, J.-H.; Sheu, S.-C., Acta Crystallographica Section E: Structure Reports Online 2011, 67, m1388.

[113]. Hsu, Y.-F.; Lin, C.-H.; Chen, J.-D.; Wang, J.-C., Crystal Growth \& Design 2008, 8, 1094.

[114]. Mangalam, N. A.; Sivakumar, S.; Sheeja, S. R.; Kurup, M. R. P.; Tiekink, E. R. T., Inorganica Chimica Acta 2009, 362, 4191.

[115]. Zink, D. M.; Grab, T.; Baumann, T.; Nieger, M.; Barnes, E. C.; Klopper, W.; Brase, S., Organometallics 2011, 30, 3275.

[116]. Spielberg, E. T.; Fittipaldi, M.; Geibig, D.; Gatteschi, D.; Plass, W., Inorganica Chimica Acta 2010, 363, 4269.

[117]. Hagrman, D.; Hammond, R. P.; Haushalter, R.; Zubieta, J., Chemistry of Materials 1998, 10, 2091.

[118]. Bernhardt, P. V.; Caldwell, L. M.; Chaston, T. B.; Chin, P.; Richardson, D. R., Journal of Biological Inorganic Chemistry 2003, 8, 866.

[119]. Jang, Y. J.; Lee, U.; Koo, B. K., Bulletin of the Korean Chemical Society 2005, 26, 925.

[120]. Trzesowska-Kruszynska, A., Journal of Molecular Structure 2012, 1017, 72. 
[121]. Angelusiu, M. V.; Barbuceanu, S.-F.; Draghici, C.; Almajan, G. L., European Journal of Medicinal Chemistry 2010, 45, 2055.

[122]. Shit, S.; Chakraborty, J.; Samanta, B.; Slawin, A. M. Z.; Gramlich, V.; Mitra, S., Structural Chemistry 2009, 20, 633.

[123]. Grimme, S., Wiley Interdisciplinary Reviews: Computational Molecular Science 2011, 1, 211.

[124]. Khalaji, A.; Nikookar, M.; Das, D., J Therm Anal Calorim 2014, 115, 409.

[125]. Shrestha, S.; Maharjan, S., Journal of Nepal Chemical Society; Vol 29 (2012) 2013.

[126]. Aljahdali, M.; El-Sherif, A. A., Inorganica Chimica Acta 2013, 407, 58.

[127]. Iwasaki, Y.; Kimura, M.; Yamada, A.; Mutoh, Y.; Tateishi, M.; Arii, H.; Kitamura, Y.; Chikira, M., Inorganic Chemistry Communications 2011, 14, 1461.

[128]. Taha, A.; Emara, A. A. A.; Mashaly, M. M.; Adly, O. M. I., Spectrochimica Acta Part a-Molecular and Biomolecular Spectroscopy 2014, 130, 429.

[129]. Adly, O. M. I.; Emara, A. A. A., Spectrochimica Acta Part a-Molecular and Biomolecular Spectroscopy 2014, 132, 91.

[130]. Alves, L. F.; Gargano, R.; Alcanfor, S. K. B.; Romeiro, L. A. S.; Martins, J. B. L., Chem. Phys. Lett. 2011, 516, 162.

[131]. Bakir, M.; Green, O.; Mulder, W. H., Journal of Molecular Structure 2008, 873, 17. 